Jahrbuch der Deutschen Dostojewskij-Gesellschaft

\title{
Anklang und Widerhall: \\ Dostojewskij in medialen Kontexten
}

Herausgegeben von Gudrun Goes 
Jahrbuch der Deutschen Dostojewskij-Gesellschaft · 2013 


\title{
Jahrbuch der Deutschen Dostojewskij-Gesellschaft
}

\author{
Herausgegeben \\ im Auftrag der Deutschen Dostojewskij-Gesellschaft \\ und im Namen des wissenschaftlichen Beirats der Gesellschaft \\ von Gudrun Goes
}

Jahrbuch 20

2013

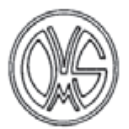

Verlag Otto Sagner

München - Berlin - Washington, D.C. 


\title{
Anklang und Widerhall: Dostojewskij in medialen Kontexten
}

\author{
Herausgegeben von Gudrun Goes
}

\author{
Verlag Otto Sagner \\ München - Berlin - Washington, D.C. 2014
}




\section{Bibliografische Information der Deutschen Bibliothek}

Die Deutsche Bibliothek verzeichnet diese Publikation in der Deutschen Nationalbibliografie; detaillierte bibliografische Informationen sind im Internet über http://dnb.ddb.de abrufbar.

Online steht dieses Jahrbuch in Kürze als Volltextversion über den Katalog der Bayerischen Staatsbibliothek München (www.bsb-muenchen.de) zur Verfügung.

\section{BS: $\begin{aligned} & \text { Bayerische } \\ & \text { StaatsBibliothek }\end{aligned}$}

(C) 2014 bei Kubon \& Sagner GmbH

$\begin{array}{ll}\text { Heßstraße 39/41 } & \text { Friedrichstraße 200 } \\ 80798 \text { München } & 10117 \text { Berlin }\end{array}$

Telefon $+49(0) 8954$ 218-107

Telefax +49(0)8954 218-226

verlag@kubon-sagner.de

«Verlag Otto Sagner» ist ein Imprint der Kubon \& Sagner GmbH

Umschlaggestaltung: Christopher Triplett, Marburg

Satz: robert jones, marburg

Druck und Bindung: Difo-Druck, Bamberg

Printed in Germany

Alle Rechte vorbehalten

ISSN $1437-5265$

ISBN: 978-3-86688-411-3

ISBN (eBook): 978-3-86688-412-0 


\section{Inhaltsverzeichnis}

\section{GUDRUN GOES}

Vorwort

HORST-JÜRGEN GERIGK

Auf den Spuren des Fürsten Myschkin: Knut Hamsuns Mysterien und

Walker Percys Der Idiot des Südens

HANNA KLESSINGER

Schuld und Erlösung: Zur Dostojewskij-Rezeption in Georg Trakls Lyrik

PETER BUKOWSKI

Fjodor Dostojewskij und Andreas Maier - eine Annäherung

STEFANIA TORRI

Dostojewskij in Deutschland und in Italien: Gemeinsamkeiten

und Unterschiede

JORDI MORILLAS

Fëdor Dostoevskij in Spanien: Ein kurzer Überblick

ANDREAS EBBINGHAUS

Übersetzungstheoretische Überlegungen zu den jüngsten deutschen Fassungen des Raskolnikow-Romans von F. Dostojewskij

CHRISTOPH GARSTKA

Starker Staat oder Bürgergesellschaft? Dostoevskijs politische Visionen im

Reiche Putins

HENRIKE SCHMIDT

Dostoevskij digital. Zum virtuellen Nachleben eines Klassikers im Internet

JÖRG POTTBECKERS

Die Spielerin, der Verführer und der Mann, der die Welt verkaufte.

Zur Dostojewskij-Rezeption im zeitgenössischen Film

SUSANNE MEISTER

Requiem für einen Suchenden: Im Gespräch mit Luk Perceval 
OLIVER BINDER

Im Netz der Vermutungen

Spurensuchen um und in Mieczysław Weinbergs Oper Der Idiot

ELENA DOBRINA

„Das Mitleid ist das wichtigste und vielleicht einzige Daseinsgesetz

der ganzen Menschheit. “Dostoevskijs Der Idiot und Schopenhauers Ethik

Rezensionen

JENIFER WASMUTH

205

GUDRUN GOES

208

Autorenverzeichnis

212 


\section{Gudrun Goes}

\section{Vorwort}

\section{Anklang und Widerhall: Dostojewskij in medialen Kontexten}

Wir befinden uns auf Spurensuche, wo können wir von Dostojewskijs literarischem Schaffen in einem anderen Bezugsfeld Gedankensplitter, Bilder, Kommentare oder Transformationen finden? Wie könnte ein Widerhall vor allem im 20. Jahrhundert dieses Dichters in Europa und nicht nur in Europa aussehen? Diesen Spuren sollte unsere Tagung nachgehen, indem Literatur und andere Medien wie u.a. Film oder auch am Rande Theater nach den literarischen Spuren des russischen Dichters befragt werden.

Anklang meint auch vordergründig, wie gehen wir einzelnen Leser mit dem Phänomen Dostojewskij um, wie haben Leser in welcher Epoche, in welchem Kontext wie auf Dostojewskij reagiert, wie wurde auch sein Schaffen in bestimmten gesellschaftspolitischen Zusammenhängen aufklärerisch eingesetzt oder manipulativ missbraucht?

Anklang beschreibt also Rezeptionsprozesse.

Auf einer zweiten Ebene sind Künstler natürlich auch als Leser gefragt, die das Schaffen des russischen Dichters auf ihre Weise antizipieren und damit direkt oder indirekt umgehen, es entstehen intertextuelle Prozesse, natürlich auch innerhalb der bildenden und der Filmkunst. Es entwickelt sich ein Widerhall, eine Reaktion zu dem erfolgten Umgang mit dem Schaffen des russischen Schriftstellers, dabei offenbaren sich neue literarische oder andere künstlerische Produkte. Natürlich kann der einzelne Künstler nur eine neue, veränderte poetische Position aus der Beschäftigung mit den Werken Fjodor Dostojewskijs erarbeiten, ohne dass es thematische Annäherungen gibt. Hier sollen Antworten vorgestellt werden.

Unser Jahrbuch stellt Ergebnisse der Tagung Anklang und Widerhall des Schaffens des russischen Schriftstellers Fjodor Dostojewskij dar, ergänzt durch zusätzliche Beiträge, die das Thema kongenial bereichern.

Besonders gut wahrnehmbar ist ein Widerhall auf das Werk Dostojewskijs, wenn wir uns einen Überblick über die Dramatisierung der Romane, Erzählungen des Dichters u.a. auf deutschen Bühnen verschaffen. Die Finanzkrise, so möchte man einschätzen, beförderte geradezu das Interesse der Regisseure, sich mit dem Roman Der Spieler auseinanderzusetzen. Aufführungen in Berlin an der Volksbühne, in Magdeburg und in anderen Städten waren zu beobachten. Der Musikdramaturg 
Oliver Binder stellt in seinem Beitrag Im Netz der Vermutungen eine Spurensuche um und in Mieczysław Weinbergs Oper Der Idiot dar, die im Frühjahr 2013 an der Mannheimer Oper uraufgeführt wurde.

Jan Jochymski inszenierte in Magdeburg den Spieler in einer eigenen Fassung in der Übersetzung von Swetlana Geier im Jahr 2012. Die Handlung der Romanvorlage Der Spieler wirkt in dieser Inszenierung auf den Leser unfertig und verkürzt. Sie legt den Schwerpunkt deutlich auf das Thema Spielsucht und verändert so das Prinzip des Romans ein Stück weit. Die Handlungen der Figuren sind dem weitestgehend angepasst, so auch die Bühne. Die Spielfläche ist mit einem eleganten, fliederfarbenen Teppich ausgelegt. Links der Roulettetisch vor einem stilisierten Kamin, in der Mitte ein ausladendes Ledersofa vor einer gold-schwarzen Wand. Eleganz und Stil finden sich auch in den Kostümen der Protagonisten wieder. Das Geld hat die Figuren längst verdorben.

Was Dostojewskij in seinem Roman erzählt, entbehrt im Wesentlichen einer stringenten Handlung. Vielmehr beschäftigt er sich mit Charakterstudien der einzelnen Person und der immerwährenden Frage, welchen Einfluss das Spiel und die Sucht auf den Menschen haben. Jan Jochymski bringt den Autor selbst mit auf die Bühne, der mit seiner Stenographin das Spielgeschehen beobachtet und immer wieder eingreift, um die Handlung weiterzubringen. Hiermit findet einerseits die Zeitnot des Autors eine Entsprechung: Dostojewskij musste den Roman innerhalb von einem Monat erstellen, da er sonst alle Rechte, auch die zukünftigen, an seinen Werken einem Verleger hätte übertragen müssen. Andererseits eröffnet der Regisseur hiermit eine zweite Ebene. Der Protagonist wird immer wieder zum Stellvertreter für die persönlichen Sorgen des Autors. Seine Stenographin Anna führt dies mit ihrer Frage ein: „Wenn die Verfassung des Autors Auswirkungen hat auf das Verhalten seiner Romanfiguren, kommt es dann, im umgekehrten Fall, auch vor, dass das Verhalten der Romanfiguren Einfluss hat auf das Leben des Autors?" Im späteren Geschehen gibt Dostojewskij dann zu: „Ja, Anna, Sie haben mich entdeckt: Ich bin ein Spieler; und ich weiß nicht, wie ich von dieser Sucht loskommen soll, ich weiß es wirklich nicht". Über die Verknüpfung der Spiel- und der Autorenebene entwickelt sich ein äußerst plastisches Bild der Problematik. In der Zeichnung der Charaktere äußert sich die Verzweiflung Dostojewskijs selbst, während dieser aus seinen eigenen Erfahrungen heraus eine Spiellogik entwirft und diese auf den Protagonisten Alexej anwendet. Anstatt in der Fiktion den Spieß umzudrehen und dem ewigen Kreislauf ein Ende zu setzen, kommt Alexej immer wieder zurück zum Spiel. Dazu lautet Dostojewskijs Anweisung: „Wir verschaffen ihm einen hohen Gewinn und werden sehen, was er damit anzufangen weiß." Letztendlich ist es aber nicht das Geld, sondern das Spiel, was ihn im Bann hält. Im Moment, als er auf die Idee kommt, Polina in die Schweiz zu folgen, geht er wieder los und setzt seine letzten 10 Cent. Mehrfach wird der Versuch gestartet: „Morgen, morgen wird alles ein Ende haben!" Doch der Kreislauf lässt sich bis zum Ende nicht durchbrechen und so kommt es einer Kapitulation gleich, wenn sich der 
Autor am Ende gemeinsam mit seiner Hauptfigur an den Roulettetisch begibt und weiter spielt. Der Regisseur lässt zwei Rollen von ein-und demselben Schauspieler gestalten: Mademoiselle Blanche und Anna, Mister Ashley, im Roman eine unheimlich beliebige Figur, die bis zum Ende fast vollständig im Dunkeln bleibt, wird er im Stück als Schlüsselfigur eingesetzt, um im Dialog mit Alexej der Handlung eine bestimmte Wendung zu geben und Fjodor Dostojewskij. Es sind jeweils zwei konträr angelegte Gestalten. Die Tante ist in der Romanvorlage ein dramaturgisch genialer Kniff. In der Magdeburger Inszenierung wird sie von einem Mann verkörpert. Jan Jochymski schafft in seiner Inszenierung etwas Faszinierendes. Er konstruiert kaum einen spannenden Plot, noch setzt er auf hochtrabende Effekte. Was den Zuschauer in den Bann zieht, ist das Subtile, das ständig gegenwärtige Zittern, die Rastlosigkeit, der Drang zum Roulettetisch. Die Figuren sind davon alle betroffen. Sobald es um das Spiel geht, starren alle wie gebannt auf das drehende Rad und die kleine weiße Kugel. Darüber entstehen weitere Aspekte: Macht, Erniedrigung, ja vermeintlich sogar die Liebe ist beeinflusst vom Spiel. Zu welcher Unaufrichtigkeit und welch abstruser Argumentation der Mensch durch das Spiel fähig wird, lässt sich rational nicht nachvollziehen. Jan Jochymski lässt es die Zuschauer fühlen. ${ }^{1}$

Die Premiere der Die Brüder Karamasow-Inszenierung in den Hamburger Kammerspielen am 30. April 2013 in der Regie von Luk Perceval wurde mit folgenden Worten angekündigt ${ }^{2}$ : Fjodor Dostojewskijs Romane sind vom Denken der Aufklärung in der Tradition Kants und Schillers geprägt. Aber möglicherweise hat der russische Dichter dieses Denken komplett missverstanden. Wenn das „moralische Gesetz in uns" für Kant die Freiheit ermöglicht, auch gegen unsere Interessen sittlich zu handeln, radikalisiert Dostojeswkij diesen Gedanken, indem er erklärt, das Beste sei, überhaupt gegen seine Interessen zu handeln und der größte Nutzen für den Menschen bestehe darin, das Unnütze zu tun, denn nur so könne man beweisen, dass man ein freier Mensch ist und „kein Schräubchen“. Und wenn bei Kant Aufklärung in dem Vermögen wurzelt seinen eigenen Verstand ohne Anleitung anderer zu gebrauchen, treibt Dostojewskij diese Idee in den „Dämonen“ bis zum Äußersten: „Wer sich entschließt, sich umzubringen, ist Gott im selben Augenblick." Missverständnisse, die es in sich haben. Sie schlugen als solche wieder auf das westliche Denken zurück mit schwerwiegenden Folgen. Nietzsche nannte Dostojewskij „den Glücksfall“ seines Lebens. Ohne das gefährliche Denken von Dostojewskijs metaphysisch obdachlosen Romanhelden, ihre antirationalen und suicidalen Züge, wäre die Entwicklung zur sogenannten Postmoderne nicht denkbar. Die Brüder Karamasow ist Dostojewskijs letzter Roman. Er ist aufgebaut wie ein Krimi. Aber spannender als die Suche nach dem Täter, ist Dostojewskijs

1 Teile dieses Textes zur Inszenierung des Spielers am Magdeburger Theater sind in einem Seminar zum Spieler im WS 2012 entstanden. Gudrun Goes

2 Siehe Homepage des Thalia Theaters Hamburg. 
Kampf gegen die Leere, die der Tod Gottes hinterlassen hat. Iwan Karamasow, einer der Brüder, sagt den entscheidenden berühmten Satz: „Wenn es keinen Gott gibt, ist alles erlaubt." Kann man, nachdem Sätze wie dieser einmal gedacht worden sind, ohne Selbstbetrug zurück in den Schoss des Glaubens und der Kirche? Was wäre die Alternative? Dostojewskij wollte eine Antwort geben in diesem Roman, und zwar eine christliche, am Ende sind es nur noch mehr Fragen geworden.

Unser Jahrbuch publiziert ein Interview mit dem Regisseur Luk Perceval, das die Dramaturgin Susanne Meister geführt hat, so gewinnen die Leser einen tieferen Eindruck in die Konzeption dieser Inszenierung.

Die Zuschauer waren in ihrer Mehrheit von der Inszenierung sehr beeindruckt, obwohl die Aufführung handlungsarm ist und durch die Kraft der Monologe und Dialoge lebt, dazu werden auch starke Bilder entwickelt. Die Reaktion zu diesem Karamasow-Projekt, wie es Till Briegleb nennt ${ }^{3}$, fällt durch die Theaterkritik nicht nur euphorisch aus. Zum einen wirke die Inszenierung zunehmend unbearbeitet wie eine eng anliegende Nacherzählung, auch werde die Typisierung zum Problem der Darstellung. Die besten Momente sieht der Kritiker in der Stille. Nach Briegleb würden zahlreiche zentrale Ideen zum Zeitvergleich taugen.

Nach Meinung von Anke Dürr ${ }^{4}$ hat Perceval seine Inszenierung der Brüder Karamasow "eindeutig zu stark reduziert". Die Entscheidung, den Roman nicht viel simpler zu machen, als er ist, sei mutig, der Preis allerdings hoch: Die Schauspieler müssten sich "meist in langen Monologen durch die Textmassen pflügen" und täten dies "mit großem Ernst". Wie sich die Protagonisten auf Schemeln "die philosophischen Grundfragen um die Ohren" hauten, habe zeitweilig die Anmutung einer Familienaufstellung; der Kriminalfall sei hingegen bloß Rahmenhandlung. [...] Perceval gebe "uns in seinem vierstündigen philosophischen Parforce-Ritt die Antwort [...]: Niemand ist unschuldig."

Matthias Heine ${ }^{5}$ findet Percevals Inszenierung stellenweise durchaus "hochkomisch" und würdigt neben den Scheiteln und Glatzen der Darsteller ausführlich das für ihn anspielungsreiche Glockenspiel-Bühnenbild von Annette Kurz. Besonders schön findet Heine die Szene zwischen Simon und Galic, "eine der schönsten Liebesszenen der gesamten Weltliteratur". Bis zur Pause hat der Kritiker "all dem gebannt, wie angenagelt" gelauscht, diese ersten zwei Stunden vergingen "wie ein irrer berauschender Traum". Danach zerschlage Perceval allerdings wieder einiges von dem Aufgebauten. Volker Corsten ${ }^{6}$ beschreibt in der Frankfurter Allgemeinen Zeitung den Prozess der Roman-Verknappung, um auch festzustellen, dass dennoch die Theaterfassung für seinen Geschmack gegen Ende ruhig noch ein

3 Till Briegleb in der Süddeutschen Zeitung vom 4./5. Mai 2013.

4 Anke Dürr in der Frankfurter Rundschau vom 02.05.2013.

5 Matthias Heine in der Welt vom 02.05.2013.

6 Volker Corsten in der Frankfurter Allgemeinen Zeitung vom 02.05.2013. 
paar Seiten kürzer hätte sein dürfen, wenn es in der Krimihandlung zur Sache geht. Alle Figuren würden hier mit viel Liebe betrachtet, Krimi und Prozessausgang interessierten Perceval hingegen nicht. Lobende Worte findet der Kritiker für den "sakral anmutenden" Bühnenraum: Eine heilige Halle, in der Lehrer Perceval mit seinen Schülern für alles Nebulöse, Schwierige erstaunlich klare und kräftige Bilder findet, für das vermeintlich Klare, Schlichte aber oft nur wässrige und matte. Hier stehe Simon als Aljoscha "mit der Stoik eines tibetischen Mönches" als "staunender, still mit sich kämpfender Novize im Zentrum - und er ist dabei meist sehr allein unter lauter Irren". Peter $\mathrm{Kümmel}^{7}$ schreibt, Perceval unternehme den "irrsinnigen Versuch" die Brüder Karamasow an einem besonderen Ort zu spielen. In jener "halben Höhe" nämlich, in der zu sehen sei, dass Erde und Himmel zusammenhängen. "Vom Schnürboden hängen lauter Stahlpendel in den leeren schwarzen Bühnenraum hinab", bei "allgemeinem Tumult stoßen sie tieftönend gegeneinander". Selbst wenn die Figuren miteinander kämpfen, erzeugten sie so eine "Art höheren Einklang". Die Pendel seien "Standleitungen zu Gott", nur benutze sie niemand. Das Spiel erinnere an die übliche Methode heutzutage Romane auf die Bühne zu bringen: Ein Spieler verkörpert eine Romanfigur und erzählt zugleich von ihr. Diese Manier habe Perceval so verfeinert, dass man bei ihm glaube, hier werde etwas entdeckt, was sonst unbemerkt geblieben wäre. Im Theatersaal aber spüre man am Ende "die Großzügigkeit von Menschen, die zumindest an diesem Abend erlebt haben, was es bedeutet, wenn Gerechtigkeit herrscht - nämlich auf der Bühne", und die nun den Wunsch nach Vergebung aller Sünden verspürten. Dramatisierungen von Dostojewskijs Werken gibt es regelmäßig auch von Volksbühnen-Chef Frank Castorf Der Spieler, Die Wirtin. In Leipzig inszenierte Sebastian Hartmann jüngst Dostojewskijs Traum eines lächerlichen Menschen.

Jörg Pottbeckers wird sich in seinem Beitrag der Rezeption der Werke Fjodor Dostojewskijs, besonders Der Spieler und Weiße Nächte, im Film widmen.

Die Reaktionen vor allem deutscher Dichter, aber nicht nur, nach der Lektüre der Romane Fjodor Dostojewskijs sind sehr vielfältig und lassen sich auf kein bestimmtes kulturelles oder zeitgeschichtliches Umfeld eingrenzen, wobei gerade in der Zeit der Moderne, in der Kunst des Expressionismus, viele geistige Verbindungen benannt wurden, das geschah implizit und auch explizit. Sehr nachhaltig ist es an dem Essay über Dostojewskij von Hermann Hesse aus dem Jahr 1919, begonnen 1915, nachzuweisen.

Der Ausgangspunkt des deutschen Dichters Hermann Hesse liegt in dem Satz begründet, dass eigentlich über den russischen Dichter alles gesagt sei, aber Dostojewskij immer wieder mit neuen Geheimnissen umhüllt werde. Hesse beschwört seinen Leser, dass man Werke des russischen Dichters lesen müsse, wenn es uns nicht gut gehe und wir das Leben als hoffnungslos empfinden würden:

7 Peter Kümmel in der Zeit vom 08.05.2013. 
„Dann sind wir nicht mehr Zuschauer, dann sind wir nicht mehr Genießer und Beurteiler, dann sind wir arme Brüder unter all den armen Teufeln seiner Dichtungen dann leiden wir ihre Leiden, starren mit ihnen gebannt und atemlos in den Strudel des Lebens, in die ewig mahlende Mühle des Todes. Und dann erhorchen wir Dostojewskijs Musik, seinen Trost, seine Liebe, dann erst erleben wir den wunderbaren Sinn seiner erschreckenden und oft so höllischen Welt." ${ }^{\text {" Im weiteren }}$ Verlauf von Hesses Überlegungen werden diese in verschiedene Abschnitte unterteilt, die sich speziellen Werken widmen. Er beginnt dabei seine Darstellung mit Gedanken an Dostojewskijs Idiot. Der oftmals hervorgehobene Vergleich Myschkins mit Jesus ist für ihn nicht sehr markierend, aber er sieht schon eine Verbindung, wenn Jesus z. Bsp. im Garten Gethsemane den letzten Kelch der Vereinsamung trinkt, mit Myschkins Aufenthalt in Pawlowsk im Haus von Lebedjew. Hesse hat auch eine Erklärung dafür, dass kaum jemand den Idioten verstehen kann. Er denkt anders, nicht logisch, sondern kindlich assoziativ, meint Hermann Hesse. ${ }^{9}$ In Hesses Auseinandersetzung mit Dostojewskijs Roman Der Jüngling ist folgender interessanter Hinweis zu erwähnen, dass der deutsche Dichter glaubt, die Europäer seien in der Kunst stets Kinder geblieben und sie brauchen die Russen noch lange Zeit als Vermittler zwischen Europa und Asien. ${ }^{10}$ Der letzte und umfangreichste Abschnitt des Essays lautet: Die Brüder Karamasow oder der Untergang Europas. Einfälle bei der Lektüre Dostojewskijs. Einfälle sollen signalisieren, dass Hermann Hesse keine systematische und in sich geschlossene Betrachtung, aber eine doch diffizile und in sich widersprüchliche Analyse vorlegen will. Den russischen Menschen sieht Hesse in den vier Karamasows gebündelt, die zugleich Mörder und Richter sind, und die dadurch den Untergang Europas provozieren werden, auch wenn dieser sich nur innerlich abspielen wird: „Jedes Symbol hat hundert Deutungen, deren jede richtig sein kann. Auch die Karamasows haben hundert Deutungen, meine ist nur eine davon, eine von hundert. Die Menschheit hat sich in dieses Buch an der Wende großer Umwälzungen ein Symbol geschaffen, ein Bild errichtet, so wie der einzelne Mensch sich im Traum ein Abbild der in ihm sich bekämpfenden und ausgleichenden Triebe und Kräfte schafft. Daß ein einzelner Mensch die „Karamasows“ schreiben konnte, ist ein Wunder. Nun, das Wunder ist geschehen, es besteht kein Bedürfnis, es zu erklären. Wohl aber besteht ein Bedürfnis, ein sehr tiefes Bedürfnis, dies Wunder zu deuten, seine Schrift möglichst ganz, möglichst allseitig, möglichst in ihrer ganzen lichten Magie zu lesen." ${ }^{11}$ Hesses Essay hat tatsächlich den Versuch unternommen, Dostojewskijs Romanwelt zu transzendieren.

\footnotetext{
8 H. Hesse: Dostojewski. In: Derselbe: Gesammelte Werke. Bd.12. Schriften zur Literatur 2. Frankfurt a. M. 1975, S. 305.

9 Vgl. ebd., S. $310 f$.

10 Vgl. ebd., S. 320.

11 Ebd., S.330-331.
} 
Es entstanden in den letzten Jahren zahlreiche Untersuchungen, die dem Phänomen Widerhall nachgegangen sind.

2006 erschien zum Beispiel das Buch von Raimund Johann Weinczyk: Myškin und Christus, ein fiktives Gespräch mit Josef Ratzinger auf der Basis des Romans Der Idiot von Fjodor Dostojewskij. Der Autor hebt u.a. hervor: „Was immer wieder neue Aspekte der Romanfigur freilegt und neue Perspektiven für die Interpretation eröffnet, bedarf einer Konsolidierung im Ausgangspunkt. Der Blick auf den Fürsten Myškin erschöpft sich z. Bsp. oft in nur einem Gedanken, Wort, Verhaltensmerkmal oder Axiom Myškins (oder seines Erfinders). Der Blick des Interpreten (Lesers) kann aber auch die eigene Kreativität sozusagen am ganz anderen Objekt unter Beweis stellen. Dann nämlich wenn sie nicht bei Myškin selbst, sondern beim Hintergrundwissen des Interpreten einsetzt. Dann wird Myškin von vornherein festgelegt, in den Mythos gebannt oder zum Demonstrationsobjekt der Philosophie Dostoevskijs bestimmt, und von all dem, was er sonst noch und für sich und den Leser sein könnte, methodisch abgeschnitten. Den ersten Schritt zu tun, heißt also: konsequent und großflächig bei Myškin zu bleiben, um danach erst die vielfältigen Möglichkeiten der Interpretation und Auseinandersetzung mit dieser Romanfigur aufzunehmen und kritisch zu sondieren. [...] Einen Dialog zwischen Ratzinger und Dostoevskij zu beginnen, heißt eben auch die Möglichkeiten der Interpretation über die Grenzen der auch auf sich bezogenen Thematik auszuweiten, es geht um einen interdisziplinären, intertextuellen Vergleich auf dialogischer Basis. Ziel ist die synchrone Zusammenführung von Dialogpartnern unter zwei Gesichtspunkten: dem der Überbrückung von Fiktion und Realität sowie der Suche nach Verbindungswegen, Barrieren oder Sackgassen durch 100 Jahre voneinander getrennter gleicher und doch ganz anderer geistiger Horizonte. "12 Nach der Analyse des ersten - Myschkinschen - Standpunkts folgt sofort die Konfrontation mit Ratzingers Standpunkt im Glauben.

Die Diskussion um die künstlerische Rezeption bestreiten die Beiträge von Horst-Jürgen Gerigk (Auf den Spuren des Fürsten Myschkin. Knut Hamsuns Mysterien und Walker Percys Der Idiot des Südens), von Hanna Klessinger (Schuld und Erlösung. Zur Dostojewskij-Rezeption in Georg Trakls Lyrik) und von Peter Bukowski (Fëdor Dostoevskij und Andreas Maier - eine Annäherung).

Ergebnisse der Aufnahme der Werke des russischen Dichters in Spanien und Italien werden von Stefania Torri (Dostojewskij in Deutschland und in Italien: Gemeinsamkeiten und Unterschiede Literatur) und Jordi Morillas (Fëdor Dostoevskij in Spanien. Ein kurzer Überblick) vorgelegt. Damit wird ein entscheidendes Problem bei der Übertragung eines Werkes in einen anderen Kulturkreis berührt, nämlich die Rolle der Übersetzung. Andreas Ebbinghaus (Übersetzungstheoretische

12 Raimund Johann Weinczyk: Myškin und Christus, ein fiktives Gespräch mit Josef Ratzinger auf der Basis des Romans Der Idiot von F. Dostoevskij. Heidelberg 2006, S. $19 \mathrm{ff}$. 
Überlegungen zu den jüngsten deutschen Fassungen des Raskolnikow-Romans von F. Dostojewskij) widmet sich in seiner Untersuchung diesem wichtigen Feld.

Spuren von Dostojewskijs Werken sind längst im Internet zu finden. Henrike Schmidt hat diese Spuren gefunden und demonstriert sie in ihrem Beitrag (Dostoevskij digital. Zum virtuellen Nachleben eines Klassikers im Internet).

Christoph Garstka folgt in seinem Beitrag (Starker Staat oder Bürgergesellschaft? Dostoevskijs politische Visionen im Reiche Putins) auch Spuren, die der Dichter Dostojewskij im politischen Heute hinterlassen hat.

Zum Abschluss der wissenschaftlichen Diskussionen in diesem Jahrbuch stellt sich die Nachwuchswissenschaftlerin Elena Dobrina mit dem Beitrag „Das Mitleid ist das wichtigste und vielleicht einzige Daseinsgesetz der ganzen Menschheit." Dostoevskijs Der Idiot Schopenhauers Ethik vor.

Die künstlerische Rezeption des Fürsten Myschkin durch andere Autoren stand am Anfang unserer Darlegungen und beendet die Auseinandersetzung in unserem Jahrbuch.

Aus technisch-organisatorischen Gründen kann die Dostojewskij-Bibliographie 2012 erst im nächsten Jahrbuch mit der von 2013 zusammen veröffentlicht werden. 


\section{Horst-Jürgen Gerigk}

\section{Auf den Spuren des Fürsten Myschkin: Knut Hamsuns Mysterien und Walker Percys Der Idiot des Südens}

\section{Vorbemerkungen zur Methode, das Vergleichen betreffend}

Die hier vorgelegten Überlegungen begeben sich auf das Gebiet der Vergleichenden Literaturwissenschaft, der Komparatistik. Verglichen werden ein Russe, ein Norweger und ein Amerikaner mit jeweils einem Werk. ${ }^{1}$ Wie das Thema meines Beitrags bereits erkennen lässt, handelt es sich um die Romane Der Idiot (Idiot) von Fjodor Dostojewskij (1869), Mysterien von Knut Hamsun (1892) und Der Idiot des Südens von Walker Percy (1966). Walker Percys Roman heißt im amerikanischen Original The Last Gentleman. Der Österreicher Peter Handke sah sich durch die Hauptperson Will Barrett so sehr an den Fürsten Myschkin erinnert, dass er seiner deutschen Übersetzung den Titel Der Idiot des Südens gegeben hat, denn Will Barrett stammt aus den Südstaaten.

Hamsun und Percy waren mit Dostojewskij vertraut. Hamsun war bekennender Dostojewskij-Verehrer, stellte ihn, wie wir wissen, an die Spitze der russischen Klassiker und gab zu Protokoll, von ihm am meisten gelernt zu haben. ${ }^{2}$ Percy wiederum hatte sich als junger Arzt während eines Praktikums am Bellevue Hospital in New York Tuberkulose zugezogen, musste deshalb eine Zeit der Rekonvaleszenz im renommierten Trudeau Sanatorium verbringen, wo er Thomas Manns Zauberberg und Dostojewskijs Idiot sowie die Brüder Karamasow (Brat'ja Karamazovy) las und durchstudierte. Diese drei Werke beeinflussten The Last Gentleman zutiefst. Percys Freund Shelby Foote, Historiker und Schriftsteller, erinnert sich an eine Unterhaltung und vermerkt: „Walker und ich sprachen über

1 Fëdor M. Dostoevskij: Idiot. Band 8 der Ausgabe: Polnoe sobranie sočinenij. 30 Bde. Leningrad: Nauka 1972-1990 (im Folgenden abgekürzt als PSS).Deutsch: Fjodor Dostojewskij: Der Idiot. Roman. Aus dem Russischen neu übersetzt von Swetlana Geier. Frankfurt am Main: Fischer Taschenbuch Verlag 2010. Knut Hamsun: Mysterier. Oslo: Gyldendal Norsk Forlag 1996. Deutsch: Mysterien. Roman. Übersetzt von J. Sandmeier. Nachwort von Edzard Schaper. Zürich: Manesse Verlag 1958 (= Manesse Bibliothek der Weltliteratur). Walker Percy: The Last Gentleman. Introduction by Robert Coles. New York: The Modern Library 1997. Deutsch: Der Idiot des Südens. Roman. Deutsch von Peter Handke. Frankfurt am Main: Suhrkamp 1988 (= Suhrkamp Taschenbuch 1531).

2 Vgl. Knut Hamsun. Im Märchenland. Reisebilder. Aus dem Norwegischen von Cläre Greverus Mjöen. München, Wien: Langen Müller 1979, S. 134-135. 
The Last Gentleman und er sagte: Shelby, der Idiot ist das, was ich geschrieben habe" (Shelby, it's The Idiot, that's what I've written). Shelby Foote meinte aber, Walker Percy habe erst nachträglich und ganz plötzlich die Gemeinsamkeiten realisiert. Walker Percy war sich zumindest hinterher im Klaren darüber, dass er Dostojewskijs Idiot vor Augen hatte, als er The Last Gentleman schrieb. ${ }^{3}$

Die Vergleichende Literaturwissenschaft unterscheidet zwischen Kontaktstudie und typologischem Vergleich. Die Kontaktstudie untersucht, wann und wie ein Autor das Werk, das ihn beeinflusst hat, gelesen und verarbeitet hat. Der typologische Vergleich hat eine solche Untersuchung nicht nötig und kümmert sich auch nicht um diesbezügliche Fakten, wenn sie vorliegen. Das bedeutet: Der typologische Vergleich ist auf Ähnlichkeit und Verschiedenheit literarischer Texte ausgerichtet, völlig unabhängig davon, ob der spätere Autor das Werk des früheren Autors gekannt hat, denn es geht ausschließlich darum, die Individualität der miteinander verglichenen Texte schärfer zu profilieren, als dies ohne den Vergleich mit anderen Texten möglich wäre.

Wenn soeben die Dostojewskij-Kenntnis Knut Hamsuns und Walker Percys hervorgehoben wurde, so geschah das in Richtung einer Kontaktstudie. Wirkungsgeschichten haben immer Kontaktstudien zur Grundlage. ${ }^{4}$ Nun zeigen aber die Literaturgeschichten, die ja per definitionem auf eine chronologische Darstellung ihrer Sachverhalte angelegt sind, dass das einzelne literarische Kunstwerk immer wieder zu einer poetologischen Analyse drängt, die es aus dem historischen Kontext herauslöst und es damit frei macht für den typologischen Vergleich im Universum der Weltliteratur. Und genau an dieser Stelle lässt sich der systematische Ort meiner Überlegungen angeben. „Auf den Spuren des Fürsten Myschkin“ - das heißt: es geht um einen typologischen Vergleich von drei Romanen.

Es fällt auf, dass alle drei Texte auf eine einzige Hauptperson zugeschnitten worden sind. Und in allen drei Fällen handelt es sich um einen jungen Mann: Fürst Myschkin ist 26 Jahre alt (er wird im Laufe des Romans 27), Johan Nagel ist 29, und Will Barrett ist 25. Immer ist die Zeitspanne der Gegenwartshandlung recht kurz. Die Gemeinsamkeiten betreffen aber noch andere Details. Alle drei Protagonisten, Myschkin, Nagel und Barrett, kommen mit der Gesellschaft, in die sie sich hineinversetzt sehen, nicht zu Recht. Alle drei werden als Sonderlinge wahrgenommen. Myschkin kehrt zurück ins Irrenhaus, Nagel gilt als „verrückt“, und Barrett sucht wegen seiner Orientierungsstörungen einen Psychiater auf.

Alle drei Autoren, Dostojewskij, Hamsun und Percy, gestalten einen jungen Mann, dem die Sozialisation nicht gelingt. Man könnte auch sagen: Das von ihrer Umwelt gelebte Wertesystem wird von diesen Protagonisten nicht akzeptiert, sondern abgelehnt. Solche Ablehnung geschieht aber nicht aggressiv, sondern durch

3 Vgl. Robert Coles: Introduction. In: Percy, op. cit. 1997, S. xi-viii, hier S.vi-vii.

4 Der Titel unserer jetzigen Tagung, „Anklang und Widerhall: Dostojewskij im Kontext der Weltliteratur“ impliziert bereits geleistete Kontaktstudien und stellt zudem neue in Aussicht. 
eine Ausweichhaltung. Keiner der drei Männer übernimmt eine soziale Rolle. Der Rückzug auf sich selbst hat aber keine soziale Relevanz, findet also keinen gesellschaftlichen Ort.

Wie aber ist Sozialisation zu definieren? Günter Hartfiels Wörterbuch der Soziologie erläutert wie folgt:

„Sozialisation, Begriff zur Beschreibung und Erklärung aller Vorgänge und Prozesse, in deren Verlauf der Mensch zum Mitglied einer Gesellschaft und Kultur wird. Durch Prozesse der Sozialisation gewinnt der menschliche Organismus seine Identität als eine in Gesellschaft handlungsfähige Persönlichkeit. Sozialisation ist zugleich

(I) Vergesellschaftung des Menschen im Sinne der Übernahme und Internalisierung (Verinnerlichung) von sozialen Wertorientierungen, Verhaltenserwartungen und sozialen Rollen als auch (II) Individuation des Menschen im Sinne von „Besonderung" seiner individuell bestimmten Auseinandersetzung mit den Aufgaben und Einflüssen seiner Gesellschaft. “ 5

Das führt zu der Erkenntnis, dass eine soziologische Theorie der Sozialisation sich auf die „Mechanismen der Vermittlung von Mensch und Gesellschaft“ richtet. Man spricht auch von einer „zweiten Geburt“ des Menschen, seiner „soziokulturellen“ Geburt. Mit ihr vollzieht sich die „Integration“ des bei der Geburt „leeren“ Menschen „in das bestehende soziale Rollensystem.“

So wäre festzustellen, dass Sozialisation als das „allmähliche Hineinwachsen des Menschen in die Gesellschaft" (so Wahrigs Deutsches Wörterbuch) 6 für Myschkin, Nagel und Barrett nicht zustande kommt, weil sie die herrschenden „sozialen Wertorientierungen, Verhaltenserwartungen und sozialen Rollen" nicht befolgen.

Für den hier vorgenommenen Vergleich der drei Texte wird die fehlende Sozialisation der Hauptgestalt zum Leitgedanken. Damit kommt ein ganz bestimmter Kontext zur Herrschaft, in dessen Scheinwerferlicht bestimmte Eigenheiten der Texte hervortreten, die sonst nicht hervortreten würden. Damit zeigt sich ein überraschendes Paradoxon. Die Vergleichende Literaturwissenschaft erweitert den Horizont des Lesers, verengt aber das Bedeutungsvolumen des literarischen Textes auf das, was hier und jetzt aufgrund des Vergleichs an ihm besonders hervortritt.

Angesichts dieses Sachverhalts darf nicht vergessen werden, dass jeder literarische Text immer in ganz verschiedenen Kontexten steht, ja sein geschichtliches Leben darin hat, in Kontexten transportiert zu werden. Er ist auf Kontexte angewiesen, um präsent zu bleiben. Damit aber ist auch immer die Gefahr gegeben, dass er durch Kontexte vereinnahmt und gegen den Strich gelesen wird. Totalitäre Staaten etwa beanspruchen gegenüber ihrer verwalteten Tradition immer ein ideologisches Deutungsmonopol. Man denke nur an die Dostojewskij-Rezeption

5 Vgl. Günter Hartfiel: Wörterbuch der Soziologie. Zweite, überarbeitete und ergänzte Auflage. Stuttgart: Kröner 1986 (= Kröners Taschenausgabe; Bd. 410), S. 618-619.

6 Gerhard Wahrig: Deutsches Wörterbuch. Neu herausgegeben von Dr. Renate Wahrig - Burfeind. Gütersloh: Bertelsmann Lexikon Verlag 1997, S. 1149. 
im sowjetischen Russland. Als positiv kann angesehen, dass die Vielfalt der möglichen Kontexte auch die Überraschungseffekte der Wirkungsgeschichte bedingen kann. Eine Literaturwissenschaft im strengen Sinne, die selbstbewusst in der Poetologie wurzelt, wird aber gegen die ideologische Vereinnahmung des literarischen Kunstwerks immer sensibilisiert sein und ihre eigenen Methoden der Textauslegung unbeirrt in Anschlag bringen.?

Skizzieren wir die verschiedenen Kontexte, die von Dostojewskijs Idiot beschworen werden. Fürst Myschkin ist impotent und gibt das gleich zu Anfang im Gespräch mit Rogoshin freimütig zu. Dostojewskijs gesellschaftstypische Allegorie veranschaulicht, dass der russische Adel keine Zukunft hat. Der Romanist Ulrich Mölk hat in seinem Artikel Stendhals „Armance“ und die Motivgeschichte des impotenten Helden $(1977)^{8}$ die hier einschlägige literarische Reihe benannt, darunter Petrons Satiricon, Ariosts Orlando furioso und, aus der neueren Zeit, Hamsuns Die Weiber am Brunnen und Hemingways The Sun Also Rises. Dostojewskijs Idiot kennt Ulrich Mölk nicht, sonst hätte er vermerkt, dass Hemingway Dostojewskijs Personenkonstellation in das Paris der „verlorenen Generation“ verpflanzt hat: mit Jake Barnes, der durch eine Kriegsverletzung impotent wurde, Lady Brett Ashley, der britischen „femme fatale," und Robert Cohn, dem jüdischen Intellektuellen, der sich zum Boxer ausbilden ließ, um seine Schüchternheit loszuwerden. Hier sehen wir den Fürsten Myschkin, Nastasja Filippowna und Rogoshin in neuem Gewand. Allerdings fehlt bei Hemingway der Mord. ${ }^{9}$

Die Epilepsie des Fürsten Myschkin erinnert gleich zu Anfang des Romans an Dostojewskijs eigene Krankheit ${ }^{10}$ und beschwört damit das Leben seines Autors; sie verweist aber auch auf die anderen Epileptiker in Dostojewskijs Romanen: auf Nelly in den Erniedrigten und Beleidigten (Unižennye i oskorblënnye), auf Kirillow in den Dämonen (Besy) und Smerdjakow in den Brüdern Karamasow. ${ }^{11}$

Die Motive Impotenz und Epilepsie werden gleich zu Anfang des Romans eingeführt, desgleichen der Begriff „Narr in Christo“ (russ.: jurodivyj). Am Ende des ersten Kapitels nennt Rogoshin den Fürsten Myschkin einen „Narren in Christo“.

7 Vgl. Horst-Jürgen Gerigk: Literaturwissenschaft - was ist das? In: Wertung und Kanon. Hg. von Matthias Freise und Claudia Stockinger. Heidelberg: Universitätsverlag Winter 2010 (= Neues Forum für Allgemeine und Vergleichende Literaturwissenschaft. Herausgegeben von Horst-Jürgen Gerigk und Maria Moog-Grünewald; Bd. 44), S.155-177.

8 In: Romanistische Zeitschrift für Literaturgeschichte. 1(1977), 4, S. 403-432.

9 Vgl. Horst-Jürgen Gerigk: Die Russen in Amerika. Dostojewskij, Tolstoj, Turgenjew und Tschechow in ihrer Bedeutung für die Literatur der USA. Hürtgenwald: Guido Pressler 1995. Darin: Der impotente Held: Hemingways „Fiesta“ und Dostojewskijs „Idiot“, S.493-495.

10 Vgl. „Das ist eine alte Krankheit.“ Epilepsie in der Literatur. Herausgegeben von Dietrich von Engelhardt, Hansjörg Schneble, Peter Wolf. Stuttgart und New York: Schattauer 2000.

11 Die Arbeitsgruppe „Epilepsie in der Literatur“ hat einen umfangreichen Sammelband zu diesem Thema herausgebracht, worin natürlich der Fürst Myschkin zu einer besonderen Reflexionsfigur wird und bis zu Julius Cäsar in Thornton Wilders The Ides of March führt. 
Und genau in diesem Sinne setzt Gerhart Hauptmann mit seinem Roman Der Narr in Christo Emanuel Quint Dostojewskijs Idiot fort ${ }^{12}$ : mit einem Helden, der an einem Christus-Wahn leidet und sich selber für den Erlöser hält, veranschaulicht als Geisteskranker. ${ }^{13}$

Die soeben gekennzeichneten Kontexte sollten vor Augen führen, dass sie mit dem hier skizzierten Kontext nichts zu tun haben. Impotenz, Epilepsie und Christus spielen in der Textreihe Der Idiot, Mysterien und Idiot des Südens keine Rolle. Sie werden regelrecht ausgeblendet, was den Fürsten Myschkin angeht. Es geht hier um die Verkennung eines Fremden im Dorf, oder, allgemein ausgedrückt, um die Verkennung eines Fremden, der in einer Gemeinschaft auftaucht, in der jeder jeden kennt. Der Vergleich der drei Texte miteinander schafft einen Referenzrahmen, der das Gemeinsame auffällig werden lässt. Die Neugier gegenüber dem Fremden lässt in allen drei Fällen immer wieder eine bestimmte Art von Dialog entstehen, die als „Pseudo-Dialog“ zu bezeichnen wäre.

Was ist ein Pseudo-Dialog? Er ist das Gegenteil von einem echten Gespräch. Über diesen Gegensatz hat Hans-Georg Gadamer in seinem Hauptwerk Wahrheit und Methode (1960) grundsätzliche Überlegungen vorgelegt. In einem echten Gespräch setzen die Gesprächspartner, so Gadamer, ihre Vorurteile, die sie ja mitbringen, aufs Spiel, indem sie die Meinung des anderen als eine potentielle Wahrheit anerkennen auch und gerade da, wo sie selber anderer Meinung sind. In einem Pseudo-Dialog aber ist das nicht der Fall.

Gadamer unterscheidet drei Formen des Pseudo-Dialogs: (I.) das Prüfungsgespräch, (II.) das therapeutische Gespräch zwischen dem Psychiater und seinem Patienten, (III.) das Verhör vor Gericht. ${ }^{14}$ In allen drei Fällen ist das Verhältnis

12 Vgl. hierzu Horst-Jürgen Gerigk: Existenzformen des absoluten Ich: Gerhart Hauptmanns „Der Narr in Christo Emanuel Quint“ und Dostojewskijs „Idiot“. In: Horst-Jürgen Gerigk: Ein Meister aus Russland. Beziehungsfelder der Wirkung Dostojewskijs. Vierzehn Essays. Heidelberg: Universitätsverlag Winter 2010 (= Beiträge zur neueren Literaturgeschichte; Bd. 275), S. 76-82.

13 Vgl. Walter Nigg: Der christliche Narr. Über Symeon von Edessa, Jacapone da Todi, Erasmus“ „Lob der Torheit“, Pilipp Neri, Cervantes“ „Don Quijote“, Heinrich Pestalozzi und Dostojewskijs „Idiot.“ (Zuerst 1956) Zürich: Diogenes 1993; Jostein Bortnes: Dostoevskian Fools - Holy and Unholy. In: The Holy Fool in Byzantium and Russia. Papers presented at a symposium arranged by The Norwegian Committee of Byzantine Studies 28 August 1993 at the University of Bergen. Edited by Ingunn Lunde. Bergen: Department of Russian Studies, University of Bergen 1995 (= Skrifter no. 8), S. 18-34.

14 Hans-Georg Gadamer: Wahrheit und Methode. Grundzüge einer philosophischen Hermeneutik. Tübingen: Mohr / Siebeck 1960. Dort S. 345-346: „Wir kennen derartiges (= Scheinfrage) etwa in der pädagogischen Frage, deren eigentümliche Schwierigkeit und Paradoxie darin besteht, daß sie eine Frage ohne einen eigentlich Fragenden ist“; und S. 363: „Wo wir wirklich den anderen als Individualität im Auge haben, z. B. im therapeutischen Gespräch und im Verhör des Angeklagten, ist die Situation der Verständigung gar nicht wahrhaft gegeben." Mit diesen zwei Sätzen skizziert Gadamer eine ganze Theorie der Kommunikation, die bislang, 
zwischen dem Fragenden und dem Befragten asymmetrisch. Im echten Gespräch hingegen sind die Gesprächspartner gleichberechtigt: es herrscht Symmetrie. Das bedeutet: jeder wird, unabhängig von seiner sozialen Stellung und Rolle außerhalb des Gesprächs, auf gleiche Weise geachtet und ernstgenommen mit Bezug auf die diskutierte Sache.

Es kann nicht geleugnet werden, dass unser Alltag von Pseudo-Dialogen durchsetzt ist, während ein echter Dialog höchst selten vorkommt, wenn auch nicht unmöglich ist. Und wer die Differenz zwischen Pseudo-Dialog und echtem Dialog einmal hergestellt hat, dem wird es leicht fallen, beide Arten der Kommunikation in der Dichtung aufzuspüren und zu registrieren. Mittel und Wege dafür, den angekündigten typologischen Vergleich durchzuführen, warten nun auf ihre Nutzung.

\section{Der Idiot}

Ein Fremder trifft morgens um 9 Uhr mit dem Zug in Petersburg ein; es ist Fürst Myschkin. Er hat eine lange Reise hinter sich, kommt aus der Schweiz, wo er fast fünf Jahre in einer Heilanstalt verbracht hat. Die Eingangsszene im Eisenbahnabteil enthält bereits die Elemente all dessen, was der Roman in vier Teilen auf siebenhundert Seiten erzählt. Zwei Unbekannte im Zug, Myschkin und Roghoshin, lernen sich kennen, und der geschwätzige Lebedew mischt sich ungefragt, schlau und unterwürfig als Mitreisender in die Unterhaltung ein. Und sofort ist von der weiblichen Hauptgestalt des Romans, Nastasja Filippowna, die Rede, die den beiden jungen Herren (Myschkin ist 26 und genauso alt wie Rogoshin), zum Schicksal wird, was sie zu Beginn der Geschichte allerdings noch nicht wissen können. Sogar das sibirische Zuchthaus, das am Ende auf Rogoshin wartet, nachdem er Nastasja im Bett erstochen hat, ist in diesem Gespräch bereits leitmotivisch präsent, wenn auch nicht mit Bezug auf ihn. Ebenso wird das düstere und phantastische Kolorit, das den Roman dominiert, gleich mit dem ersten Absatz realistisch beschworen. Es heißt:

„Ende November, bei Tauwetter gegen neun Uhr morgens, näherte sich ein Zug der Petersburg-Warschauer Eisenbahnlinie mit Volldampf Petersburg. Es war so feucht und neblig, dass es nur zögernd hell wurde; aus den Waggonfenstern ließ sich auf zehn Schritte rechts und links vom Bahndamm kaum etwas erkennen. Ein Teil der Reisenden kehrte aus dem Ausland zurück [...]. Alle waren verständlicherweise

soweit ich sehe, gar nicht entfaltet wurde. Vor allem aber wird hier der Literaturwissenschaft ein wesentliches Anwendungsfeld erschlossen. Einen ersten Schritt in dieser Richtung unternimmt mein Aufsatz: „Dialogue and Pseudo-Dialogue.“ In: Dostoevsky’s Brothers Karamazov. Art, Creativity and Spirituality. Edited by Predrag Cicovacki, Maria Granik. Heidelberg: Universitätsverlag Winter 2010 (= Beiträge zur slavischen Philologie. Herausgegeben von Edith W. Clowes, Horst-Jürgen Gerigk, Urs Heftrich, Jens Herlth, Adrian Wanner; Bd. 16), S. $29-44$. 
müde, alle hatten nach dieser Nacht schwere Lider, alle fröstelten, alle Gesichter waren blaßgelb von der Farbe des Nebels draußen." 15

Fürst Myschkin ist nach seiner Ankunft in Petersburg zunächst allein unterwegs. Er besucht die Familie Jepantschin. Frau Jelisaweta Jepantschina ist eine sehr entfernte Verwandte, die er bislang nie gesehen hat; sie kennt seine Geschichte, ihr hatte er geschrieben, aber auf seinen Brief keine Antwort erhalten. Nun ist er da, höflich, freundlich, ärmlich gekleidet, mit einem Bündel unterm Arm. Das ist sein ganzes Gepäck. Im Haus der Jepantschins führt er ausgiebige, lustige und ernste Gespräche mit den drei Töchtern Alexandra, Adelaida und Aglaja. Auf diese Weise lernen nicht nur sie den Fürsten Myschkin kennen, sondern auch die Leser. Dostojewskijs Darstellungstechnik besteht darin, dass sein imaginärer Erzähler den Fürsten Myschkin wie das Auge einer (Film-) Kamera umkreist. Das heißt: Er wird immer nur von außen geschildert, gewinnt Profil durch das, was er sagt und tut. Was er denkt und fühlt, erfahren wir nicht, wenn er es nicht äußert. Im vorausgehenden Roman, Verbrechen und Strafe (Prestuplenie in nakazanie), war Dostojewskij völlig anders vorgegangen. Sofort werden wir zum Zeugen der Bewusstseinstätigkeit Raskolnikows. Seine geheimsten Gedanken, Ängste und Gefühle werden durch seine inneren Monologe und seine Träume mitgeteilt. Es findet eine regelrechte Bewusstseinsfotografie statt. Die Innenwelt des Fürsten Myschkin hingegen wird dem Leser nicht geschildert. Wir müssen sie erschließen. Dostojewskij präsentiert uns das Rätsel Myschkin. Man darf sagen: Fürst Myschkin ist die Mona Lisa der russischen Literatur. Obwohl er die Hauptperson ist, haben wir als Leser keinen direkten Zugang zu seiner Innerlichkeit. Und das macht seine Interpretation so schwierig.

Immer wieder bringt Dostojewskij den Fürsten Myschkin in Situationen, in denen er von seiner Umwelt verkannt wird. Die Verkennung wird Dostojewskij zum Prinzip der Profilierung seines Helden. Bereits der Titel des Romans liefert die Formel der Verkennung: Fürst Myschkin ist zwar ein Idiot, aber auch keiner. Alexandra Jepantschina, eine der drei Töchter des Generals Jepantschin, die zu Beginn des Romans eine Narrenprobe am Fürsten Myschkin durchführen, meint: „Dieser Fürst ist vielleicht ein großer Schwindler und gar kein Idiot." ${ }^{16}$ Und der Fürst selber sagt über sich:

„Jetzt gehe ich zu den Menschen [...]. Der Verkehr mit den Menschen wird mir vielleicht langweilig und schwer sein. Vorläufig bin ich willens, gegen alle höflich und aufrichtig zu sein, mehr kann doch niemand von mir verlangen. [...]. Alle halten mich für einen Idioten, und ich war wirklich einmal so krank, dass ich einem Idioten glich, aber wie kann ich denn jetzt noch ein Idiot sein, wenn ich selbst einsehe, dass man mich für einen Idioten hält.“ 17

15 Dostojewskij: Der Idiot, op. cit., S.7. PSS 6, S. 5.

16 Ebd., S. 82. PSS 8, S.48.

17 Ebd., S. 119. PSS 8, S. 64. 
Das Wort „Idiot“ durchzieht den Roman von Anfang bis Ende in allen nur denkbaren Bedeutungen und Bedeutungsschattierungen. Und Dostojewskij setzt eine besondere Pointe, wenn er ausgerechnet dem Direktor der Heilanstalt, Dr. Schneider, über den Fürsten Myschkin sagen lässt, dessen ,geistige Organe seien zutiefst beschädigt" (soveršennoe povreždenie umstvennych organov), als läge hier ein endogener Prozess vor. ${ }^{18}$ Dass Myschkin aufgrund dessen, was er erleben musste, den Verstand verloren hat, bleibt ungesehen. Es handelt sich um eine Verkennung als fundamentale Fehldiagnose, mit der in Wahrheit Dr. Schneider zum Idioten abgestempelt wird.

In diesem Zusammenhang verdient die Verkennung des Fürsten Myschkin, wie sie Jewgenij Pawlowitsch Radomskij liefert, eine ganz besondere Aufmerksamkeit. Dostojewskij stellt nämlich hier dem Leser eine Falle, indem er seinen imaginären Erzähler sagen lässt, die von Radomskij gegebene Einschätzung Myschkins sei „vernünftig und klar" und sogar „von außerordentlicher psychologischer Feinheit“ (Razumno i jasno, i, povtorjaem, s črezvyčajnoju daže psichologiej.) ${ }^{19}$ Der Erzähler vertritt hier den Standpunkt Radomskijs, dessen Selbsteinschätzung. Dem Dostojewskij-Kenner aber ist bereits der Name Radomskij ein Warnsignal, denn Radom ist eine polnische Stadt. Es ist seit dem Totenhaus (Zapiski iz Mërtvogo doma, 1862) und dem Spieler (Igrok, 1866) bekannt, was Dostojewskij von den Polen hielt. Radomskij redet Unsinn, allerdings mit „außerordentlicher psychologischer Feinheit." Poetologiosch gesehen, lässt Dostojewskij hier, im zweitletzten Kapitel des Romans (Teil 4, Kap. 9), kurz vor der Katastrophe die Handlung des ersten Teils mit Myschkins Heiratsantrag als Zentrum zusammenfassen. Die Perspektive der Verkennung soll den Leser dazu bringen, die Wahrheit der Beziehung des Fürsten Myschkin zu Nastasja Filippowna selber zu ergründen, ehe deren Ermordung als factum brutum der letzten Szene zum Thema wird.

Eine völlig andere Art der Verkennung liefert der diffamierende Zeitungsartikel, den Kolja Iwolgin einer empörten Zuhörerschaft, unter ihnen auch Fürst Myschkin, vorliest (Teil 2, Kap. 8). Auch hier wird die Handlung des ersten Teils gebündelt, inklusive ihrer Vorgeschichte in der Schweiz. Während jedoch später Radomskij mit seiner Analyse dem Fürsten ein verständnisvoller Freund sein will, ist der Zeitungsartikel voller Bosheit. Die Lauterkeit des Fürsten Myschkin erscheint plötzlich als Verstellung, hinter seinen Handlungen wird ein ausgekochter Betrüger ermittelt, der sich hinter seiner Idiotie verbirgt, um ein lustiges Leben inmitten heiratswilliger junger Damen zu führen: „Was konnte es auch Verlockenderes geben: ein Aristokrat, ein Millionär, ein Idiot - alles auf einmal, so ein Mann ist ja nicht einmal mit der Laterne zu finden und auch nicht auf Bestellung zu haben. ${ }^{20}$ Dostojewskijs Verständnislenkung hat aber den Leser bereits derart

18 Ebd., S. 187. PSS 8, S. 508.

19 Ebd., S. 838. PSS 8, S. 481.

20 Ebd., S. 382. PSS 8, S. 219. 
präpariert, dass er die hier vorliegende, absichtliche Verkennung sofort als boshafte Unterstellung durchschaut. Noch im ersten Teil hat Dostojewskij auch den Leser dazu gebracht, Myschkin, sei es auch nur für einen Augenblick, zu verkennen: als Myschkin nämlich plötzlich das Schreiben seines Anwalts hervorzaubert, das ihm eine millionenschwere Erbschaft zusichert (Teil 1, Kap. 15). Der Idiot ist mit einem Mal ein Millionär. Wer weiß, was er noch alles ist? Man sieht hier, dass Dostojewskij die Möglichkeit der Verkennung als Spannungsmittel einsetzt. Der höfliche Fremde erregt die Neugier seiner Umwelt, und der Leser sieht sich auf die Folter gespannt, möchte das Rätsel Myschkin lösen. Der rote Faden der Liebesgeschichte mit Myschkin und Nastasja im Zentrum, flankiert von Aglaja Jepantschina, fokussiert dieses Rätsel. Schon der Titel des Romans lieferte die Formel der Verkennung: Der Idiot. Bei Knut Hamsun ist es ebenso.

\section{Mysterien}

Johan Nagel ist der von Geheimnissen umwitterte Held des Romans. Wir erfahren nicht, woher er kommt, und am Ende verschwindet er im Meer: ein allegorischer, selbstgewählter Tod. Aus dem Nirgendwo ins Nichts. Das veranschaulichte Allgemeine besteht offenbar darin, dass die Wirklichkeit unseres Lebens nur blinde Motive kennt: Begonnenes wird nicht vollendet, und schon sind wir wieder verschwunden. Sehen wir uns an, wie der Roman beginnt:

„Um die Mitte des vorigen Sommers war eine kleine norwegische Küstenstadt der Schauplatz einiger höchst ungewöhnlicher Begebenheiten. Ein Fremder tauchte auf, ein gewisser Nagel, ein merkwürdiger und eigentümlicher Scharlatan, der eine Menge auffallender Dinge trieb und ebenso plötzlich wieder verschwand, wie er gekommen war. Dieser Mann erhielt sogar einmal Besuch von einer jungen, geheimnisvollen Dame, die in Gott weiß welcher Angelegenheit kam und nicht wagte, sich länger als ein paar Stunden am Ort aufzuhalten. Doch dies alles ist nicht der Anfang $[\ldots]^{\ltimes 21}$

Mit wenigen Zeilen skizziert Hamsun hier seinen ganzen Roman: Ein Fremder kommt in eine Stadt und verschwindet ebenso plötzlich wieder, wie er gekommen ist. Dazwischen geschehen einige „höchst ungewöhnliche Begebenheiten“. Die gleiche Makrostruktur kann für Dostojewskijs Idiot geltend gemacht werden.

Hamsun legt seine Hauptgestalt darauf an, ständig verkannt zu werden, aber auch selber dafür zu sorgen, verkannt zu werden. Das heißt: Johan Nagel, 29 Jahre alt, steht nicht nur der Welt, sondern auch sich selbst zweifelnd gegenüber. Er will im Umgang mit der Welt erfahren, wer er selbst ist. Und er kommt mit einer solchen Haltung nirgends zur Ruhe. Er lehnt die Welt und sich selbst derart ab, dass er schließlich Selbstmord begehen will. Er trinkt aus einem Fläschchen, das er zu diesem Zwecke stets bei sich führt, Salzsäure und legt sich, allein im Wald, zum

21 Hamsun: Mysterien, op. cit., S. 8. Mysterier, op. cit., S. 5. 
Sterben hin. Völlig übermüdet versinkt er in einen tiefen Schlaf. Das Fläschchen aber enthielt nur Wasser. Johannes Grögard, genannt „Minute“, hatte das Wasser eingefüllt, um ihm etwas Gutes anzutun. Und so erwacht der Weltverächter schließlich. Es ist ein schöner Tag, und Nagel ist, inmitten der Natur, mit einem Mal froh, dass er lebt.

Die Hochstimmung hält jedoch nicht lange an. Nagel geht ins Central Hotel zurück, wo er wohnt, bezahlt seine Rechnung, springt am Kai ins Meer und ertrinkt.

Ein lakonisches Gespräch auf der letzten Seite beschließt ein Jahr später den Roman. Dagny Kielland und Martha Gude, zu denen Nagel enge, wenn auch keine festen Beziehungen geknüpft hatte, gehen spazieren. Nagel und Minute sind tot und schrumpfen im Gespräch der beiden Frauen ins Anekdotische. Das Leben geht weiter.

Und so wird Nagels letzter Monat auf dieser Erde, den der Roman geschildert hat, zur Allegorie eines „Ausländers des Lebens“, der als Fremder kam und als Fremder ging. Ein Fremder ohne Heimat in der bestehenden Welt.

Hamsun konstruiert das Geschehen so, dass sein Held als „unbeschriebenes Blatt" in einer Kleinstadt die verschiedensten sozialen Rollen übernimmt, die sich ihm gleichsam automatisch anbieten, und in diesen Rollen sich selbst und seine Umwelt beobachtet, ohne in einer dieser Rollen wirklich aufzugehen. Spannungstechnisch bedeutet das: Hamsun stellt immer wieder konventionelle Erwartungshaltungen der Umwelt gegenüber dem Helden her, denen dieser dann aber nicht entspricht.

So kommt der Fremde mit einem Geigenkasten im Central Hotel an. Natürlich denkt man, er könnte ein Geiger sein. Der Geigenkasten enthält aber nur schmutzige Wäsche, wie das Zimmermädchen bezeugt. Also ist der Fremde gar kein Geiger, bis er plötzlich im kleinen Kreis auf der Geige des Organisten der Stadt einen ungarischen Tanz von Johannes Brahms spielt.

Es bleibt nichts so, was es zunächst scheint. Johan Nagel gesteht Dagny Kielland seine Liebe. Sie aber weist ihn ab, da sie, eine Pfarrerstochter, ohnehin mit einem Leutnant der Marine, der sich auf See befindet, verlobt ist. Da macht Johan Nagel, 29 Jahre alt, Martha Gude, einer „alten Jungfer“ von 42 Jahren, einen Heiratsantrag, die sich aber schämt, nachdem sie zunächst eingewilligt hat, und ihm entflieht.

Der Mechanismus der Freiheit, den uns Nagel demonstriert, hat folgende Dynamik: Nagel will sich nicht durch soziale Rollen festlegen lassen, spielt seiner Umwelt deshalb verschiedene soziale Rollen vor, unterstellt aber gleichzeitig den Personen seiner Umwelt ein Rollenspiel, dem er kritisch begegnet: als aktives Chamäleon, das überall aktive Chamäleons wittert. Er glaubt keinem die demonstrierte soziale Rolle, und natürlich auch sich selbst nicht und verhält sich deshalb widersprüchlich zu seiner Umwelt. Ihm geht aber in seiner Skepsis gegenüber dem „Man-selbst“ das „eigentliche Selbst“ ab. Und so lebt er in der Selbstentzweiung als unglückliches Bewusstsein. Der Ausweg ist Selbstmord als logische Konsequenz. 
Alles, was jemand sagt, steht in Hamsuns Mysterien immer sofort in der Möglichkeit, tendenziös oder sogar erfunden zu sein, wenn nicht sogar erlogen. Einen übergreifenden, allwissenden Erzähler gibt es nicht. Die Lektüre dieses Romans erzieht den Leser mithin zu einer besonderen Wachsamkeit.

Man denke an das zentrale Gespräch Nagels mit seiner Ex-Geliebten, die plötzlich anreist und ihn aufsucht. Dieses Gespräch ist ein Musterbeispiel für Hamsuns Entfaltung seines Gegenstandes. Wir befinden uns im zwölften der insgesamt dreiundzwanzig Kapitel des Romans. Wie wichtig Hamsun dieses Kapitel ist, sieht man daran, dass es gleich im ersten, soeben bereits zitierten Absatz des Romans heißt: „Dieser Mann erhielt sogar einmal Besuch von einer jungen geheimnisvollen Dame, die in Gott weiß welcher Angelegenheit kam und nicht wagte, sich länger als ein paar Stunden am Ort aufzuhalten." ${ }^{22}$ Dieses zwölfte Kapitel ist psychologisch und poetologisch das Zentrum des Romans: Psychologisch, weil hier erkennbar wird, dass sich Johan Nagel von seiner Vergangenheit getrennt hat und sich von ihr nicht einholen lassen will. Poetologisch lässt Hamsun hier exemplarisch deutlich werden, dass er keinen Roman im üblichen Sinne erzählt, sondern blinde Motive hintereinander stellt, die durch Johan Nagel zusammengehalten werden. Die „Dominante“ (im Sinne Broder Christiansens), die für die Leser die „Objektsynthese“ ausrichtet ${ }^{23}$, liegt hier nicht im Verlauf einer Handlung (wie in Dostojewskijs Idiot), sondern im Panorama der Rollen, die sich Nagel zuschieben, von ihm aber hinter sich gelassen werden, so dass er dadurch ex negativo sein Profil erhält. Der erste Absatz des Romans nennt ihn einen „Scharlatan,“ was allerdings eine rein formale Kennzeichnung bleibt, sozusagen „erlebte Rede“ der Umwelt, denn Johan Nagel hat durchaus einen Ehrenkodex, zu dem etwa seine Hilfsbereitschaft gehört.

Nagel erhält im zwölften Kapitel Besuch von seiner Ex-Geliebten, die „Kamma“ heißt, ihr Gesicht verschleiert hat und vierundzwanzig Stunden gereist ist, um ihn im Central Hotel aufzusuchen. Sie haben sich längere Zeit nicht gesehen. Ihr Gespräch springt immer wieder zwischen „Sie“ und „Du“ hin und her. Man war sich nah, und ist sich nun fern. Sie will wissen, warum er sich „an einem solchen Ort" versteckt, einer Kleinstadt, so unbedeutend, dass sie nicht einmal den Namen kennt. Der Leser fragt sich nun natürlich auch, warum denn Nagel sich versteckt hält. Darauf aber gibt Hamsun keine Antwort. Nagel wiederum will wissen, warum

22 Vgl. ebd.

23 Vgl. Broder Christiansen: Psychologie der Kunst. (Zuerst 1909.) Berlin-Steglitz: B. Behrs Verlag, Friedrich Feddersen 1912, S. 241-242. Hierzu Horst-Jürgen Gerigk: Wer ist Broder Christiansen? Differenzqualität, Dominante und Objektsynthese: drei Schlüsselbegriffe seiner „Philosophie der Kunst“ (1909). In: Figurationen der literarischen Moderne. Helmuth Kiesel zum 60. Geburtstag. Herausgegeben von Carsten Dutt und Roman Luckscheiter. Heidelberg: Universitätsverlag Winter 2007 (= Beiträge zur neueren Literaturgeschichte; Bd. 285), S. 85106. 
sie gekommen sei, er fragt sie, ob sie Geld brauche. Sie spricht davon, dass er ja Geburtstag habe.

Hamsun konstruiert hier virtuos einen Pseudo-Dialog. Jeder will den anderen ausfragen: Es entsteht so ein gegenseitiges Verhör, bei dem nur herauskommt, dass sie von ihm Geld haben will, 250 Kronen, die er ihr schließlich auch mitgibt. Der Erzähler stellt fest:

„Das Gespräch der beiden war stockend und dunkel, mit halben Worten, deren Sinn nur sie allein verstanden, und mit vielen Andeutungen auf die Vergangenheit. Sie hatten sich schon früher getroffen und kannten einander. Die Zusammenkunft währte keine ganze Stunde. Die Dame sprach mehr Dänisch als Norwegisch.“ ${ }^{24}$

Der Leser fragt sich: Was bedeutet das, „mehr Dänisch als Norwegisch“? Ist die Dame eine Dänin? Sie redet Johan Nagel mit „Simonsen“ an. „Der alte nette Kosename“, sagt sie. Und sie amüsiert sich darüber, dass er sich hier für einen „Agronomen“ ausgibt. „Höre, du bist ja Agronom hier, nicht? Hahaha [...].“ Dann springt sie wieder aufs "Sie“ über: „[...].und hier gehen Sie umher und spielen Komödie und setzen die Bewohner mit sonderbaren Einfällen in Erstaunen." Vorher sagt sie:

„Warum kann ich mich niemals von dir losreißen? Ich weiß, dass du verrückt bist [...]. Aber ich kann mich trotzdem nicht von dir befreien. Doktor Nissen hat gesagt, du seist verrückt [...], du musst verrückt sein, da du dich an einem solchen Ort wie diesem hier hast niederlassen und dich Agronom nennen können. “25

Aber wer ist Doktor Nissen? Und wo und wann und unter welchen Umständen hat er sich so geäußert? Wir erfahren es nicht. Später fragt Dagny Kielland Johan Nagel:

„Sogar Ihre breiten Schultern kamen mir verdächtig vor, ich dachte, dass sie aus Watte sein könnten. Ich gestehe offen ein, dass ich vorhin in dem Zimmer dort Ihren Mantel untersuchte, ob die Schultern nicht ausgestopft seien. [...]. Wer sind Sie eigentlich? Und warum sind Sie in diese Stadt gekommen? Sie sind ja nicht einmal unter ihrem eigenen Namen hier. Sie heißen ja eigentlich Simonsen, recht und schlecht Simonsen! Das habe ich durch das Hotel gehört. Eine Dame soll Sie besucht haben, die Sie kannte und die Sie Simonsen anredete, ehe Sie es verhindern konnten." 26

Der Roman gibt auf all diese Fragen und auf andere mehr keine verbindliche Antwort. Wir werden mit unseren Mutmaßungen allein gelassen. Denn nicht zufällig lautet sein Titel Mysterien.

24 Hamsun: Mysterien, op. cit., S. 253. Mysterier, op. cit., S. 121-122.

25 Ebd., S. 258. Mysterier, op. cit., S. 124.

26 Ebd., S. 351-352. Mysterier, op. cit., S. 168. 
Ein normaler Romanleser, der darauf aus ist, dass die Handlung in eine Pointe einmündet, aus der alles Vorherige seinen Sinn erhält, wird sich von Knut Hamsuns Vorgehen in seinem Roman Mysterien fundamental irritiert sehen. $\mathrm{Zu}$ Recht aber müssen wir fragen: Was hatte Knut Hamsun mit solcher Düpierung der konventionellen Erwartungshaltung des Lesers im Sinn? Die Antwort: Hamsun gestaltet am Beispiel eines Fremden, der in einer Kleinstadt absteigt, die ihm unbekannt ist, den automatischen Zwang der Gesellschaft, dem Individuum eine soziale Rolle aufzubürden. Es sind ganz verschiedene Rollen, die dieser Fremde übernimmt, weil er sich in sie hineingestoßen fühlt, ja sie sogar spielerisch ausprobiert: öffentlich, privat und intim. In keiner Rolle aber, das konnten wir schon feststellen, kommt er zur Ruhe, da jede, wie er es ja selber formuliert hat, auf „Humbug" hinausläuft. Und deshalb begeht er schließlich erfolgreich Selbstmord. Er tut dies nicht, weil er etwa arm oder tödlich krank wäre, denn er hat Geld und ist gesund. Deshalb ist sein Selbstmord die Ablehnung der conditio humana überhaupt. Sein Aufenthalt als Fremder in der ihm unbekannten Kleinstadt zeigt ihm wie unter einer Lupe die conditio humana. Das Meer, über das er mit dem Dampfschiff gekommen war, nimmt ihn als einen Selbstmörder wieder auf: den „Ausländer des Lebens.“

\section{Der Idiot des Südens}

Von Mord wie bei Dostojewskij und von Selbstmord wie bei Knut Hamsun ist in Walker Percys Der Idiot des Südens nicht die Rede, wohl aber geht es um Verkennung. Und damit befinden wir uns auf der Linie unseres Vergleichs. Der Held, Will Barrett, 25 Jahre alt, leidet allerdings an einer psychischen Krankheit und begibt sich deshalb in psychiatrische Behandlung. Seine Pseudo-Dialoge mit dem Psychiater Dr. Granow befinden sich im ersten Kapitel im siebten Abschnitt und dürfen als maßgebend für die anthropologische Prämisse des Romans angesehen werden.

Fürst Myschkin hat keinen Beruf. Welchen sollte er auch ausüben? Und von Johan Nagel dürfen wir annehmen, dass er weder ein Agronom noch irgendetwas anderes wirklich war. Will Barrett allerdings ist in New York City im Kaufhaus Macy's als Entlüftungs-Ingenieur angestellt. Er arbeitet von Mitternacht bis $8 \mathrm{Uhr}$ morgens. Im amerikanischen Original nennt ihn der Erzähler „engineer“, denn Barrett hat ja beim Militär eine Ausbildung als Elektronik-Fachmann erhalten. Handke übersetzt „engineer" durchgehend mit „Techniker“. Kurzum: Will Barrett ist mit seinem Job bei Macy's durchaus sozial integriert, verdient sich seinen Lebensunterhalt, hat aber dessen ungeachtet Schwierigkeiten mit seiner Umwelt. Denn er stammt ja aus dem „Süden“. Und „the South“, das ist nicht nur eine geographische Kennzeichnung, sondern immer auch die Kennzeichnung einer Mentalität. Die Menschen, die aus New York stammen und Yankees genannt werden, bilden einen Gegensatz zum Southerner. Der Idiot des Südens ist ein Fremder in New York. Es genügt ein Blick auf das Werk William Faulkners. 
Walker Percy ist darauf aus, die Fremdheit seines Helden unter seinen eigenen Landsleuten zu veranschaulichen. Deshalb ist er ein Südstaatler. Gleichzeitig aber hat sich Will Barrett nicht dem Aufstiegsstreben des amerikanischen Traums unterworfen und widersteht damit auch der Tradition seines Elternhauses. Während einer Rückkehr in den Süden leidet er an einer doppelten Heimatlosigkeit, weil er erfahren muss, dass die Gegend, aus der kam, nicht mehr das ist, was sie war.

Er hat sein Studium der Rechtswissenschaften an der Princeton University abgebrochen, nimmt, wie bereits erwähnt, einen unprätentiösen Posten in einem Kaufhaus in New York an und bezieht ein billiges Quartier in einem Haus der YMCA. Nach dem Tod seines Vaters ist ihm ein Erbe zugefallen, das er allerdings auf recht spezielle Weise nutzt.

Der Roman beginnt mit einer Schlüsselszene. Der „Techniker“ hat sich für viel Geld ein Fernrohr gekauft, eine deutsche Produktion mit dreibeinigem Stativ. Anstelle der üblichen Sammellinse war an das Fernrohr eine „35-MillimeterKamera" angebracht. Das Ganze kostet 1.900 Dollar. Er stellt dieses Fernrohr im Central Park auf und beobachtet die Menschen. Er will nur beobachten, aber nicht mit ihnen ins Gespräch kommen. Nun aber passiert es, denn er verliebt sich in eine unbekannte Frau, die in seinem Fernrohr sichtbar wird. Es ist Liebe auf den ersten Blick.

Damit wird die Situation des Helden unvermittelt ins Bild gehoben, in ein Sinnbild. Er kommt mit den Menschen nicht zurecht, will keine Nähe und ist doch von ihnen fasziniert, solange sie nur fern genug sind. Er stellt dieser Frau nach, weil sie eine Unbekannte ist. Nach fünf Jahren Behandlung durch den Psychiater Dr. Granow in New York, will er nicht weiter behandelt werden. „Es hatte ihn gekränkt, dass Dr. Granow ihn verdächtigte, verrückt zu sein" (It had offended him that Dr. Granow had suggested that he might be crazy). ${ }^{27}$

Woran aber leidet Barrett? Er sieht sich immer wieder von Zuständen des Umherirrens heimgesucht. Aufgrund dieser Zustände wurde er aus der Armee entlassen: Man hatte ihn geistesabwesend an Kampfplätzen des amerikanischen Bürgerkriegs aufgegriffen. Außerdem leidet er seit seiner Kindheit an sogenannten „déjà vu-Erlebnissen“: „Wie einen bekümmerten alten Mann“ überfällt ihn „die übermächtige Empfindung, dass all dies sich schon längst ereignet hatte und dass etwas anderes bevorstünde und wenn es einträfe, dann wüsste er um das Geheimnis des eigenen Lebens. ${ }^{\text {“28 }}$ Es war ihm, als sprängen die Dinge um in etwas „Weißes und Dichtes." Die Zeit erhielt ein Gewicht, für das es keine Sprache gab. Und er selbst „entfiel“ der Welt und erwachte Stunden später in seinem Bett, erholt, aber immer noch im Bann des Erlebten.

All dies formuliert der Erzähler. Barrett selbst bespricht seine Erlebnisse nur mit Dr. Granow, der ihn nicht versteht. Er selbst aber versteht sich auch nicht; er ist

27 Percy: Idiot des Südens, op. cit., S. 50. Last Gentleman, op. cit. S. 38.

28 Ebd, S. 22, Last Gentleman, S. 19. 
also unfähig, sich als Einsiedler in einer eigenen Welt selbstzufrieden abzukapseln. Das Ergebnis ist ein dialektisches Verhältnis zu den Ansprüchen der Außenwelt. Immer wieder entzieht er sich dem Sog der Sozialisation.

„Seine Schwierigkeit, das waren immer noch die Gruppen. Nach mehreren Jahren der Analyse und der Gruppentherapie war er da allerdings um einiges wendiger geworden. Er richtete sich so sehr nach seinen augenblicklichen Gruppengenossen aus und wurde so gewitzt im Rollenspiel (wie die Sozialwissenschaftler das nennen), dass er geradezu in der Gruppe verschwand. Wie jedermann weiß, ist New York bekannt für die Vielzahl der verschiedenen Gruppen, zu denen man gehören kann, so dass zuzeiten sogar ein Normalmensch nicht mehr weiß, wo sein Platz ist. Folglich wechselte der junge Mann, der ohnedies schon nicht wusste, wo sein Platz war, von Tag zu Tag sein Gesicht. Zwischendurch war sein Rollenspiel so vollkommen, dass er aufhörte, der zu sein, der er war, und jemand anderer wurde. ${ }^{29}$

Kurz vorher lesen wir:

„Obwohl er so umgänglich und gewinnend war, wie man es sich nur wünschen konnte, fiel es ihm schwer, zu tun, was die Gruppe von ihm erwartete. Zunächst erfolgreich, passte er doch auf die Dauer in keine Gruppe - und das war etwas Ernstes. Sein Arzt redete eingehend über die Gruppe: was denn seine Rolle darin sei? Und genau das war die Schwierigkeit: entweder verschwand er in der Gruppe, oder er kehrte ihr den Rücken. “30

Wie beim Fürsten Myschkin und bei Johan Nagel wird Will Barretts Selbstverständnis aus Quellen gespeist, die sich einer eindeutigen Bestimmung entziehen. Das Ich strebt jeweils zum Absoluten, das ein gesellschaftliches Vakuum bleibt. Gleich zu Anfang liefert uns Percy ein sozio-psychologisches Porträt seiner Hauptgestalt:

„Er war eine angenehme Erscheinung. Obwohl nur mittelgroß und außergewöhnlich bleich, war er doch stark, schnell und beweglich. Abgesehen von einem tauben Ohr, war er vollkommen gesund. So ansehnlich er einerseits war, so schweigsam war er andererseits. Deswegen konnten die Mädchen wenig mit ihm anfangen. Männer dagegen mochten ihn. Sie merkten mit der Zeit, dass er umgänglich und gutherzig war. Er war einer von denen, an die sich Mitschüler gerne erinnern; sie hatten ihr Vergnügen daran, ihm den Arm um den Nacken zu legen und ihn herumzuschubsen. So gut er aussah und so liebenswürdig er war, er prägte sich einem nicht ein. Derselbe Witz wurde ihm in der Regel zwei- oder dreimal erzählt. “31

Mit solcher Profilierung, die der Text selber liefert, beenden wir unsere Erläuterungen zu diesem Roman. Es sind nun die soziologischen und psychologischen

29 Ebd., S. 32. Last Gentleman, S. 20-21.

30 Ebd., S. 24. Last Gentleman, S. 13.

31 Ebd., S. 19. Last Gentleman, S. 8-9. 
Koordinaten sichtbar geworden, in die Walker Percy seinen Roman einzeichnet. Er versetzt seinen Helden in Situationen, in denen dessen Schwierigkeiten mit Gruppen und mit sich selbst zum Ausdruck kommen, und natürlich wird auf die Darstellung der Beziehungen Will Barretts zum weiblichen Geschlecht eine besondere Sorgfalt verwendet. Unsere Überlegungen sollten in aller Kürze verdeutlichen, was Walker Percy gemeint hatte, als er, nach Abfassung seines Romans, zu seinem Freund Shelby Foote sagte: "Shelby, der Idiot ist das, was ich geschrieben habe" (Shelby, it's The Idiot, that's what I've written). ${ }^{32}$

\section{Fazit}

Alle drei Romane entfalten vor unseren Augen ein und denselben Gegenstand: Ein Fremder kommt in eine Stadt und wird zum Zentrum von Mutmaßungen und Verkennungen. Es handelt sich um Varianten des Topos „der Fremde im Dorf“, wie sie etwa auch in Gogols Toten Seelen (Mërtvye duši) und Franz Kafkas Schloss vorliegen. In diesen beiden, zuletzt genannten Fällen aber hat die Hauptgestalt jeweils ein geheimes Ziel, das ihre Umwelt nicht kennt. Gogols Tschitschikow will durch den Ankauf sogenannter "toter Seelen“, die er dann als lebende verkaufen will, die Bank betrügen und reich werden, und Kafkas angeblicher Landvermesser will das Schloss ausspionieren.

Dostojewskijs Fürst Myschkin, Hamsuns Johan Nagel und Percys Will Barrett aber haben kein „geheimes Ziel“: sie sehen sich in die Welt hineingeworfen und suchen sich zu Recht zu finden. Alle drei jungen Leute sind auf der Suche nach sich selbst, ohne institutionelle Deckung in einer vaterlosen Gesellschaft. Jeder von ihnen wird von einem Ehrenkodex bestimmt, der nicht verbalisiert wird und von uns, den Lesern, zu erschließen ist. Dieser Ehrenkodex hat in der bestehenden Gesellschaft keinen Ort, bleibt mögliche Zukunft.

Alle drei bleiben jeweils in der Welt ein Fremder und ziehen sich aus der Welt zurück: Myschkin in den Wahnsinn, Nagel in den Selbstmord, Barrett in wiederkehrende Absenzen. Alle drei werden von einem Arzt für verrückt erklärt: Myschkin von Dr. Schneider, Nagel von Dr. Nissen, Barrett von Dr. Gamow. Solche Verrücktheit hat eine durchgehende Todesbewusstheit zur Folie. Fürst Myschkin erzählt passioniert von einer Hinrichtung in Lyon, deren Zeuge er wurde, und diskutiert mit Rogoshin in dessen düsterem Hause die dort an prominenter Stelle sichtbare Kopie von Holbeins Christus im Grabe. Es ist ein Bild, das im Betrachter die Frage aufkommen lässt, ob man bei solchem Anblick seinen Glauben verlieren könne. Johan Nagel wiederum trägt für den Fall, dass ihm sein Selbstmord notwendig erscheine, immer ein Fläschchen mit Salzsäure bei sich. In der von Hamsun beschworenen Welt fehlt der christliche Glaube. Man denke nur an die Zwangstaufe, die an Minute vollzogen wird: Hier wird Wirklichkeit als Satire konstituiert. Aus Walker Percys Roman allerdings spricht ein existenzphilosophisch reflektierter

32 Ebd., S. 19. Last Gentleman, S. 8-9. 
Katholizismus. Die Fortsetzung des Romans Der Idiot des Südens hat bezeichnenderweise den Titel Die Wiederkehr (The Second Coming, 1980). Die Gewährsleute Percys heißen Søren Kierkegaard und Romano Guardini und haben bereits dem Idiot des Südens das Motto geliefert. Man könnte sagen: Knut Hamsun und Walker Percy haben jeweils kreative Meditationen über den Fürsten Myschkin geschrieben. ${ }^{33}$

Der Idiot, Mysterien und Der Idiot des Südens im Vergleich gelesen, stellen einen Denkraum her, worin der Konflikt von Subjektivität und Gesellschaft zum dominierenden Kontext wird. Dieser Kontext erweist sich als wesentlich für alle drei Texte, reduziert jedoch jeweils ihr Bedeutungsvolumen.

Jeder der drei Texte kehrt, nach dem Vergleich auf der Basis des hier geltend gemachten Kontextes, zu sich selbst zurück, offen für andere Kontexte. Die hier durchgeführte Untersuchung hat jedoch unser Sensorium geschärft. Eine Interpretation hat nicht dadurch ihr Ziel erreicht, dass sie sich an die Stelle des Textes setzt, ihn regelrecht abhakt, sondern dadurch, dass sie den Wunsch weckt, jetzt den Text noch einmal mit neuen Augen zu lesen.

Wir möchten unsere Überlegungen mit einem Hinweis Hegels auf den „Roman im modernen Sinne“ abschließen. Hegel starb 1831. Er konnte also Dostojewskij und dessen Nachfolger noch nicht kennen. In seinen Vorlesungen über die Ästhetik sagt er:

„Der Roman im modernen Sinne setzt eine bereits zur Prosa gewordene Wirklichkeit voraus, auf deren Boden er sodann der Poesie [...], soweit es bei dieser Voraussetzung möglich ist, ihr verlorenes Recht wieder erringt. Eine der gewöhnlichsten und für den Roman passendsten Kollisionen ist deshalb der Konflikt zwischen der Poesie des Herzens und der entgegenstehenden Prosa der Verhältnisse, so wie dem Zufalle äußerer Umstände. “" ${ }^{34}$

Hierzu ist festzustellen, dass wir es in unseren drei Fällen mit einer unerlösten Subjektivität zu tun haben, die jeweils anders begründet wird.

33 Zur Einordnung des Romans „Der Idiot“ in Dostojewskijs Gesamtwerk vgl. jetzt Horst-Jürgen Gerigk: Dostojewskijs Entwicklung als Schriftsteller. Vom „Toten Haus“ zu den „Brüdern Karamasow."Frankfurt am Main: Fischer Taschenbuch Verlag 2013 (= Fischer Klassik).

34 Vgl. Georg Wilhelm Friedrich Hegel: Vorlesungen über die Aesthetik. Dritter Band. In: Hegel, Sämtliche Werke. Jubiläumsausgabe in zwanzig Bänden. Neu herausgegeben von Hermann Glockner. Stuttgart-Bad Cannstatt: Friedrich Frommann Verlag (Günther Holzboog) 1964, Bd. 14, S. 395. 


\section{Hanna Klessinger}

\section{Schuld und Erlösung: Zur Dostojewskij-Rezeption in Georg Trakls Lyrik}

„Die Romane, die ich von ihm kenne, könnten alle ,Die Geschichte eines Verbrechens" heißen", so Albertine in Marcel Prousts Die Gefangene; gemeint sind die Romane Dostojewskijs, und Albertine fährt fort: „Er ist offenbar ganz besessen von dieser Vorstellung, es ist nicht natürlich, dass er nur von so etwas spricht. ${ }^{\text {"1 }}$

Auch auf den expressionistischen Lyriker Georg Trakl ist das zentrale Thema von Dostojewskijs Romanen nicht ohne Wirkung geblieben: ${ }^{2}$ Im Kaspar Hauser Lied $^{3}$ erinnert der Vers „Und im dämmernden Hausflur der Schatten des Mörders“4 an eine Szene aus Dostojewksijs Roman Der Idiot, wo Rogoschin dem Fürsten Myschkin im dunklen Flur des Hotels auflauert. ${ }^{5}$ Das Motiv kehrt wieder in Trakls Prosagedicht Verwandlung des Bösen als „kalte Stirne des Mörders im Dunkel des Hausflurs“; in der Brenner-Fassung taucht mit dem „schwarzen Wahnsinn des Messers" auch die Waffe Rogoschins auf. ${ }^{6}$ Außerdem scheinen Figuren wie der junge Novize (in den Gedichten Psalm I und Helian), der an Aljoscha Karamasow erinnert, ${ }^{7}$ und typische Gestalten (die Dirne, der Mörder) aus Dostojewskijs Romanwelt entlehnt.

1 Zitiert nach: Horst-Jürgen Gerigk: Die Gründe für die Wirkung Dostojewskijs. In: Dostoevsky Studies 2 (1981), S. 3-26, hier S. 8.

2 Der Aufsatz ist die schriftliche Fassung eines Vortrags, den ich unter demselben Titel am 05.03.2013 in der Georg-Trakl-Forschungs- und Gedenkstätte in Salzburg gehalten habe.

3 Georg Trakls Gedichte werden in den Fassungen der Gedichtsammlungen Gedichte (1913) und Sebastian im Traum (1915) zitiert nach: Georg Trakl: Dichtungen und Briefe. Historischkritische Ausgabe, hg. von Walther Killy und Hans Szklenar, Bd. 1, Salzburg, 2., erg. Aufl. 1987 (im Folgenden: HKA). In Fragen der Datierung, verschiedener Fassungen sowie der Textgenese beziehe ich mich auf: Georg Trakl: Sämtliche Werke und Briefwechsel, Innsbrucker Ausgabe, hg. von Eberhard Sauermann und Hermann Zwerschina, Bd. II, Basel und Frankfurt a. M. 1995, S. 465-470 (im Folgenden: IA).

4 HKA I, S. 95, V. 19.

5 Auf diesen Bezug verweist bereits Reinhold Grimm: Georg Trakls Verhältnis zu Rimbaud. In: Germanisch-Romanische Monatsschrift N. F. 9 (1959), S. 288-315, hier 313.

6 IA III, S. 289f. (Textstufe 3D); vgl. HKA II, S. 169-173.

7 Hierauf verweist Richard Detsch: Die Beziehungen zwischen Carl Dallago und Georg Trakl. In: Walter Methlagl, Eberhard Sauermann und Sigurd Paul Scheichl (Hg.): Untersuchungen zum Brenner. Festschrift für Ignaz Zangerle. Salzburg 1981, S. 158-176, hier S. 166. 
Wiederholt nennt Trakl auch die Gestalt der „Sonja“, die auf die gleichnamige Romanfigur aus Dostojewskijs Schuld und Sühne verweist und dort als Erlöserin des Mörders Raskolnikow auftritt: „Sonja“ begegnet in Trakls lyrischem Kleinzyklus, Die Verfluchten, ${ }^{8}$ der im letzten Vers mit der Erscheinung Sonjas endet („Sonja lächelt sanft und schön"). Sonja ist außerdem titelgebend für das Figurengedicht Sonja, ${ }^{9}$ in dessen Text der Name formelhaft als possessives Genitivattribut wiederkehrt („Sonjas Leben“, „Sonjas Schritt“, „Sonjas [...] Brauen“). Schließlich findet sich die Figur in dem bereits erwähnten Prosagedicht Verwandlung des Bösen (Brenner-Fassung): „Leise läutet im blauen Abend Sonjas Gestalt““.

In Dostojewskijs Roman Schuld und Sühne ${ }^{11}$ verbindet sich mit dieser Figur die Hoffnung auf eine Erlösung des Mörders Raskolnikow durch die Kraft der Liebe. Auch bei Trakl erinnert die Evokation Sonjas inmitten einer Szenerie des Bösen (vgl. die Titel Verwandlung des Bösen und Die Verfluchten) an die Erlöser-Rolle Sonjas. Doch Trakls Darstellung der Figur - im Zeichen von Verschwinden, Abwesenheit und Tod (ich werde darauf noch genauer eingehen) - deutet zugleich auf einen Widerruf von Dostojewskijs Liebesutopie. Diese Beobachtung werde ich im Folgenden exemplarisch anhand einer intertextuellen Analyse der beiden ,Sonja-Gedichte - des Figurengedichts Sonja und des Gedichts Die Verfluchten erläutern und differenzieren. Trakls intertextueller Dialog mit Dostojewskij soll charakterisiert und seine mögliche Funktion - für die Aussage der Gedichte bestimmt werden.

Hierzu muss ich vorausschicken, dass der Dostojewskij-Bezug nicht exklusiv auftritt - sondern in der für Trakl typischen „simultanen Rezeption“ (Bernhard Böschenstein $)^{12}$ mehrerer Bezugsautoren. Vor allem die späteren Gedichte der posthum erschienenen Sammlung Sebastian im Traum sind wie Mosaike aus Zitaten zusammengesetzt: So treffen Verse und Motive romantischer Dichtung etwa von Novalis und Friedrich Hölderlin - auf Anleihen aus moderner, symbolistischer Dichtung, insbesondere von Arthur Rimbaud, Paul Verlaine und Hugo von Hofmannsthal. Immer wieder nimmt Trakl Bezug auf wichtige Identifikations-

8 HKA I, S. $103 \mathrm{f}$.

9 HKA I, S. 105.

10 IA III, S. 289.

11 Zur Zitierweise: Ich verwende den prominenten und zu Trakls Zeiten geläufigen (Unter-)Titel des Romans (anstelle der präziseren Übersetzung Verbrechen und Strafe, die sich inzwischen durch die Neuübersetzung von Swetlana Geier durchgesetzt hat). Der Roman wird im Folgenden zitiert nach der von Trakl höchstwahrscheinlich benutzten Ausgabe: F. M. Dostojewski: Rodion Raskolnikoff. (Schuld und Sühne). Roman. Übertragen von Michael Feofanoff. 2 Bde. München: Piper 1908. Der Nachweis der Zitate und Hinweise erfolgt im Text, wie in der Dostojewskij-Forschung üblich, durch Angabe des entsprechenden RomanTeils (in römischen Ziffern) sowie des Kapitels (in arabischen Ziffern).

12 Vgl. Bernhard Böschenstein: Hölderlin und Rimbaud. Simultane Rezeption als Quelle poetischer Innovation im Werk Georg Trakls. In: Walter Weiss und Hans Weichselbaum (Hg.): Salzburger Trakl-Symposion. Salzburg 1978, S. 9-27. 
figuren der Moderne, etwa auf Friedrich Nietzsche - der in vielerlei Hinsicht als Antipode Dostojewskijs gelten kann.

Die neuere Trakl-Forschung hat diesem Zitatenreichtum zunehmend Rechnung getragen - in Studien, die den intertextuellen Dialog Trakls mit fremder Dichtung rekonstruieren und für die Interpretation fruchtbar $\mathrm{zu}$ machen versuchen. ${ }^{13}$ Allerdings ist die Funktion der Intertextualität umstritten: Sind die Verweise auf fremde Dichtung nichts weiter als ein literarisches Spiel, in dem sich eine abstrakte, nicht welthaltige, sondern sich nur selbst bespiegelnde Literatur offenbart? Sind Trakls intertextuelle Dialoge ein literarisches Spiel, das nichts weiter hervorbringt als „sich selbst meinende Bilder“? ${ }^{14}$

Es geht also um die für die Trakl-Forschung insgesamt entscheidende Frage nach der Hermetik von Trakls Lyrik, die einer Forschungsmeinung nach als abstrakte, dem Verständnis unzugängliche ,reine ' Poesie für sich selber steht. ${ }^{15}$ Demgegenüber gibt es eine andere Richtung - der ich selbst zugehöre,$-{ }^{16}$ die

13 Wegweisend für die Trakl-Forschung war diesbezüglich der Aufsatz von Reinhold Grimm: Georg Trakls Verhältnis zu Rimbaud. In: Germanisch-Romanische Monatsschrift N. F. 9 (1959), S. 288-315. Als aktuelle Studie zur Intertextualität sei genannt: Anette Hammer: Lyrikinterpretation und Intertextualität. Studie zu Georg Trakls Gedichten Psalm I und De profundis II. Würzburg 2005. Der vorliegende Aufsatz knüpft im Wesentlichen an Methode und Ergebnisse meiner Dissertation zur Intertextualität bei Trakl an: Hanna Klessinger: Krisis der Moderne. Georg Trakl im intertextuellen Dialog mit Nietzsche, Dostojewskij, Hölderlin und Novalis. Würzburg 2007 (Klassische Moderne, 8).

14 So die Formulierung, mit der Wolfgang Preisendanz: Auflösung und Verdinglichung in den Gedichten Georg Trakls. In: Wolfgang Iser (Hg.): Immanente Ästhetik. Ästhetische Reflexion. München 1966, S. 227-261, hier S. 241, die These von der Selbstbezüglichkeit von Trakls Zitaten untermauert.

15 Seit Walther Killys Trakl-Interpretationen wird die Unverständlichkeit bzw. ,Hermetik ${ }^{`}$ von Trakls später Lyrik diskutiert. Vgl. Walter Killy: Wandlungen des lyrischen Bildes [1958], 5., erw. Aufl. Göttingen 1967; sowie Ders.: Über Georg Trakl [1960], 3., erw. Aufl. 1967. Für Killy verzichtet Trakls Sprache auf jede Referenz; es sei für „diese Sprache bezeichnend, daß sie häufig spricht, ohne eigentlich mitzuteilen.“ (Killy 1958, 125). Denn „[w]ichtiger als der Gehalt war für Trakl der sinnliche Klang des Satzes." (ebd., 122). Auch für die Tübinger Forschergruppe um Gotthart Wunberg, welche die „Text-Verfahren“ der literarischen Moderne systematisch rekonstruiert hat, ist Trakls Poesie Inbegriff einer referenzlosen, ,autonomen' lyrischen Sprache der Moderne. Vgl. Moritz Baßler, Christoph Brecht, Dirk Niefanger und Gotthart Wunberg: Historismus und literarische Moderne. Tübingen 1996, S. 211-220. Neuerdings hat Hans-Georg Kemper: „Und dennoch sagt der viel, der ,Trakl“ sagt“. Zur magischen Verwandlung von sprachlichem ,Un-Sinn“ in Traklschen ,Tief-Sinn`. In: Károly Csúri (Hg.): Georg Trakl und die literarische Moderne. Tübingen 2009, S. 1-30, versucht, die These von Trakls moderner Hermetik historisch zu differenzieren und zu präzisieren: In der Korrelation von Schönheit (Wohlklang) und Unverständlichkeit sieht er eine moderne Transformation magischen Sprechens, in der ein an sich Unsagbares (Kemper bezieht es auf Trakls Schwester) sprachlich umkreist wird.

16 Ausführlich dargelegt und begründet in: Klessinger 2007. Vgl. auch Rémy Colombat: Psalm (I) (2. Fassung). In: Hans-Georg Kemper (Hg.): Interpretationen. Gedichte von Georg Trakl. Stuttgart 1999, 60-79, hier 64f.: Für ihn verstellt ein Vorurteil der Modernität den Blick auf 
versucht, die ästhetische Eigenart, Vieldeutigkeit und radikale Modernität zu würdigen und dabei trotzdem die Hermetik von Trakls Gedichten zumindest teilweise aufzubrechen und einer Interpretation zu öffnen: Dabei dienen die intertextuellen Verweise als eine Art Anker, da sie auf leichter zugängliche Kontexte eben etwa auf die Romane Dostojewskijs - verweisen. Und im Dialog mit diesen Bezugs- oder Prätexten lassen sich auch Trakls scheinbar so monologische, selbstbezügliche Gedichte zum Sprechen bringen: Es geht also darum, die „Dialogizität" von Trakls Gedichten zu bestimmen, also die semantische und ideologische Spannung zwischen seinen Antwortgedichten und den zitierten Bezugstexten, die von der Hommage bis zum Widerruf reichen kann. ${ }^{17}$ Die punktuellen Zitate können dabei umfassende Kontexte evozieren: Wenn Trakl etwa auf Leitfiguren der Moderne wie Dostojewskij und Nietzsche anspielt, verwendet er ,CodeWörter', die ganze ästhetische, philosophische und gesellschaftskritische Debatten der Zeit aufrufen.

Um den kulturgeschichtlichen Kontext besser zu verstehen, in dem Trakls Lektüren stehen, möchte ich nun - bevor ich zu den Gedichtinterpretationen komme - die zeitgenössischen Bedingungen von Trakls Dostojewskij-Rezeption knapp skizzieren:

\section{Trakls Rezeptionsbedingungen}

Trakls Begegnung mit dem Werk Dostojewskijs reicht in die Salzburger Schulzeit zurück, was eine Bemerkung des Jugendfreunds Erhard Buschbeck bestätigt, nach der Trakl Dostojewskij „sehr früh und mit vollem Einsatz zu lesen begann und bald ganz kannte. "18 In seinen frühen Gedichten der sogenannten Sammlung 1909 finden sich Spuren dieser Lektüre: In der dritten Strophe des Gedichts Naturtheater findet sich eine erste Anspielung auf Dostojewskijs Roman im „Spiel / Verlorner Tage, ohne Schuld und Sühne“ “. ${ }^{19}$

Trakls inhaltliche Auseinandersetzung mit dem Werk Rimbauds und auf die Mitteilungsfunktion seiner Lyrik.

17 Den Begriff verwende ich im Sinne der Intertextualitätstheorie von Ulrich Broich und Manfred Pfister (Hg.): Intertextualität. Formen, Funktionen, anglistische Fallstudien. Tübingen 1985. Ein Optimum an Dialogizität liegt nach dieser Konzeption in einer „differenzierte[n] Dialektik von Anknüpfen und Distanznahme“ (ebd., S. 29).

18 Brief an Ludwig von Ficker vom 23. Oktober 1925. Zitiert nach: Erinnerung an Georg Trakl. 3. erw. Auflage. Salzburg 1966, S. 140. In einer von Trakl verfassten Literaturrezension (Salzburger Volksblatt vom 22. August 1908) findet sich ein vergleichender Hinweis auf die „russischen Epopöen“ als „Urquell der gewaltigsten Geistesrevolution“ (HKA I, S. 209). Hans Weichselbaum: Georg Trakl. Eine Biographie mit Bildern, Texten und Dokumenten. Salzburg 1984, S. 50f., hat auf die mögliche Vermittlung der frühen Dostojewskij-Lektüre durch Otto Weininger hingewiesen, der in Geschlecht und Charakter Dostojewskij „einen der größten Geister" nennt und auf die Figur der Sonja verweist.

19 HKA I, S. 241. 
Auf einem erhaltenen Bücherverzeichnis Trakls sind die Werke Dostojewskijs an erster Stelle aufgeführt. ${ }^{20}$ Hier ist hinter den Namen des Autors die Verlagsangabe „Piper" gesetzt. Trakl hat also Bände der seit 1906 von dem Konservativen Arthur Moeller van den Bruck herausgegebenen Werkausgabe des Münchner PiperVerlages besessen. ${ }^{21}$ Die Mitarbeit Dmitrij Mereschkowskijs an dieser Ausgabe kann als programmatisches Signal an den anvisierten Leserkreis gelten, war der russische Symbolist doch bereits ein beliebter Autor der jüngeren Generation. ${ }^{22}$

Eine ästhetische Opposition Dostojewskij - Goethe wird in einer TagebuchAufzeichnung von Trakls Innsbrucker Bekanntem Karl Röck deutlich: „DO 27.6. [1912] abds mit Georg Trakl in der Stehbierhalle (Marmeladow ... er gegen Goethe, für Dostojewski. [...] “..23 Mit der Opposition zu Goethe markiert Trakl, wie Sieglinde Klettenhammer herausgestellt hat, seine Ablehnung neo-klassizistischer Positionen, etwa im George-Kreis. ${ }^{24}$ Der Name Marmeladow in Röcks knappem Eintrag verweist auf eine Romanfigur aus Dostojewskijs Schuld und Sühne - auf Sonjas Vater, den Trinker Marmeladow, der in seinem berühmten "Gerichtshymnus" (Konrad Onasch) ein erneutertes Christentum der Vergebung einfordert.

Den weltanschaulichen, religiösen Bekenntnischarakter von Trakls Hinwendung zu Dostojewskij dokumentiert ein von Hans Limbach aufgezeichnetes Gespräch zwischen Trakl und dem Nietzscheaner Carl Dallago im Januar 1914. ${ }^{25}$ Im sogenannten ,Limbach-Gespräch` erscheint für Trakl ein christlicher Dostojewskij als weltanschaulicher Gegenpol zu Nietzsche, den Trakl als „wahnsinnig“ bezeichnet. ${ }^{26}$ „Besonders lieb war ihm Dostojewski“, so erinnert sich Limbach und fährt fort:

Von einigen seiner Gestalten, wie Alioscha Karamasoff und Sonja aus „Schuld und Sühne“, redete er mit tiefer Ergriffenheit. Soviel ich mich erinnere, sprach er aus Anlaß von Sonja das schöne Wort aus - wieder mit wild funkelnden Augen -:

20 Trakl besaß die Romane Brüder Karamasow, Der Idiot, Raskolnikow [Schuld und Sühne], Die Dämonen und Das Gut Stepantschikowo sowie Die Politischen Schriften Dostojewskijs (vgl. HKA II, S. 727).

21 F. M. Dostojewski: Sämtliche Werke. Unter Mitarbeiterschaft von Dmitri Mereschkowski, Dmitri Philosophoff u.a. hrsg. v. Moeller van den Bruck. München 1906-1919. Zur Editionsgeschichte der Piper-Ausgabe vgl. Christoph Garstka: Arthur Moeller van den Bruck und die erste deutsche Gesamtausgabe der Werke Dostojewskijs im Piper-Verlag 1906-1919. Frankfurt a.M. u.a. 1998. Zu den deutschen Dostojewskij-Übersetzungen bis 1905 vgl. ebd., S. 7-9.

22 Vgl. Georg Heyms Tagebucheintrag: „Hölderlin, Nietzsche, Mereschkowski, Grabbe / die 4 Helden meiner Jugend“ (Georg Heym: Dichtungen und Schriften. Hg. von Karl Ludwig Schneider. Bd 3: Tagebücher, Träume, Briefe. Hamburg, München 1960, S. 86).

23 Karl Röck: Tagebuch 1891-1946. Hg. von Christine Kofler. Bd. 1. Salzburg 1976, S. 165.

24 Vgl. Sieglinde Klettenhammer: Stefan George und seine ,Jünger ${ }^{\star}$ in der Provinz. Das Verhältnis der Brenner-Gruppe zum George-Kreis. In: George-Jahrbuch 2001, S. 76-118, hier S. 101.

25 Hans Limbach: Begegnung mit Georg Trakl. In: Erinnerung an Georg Trakl. 3., erw. Auflage. Salzburg 1966, S. 117-126.

26 Vgl. ebd., S. $124 f$. 
„Totschlagen sollt' man die Hunde, die behaupten, das Weib suche nur Sinnenlust! Das Weib sucht ihre Gerechtigkeit, so gut, wie jeder von uns“. ${ }^{27}$

Zuvor hatte Trakl im Gespräch bereits - mit Verweis auf „Sie sollen ein Fleisch

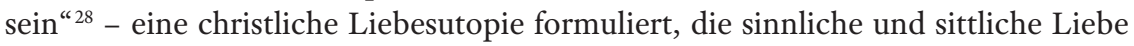
vereinigt, und sich damit ganz offensichtlich an Dostojewskijs Liebesideal orientiert.

Mit seiner ideologischen Hinwendung zum religiösen Dichter Dostojewskij stand Trakl nicht allein: Die Dostojewskij-Rezeption im Brenner, in deren Kontext Trakls produktive Aneignung gehört, lässt sich mit christlichen Tendenzen im Brenner verbinden. ${ }^{29}$ Seitdem der Nietzsche-Enthusiasmus im Laufe des Jahres 1913/1914 in eine Krise gerät, finden kontrastive Beiträge Eingang in den Brenner. Durch die Aufsätze Karl Borromäus Heinrichs und die Kierkegaard-Kommentare und -Übersetzungen Theodor Haeckers gewinnt „der in Sünde, Schuld und seelischer Zerrüttung lebende Mensch auf der Suche nach Gott“ - den Dostojewskijs Romane ja immer wieder darstellen - eine „kulturkritische Relevanz“. ${ }^{30}$ Trakls Poetik vom ,Gedicht als Sühne، wird von der Forschung in diesen kulturgeschichtlichen Kontext gestellt und auf die christliche Dostojewskij-Rezeption im Brenner zurückgeführt. ${ }^{31}$

Zusammenfassend lässt sich festhalten: Trakls Dostojewskij-Rezeption findet in einem bestimmten weltanschaulichen Klima statt. Sie fällt in die Zeit einer besonderen Dostojewskij-Faszination: Viele expressionistische Generationsgenossen Trakls beriefen sich in ihrem Entwurf eines ,neuen Menschen' emphatisch auf Dostojewskij. Die zahlreichen Spuren, die Dostojewskijs Romanwelt in der Literatur der Klassischen Moderne hinterlassen hat, gründen aber nicht nur im weltanschaulichen Gehalt seiner Romane, sondern auch im spezifischen Stil des russischen Romanciers. Ihre Gründe liegen nämlich nicht zuletzt in der - vom Autor strategisch entworfenen - Wirkungsmacht seiner Prosa, die um die Jahrhundertwende dann in besonderem Maße den Nerv der Zeit traf.

27 Ebd., S. 125.

28 Ebd., S. 124.

29 Diese Zusammenhänge sind von der Innsbrucker Trakl-Forschung, insbesondere den Arbeiten von Alfred Doppler, Walter Methlagl und Sieglinde Klettenhammer, erhellt worden. Als Untersuchung zu Trakls Stellung im Brenner sei hier stellvertretend genannt: Alfred Doppler: „Der Brenner“ als Kontext zur Lyrik Georg Trakls [1979], in: Ders.: Die Lyrik Georg Trakls. Beiträge zur poetischen Verfahrensweise und zur Wirkungsgeschichte, Wien u.a. 1992, S. 94103.

30 Klettenhammer 2001, S. 112.

31 Weichselbaum 1994, S. 116, vermutet, dass die Dostojewskij-Rezeption im Brenner von Trakl angeregt sein könnte. Zum Gegensatz Nietzsche-Dostojewskij bei Trakl vgl. auch Walter Methlagl: Nietzsche und Trakl. In: Rémy Colombat (Hg.): Frühling der Seele. Pariser TraklSymposion. Innsbruck 1995, S. 81-121. 
Horst-Jürgen Gerigk hat in seiner wegweisenden wirkungsästhetischen Analyse gezeigt, wie genau Dostojewskij offensichtlich die Wirkung seiner Romane kalkuliert hat..$^{32}$ Er unterstellt ihm sogar eine „machiavellistische Poetik“, mit der er das Interesse der Zuhörer bzw. Leser „erzwingen“ wolle. ${ }^{33}$

Als thematische Wirkungsfaktoren nennt Gerigk etwa die konstante Verwendung - und charakteristische Vermengung - der fünf Themenbereiche Verbrechen, Krankheit, Sexualität, Religion und Politik. In allen großen Romanen Dostojewskijs kreist die Handlung um das Thema des Verbrechens, genauer des Mordes - was ja auch, wie eingangs zitiert, Prousts Albertine nicht entgangen war. Häufig sind Verbrechen und Sexualität verbunden, etwa im Lustmord Rogoschins an Nastassja Filippowna im Roman Der Idiot.

Der zweite Wirkungsfaktor, das Thema der Krankheit, wird von Dostojewskij wiederum mit Verbrechen und Schuld verbunden: Für Dostojewskij dienen körperliche und psychische Ausnahmezustände, wie Gerigk herausstellt, als Kennzeichen eines „falschen Bewusstseins “. ${ }^{34}$ So fällt der Mörder Raskolnikow aus Schuld und Sühne nach seinem Mord in Krankheit und Delirium - was als Rebellion seines Gewissens verstanden werden kann.

Gerigk bemerkt außerdem, dass Dostojewskij die Sexualität - den dritten Wirkungsfaktor - in seinen Romanen stets „mit dem Stigma des Verbotenen“ versehe und zum „Zwillingsbruder des Verbrechens“ stilisiere. ${ }^{35}$ Dabei verwende er häufig sadistische Elemente. An diesem vierten Wirkungsfaktor stellt Gerigk den Effekt des „Fremdartigen, ja Abartigen und oftmals Exotischen, immer aber Extravaganten" heraus. ${ }^{36}$ Er entsteht durch die Verbindung der Religion mit anderen Themenkreisen, etwa mit dem Verbrechen oder der Sexualität. Illustrieren mag dies exemplarisch die Szene der Lazarus-Lesung in Schuld und Sühne, in der die ,heilige Dirne' Sonja versucht, den Mörder Raskolnikow durch die gemeinsame Bibel-Lektüre zu bekehren:

Der Lichtstumpf begann in dem schiefen Leuchter auszugehen und beleuchtete trübe in diesem armseligen Zimmer den Mörder und die Dirne, die so sonderbar beim Lesen des ewigen Buches zusammengekommen waren. (IV, 4)

Auch Trakl erweist sich vor diesem Hintergrund als idealtypischer DostojewskijLeser: In manchen Gedichten erzeugt er - durch vergleichbare Motivkombinationen - eine spezifische Stimmung, die an Dostojewskijs Romane erinnert: Als frühes Beispiel sei die dritte Strophe von Trakls Romanze zur Nacht aus der Sammlung Gedichte (1913) angeführt:

32 Horst-Jürgen Gerigk: Die Gründe für die Wirkung Dostojewskijs. In Dostoevsky Studies 2 (1981), S. 3-26.

33 Ebd., S. 4.

34 Vgl. ebd., S. 10-13.

35 Ebd., S. 14.

36 Ebd., S. 16. 
Der Mörder lächelt bleich im Wein,

Die Kranken Todesgrausen packt.

Die Nonne betet wund und nackt

Vor des Heilands Kreuzespein. ${ }^{37}$

Die spezifische Verbindung von Verbrechen, Rausch, Krankheit, Religion und Sexualität erzeugt genau jene Atmosphäre, die um 1900 die Wirkmacht der Romane Dostojewskijs ausmachte. Doch Trakls Rezeption erschöpft sich nicht in Stimmung und Effekt, sondern lässt eine konzeptionelle Auseinandersetzung mit Dostojewskijs Werk erkennen. Die folgende intertextuelle Interpretation kann zeigen, wie sich in Trakls Rezeption die Faszination durch Dostojewskijs düstere Romanwelt und seine religiöse Erneuerungsutopie mit einer unüberwindbaren Skepsis mischt. Dabei wird zu zeigen sein, dass er diese Skepsis - die bis zum Widerruf der Utopie reicht - in der Dostojewskij-Lektüre spiegeln kann. Denn auch Dostojewskij selbst ist nicht so eindeutig, wie manche seiner Rezipienten behauptet haben.

Nun komme ich zu dem spezifischen Dostojewskij-Bild Georg Trakls und beginne mit dem ersten Beispiel: dem Sonja-Gedicht Die Verfluchten. Ich werde zunächst die formale und inhaltliche Struktur des Gedichtes analysieren, erste Interpretationsansätze formulieren und erst dann, auf dieser Grundlage, den Dialog mit Dostojewskij rekonstruieren. ${ }^{38}$

\section{>Die Verfluchten<}

\section{Die VERFLUCHTEN}

1

Es dämmert. Zum Brunnen gehn die alten Fraun.

Im Dunkel der Kastanien lacht ein Rot.

Aus einem Laden rinnt ein Duft von Brot

Und Sonnenblumen sinken übern Zaun.

Am Fluß die Schenke tönt noch lau und leis.

Guitarre summt; ein Klimperklang von Geld.

Ein Heiligenschein auf jene Kleine fällt,

Die vor der Glastür wartet sanft und weiß.

37 HKA I, S. 16.

38 Mit dieser Methode einer ,parallelen Lektüre' orientiere ich mich an der rezeptionsästhetischen Intertextualitätstheorie von Peter Stocker: Theorie der intertextuellen Lektüre. Modelle und Fallstudien. Paderborn u.a. 1998. 
O! blauer Glanz, den sie in Scheiben weckt,

Umrahmt von Dornen, schwarz und starrverzückt.

Ein krummer Schreiber lächelt wie verrückt

Ins Wasser, das ein wilder Aufruhr schreckt.

2

Am Abend säumt die Pest ihr blau Gewand

Und leise schließt die Tür ein finstrer Gast.

Durchs Fenster sinkt des Ahorns schwarze Last;

Ein Knabe legt die Stirn in ihre Hand.

Oft sinken ihre Lider bös und schwer.

Des Kindes Hände rinnen durch ihr Haar

Und seine Tränen stürzen heiß und klar

In ihre Augenhöhlen schwarz und leer.

Ein Nest von scharlachfarbnen Schlangen bäumt

Sich träg in ihrem aufgewühlten Schoß.

Die Arme lassen ein Erstorbenes los,

Das eines Teppichs Traurigkeit umsäumt.

Ins braune Gärtchen tönt ein Glockenspiel.

Im Dunkel der Kastanien schwebt ein Blau,

Der süße Mantel einer fremden Frau.

Resedenduft; und glühendes Gefühl

Des Bösen. Die feuchte Stirn beugt kalt und bleich

Sich über Unrat, drin die Ratte wühlt,

Vom Scharlachglanz der Sterne lau umspült;

Im Garten fallen Äpfel dumpf und weich.

Die Nacht ist schwarz. Gespenstisch bläht der Föhn

Des wandelnden Knaben weißes Schlafgewand

Und leise greift in seinen Mund die Hand

Der Toten. Sonja lächelt sanft und schön. ${ }^{39}$

Das Gedicht Die Verfluchten entstand im Mai 1913 und erschien erstmals im Brenner-Heft vom 1. Juni 1913. ${ }^{40}$ Die Brenner-Fassung wurde von Trakl ferner in

39 HKA I, $103 f$.

40 Eine abweichende Fassung erschien in der Anthologie >Die Pforte. Eine Anthologie Wiener Lyrik<. Heidelberg 1913, S. 76f. (vgl. IA II, 441f. (Textstufe 3D)). 
den posthum erschienen Gedichtband Sebastian im Traum (1915) aufgenommen und gehört dort dem Zyklus Der Herbst des Einsamen an.

Sieglinde Klettenhammer verweist in einer vergleichenden Interpretation mit den Gedichten Sonja und Afra auf die strukturbildende Funktion der Spannung von Heiligem und Bösem. ${ }^{41}$ In der Figur der Sonja sieht sie diese Gegensätze, die sich den verschiedenen Figurationen des Weiblichen im Gedicht zuordnen, in einer Figur zusammengeführt. Neben Klettenhammer haben Alfred Doppler, Adrien Finck und Richard Detsch auf einen möglichen Dostojewskij-Bezug im Gedicht hingewiesen..$^{42}$

Die 36 Verse des Gedichts, jambische Fünfheber in durchgehend männlichen Kadenzen, sind zu 9 Vierzeilern in umarmenden Reimen zusammengeschlossen, die sich wiederum in drei Strophengruppen gliedern. ${ }^{43}$ Die drei Teile stellen drei Szenen vor; hier verbindet sich der frühexpressionistische Reihungsstil mit der narrativen Struktur, wie sie typisch ist für Trakls späte Lyrik. Die fragmentierte Handlung lässt sich wiefolgt wiedergeben: Der Text beginnt im ersten Teil mit der Szene einer Lockung. Auf die Anziehung einer unschuldigen, heiligen Dirne reagiert ein „krummer Schreiber“ (V. 11), wohl ein Bild für das (als hässlich abgewertete) männliche Begehren. Im zweiten Teil kommt es zu einer tödlichen körperlichen Begegnung zwischen einer als Allegorie der Pest oder als Pestkranke dargestellten weiblichen Figur (der Mutter?) und einem Knaben. Der dritte Teil übernimmt und variiert die Handlungsmotive der vorangehenden Teile. Er beginnt zunächst mit einer Wiederholung der Konstellation von weiblicher Attraktion und schuldhafter männlicher Erregung. Auf die Erscheinung einer Frauengestalt im blauen Mantel der Mutter Maria folgt „glühendes Gefühl // Des Bösen“ (V. 28f.), auf dessen Schuldhaftigkeit mit einer Sühnehandlung reagiert wird (vgl. das Niederbeugen auf die verschmutzte Erde). Schließlich kommt es zu einer erneuten körperlichen Begegnung, die den nachtwandelnden Knaben mit einer „Toten“ zusammenführt, bevor im Schlussvers die Erscheinung Sonjas evoziert wird: "Sonja lächelt sanft und schön“. ${ }^{4}$

41 Sieglinde Klettenhammer: Figurationen des Weiblichen in der Lyrik Georg Trakls. In: Zyklische Kompositionsformen in Georg Trakls Dichtung. Szegeder Symposion. Hrsg. v. Károly Csúri. Tübingen 1996, S. 189-215.

42 Vgl. Doppler 1992, S. 96; Adrien Finck: Georg Trakl. Essais d'interprétation. Lille 1974, S. 233; sowie Richard Detsch: The Dead Child. In: Austriaca 25 (1987), S. 99-113, bes. 108ff. Die folgende Interpretation schließt an das zentrale Kapitel meiner Dissertation an, das Trakls intertextuellen Dialog mit Dostojewskij im Prosagedicht Verwandlung des Bösen und in den Sonja-Gedichten Die Verfluchten und Sonja untersucht: Klessinger 2007, S. 59-114.

43 Zur Beliebtheit gereimter Vierzeiler mit jambischen Fünfhebern in der Lyrik der Jahrhundertwende vgl. Horst J. Frank: Handbuch der deutschen Strophenformen. 2., durchges. Aufl. Tübingen, Basel 1993, Ziffern 4.88-4.110. Die Verfluchten folgt dem Muster 4.101, einer Variante, die v. a. bei den Frühexpressionisten begegnet.

44 Die Fassung der Pforte nimmt in der Schlussstrophe nicht die direkte körperliche Begegnung, sondern das Krankheits-Motiv des Mitteleteils auf und schildert ein nächtliches Krankenlager 
Das zentrale Thema des Geschlechterverhältnisses wird lexikalisch untermalt durch eine Häufung von Wörtern aus den Wortfeldern optischer, akustischer, haptischer und olfaktorischer Wahrnehmungen, die zur sinnlichen Intensität des Textes beitragen. Strukturbildend sind die nachgestellten Adjektivpaare, die sich in jeder Strophengruppe dreimal finden. Das Gedicht beginnt im ersten Teil (der erotischen Lockung) mit einer Häufung der Sinneseindrücke: In der Dämmerung treten die Geräusche des Lachens, Tönens, Summens sowie der „Klimperklang von Geld" hervor, begleitet von einem „Duft von Brot", worauf im dritten Teil der „Resedenduft" (V. 28) und das „Glockenspiel“ (V. 25) antworten. Besondere Bedeutung kommt der Vielzahl von Farbwörtern zu. Sie sorgen für die Bildhaftigkeit des Triptychons, dessen Tableaux in den Farben Rot, Blau, Braun sowie im Kontrast von Schwarz und Weiß gehalten sind. Im Kontext des Gedichts gewinnen die Farben einen thematischen Signalcharakter.

So ist die Sphäre des Geschlechtlichen in allen drei Strophengruppen mit der Farbe Rot verbunden. Die Farbe taucht auf als lachendes Rot im Kontext der Lockung gleich in der einleitenden ersten Strophe (V. 2), im „aggressiv-phallischen“ (Gunther Kleefeld) Bild der „scharlachfarbnen Schlangen“ am Höhepunkt der tödlichen Umarmung im zweiten Teil und im Schlussteil, wo eine (männliche) ,Büßergeste', das Senken der Stirn auf die von Unrat beschmutzte Erde, das auf das wollüstige „Gefühl // Des Bösen“ folgt, in rotes Licht, in den „Scharlachglanz der Sterne", getaucht ist. Die Farbe Blau ist den weiblichen Figuren zugeordnet. Sie begegnet in Verbindung mit der Frauengestalt im blauen Gewand, auf das im ersten Teil zunächst nur ein „blauer Glanz“ (ihr Spiegelbild?) in der Scheibe der Glastür hindeutet. Im zweiten Teil wird der weiblichen Figur explizit ein „blau[es] Gewand“ zugeordnet; im Schlussteil kehrt die Farbe als schwebendes „Blau“ wieder, das sich im „süße[n] Mantel einer fremden Frau“ (gelesen als Apposition) konkretisiert (und an den blauen Mantel der Mutter Maria erinnert).

Der Text changiert in seinen drei Teilen zwischen verschiedenen Frauenbildern (kindliche Dirne, Pest-Allegorie, Heilige), suggeriert jedoch zugleich - über das gemeinsame Merkmal der blauen Kleidung - eine Identität dieser Figuren. Auch Sonja, die sich mit der kindlichen Dirne der ersten Strophengruppe - und über diese mit den anderen Frauengestalten - verbinden lässt, ist in diese ambivalente, changierende Einheit einbezogen.

Die semantische Struktur des Gedichts wird ferner bestimmt durch Verben bzw.

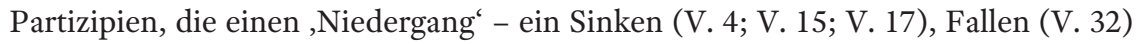
und Stürzen (V. 19) - , eine Auflösung - ein Rinnen (V. 3), Loslassen (V. 23) und Ersterben (V. 23) - sowie eine Unordnung - ein Verrücken (V.11), Aufrühren bzw. Schrecken (V. 12) und (Auf-)Wühlen (V. 22; V. 30) ${ }^{45}$ - anzeigen.

(und einen Todeskampf?), bevor auch hier das rätselhafte Erscheinen Sonjas das Gedicht abschließt (vgl. IA II, 442).

45 Vgl. auch den „Unrat“ (V. 30). 
Durch den Kontext einer unaufhaltsamen Auflösung scheint die ,Unwirklichkeit von Sonjas rätselhaftem Erscheinen am Schluss des Gedichts besonders markiert: „Sonja lächelt sanft und schön“. Die Schönheit ihres Lächelns kontrastiert mit den vorangehenden Bildern des Hässlichen, der Krankheit, Unordnung und Gewalt. Sie erscheint zunächst als Gegenbild zu den in schuldhafte Geschlechterkonstellationen verstrickten „Verfluchten“. Das im Kontext des Gedichts bereits erotisch konnotierte Motiv des Lächelns (vgl. in der ersten Strophengruppe das lockende, lachende Rot, das Lächeln des männlichen Begehrens sowie das assoziativ verbundene Motiv des Mundes) lässt die Gestalt als Verkörperung sinnlicher Schönheit erscheinen. Das Schlussbild könnte so als Ausdruck ,positiver ${ }^{\text {- vom }}$ Fluch des Bösen befreiter bzw. befreiender - Erotik gedeutet werden, die mit der visionären Gestalt Sonjas verbunden wäre.

Ihre mögliche Identität mit der (widersprüchlichen) Figur der kindlichen Prostituierten der ersten Strophengruppe ${ }^{46}$ - über die sie zugleich mit den beiden anderen Frauenfiguren im blauen Gewand verbunden ist - zeigt, dass sich die Figur der Sonja nicht eindeutig vom Hintergrund schuldhafter Verstrickungen abhebt.

Soviel zur Gedichtstruktur - und was hat das alles nun mit Dostojewskij zu tun?

Als markierte Verweise auf seinen Roman Schuld und Sühne fallen zunächst nur auf: Die ,onomastische' Markierung, mit der - punktuell und erst am Ende des Gedichts - auf die weibliche Hauptfigur des Romans, Sonja, verwiesen wird. Damit verbindet sich das Motiv einer kindlichen ,heiligen Dirne' in der ersten Strophengruppe. Auch Dostojewskijs Sonja Marmeladowa, die Tochter eines Trinkers, verdingt sich als Prostituierte, um ihre schwindsüchtige Stiefmutter und ihre verwahrlosten Geschwister zu unterstützen. Die Erlöserin ist bei Dostojewksij also selbst eine Sünderin, ein gefallenes Mädchen, das jedoch seine Reinheit durch seinen christlichen Glauben bewahren konnte.

Bei Trakl erinnert die Evokation Sonjas inmitten einer Szenerie des Bösen an die Erlöser-Rolle Sonjas in Dostojewskijs Roman. Doch Trakls Darstellung der Figur im Zeichen von Verschwinden, Abwesenheit, Tod und Schuld - scheint Dostojewskijs Liebesutopie zugleich zu widerrufen, denn Dostojewskijs Roman nimmt am Ende eine positive, hoffnungsvolle Wendung.

\section{$>$ Schuld und Sühne<}

Mit dem Roman Schuld und Sühne verbindet Dostojewskij ein ethisches Anliegen. Es geht ihm darum, eine christliche Moral im Zeitalter von Atheismus und Nihilismus zu begründen. Liest man den Roman, wie Trakl es wohl getan hat, von Nietzsche herkommend, so sticht Dostojewskijs kulturkritische Ausrichtung besonders ins Auge. Sie zeigt sich auch in der Tatsache, dass Verbrechen und Strafe ein Gegenwartsroman ist. Er spielt im Sommer des Jahres 1865, also nur ein Jahr

46 Vgl. die Wiederholung des Attributs bzw. Adverbs „sanft“ (V. 8, V. 36). 
vor seinem Erscheinen. Im Zentrum der Handlung steht ein Mörder aus Überzeugung. Der junge ehemalige Student Rodion Raskolnikow, der sich von seinen Mitmenschen zurückgezogen hat, entwirft eine Theorie, aus der er ein Recht auf Verbrechen ableitet. Diese Selbstermächtigung, die Raskolnikow aus seiner ,Napoleonischen Theorie' ableitet und mit der er sich als großes Individuum jenseits moralischer Normen feiern will, wurde v. a. um die Jahrhundertwende gelesen als Vorwegnahme von Nietzsches Idee des Übermenschen. Raskolnikow erschlägt daraufhin eine alte Pfandleiherin, die er für eine wertlose „Laus“ hält, und ihre Schwester, die unerwartet am Tatort erscheint. Mit der Realität dieses Doppelmords wird Raskolnikow nicht fertig. Obwohl er keine - bewusste - Reue empfindet, treibt es ihn dennoch zum Geständnis und zur Annahme der Strafe. Mit Raskolnikows Bereitschaft zur Sühne seines Verbrechens (durch das „Leiden“ einer achtjährigen Zwangsarbeit in Sibirien) soll gezeigt werden, dass unter der Oberfläche eines ,falschen' Bewusstseins noch ein Keim zu spiritueller Erneuerung im Sinne einer christlich-orthodoxen Sittlichkeit vorhanden sein kann. Dieser tritt in einem schmerzlichen Bewusstwerdungsprozess zutage, der kurz nach der Tat einsetzt und mit dem Ende des Romans noch nicht abgeschlossen ist. Vor allem in der Liebesbegegnung zwischen Raskolnikow und der unschuldigen, tief gläubigen Dirne Sonja Marmeladowa zeigt sich die Hoffnung auf eine allmähliche „Auferstehung“ (Erneuerung) des Sünders, auf seine Rückkehr ins Leben und in die Gesellschaft, von der er sich durch sein Verbrechen entfernt hatte. Ein Epilog in zwei kürzeren Kapiteln zeigt den Täter anderthalb Jahre später (zur Osterzeit) im sibirischen Zuchthaus und gibt - neben einem knappen Rückblick auf Prozess und Verurteilung zu acht Jahren Zwangsarbeit (fünf Monate nach der Tat) - einen hoffnungsvollen Ausblick auf die verbleibenden sieben Jahre in Sibirien.

Hier verdichten sich die religiösen Motive. Die Sühne, der „Leidensweg“ Raskolnikows, wird motivisch in die Nähe zur Passion Christi gerückt, die Hoffnung auf Raskolnikows „Auferstehung“ wird zeitlich in der Karwoche situiert (vgl. Epilog, 2). ${ }^{47}$

Dem plötzlichen Erwachen dieser Liebe zu Sonja - zwei Wochen nach Ostern wird die Vision eines biblischen Menschentums vorangestellt, das sich für Raskolnikow im Anblick der sibirischen Nomaden offenbart:

Dort in der unübersehbaren Steppe, übergossen von der Sonne, zeigten sich in kaum merklichen dunklen Punkten die Zelte eines Wandervolkes. Dort lag Freiheit, dort lebten andere Menschen [...], dort schien die Zeit stehen geblieben zu sein, als wäre das Jahrhundert Abrahams und seiner Herden noch nicht vorüber. (Epilog, 2)

47 Während seiner Genesung im Lazarett, wo er die letzte Fastenwoche und die erste Osterwoche verbringt, erinnert er sich an seine Träume während der Krankheit (vgl. Epilog, 2). Die Genesung wird zur Heilung des falschen Bewusstseins. Im entscheidenden ,Trichinen-Traum ‘ wird ihm seine Theorie als „Pest“ erkennbar, die die gesamte Gesellschaft infiziert und zersetzt. 
Nach dem (zweiten) Kniefall vor Sonja, in dem Raskolnikow seine Liebe erkennt, werden Auferstehungs- und Liebesutopie zusammengeführt:

Sie wollten sprechen, aber konnten nicht. Tränen standen in ihrer beider Augen. Beide waren bleich und abgemagert, aber in diesen kranken und bleichen Gesichtern leuchtete schon die Morgenröte einer neuen Zukunft, der völligen Auferstehung zu neuem Leben. Die Liebe hatte sie erweckt, das Herz des einen enthielt eine unerschöpfliche Lebensquelle für das Herz des anderen. (Epilog, 2)

Gerade der kurze Epilog, der den weitaus geringsten Teil des Romans ausmacht, hat dessen Wirkungsgeschichte, v. a. die christliche Rezeption, entscheidend bestimmt. Führt man sich jedoch den Hauptteil vor Augen, der auf ca. 700 Seiten in dominant interner Fokalisierung die psychischen Abgründe des Protagonisten minutiös wiedergibt, so wirkt die positive Schlusswendung fast erzwungen. Das ikonische Liebespaar - der Verbrecher und die ,heilige Dirne - und die mit ihm verbundene Erlösungsvision wurden sogar als kitschig kritisiert; schon angesichts der seiner Meinung nach etwas dick aufgetragenen ,Lazarus-Lesung' beschwerte sich Vladimir Nabokov: „Der Killer und die Nutte lesen gemeinsam das ,Buch der Bücher` - welch ein Unsinn!“48

Liegt auch in Trakls ambivalenter, fragiler, verrätselter Sonja-Figur eine versteckte Kritik an Dostojewskij? Wird dessen Liebesutopie im Gedicht widerrufen? Diese Fragen lassen sich differenzierter beantworten, wenn man vergleichend das Figurengedicht Sonja hinzuzieht. In ihm glaubt nämlich Walter Methlagl einen dezidierten Widerruf des sibirischen Epilogs zu erkennen. ${ }^{49}$

\section{$>$ Sonja<}

SONJA

Abend kehrt in alten Garten;

Sonjas Leben, blaue Stille.

Wilder Vögel Wanderfahrten;

Kahler Baum in Herbst und Stille.

Sonnenblume, sanftgeneigte

Ueber Sonjas weißes Leben.

Wunde, rote, niegezeigte

Läßt in dunklen Zimmern leben,

Wo die blauen Glocken läuten;

Sonjas Schritt und sanfte Stille.

48 Vladimir Nabokov: Lectures on Russian Literature. Hg. von Fredson Bowers. London 1982, S. 110. Zitiert nach: Gerigk 1981, S. 16.

49 Vgl. Walter Methlagl: Sonja und Afra. In: Austriaca 13 (1987). Nr. 25, S. 67-87. 
Sterbend Tier grüßt im Entgleiten,

Kahler Baum in Herbst und Stille.

Sonne alter Tage leuchtet

Ueber Sonjas weiße Brauen,

Schnee, der ihre Wangen feuchtet,

Und die Wildnis ihrer Brauen. ${ }^{50}$

Das liedhafte Gedicht in trochäischen Vierhebern entstand 1913. Es erschien im Brenner vom 1. Dezember 1913. Im Zyklus Der Herbst des Einsamen der Sammlung Sebastian im Traum folgt es auf das frühere Sonja-Gedicht Die Verfluchten, an dessen Schlussbild, die Evokation Sonjas, es unmittelbar anschließt.

Eine besondere strukturbildende Funktion kommt dem zweiten Vers jeder Strophe zu, der der Titelfigur gewidmet ist. Hier - in den Versen 2, 6, 10 und 14 werden semantische und syntaktische Muster wiederholt und variiert: Der Name Sonja kehrt als vorangestelltes Genitivattribut in jedem dieser Verse wieder, zweimal unmittelbar am Verseingang als erstes Glied einer Nominalgruppe („Sonjas Leben, blaue Stille“ - „Sonjas Schritt und sanfte Stille“), zweimal an zweiter Position einer Präpositionalgruppe („Über Sonjas weisses Leben“ - „Über Sonjas weisse Brauen“). Zahlreiche Klangfiguren prägen die melodische Sprache des Liedes. Eine Besonderheit stellen hier die identischen Reime dar.

Die elliptische Syntax erzeugt zusammen mit den lexikalischen und syntaktischen Wiederholungsstrukturen den Eindruck eines formelhaften Sprechens, das die Gestalt der Titelfigur gleichsam beschwörend herbeirufen soll. Die unmittelbare Präsenz der Figur in scheinbar lose gereihten Bildern steht im Gegensatz zu ihrer Schemenhaftigkeit, denn die Verse lassen keine konkrete Gestalt vor den Augen des Lesers entstehen. In den ihr gewidmeten Versen der ersten drei Strophen (V.2, V.6, V.10) erfolgt die Kennzeichnung Sonjas lediglich über Abstrakta (Sonjas „Leben“ (V.2, V.6), Sonjas „Schritt“ (V. 10)). Diese können eher als Anzeichen bzw. Spuren ihrer Existenz denn als direkte Beschreibungen gelten und sind jeweils in die Nähe der "Stille“ - als Bild der Nichtexistenz bzw. Abwesenheit (von Geräusch) - gesetzt („Sonjas Leben, blaue Stille“; „Sonjas Schritt und sanfte Stille"). Auf ein mögliches Prostituiertendasein der Figur wird nur in flüchtigen Andeutungen verwiesen - in den Versen 7 und 8 („Wunde, rote, niegezeigte, / Lässt in dunklen Zimmern leben“). Auch hier steht der Aspekt des Verborgenen („[N]iegezeigte[n]“) und der Zurückgezogenheit (,in dunklen Zimmern") dieser Schattenexistenz im Vordergrund. Das Bild von der roten Wunde lässt sich assoziativ mit dem des sterbenden Tiers verbinden, was an eine Täter-Opfer-Konstellation der Geschlechter erinnert, wie sie auch in den Verfluchten dargestellt wird. Der (mögliche) Hinweis auf Sexualität und Gewalt erfolgt jedoch hier unter Ausblendung der Täterseite. Die Figur wird isoliert (in ihrem

50 HKA I, 105. 
Alleinsein) gezeigt. Auf den Versuch einer Kontaktaufnahme mit der Umwelt deutet nur die Geste des Grußes („Sterbend Tier grüßt im Entgleiten“ (V. 12)), die zugleich von zwei Vorstellungen der Vergänglichkeit gerahmt wird - dem „Sterben“ und dem „Entgleiten“ -, was ihre Flüchtigkeit und Vergeblichkeit besiegelt. Die einzige direkte körperliche Berührung verbindet die Figur schließlich mit der sie umgebenden Schneelandschaft, mit der sie gleichsam zu verschmelzen scheint: „Schnee, der ihre Wangen feuchtet, / Und die Wildnis ihrer Brauen“. ${ }^{51}$

Hier geht die erste Konkretisierung der Figur, deren Gesicht nun fragmentiert über Brauen und Wangen in den Blick kommt, paradoxerweise einher mit ihrem (endgültigen) Verschwinden im winterlichen Hintergrund, von dessen leuchtender Schneelandschaft sich das Weiß ihrer Brauen nicht mehr abhebt. Schließlich deutet auch die Metaphorik des Schlussverses auf eine Verschmelzung von Figur und Natur - mit dem vegetativ-animalischen Bild von der „Wildnis ihrer Brauen“.

Walter Methlagl hat sich mit seiner These, Trakl formuliere mit dem Gedicht Sonja einen intertextuellen Widerruf Dostojewskijs, auf die konzeptionell entscheidende Schlusspassage des Romans bezogen. ${ }^{52}$ Trakls Vers „Sonne alter Tage leuchtet" verweise auf die Lichtmetaphorik des Epilogs, ${ }^{53}$ wobei die „alte[n] Tage“ aufgrund der Verkehrung der Szene ins Winterliche nicht auf die rückwärtsgewandte Utopie eines biblischen Menschentums, sondern auf eine Endzeit hindeuteten. In diese apokalyptische Vision fügt sich nach Methlagl auch die allmähliche Auflösung der Sonja-Figur. Im Anschluss an Methlagl lassen sich weitere Widerrufsignale in den beiden ,Sonja-Gedichten' feststellen - doch gehört es zur bereits angedeuteten Ambivalenz, mit der Trakl diese Figur zeichnet, dass dieser Widerruf keineswegs eindeutig ist. Vielmehr handelt es sich, so meine These, um eine kongeniale Dostojewskij Rezeption, denn Dostojekwskij selbst hat seinem Roman eine skeptische Perspektive eingeschrieben: So scheint es vor allem die Widersprüchlichkeit von Dostojewskijs ,ethischem Realismus', die Gefahr seines Scheiterns zu sein, die Trakl in seinen Sonja-Gedichten reflektiert und die Dostojewskij für ihn zur Identifikationsfigur modernen Dichtertums werden lassen.

\section{Intertextuelle Verweise}

Zunächst seien jedoch weitere strukturelle Gemeinsamkeiten zwischen Trakls beiden Sonja-Gedichten und dem Roman knapp zusammengefasst: Da ist zunächst die Täter-Opfer-Konfiguration, gespiegelt im Geschlechterverhältnis, als wichtiges Strukturmerkmal von Dostojewskijs Roman. Ein Reflex könnte sich in der roten Wunde der weiblichen Opferfigur in Trakls Gedicht finden, die mit dem Motiv des

51 M. E. lässt sich der Schlussvers (trotz des trennenden Kommas) als Nebenordnung zum vorangehenden Relativsatz lesen, so dass die Nominalfügung der Schlussverse wie folgt aufgelöst werden könnte: „Schnee, der ihre Wangen und die Wildnis ihrer Brauen feuchtet.“

52 Vgl. Methlagl 1987, 72f.

53 Vgl. auch Porfirijs Aufforderung an Raskolnikow: „Werden Sie eine Sonne und alle werden sie sehen."(VI, 2). 
sterbenden Tiers verbunden ist. Dieses Motiv findet sich auch bei Dostojewskij, der die wehrlose Kreatur über Motivkorrespondenzen mit den weiblichen Opferfiguren verbindet. So nimmt der Mörder Raskolnikow im berühmten „PferdchenTraum“ (I, 5) seine spätere Tat vorweg: Das kindliche Traum-Ich Raskolnikows wird Zeuge einer Misshandlung. Ein Bauer prügelt sein Pferd und erschlägt es schließlich mit einer Axt, der späteren Mordwaffe Raskolnikows. Der entsetzte Knabe Raskolnikow fällt der geschundenen Kreatur unter Tränen um den Hals. (Die Nähe dieser Episode aus Dostojewskijs Roman zu Nietzsches späterem ,TurinErlebnis' ist oft betont worden - sie mag auch Trakl fasziniert haben, zumal die Opposition Nietzsche-Dostojewskij im Brenner-Kreis diskutiert wurde.) Durch das Motiv der „sanften Augen“ - auch Trakl verwendet dieses Adjektiv - ist das sterbende Pferdchen mit den weiblichen Opferfiguren des Romans verbunden: mit Lisaweta, dem zweiten Opfer des Doppelmörders Raskolnikow, und mit der duldsamen Prostituierten Sonja, die sich für ihre Familie aufopfert:

Ihr armen Geschöpfe mit euren sanften Augen ... Ihr Lieben! Warum weinen sie nicht? Warum stöhnen sie nicht? Sie geben alles hin ... blicken sanft und still ... Sonja! Sonja! Stille Sonja! (III, 6)

Und eine solch passive, duldende Opferfigur soll einen Sünder, einen Mörder erlösen können allein durch ihre Liebe, in der sich nach Dostojewskijs Liebesutopie sinnliche Liebe und christliches Mitleid vereinen? Mit dieser etwas vereinfacht formulierten Frage möchte ich auf die äußerst prekäre Konstellation des Romans hinweisen, die sich in vielen psychologischen Details offenbart, die ich hier nicht erörtern kann. ${ }^{54}$ Auf sie scheint Trakl zu antworten: Seine Darstellung einer schemenhaften Figur im Zeichen von Verschwinden, Abwesenheit und Tod liest sich zwar wie ein Widerruf von Dostojewskijs Liebesutopie. Zugleich berührt sie jedoch das Kernproblem der komplexen Romankonstruktion. Ein genauer Blick auf den Roman zeigt, dass auch Dostojewksij ihm eine skeptische Perspektive eingeschrieben hat - in der Trakl die eigene Skepsis spiegeln.

Denn auch im Roman scheint die ,Unwirklichkeit' Sonjas markiert; so ist das Farblose, Zurückgenommene, Schemenhafte der Figur, das bei Trakl auffällt, bereits im Roman vorgebildet (vgl. II, 7; III, 4; IV, 4; V, 1-4; VI, 4): Dort wird Sonja als „klein“ und „mager“ beschrieben, sie erscheint überaus schüchtern und bescheiden, zögerlich (gleich bei ihrem ersten Erscheinen bleibt sie auf der Schwelle stehen, immer bereit, sich zurückzuziehen). Als sie in Raskolnikows Kammer auftaucht, macht sie sogleich eine Bewegung, ,als wollte sie wieder gehen (III, 4). Ihre Stimme ist „leise“, „schwach“, ihr Blick gesenkt. Raskolnikow spricht sie folgendermaßen an: „Wie mager sie sind! Sehen sie nur ihre Hand! Ganz durchsichtig. Diese Finger, wie bei einer Toten!“ (IV, 4).

54 Ausführlicher gehe ich auf diese Zusammenhänge ein in: Klessinger 2007, bes. S. 97-102. 
Dostojewskij markiert seine Skepsis gegenüber dem Liebesideal im Roman noch auf eine andere Weise, auf die sich ebenfalls ein Reflex bei Trakl findet. Die gute Wendung, das utopische Ende des Romans, hängt ab vom Gelingen einer zwischenmenschlichen Begegnung, die schon durch die konsequent ambivalente Figurenzeichnung im Roman gefährdet ist. So lässt sich nachweisen, dass Dostojewskij den inneren Konflikt seines Helden in der Figurtenkonstellation des Romans externalisiert hat. Denn es gibt einen pessimistischen Doppelgänger Raskolnikows, den sadistischen Lüstling Swidrigaijlow, dem die entscheidende Liebesbegegnung verwehrt wird (er scheitert mit seiner Werbung um Raskolnikows Schwester Dunja). Im Kontrast zu dem läuternden Leiden einer Zwangsarbeit in Sibirien, das Raskolnikow in Begleitung Sonjas auf sich nimmt, zieht er eine andere Konsequenz: Er erschießt sich. Die Nacht, die seinem Selbstmord vorangeht, wird im Roman in einem signifikanten Wechsel des Erzählfokus - detailliert geschildert (vgl. VI, 6). Viele Elemente dieser von Alptraumschilderungen durchsetzten Passage lassen sich in Trakls Gedichten nachweisen (z.B. in der Wasser-Metaphorik in Verwandlung des Bösen). ${ }^{55}$ Im Kontext des Figurengedichts Sonja erinnert das Übergehen von der ,gebändigten“ Natur des Gartens in die „Wildnis“ des Schlussbildes an Swidrigaijlows Angst vor der Natur - im Roman ein Bild für die metaphysische Unbehaustheit des modernen Menschen.

Vor dem Hintergrund einer Dostojewskij-Lektüre scheint Trakl das existenzbedrohliche Scheitern zwischenmenschlicher Begegnung, das sich in der Vergeblichkeit einer Kontaktaufnahme ausdrückt, noch auf andere Weise zu markieren: Man denkt an die Episode Bei nassem Schnee aus Dostojewskijs Aufzeichnungen aus dem Kellerloch (1864). Der Untergrundmensch verspielt hier die Chance auf eine rettende Liebesbegegnung, indem er die Prostituierte Lisa demütigt, die daraufhin in das nächtliche Schneetreiben Sankt Petersburg entflieht - eine Szene, der das Entschwinden Sonjas im Gedicht nachgebildet sein könnte.

\section{Spiegel der eigenen Skepsis - die poetologische Bedeutung des Dostojewskij- Bezugs}

Nach diesen knappen Hinweisen kann ich abschließend noch einen Ausblick auf die mögliche Funktion dieser Bezugnahmen geben. Festhalten lässt sich die Ambivalenz von Trakls Sonja-Figur, die sich als eine "Figur in der Schwebe“ kennzeichnen lässt. So scheint es vor allem die Widersprüchlichkeit von Dostojewskijs ethischer Kunst zu sein, mit der sich Trakls Rezeption verbinden lässt, und die Dostojewskij für ihn zu einer Identifikationsfigur modernen Dichtertums werden lassen: Die Sonja-Gedichte lassen sich im Kontext von Trakls Suche nach einer ethischen Kunst der Moderne lesen, in der die (verfehlte) Liebesbegegnung auch zur poetologischen Metapher wird. Die Figur der Sonja ist vor diesem Hintergrund auch bei Dostojewskij als Ausdruck verzweifelter Hoffnung lesbar.

55 Vgl. hierzu Klessinger 2007, S. 109-113. 
Dass Dostojewskij in der schonungslosen Darstellung menschlicher Abgründe die (eigenen) Zweifel immer mit zur Darstellung bringt, der Akzent der Darstellung also nicht auf dem Erreichen, sondern auf dem verzweifelten Ringen um das sittliche Ideal liegt (für das es nach Dostojewskijs Analyse keine Alternative gibt), mag ihn für Trakl zur Identifikationsfigur seines Dichtertums machen.

Trakl scheint Dostojewskijs Kulturkritik, das Bewusstsein einer Gefahr, die vom unbewältigten Bösen in einer entfremdeten Moderne ausgeht, - aus einer Situation existentieller Betroffenheit, diffuser Schuldgefühle heraus - zu teilen und nach einer dichterischen Antwort zu suchen. Dostojewskijs gesellschaftliche Außenseiterfiguren bieten dabei nicht zuletzt ein Vorbild für das dichterische Selbstverständnis. So liegt etwa in dem Titel des Sonja-Gedichts Die Verfluchten auch eine mögliche poetologische Bedeutung: ,les poètes maudits‘

Wie prekär eine ethische Dichtung als Sühne im Anschluss an Dostojewskij ist, deuten die - poetologisch lesbaren - Motive der Stille, der Verstummens bzw. des stummen, wortlosen Lächelns. Sie scheinen in einer zunehmenden Skepsis gegenüber der Möglichkeit von Mitteilung zu gründen. Trakls Sprachskepsis ist m. E. ethisch begründet; die Unmöglichkeit von Mitteilung - und auch die ,Verrätselung'/Hermetik der späten Gedichte - hängt eng mit dem Scheitern zwischenmenschlicher Bindung zusammen, so dass das Scheitern der Liebe auch zum Symptom für die Grenze bzw. das Scheitern der Dichtung wird. In Trakls vielzitiertem Aphorismus verbirgt sich auch die Anspielung auf Dostojewskijs Roman, auf die Motive Schuld und Sühne:

Gefühl in den Augenblicken totenähnlichen Seins: Alle Menschen sind der Liebe wert. Erwachend fühlst du die Bitternis der Welt; darin ist alle deine ungelöste Schuld; dein Gedicht eine unvollkommene Sühne. ${ }^{56}$

56 HKA I, S. 463. 


\section{Peter Bukowski}

\section{Fjodor Dostojewskij und Andreas Maier - eine Annäherung}

Politische und ideologische Gesichtspunkte ziehen sich wie ein roter Faden bis in unsere Tage durch die Rezeption des Romans Böse Geister (Besy). Schon früh haben bedeutende Philosophen wie Nikolaj Berdjaev, Dmitrij Merežkovskij, und Lev Šestov den Roman als prophetische Voraussage der russischen Revolution und der totalitären Systeme des 20. Jahrhunderts gesehen.

In eine ähnliche Richtung gingen auch die Ausgangsfragen auf dem Dresdner Symposium im November 1996 zum Thema Das Prophetische in Dostojewskijs Dämonen: „Und wer sind die Teufel? Die russischen Terroristen? Die Gangster der heutigen Verbrecherwelt?" ${ }^{1}$

In den sechziger Jahren des 20. Jahrhunderts war es gerade dieser Roman, der die ersten Schritte auf dem Weg zur Perestrojka begleitete. Er wurde sowohl von den liberalen Kräften als auch von Vertretern nationalistisch-religiöser Ideen für sich in Anspruch genommen. So galt der Protagonist Petr Verchovenskij aus diesem Roman als Hauptdämon, der auf die stalinistischen Verbrechen hinwies. Aus Sicht der Nationalpatrioten hingegen waren gerade die Dämonen die Reformer, die sich an Westeuropa orientierten und materielle Bedürfnisse verabsolutierten. Allein der Begriff „Dämonen“ wurde zu einem Schimpfwort gegenüber dem jeweiligen politischen Gegner. ${ }^{2}$

In jüngster Vergangenheit war es Jan Philipp Reemtsma, der den Roman politisch instrumentalisierte. Er übertrug in seinem Vortrag Dämonen? Dostojewskij als Analytiker des modernen Terrorismus das Geschehen auf die RAF. ${ }^{3}$

Reemtsma geht davon aus, dass der Terrorismus im Normalfall Motive und Gründe hat. Seine These lautet: Genau wie bei Dostojewskijs Dämonen könne auch bei der RAF keine Rede von ernsthaften politischen Zielen oder Absichten sein. Deshalb müsse auch keine Diskussion darüber geführt werden.

Einen anderen Ansatzpunkt wählt Andreas Maier in seinem Dostojewskij-Verständnis aus.

1 Klappentext in: Olga Großmann, Roland Opitz (Hg.):Das Prophetische in Dostojewskijs Dämonen. Weimar 1998.

2 Karla Hielscher: Wer sind die „Dämonen“ heute? Zur aktuellen Instrumentalisierung von Dostojewskjs Roman. In: Ebd. S. 139-149.

3 Vortrag am 19.02.2007 in der Reihe: nachgedacht. Geisteswissenschaft in Hamburg. 
„Dostojewski hat das zaristische Russland ebenso wenig interessiert wie mich die Bundesrepublik. Uns geht es um Menschen, aber letztlich nicht um Menschen in einer bestimmten Zeit, an einem bestimmten Ort [...].“4

Es geht also nicht mehr um gesellschaftliche Theorien oder politische Ideen in einer bestimmten historischen Situation. Maier fordert damit eine neue Lesart des Romans Böse Geister heraus.

Anhand seiner Äußerungen über Dostojewskijs Erzählhaltung in den Frankfurter Poetikvorlesungen sowie seiner beiden Romane Klausen und Kirillow möchte ich darlegen, ob und inwieweit Maier diesem Ansatzpunkt folgt und seiner Herausforderung gerecht wird. Erhalten wir durch Andreas Maier einen neuen, einen anderen Zugang zu Dostojewskijs Roman Böse Geister?

In meinen Ausführungen werde ich nur insoweit auf Dostojewskijs Roman eingehen, wie die Parallelen zu den Romanen Maiers deutlich werden.

Das Ziel des Erzählens von Maier ist die Auflösung von Gewissheiten. „[...] der Erzähler selbst, die auktoriale Stimme, ist holprig wie ein Mensch. ${ }^{\text {“5 }}$ Mit dieser Erzählhaltung bezieht sich Maier in seinen Poetikvorlesungen direkt auf Dostojewskij:

„Er hat das Objektive, den Sprecher von außen, weitestgehend getilgt. Alles Reden ist schwammig bei ihm, auch die einzelnen Personen zeigen Kohärenz eher dadurch, dass sie dauernd zerfallen in die verschiedensten Richtungen."

Die besondere Darstellungsweise in den Romanen Dostojewskijs hat Michail Bachtin unter dem Begriff „Polyphonie“ gefasst.

Im polyphonen Roman würden gegensätzliche Positionen vertreten, zu denen der Autor keine Stellung bezieht. Dabei handelten die Personen oft im Widerspruch zu ihrer Idee und sind dadurch nicht mit sich selbst identisch.

„Das wahre Leben eines Menschen erfüllt sich der künstlerischen Idee Dostojewskijs nach gleichsam im Punkt dieser Nichtidentität mit sich selbst.[...]."

Diese Widersprüchlichkeit zeigt sich auch im Kommunikationsverhalten der Menschen.

„Bei Dostojewskij reden die Menschen unablässig. Die großen späten Romane ... bestehen weitgehend aus gesprochener Sprache [...]. Was machen die Menschen im Reden bei Dostojewskij? Nun, zum einen breiten sie sich aus [...]. Zum anderen verwirren sie sich dauernd. Es gibt bei Dostojewskij nie ein gelingendes Gespräch. Alle reden im Grunde dauernd aneinander vorbei [...] jeder befindet sich in seiner eigenen Welt. ${ }^{\text {8 }}$

\footnotetext{
4 Andreas Maier: Ich, Frankfurter Poetikvorlesungen, Frankfurt/M. 2006, S. 105.

5 Andreas Maier (2006), S. 112

6 Ebd., S.110

7 Michail Bachtin: Probleme der Poetik Dostoevskijs. München 1971, S. 67.

8 Andreas Maier (2006), S. 109.
} 
Der Grund für die Verwirrung, die auch das wesentliche Thema dieser beiden Romane Maiers darstellt, besteht darin, dass sich die Menschen einander ebenso wie sich selbst ständig widersprechen:

„Die Verwirrung als das eigentliche Thema, die Verwirrung unter den Menschen, also dass Wahrheit hier unter uns nicht möglich ist, sondern nur für den einzelnen. Konkreter gesagt: dass ich Wahrheit für mich erreichen kann, dass es aber an der Wahrheit und an Gott vorbeigeht, wenn ich in der Menschenwelt, im Austausch mit anderen und im diskursiven Ausgleich Wahrheit möglich machen will. “9

Andreas Maier geht es um diese Wahrheit und er bezieht sich dabei auf das Matthäusevangelium, das die Wahrheit „wie eine Flaschenpost durch die Jahrtausende ${ }^{\text {"10 }}$ geschickt hat.

Jeder Mensch könne nach Maier fast jede Handlung als richtig oder falsch erkennen.

„Die Wahrheit ist ein Zaubermittel, und weil sie innerhalb einer Sekunde erlöst, weiß auch jeder, dass es sie gibt und was sie ist und was sie beinhaltet, denn sie ist das Einfachste von der Welt, darum gehen meine Bücher, von da haben sie ihren Wesenskern. ${ }^{\text {11 }}$

Für Maier ist Dostojewskij der Schriftsteller, der die Botschaft des Matthäusevangeliums weiterträgt.

Welch eine Bedeutung die Wahrheit für Dostojewskij besaß, mag beispielhaft ein Zitat illustrieren. Der Protagonist im Traum eines lächerlichen Menschen (Son smešnogo čeloveka) sagt:

„Denn ich habe doch die Wahrheit gesehen, ich weiß: die Menschen können schön und glücklich sein, ohne dabei die Fähigkeit, auf der Erde zu leben, zu verlieren. [...] Ich habe die Wahrheit gesehen - nicht dass ich sie mit meinem Verstand erfunden hätte, nein, ich habe sie gesehen, gesehen. Und ihr lebendiges Angesicht hat meine Seele bis in alle Ewigkeit erfüllt. ${ }^{12}$

Nach Maier ist der Höhepunkt jeder Massenszene in Dostojewskijs Romanen das Chaos, der Skandal. Besonders deutlich wird dieses in dem Roman Böse Geister.

Der Erzähler in Böse Geister hat es sich zur Aufgabe gemacht, die Ereignisse in der Stadt aufzuklären, Klarheit in die Beziehungen Stavrogins zu der ihn umgebenden Gesellschaft und in das Chaos um die Anschläge zu bringen. Er schränkt aber seine Aufgabe als Chronist von vornherein ein, indem er seine Unerfahrenheit betont. Er gehört einerseits dem Kreis der beteiligten Personen an, versucht jedoch andererseits die Ereignisse objektiv zu schildern. Wir finden hier auf den ersten

9 Ebd., S. 115

10 Ebd., S. 96

11 Ebd., S. 141

12 F.M. Dostojewski: Aus dem Dunkel der Großstadt. München 1925, S. 472 f. 
Blick alle Kennzeichen des auktorialen Erzählens. Nach Jochen Vogt beinhalten diese:

„[...] die Kommentarfunktion des Erzählers, die sich in Erzähleinmischungen, Anreden an den Leser, reflektierenden Abschweifungen ausdrückt..." ${ }^{13}$

Dazu kommen noch Hintergrundinformationen, Vor- und Rückgriffe.

Der Chronist berichtet allerdings nur scheinbar objektiv, zum Teil stellt er auch Hypothesen auf, vieles bleibt im Dunkeln. Es wird nicht klar, inwieweit er genauere Kenntnisse hat.

In Böse Geister brodelt es ständig in der Gerüchteküche und der Erzähler ist mittendrin in dieser Gerüchteküche, trägt weniger zur Aufklärung als zur Verwirrung bei.

Schon um Nikolaj Stavrogin ranken sich die unterschiedlichsten Meinungen. Er bleibt letztlich undurchschaubar und gerade das erzeugt Mutmaßungen und Gerede. Auch das skandalöse Auftreten, als er Petr Gaganov, ein Vorstandsmitglied des Klubs, zunächst an der Nase durch den Saal zieht und bei der Entschuldigung ins $\mathrm{Ohr}$ beißt, bleibt unerklärlich und unaufgeklärt.

Der großsprecherische und emotionslose Petr Verchovenskij drängt sich ihm auf und will ihn als Führer des revolutionären Kreises gewinnen. Stavrogin jedoch begegnet ihm distanziert und mit Verachtung.

Für seine Zwecke benutzt Verchovenskij Aleksej Kirillov. Dieser hat mit seinem Freitod sein eigenes Ziel. Wer den Schmerz und die Angst überwindet, erreicht die vollkommene Freiheit. Er will mit seinem Opfer die Menschen von einem Leben befreien, das Betrug, Schmerz und Last ist.

Der Höhepunkt der Verwirrung und aller Gerüchte ist schließlich die Situation auf dem Fest beim Gouverneur von Lembke:

„Am Ende glaubte niemand mehr, der feierliche Tag könne ohne einen kolossalen Zwischenfall verstreichen ohne „die Lösung aller Rätsel“, wie manche [...] es ausdrückten. Im Ganzen war das Gerede chaotisch, zusammenhanglos, trunken und unruhig, so dass es schwer war, sich einen Überblick zu verschaffen und irgendwelche Schlüsse zu ziehen. Gerüchte kamen auf. Die Tatsachen waren im allgemeinen mehr oder weniger bekannt, aber es war offenkundig, dass außer den Tatsachen gewisse Ideen aufgetaucht waren, und zwar, was das Wichtigste war, unzählbar viele. Es war schlechthin unmöglich sich unter ihnen zurechtzufinden. “14

Maiers Annäherung an Dostojewskij bezieht sich auf die Erzählhaltung, die Personendarstellung sowie auf bestimmte Ereignisse und Handlungsabläufe.

In dem Roman Klausen ist der Handlungsort eine Kleinstadt in der Nähe von Bozen. Der Protagonist des Romans ist Josef Gasser, ein Einheimischer, der in

13 Jochen Vogt: Aspekte erzählender Prosa. Eine Einführung in Erzähltechnik und Romantheorie. Opladen 1972, S. 58.

14 Fjodor Dostojewskij: Böse Geister., Zürich 1998, S. 649. 
Berlin studiert hat, jetzt zurückgekehrt und den Klausenern äußerst suspekt ist. Um ihn ranken sich die widersprüchlichsten Meinungen:

„Es wurde viel über ihn erzählt und später wurde noch mehr erzählt... der Eindruck, den Gasser in Klausen hinterlassen hatte, radikalisierte sich nach den Vorfällen im Gerede der Leute von Tag zu Tag. Eine Zeitlang hieß es, er sei in Deutschland Lehrer geworden oder Sozialarbeiter. [...] Gasser wurde teils zu einem Gewalttäter, teils zu einer Art Widerstandsheld gemacht ${ }^{\text {"15 }}$

Es geschieht Ungeheuerliches in dem Ort: Vogelschützer protestieren gegen die Lichtkanone einer Disco, eine Demonstration findet statt, Flugblätter tauchen auf und im Zentrum steht eine Bürgerinitiative gegen die Autobahnbrücke, ein Anschlag wird verübt, der aber tatsächlich gar keiner war.

Obwohl oder gerade weil Gasser nicht Stellung für oder gegen die Autobahnbrücke bezieht, hält man ihn nicht nur für arrogant, sondern für gefährlich.

Einer der angeblichen Rebellen ist auch Leopold Auer, ein Einheimischer, der Gedichte schreibt und sogenannte „pazzi“ (Fratzen) der Bewohner zeichnet. Er wird zu einem Katalysator des Geschehens, so der Aktion auf der Autobahnbrücke, gemacht, der den geistigen Nährboden für den Terror geliefert hat.

Er ist zwar an der Aktion beteiligt, hindert aber lediglich die Autos am Weiterfahren.

Im Übrigen zieht er sich immer mehr zurück.

„Ab einem gewissen Stadium redet man nicht mehr, man ist vielmehr darüber hinaus, und ab diesem Stadium beginnen sich auch plötzlich solche Menschen wie Badowsky an einen zu hängen und selbst das Wort zu führen, das verselbstständigt sich immer mehr und am Ende geschehen irgendwelche Dinge nur auf Grund dieser Verselbstständigung, aber man selbst habe damit schon lange nichts mehr zu tun. ${ }^{\text {“16 }}$

Dieser Badowsky erscheint irgendwann in Klausen und ist überall anzutreffen. Er ist es, der sich provozierend in ein Gespräch zwischen Professor Klein und seinem Assistenten einmischt und den Professor brüskiert.

„Hier Moment [...] habe ich Sie nicht eben gefragt, ob Sie Professor sind? Für was sind Sie denn Professor?" ${ }^{{ }_{17}}$

Klein lässt sich auf dieses Gespräch ein, um dann auf seine Frage, ob er, Badowsky, sich im Unibetrieb auskenne, zu hören:

„Ich kenne mich überall aus, und vor allem natürlich kenne ich mich mit solchen wie Ihnen aus. ${ }^{\text {18 }}$

15 Andreas Maier: Klausen, Frankfurt/M, 2002, S. $13 \mathrm{ff}$.

16 Ebd., S. 170.

17 Ebd., S. 59.

18 Ebd. 
Schließlich spricht Badowsky von Gescheiterten und bezeichnet diejenigen, die nicht gescheitert sind wie z.B. die Professoren als das Erbärmlichste auf der Welt. Auf der Demonstration ruft Badowsky zu den verrücktesten Dingen auf. Er schien das alles auswendig gelernt zu haben und nun mit großer Begeisterung nachzuplappern.

Die Parallelen dieser drei Protagonisten zu Nikolaj Stavrogin und Petr Verchovenskij sind offensichtlich.

Die klarsten Gemeinsamkeiten im Handlungsablauf zeigen sich schließlich in der Darstellung der Versammlung in Klausen, die ebenso wie das Fest in den Bösen Geistern in einem Skandal endet.

„Viele redeten seit einigen Tagen in diesen ungewissen Formeln, sprachen von der ganzen Sache oder der Angelegenheit insgesamt, denn sie konnten nichts konkretisieren, sie erwarteten nur ständig etwas, wenn auch sicherlich nicht das, was dann eintrat. [...] Alle riefen durcheinander, jeder nahm die verschiedensten Positionen ein, und niemand wusste, wovon überhaupt gesprochen wurde. [...] Es blieb nicht aus, dass später unzählige Versionen berichtet wurden, an allen möglichen Orten. Je weniger man sagen konnte, woher (also von wem) dieses Gerücht eigentlich stammte, desto exakter wurde es. ${ }^{\text {"19 }}$

Auch in Klausen haben wir es wie in den Bösen Geistern mit einem Chronisten zu tun. Er weiß ebenso wenig alles wie derjenige in Böse Geister. So bleibt vieles offen, wer z.B. das Flugblatt verfasst hat, wer letztlich für den sogenannten Anschlag auf die Autobahnbrücke verantwortlich ist. Es bleiben Zweifel und Unsicherheit. Und der Chronist trägt dazu bei. Das bevorzugte Stilmittel ist die indirekte Rede. Fast allen Gesprächen liegen Gerüchte zugrunde.

So heißt es am Ende des Romans:

„Kurzum: Niemand wusste eigentlich recht, was an diesem Tag passiert war, was aus Zufall geschehen, was vorsätzlich vonstattengegangen war. Aus der Nähe betrachtet, löste sich das Geschehen in einem Kosmos von Möglichkeiten auf. “20

Der letzte Satz in Klausen lautet: „Lasst mich eine Fratze malen, eine Fratze mit aufgerissenem Mund! ${ }^{21}$ Er steht mehrfach unterstrichen auf einem Zettel, der in der Kammer Leopold Auers hängt.

Damit zitiert Maier direkt die Worte Aleksej Kirillovs. Dem Roman Kirillow dient dieser Satz auch als Leitwort.

Schauplatz der Handlung ist in Maiers Roman Frankfurt/M. und am Ende Gorleben.

Der Schriftsteller schildert eine Gruppe von Studenten, zu denen auch einige junge Leute aus Russland gehören, in ihrer Suche nach Sinn und Wahrheit sowie

19 Ebd., S. 190 ff.

20 Ebd., S. 214.

21 Ebd., S. 215. 
nach Aktionen. Die Gruppe trifft sich vor allem in Kneipen. Es wird diskutiert, gefeiert, getrunken und es werden Aktionen geplant. Am Ende fährt die Gruppe nach Gorleben, um gegen die Atommüll-Transporte zu demonstrieren.

Im Mittelpunkt stehen der Politikersohn Julian Nagel und der Student Frank Kober.

Andrej Kirillow wird von Anton Kolakow, einem der jungen Leute aus Russland, erstmals aufgrund der Ähnlichkeit mit Kober erwähnt. Dieser wirkt verschlossen. Er hat seine chaotischen Zeiten hinter sich und ist unauffällig geworden ebenso wie Andrej Kirillow.

Dieser stammt aus einem Dorf bei Chabarovsk. Er wird als merkwürdige Gestalt bezeichnet, sei oft sehr still, habe aber früher verrückte Dinge getan. Von ihm existiert ein Manifest, das die Gruppe von Kolakow erhält. Dieses Manifest beinhaltet folgende Aussagen:

„..das ganze Unglück (komme) dadurch, dass die Menschen [...]... nach ihrer Glückseligkeit streben oder nennt es meinetwegen auch Bequemlichkeit. ... Der Handwerker des einundzwanzigsten Jahrhunderts [...] fährt zwei- oder dreimal im Jahr in Urlaub, kauft Unterhaltungselektronik, er beansprucht Autos, Banken ... er benötigt riesige Flughäfen, [...] er braucht ein monströses Verkehrsnetz, er setzt riesige Autofabriken voraus, die Stromwirtschaft, die Nahrungsmittelwirtschaftskonzerne [...]. Er ist vernetzt und verfangen in einem riesigen kollektiven System, das allein ...funktioniert durch Abermillionen Menschen, die genauso sind wie er. Das ist das Kirillowsche Gesetz. “22

Es gebe keine dunkle Macht, es gebe nur die Menschen.

Das Manifest wird auch als „Traktat über den Weltzustand“ bezeichnet.

In Julian Nagel, einem der Wortführer der Studentengruppe, verbinden sich jugendlicher Protest, Idealismus und blinder Aktionismus. Er ist es, der andere Menschen brüskiert und Skandale auslöst.

So wirft er einem Beamten vor, dass dieser für all die Fragen, die er den Besuchern der Behörde stellt, keinerlei Verantwortung übernimmt, dass ihm letztlich alles egal ist.

„[...] diese Verhaltensweise ist es, die die Welt täglich in den Abgrund stürzt. ... Sie mein lieber Herr [...], Sie mit ihrer ganzen Grundlosigkeit[...]. Sie sind das Unglück dieser Welt, und zwar höchstpersönlich. ${ }^{\text {"23 }}$

Auf einer Party seines Vaters mit hochrangigen Landespolitikern beschimpft Julian einen der Gäste, der sich in ein Gespräch zwischen Julian und seinen Freunden einmischt als „verdammten kleinen sekttrinkenden Wichser“ ${ }^{24}$

22 Andreas Maier: Kirillow. Frankfurt/M. 2005, S. 136 f.

23 Ebd., S. 61.

24 Ebd., S. 98. 
$\mathrm{Zu}$ einer Eskalation und einem Skandal kommt es nur nicht, weil Frank Kober dazwischen geht und sich mit einem abgebrochenen Sektglas in Unterarm und Hand schneidet und damit vom Streit ablenkt.

Julian erscheint hier als unmittelbarer Nachfolger Nikolaj Stavrogins. Julian ist es auch, der das Traktat begeistert aufgreift. Er sucht die Praxis zu Kirillows Theorie.

Beim Anblick von Jesus am Kreuz bemerkt er, dass Jesus durch alle hindurchschaut.

„Da hängt die Wahrheit, sagte Julian.“25

Dieses Hindurchschauen sieht er in der Sprache des Glaubens verkörpert: Sie sei das einzige ohne Richtung, Fortschritt und Wachstum, die ansonsten in der Welt herrschten.

Dieses Durchschauen ist ein Durchschauen der weltlichen Verstrickung, die Julian so beschreibt:

„Die Katastrophe war elementar. Sie steckte in jedem Schuh, in jedem Meter Straße, in jedem Auto, in jeder Jacke, in jedem Gramm Mehl ..."26

Für Julian gibt es nur eine Lösung, um sich aus dieser Verstrickung zu befreien: sich selbst zu töten.

Bei Julian führt diese Idee zu einem blinden Aktionismus. In Gorleben rast er mit einem Traktor auf eine Polizeikette zu. Er wird angeschossen und aus dem Führerhaus geschleudert. Beim Zurücksetzen des Traktors durch einen Polizisten wird Frank Kober überfahren. Sein Tod ist ein unglücklicher Zufall.

Am Ende knüpft Maier noch einmal eine Verbindung zu seinem Roman Klausen. Kurz vor der Aktion mit dem Traktor sagt Julian:

„Manchmal komme ich mir vor wie eine Fratze, und wenn ich mir so vorkomme, dann möchte ich meine Zunge herausstrecken, der ganzen Welt ... nein, nicht der ganzen Welt, sondern bloß den Menschen, also, das heißt [...] eigentlich bloß mir. ${ }^{\text {“27 }}$

In Kirillow finden sich ebenfalls auf den ersten Blick die genannten Merkmale auktorialen Erzählens. Aber auch hier bleibt der Erzähler in vielen Punkten unwissend. So wird das Geschehen um die Gullideckel-Aktion (Gullideckel werden nachts auf parkende Autos geworfen) nie aufgeklärt. Auch die genauen Umstände des Todes von Frank Kober werden nicht weiter verfolgt. Gespräche werden häufig nicht zu Ende geführt oder mit der Formel „etc.“ abgebrochen.

Thomas Steinfeld hält Maiers Roman für misslungen, da es nur zwei Möglichkeiten gebe, Dostoevskijs Besy für die Gegenwart neu zu schreiben. Man könne sie entweder zitieren, dann müsse man ihren weltanschaulichen Ernst übernehmen, oder aber parodieren, dann müsse der Autor das historische Modell verkleinern.

25 Ebd., S. 203.

26 Ebd., S. 215.

27 Ebd., S. 345 f. 
Nach Steinfeld sind die Personen Dostoevskijs „Sendboten als ausführende Organe einer höheren, theoretischen Gewalt“. ${ }^{28}$

In die gleiche Richtung geht die Kritik von Tilman Krause.

„Für Dostojewskij gilt: Seine Nöte gehören in seine Zeit. In eine repressive Gesellschaft, zu einem bestimmten philosophisch-politischen Diskurs. Dergleichen scheint heute unübertragbar. Ein deutscher Kirillow ist heute lächerlich wohlfeil. “29

Beide Kritiker gehen davon aus, dass Dostoevskij in dem Roman Böse Geister eine konkrete historische Situation schildert, in der sich die liberale Intelligenzija und terroristisch-anarchistische Gruppen bzw. weltanschauliche politische Theorien und Ideen gegenüberstehen. Damit schließen sie an die eingangs erwähnte Rezeption des Romans an.

Unter dieser Voraussetzung wäre eine Aktualisierung des Romans in der Tat ein fragwürdiges Unterfangen und die direkten, zum Teil ja fast wörtlichen Bezüge Maiers in der Personendarstellung, in den Ereignissen und Handlungsabläufen blieben sehr plakativ.

Es ist jedoch die Erzählhaltung, wie sie in Böse Geister herrscht, an die Maier anknüpft. Indem Ulrich Greiner diese in den Mittelpunkt stellt, kommt er zu einer ganz anderen Wertung des Romans Kirillow als Thomas Steinfeld und Tilman Krause.

„In Klausen springt die Erzählstimme von Person zu Person, von innen nach außen, und wir erleben, wie sich diese Sinnsucher und Kneipenschwätzer immer tiefer in eine irreale Welt eingraben, wobei ganz unklar ist, was eigentlich die reale wäre. Unmerklich (auch das hat Maier von Dostojewskij gelernt) sind die Übergänge vom Schwach- zum Tiefsinn, vom Komischen ins Tragische, vom Halluzinatorischen ins Seherische. Meisterhaft das Anschwellen der Kakophonie bis hin zu einer Philosophie der unbedingten, abstrakten Tat, die aber zu nichts führt [...]. Kirillow ist abgrundtief ernst und verzweifelt komisch, und anders kann man unsere Lage nicht nennen. “30

Maier schildert seine Personen und die Ereignisse bewusst nach dem Vorbild der Bösen Geister, um ebenso wie Dostoevskij das Reden und das Verhalten der Menschen aufzudecken und das unabhängig von Zeit und Ort.

Die Verwirrung, die Unmöglichkeit, im Austausch mit anderen die Wahrheit zu finden, herrscht im zaristischen Russland ebenso wie unter Kleinbürgern in einer Kleinstadt oder Studenten in der Großstadt vor. Es gibt keine Gewissheiten. Und letztlich verliert sich alles in einem Dickicht von Mutmaßungen, Gerüchten und Verdächtigungen.

28 Thomas Steinfeld: So niedlich sind die Dämonen, in: Süddeutsche Zeitung vom 15.03.2005, o.S.

29 Tilman Krause: Die Falschen, in: Die Welt vom 19.02.2005, o.S.

30 Ulrich Greiner: Die Sünden dieser Welt. Mit „Kirillow“ erreicht Andreas Maier eine neue Stufe seines Könnens, in: Die Zeit vom 17.03.2005 o.S. 


\section{Stefania Torri}

\section{Dostojewskij in Deutschland und in Italien: Gemeinsamkeiten und Unterschiede ${ }^{1}$}

Allgemein kann man sagen, dass er in den beiden Ländern im Zeitraum von 1881 1927 aus zwei verschiedenen Perspektiven betrachtet wird: In Italien ist es die eines Dichters, die dem stilistisch-literarischen Bereich neue Impulse gibt, in Deutschland hingegen die eines Vertreters einer neuen, „verkehrten“ Welt. Diese Sicht der Dinge führt dazu, die jeweilige eigene Seite kritisch zu definieren und die Möglichkeit eines neuen Anfangs zuzulassen. Da unterschiedliche kulturelle Terrains differenziertere Fragen aufwerfen, kann man Unterschiede, Begriffe oder Motive erkennen, die jeweils nur auf einer Seite anzutreffen sind. Andererseits gibt es durchaus auch Gemeinsamkeiten.

Zunächst werden spezifische Eigenheiten Dostojewskijs wie die große Bereitschaft zum Leiden, die Neigung zu Themen wie Krankheit und Verbrechen und die Idee vom eigenen Volk als einem auserwählten als typisch russisch bezeichnet. Sein Russentum zieht sich wie ein roter Faden durch, in Italien spielt es hingegen eine untergeordnete Rolle. Vor allem sieht man an den programmatischen Theorien der literarischen Zeitschriften, dass in Italien die Frage seines „Russentums“ an Bedeutung verliert. Eher findet man Interesse daran, den russischen Autor anhand universell gültiger Interpretationskriterien zu bewerten, und bringt ihn daher weniger mit seiner Volkszugehörigkeit in Verbindung.

In der Frührezeption beider Länder tritt er als primitiver Schriftsteller in Erscheinung, der die Konfrontation mit einer soliden kulturellen Vergangenheit nicht kennt. Es ist von Wurzellosigkeit und Urwüchsigkeit die Rede, Charakteristika, die Autoren wie Brandes und Bierbaum ${ }^{2}$ als neu empfinden, gerade in einer Zeit, in der z. B. das Programm der sogenannten Heimatkunst aktuell war, in der eine machtvolle Volkskunst für die Nation verkündet worden war, eine Kunst „getragen von der Eigenart unserer Gaue, auf dem Boden unsrer Landschaften, von der Kühnheit

1 Es handelt sich hier dabei um das Schlusskapitel meiner Dissertation, im Verlag Kubon und Sagner 2011 erschienen (Vgl. S. TORRI Dostojewskij in der deutschen und italienischen Literatur. Eine komparative Studie (1881-1927). Otto Sagner, München 2011.)

2 Alle erwähnten Autoren werden in der nachgedruckten Bibliographie angeführt und zwar in der Sektion „Primärliteratur“ (1.A Ausgewählte Texte der Dostojewskij-Rezeption in Deutschland und 1.B Ausgewählte Texte der Dostojewskij-Rezeption in Italien). 
echten Deutschtums durchlodert". ${ }^{3}$ In Italien spricht Ciampoli über das vornehme griechische Erbe, das die Italiener in Form der ästhetischen Mittel bei dem Kontakt mit Dostojewskij erwarten würden, aber nicht fänden. In diese Richtung gehen auch die Bemerkungen von Capuana, der im kulturellen Erbe des lateinischen und griechischen Klassizismus eine Garantie für Harmonie und Heiterkeit der Form jeglichen Kunstwerks sieht. Er verweist aber auf den Gebrauch einer für das „gemeine" Volk bestimmten Sprache. Der Vorwurf der Bindungslosigkeit des Autors bedeutet hier, dass man bei ihm eine Auseinandersetzung mit den bekannten stilistischen Mustern vermißt. In der Frührezeption lässt sich in Italien die Anspielung auf die Bedeutung der Sprache auch direkt auf die questione della lingua zurückführen. In Dostojewskij sieht man den Literaten, der Geheimnissvolles in einer authentischen, volkstümlichen Sprache wiedergeben kann (Carletti, De Gubernatis).

Darüber hinaus finden sich auf den Seiten der italienischen Aufsätze über ihn deutliche Spuren der italienischen Klassiker, die meistens in Form von Zitaten wiedergegeben werden. Hin und wieder werden Textstellen oder Parodien benutzt, die Auskunft über die Bedeutung der ,Sprache“ geben. Die literarische Sprache ist also ein Instrument, ein Ausdrucksmittel, um über Dichtung zu argumentieren (Ciampoli, Jannis, Galletti).

In Deutschland findet man in der Sekundärliteratur von Anfang an eine explizite Reflexion über den russischen Charakter, dem ein deutscher radikal gegenüber gestellt wird. Es entsteht damit eine Polarisierung des russischen und des deutschen Wesens. Es wird offensichtlich, wie im deutschen Kontext diejenigen russischen Charakteristika Dostojewskijs in den Vordergrund rücken, die mit menschlichen Eigenschaften verbunden werden, z. B. mit Begriffen wie Mitleid oder Demut. Die deutsche Gesellschaft dieser Zeit fühlt sich von solcher Bereitschaft zur Erniedrigung sehr angesprochen. Das Niedrige wird erhöht und eine sympathisierende Philosophie bricht sich Bahn. Dostojewskij ist Verkünder einer authentischen Moral des Altruismus (Ernst, Bierbaum). Die Kommentatoren beklagen den Verlust des wahren Christentums bei den Deutschen durch die Säkularisierung der Kirche und loben die Authentizität des russischen Christentums, das sich wirklich in die Rolle der Armen hineinversetzten kann (Bierbaum, Brandes, Ernst). In diesem Zusammenhang spielt die Auseinandersetzung mit Nietzsche eine große Rolle. Dieser hat die Aufgabe, den deutschen Charakter zu vertreten und zu verteidigen aber auch gleichzeitig dessen Zerbrechlichkeit zu enthüllen. Mutmaßlich deutsche Merkmale wie Selbstverwirklichung, Vornehmheit, Vertrauen in den Menschen werden von der neuen „bescheiderenen“ russischen Welt in Frage gestellt. Das Mitleid ist eine Art, sich der Schwäche des Menschen zu nähern (Bierbaum) und ein Merkmal der russischen Literatur, die sich durch Sensibilität für soziale Aspekte auszeichnet (Luxemburg). Nach Meyer Graefe kann Dostojewskij

3 E. Wachler: Die Läuterung deutscher Dichtkunst im Volksgeiste, 1897, S. 27. 
u. a. deswegen mit den Klassikern verglichen werden, weil er authentisches Mitgefühl zu erwecken im Stande ist. Seine Bereitwilligkeit zum Mitleiden ist für Kracauer sogar übertrieben. In der italienischen Rezeption findet das Mitleidsgefühl keine große Beachtung. Die körperliche Schwäche Dostojewskijs selbst ist die Quelle für das Mitleidsgefühl, wie aus einer Ciampoli-Beschreibung hervorgeht. Toffanin vergleicht das Mitleid Dostojewskij mit dem von Dante, aber dieses Gefühl besitzt keinerlei belehrende Funktion wie bei den Deutschen. Galletti mit seiner Verteidigung des Westens wird vom Mitleid wie von einer erniedrigenden Schwäche der russischen Welt abgestoßen.

Was das Element der Demut betrifft, so wird es als typisch russisch bezeichnet (Brandes, Bierbaum) und Nietzsches Wille zur Macht entgegengesetzt (Meyer). Demut ist aber auch ein Gefühl, das in der russischen Seele neben anderen gegensätzlichen wie Dämonismus (Zweig) oder Hass (Kracauer, Irene Forbes Mosse) seinen berechtigten Platz hat. Bahr sieht in der Persönlichkeit Dostojewskijs Züge der Demut von selbstlosem Altruismus begleitet. In Italien fällt die Demut als typisch russische Eigenschaft niemanden auf. Hier werden die Demütigen als eine richtige „Klasse“ betrachtet, zum Beispiel bei Carletti, der Dostojewskijs Sympathie für die Erniedrigten und Unterdrückten preist. Borgese verweist auf die Liebe, die Dostojewskij den Gedemütigten in Russland entgegenbringt und auf deren heilsame Wirkung.

Auch die Wahrnehmung des Leidens Dostojewskijs hat in Deutschland extremistischen Charakter, es wird als das Leiden eines Menschen angesehen, der die außerordentliche, übermenschliche Fähigkeit besitzt, solches zu erdulden. Aus der Perspektive von Brandes biographischer Rekonstruktion heraus hat das Leiden etwas Unerträgliches: Wie andere extrem leidgeprüfte Personen bringt auch ihm nur der Tod wahren Frieden. Dostojewskijs Leidensfähigkeit ist nach Ernst für einen Europäer von fast krankhafter Intensität. Kracauer betrachtet das Leiden als notwendige Etappe im Leben eines jeden großen Menschen auf dem Weg zu Gott. Der Idiot ist nach Hesse ein Beispiel für einen Menschen, der lächelnd Unerträgliches hinnimmt.

Während in Deutschland das extremistische Leiden Dostojewskijs als unerreichbares Vorbild für einen normalen Menschen gilt, hat es in Italien bloß literarischen Wert: Die biographische Rekonstruktion an sich interessiert viel weniger. Dostojewskij gerät eher zu einem Vorwand, über die Wechselbeziehung zwischen Leben und Kunst zu reden, wo das Leiden einen wichtigen Platz einnimmt. De Gubernatis liegt am Herzen, die Gestalt eines Schriftstellers zu präsentieren, der sich der Literatur wie einer regelrechten Mission widmet. Ein Schriftsteller muss erst gelitten haben, um die Früchte seiner Mühen ernten zu können. In den zwanziger Jahren wird in Italien das Thema Leiden oft mit ästhetischen Aspekten in Verbindung gebracht. Der italienische Literat soll dem Beispiel Dostojewskijs bei der Wiedergabe der schmerzlichen Seiten des Lebens folgen. Er soll die Ausländer nicht bloß passiv imitieren, sondern eigene Lösungen anbieten. Man lernt einen 
Autor kennen, der bewusst die problematischen Seiten der Gesellschaft thematisiert (Galati, Gasparini), ohne sich den Kopf über zu viele theoretische Vorschriften zu zerbrechen. In den Texten Borgeses sieht man, dass die degenerativen, pathologisierende Aspekte hinter den literarischen Fähigkeiten Dostojewskijs zurücktreten. Dostojewskijs Schöpfungen werden außerdem literarische Genauigkeit und Würde zugestanden. Er hilft, die Wechselbeziehung zwischen Leben und Kunst mit Maß abzulesen: die Wiedergabe des Leidens im Werk erklärt sich durch schmerzlicher Lebenserfahrung, so wie bei Leopardi und Dante (Anile).

Auf beiden Seiten findet man allgemeine Betrachtungen über das Thema Krankheit in seinem Leben und Werk. In Deutschland bezieht man sich explizit auf die Epilepsie. Die Krankheit birgt großes Potential für eine künstlerische Tätigkeit des Menschen: Sie kann eine Bereicherung für den Dichter sein, weil sie ihm Kreativität verleiht (Brandes), sie hat eine mystische Komponente (Schweisheimer), sie kann Reisebegleiterin zum Unbewussten sein (Hesse, Zweig), sie kann Mittel sein, um schwerste Wahrheiten auszudrücken (Meyer). In Italien gewinnt das Thema Krankheit ab Ende der zwanziger Jahre zentrale Bedeutung, früher sprach man eher von Verbrechen und Wahnsinn. Erst im Text Galatis von 1927 findet man die Würdigung des kranken Menschen in seiner besonderen Authentizität, welche die Mittelmäßigkeit des Durchschnittsmenschen demaskiert. Borgese verkündet sogar die Idee einer Regenerationspsychiatrie, bei der die Krankheit selbst einen Heileffekt auf den Menschen habe. Anile sieht dies offenbar ähnlich, weil er das Zuchthaus für einen Ort der inneren Verwandlung hält. Epilepsie ist demnach eine Krankheit, welche die Möglichkeit literarischer Qualität garantiert, sie wird in krassem Gegensatz zu der „Kälte“ der exakten Wissenschaften gesehen.

In enger Verbindung mit dem Thema Krankheit steht das Thema des Verbrechens oder des Verbrechers. Anfangs sind in Deutschland die Lombroso-Studien des kriminellen Typus, in dem Genialität und Wahnsinn eng miteinander verbunden sind, aktuell, dass Brandes eine derartige körperliche Beschreibung Dostojewskijs lieferte, der zufolge die körperlichen Züge Ausdruck einer psychischen Störung sind. In Brandes Text verschmelzen dann beide Aspekte: Das Verbrechen ist Bestandteil der Krankheit. Später hat das Thema Verbrechen in vielerlei Hinsicht eine aktive Rolle inne: als Anklage gegen die Ungerechtigkeit der bürgerlichen Gesellschaft (Luxemburg), als Suggestion für den Leser (Meyer-Graefe), als Chance, das Gute zu erreichen (Hesse).

In Italien erfährt die Kriminalpsychologie Dostojewskijs die richtige naturalistische „Kälte“ und Sachlichkeit bei Carletti. Ciampoli gibt neue Impulse zur Diskussion über das Verbrechen. Bei ihm vereinigt sich das Verbrechen mit dem Wahnsinn und herrscht die philanthropische Komponente vor: Dostojewskij will gütiger Reformer der Kriminalgesetze sein, wie Beccaria es war. Ciampoli sieht es als Dostojewskijs Verdienst, einem Wahnsinnigen menschliche Werte zuzugestehen. Seither hat der Verrückte ein Gewissen. Nach Ferri ist Dostojewskij in 
seiner Gedankenwelt Vorläufer einer Kriminalanthropologie, da er Verbrechen systematisch durchleuchtet. Bei Borgese ändert sich die Auffassung vom Wahnsinn: Es handelt sich nicht mehr um eine Krankheit, sondern um eine Methode, um die Irrationalität des Lebens wiederzugeben.

Anders als in Italien wird in deutschen Texten das Element der Grausamkeit als typische Eigenschaft des Autors beschrieben. Nach Meyer ist sie „asiatisch“, bei Brandes sogar eine raffinierte stilistische Wahl und nach Bierbaum eine Komponente seines Humors.

Ein weiteres Element, das vorwiegend in Deutschland hervorgehoben wird, ist die Mystik. Dostojewskij ist Träger einer neuen Mystik. Gerade um 1900 orientieren sich Literaten und Vertreter neuer religiöser und ideologischer Bewegungen an einem Wissen jenseits der Wissenschaften und ziehen Gewinn aus dem Umgang mit dem Unverständlichen und Unheimlichen. Aus der Dostojewskij-Rezeption wird erkennbar, wie Mystik explizit als Bestandteil des eigenen Kulturerbes betrachtet wird, aber auch, wie Dostojewskij selbst Träger einer neuen Mystik ist. Ernst beschreibt die Mystik als Merkmal des Westens und als Element, mittel dessen sich Heiterkeit immer in harmonische Verbindung mit der Natur bringen lässt. Er lehnt aber den Vergleich mit Franziskus ab, der für ihn eine ideelle Fusion mit der Natur versinnbildlicht. Brückner sieht die mystischen Merkmale in der Person Dostojewskijs, der scharfe Sinne besitzt und Visionär, Mystiker, Ekstatiker und Weissager in einer Person ist. Attentus spürt die Mystik sowohl in der kristallenen Geschlossenheit Dantes als auch im freien Menschentum Dostojewskijs. Kracauer findet mystische Elemente sogar in der bolschewistischen Bewegung. Lucka hingegen kann in Dostojewskij keine typischen Merkmale einer deutschen Heiterkeit wiedererkennen: Es gebe bei ihm keinen Mystiker wie in der Gotik und keine Weltsicht wie beim heiligen Franziskus. In Italien hat Mystik immer eine negative Konnotation: Bei Carletti wird Dostojewskij gerade wegen der von ihm geschilderten mystisch-pathologischen Welt als für den westlichen Leser unverständlich geschildert. Capuana ist gegen eine mystische Pathologie, denn Mystik geht fast immer mit Weltfremdheit einher. Toffanin empfindet in Anlehnung an Gioberti die Weltfremdheit der Mystiker als Gefahr für die Solidität der Kirche als „politische“ Institution. Bei Galletti basiert die Kritik an Osteuropa stark auf der Ablehnung des russischen Mystizismus Dostojewskijs.

Die Feststellung der Widersprüchlichkeit und des Zusammenwirkens der Kontraste allgemein ist ein typisches Merkmal der deutschen Rezeption. Zweig legt dar, dass der Leser lernt, demütig zu sein und das Leben dämonisch zu finden. Kracauer hebt die gegensätzlichen Gefühle der weiten russischen Seele hervor, wo demütige Ergebung neben anderen negativen Gefühlen wohnt. Auf dieser Linie bleibt auch Irene Forbes Mosse, die in den Figuren Dostojewskijs Demut und gleichzeitige Wildheit als typisch russisch bezeichnet. Wie auch die russische Literaturwissenschaftlerin Elena Vassilieva betont, wird eine solche Charakteristik auch in der deutschen Kritik der damaligen Zeit thematisiert: sie zitiert Leo 
Löwenthal, der in seiner soziologischen Darstellung der Kritik zu Dostojewskij auf die „Technik“ der coincidentia oppositorum aufmerksam macht und nennt als Gründe: „so geht die coincidentia oppositorum unmittelbar auf den gesellschaftlichen Widerspruchscharakter selbst“. ${ }^{4}$

Besonders in den Texten Hesses ist zu erkennen, dass das Zusammenleben der Kontraste zu einer neuen Lebenssicht führt: das Chaos kann sich als neue Möglichkeit anstelle der trügerischen geltenden Moral durchsetzen. Die Skepsis gegenüber einer anonym gewordenen Realität ist ein Spezifikum der deutschen Kultur und zeigt sich in vielerlei Hinsicht. Zum Beispiel erkennt die Kritik in Dostojewkijs Werk eine neue Art der psychologischen Darstellung, die nicht auf Gewißheit, sondern auf die Relativität der Gefühle basiert: Dostojewskij zeigt keine Einheitlichkeit der Figuren (er porträtiert nur Teilmenschen, Ernst) und stellt nur Momente ihrer Emotionen dar (er schafft eine „Momentpsychologie“, Meyer). Er bestreitet die rationale Sicherheit zugunsten einer innovativen „Philosophie des Irrationalen“ (Hueck). Besonders in den zwanziger Jahren herrscht eine Idee von Dostojewskij als Träger der Kraft, gegen die gesellschaftlichen Normen und die traditionellen Gesetzen zu gehen (Hesse, Zweig, Luxemburg). Diese Kraft richte sich gegen die formalen stilistischen Vorschriften der Literatur oder gegen die sozialen Normen, die einen Mord bestrafen und keinen Exzess dulden. Er erinnert daran, dass die konventionellen Normen durch Gefühle überwunden werden können. Das wird erkennbar zum Beispiel an dem Konzept der Figuren von Zweig: Sie sehnen sich nach einer Welt ohne feste moralische Vorschriften, sie leiden mit ihren Mitmenschen. Auf der literarischen Seite widerspiegelt sich diese revolutionäre Seite Dostojewskijs auch in seinen „neuen Realismus“, der den Menschen aus seiner Lethargie reißt. Neue Elemente wie Spannung (Ernst, Meyer-Graefe, Brückner) und Unberechenbarkeit werden als Bestandteil der literarischen Kunst Dostojewskijs anerkannt.

Im Gegensatz zu Deutschland, wo Irrationales und Unkonventionelles immer wieder im Vordergrund stehen, führt Dostojewskij in Italien den Leser in eine vollkommen rationale Welt. Der Leser wird nicht getäuscht, sondern durchwegs über die künstreichen Finessen ins Bild gesetzt (Vorwegnahme der Katastrophe, sorgfältige Planung der Arbeit, Genauigkeit und extreme Logik bei der Konzeption der Figuren und der Techniken). Dostojewskij wird zur Gänze als Literat wahrgenommen: als Dichter mit dem Mut zum Hässlichen, als Autor, der nicht nur für seine philosophischen oder theologischen Überlegungen geschätzt wird, sondern der seiner stilistischen Feinheiten wegen ernstgenommen werden muss. Dostojewskij sei kein Autor, dessen Inspiration rein instinktiv sei, sondern Künstler, der überzeugt mit Verstand und Logik arbeite. (Gasparini).

4 LL, 199 zitiert von E. Vassilieva: The reconstruction of the Dostojewskij-mythos: his reception by German-speaking intellectuals, 1882-1950. 
In beiden Kulturen zeigt sich im Allgemeinen die Schwierigkeit, Neues zu akzeptieren. In Deutschland hat zum Beispiel Bierbaum - trotz großer Bewunderung - starke Bedenken, den Extremismus Dostjewskijs als allgemeingültige Moral zu akzeptieren.

In Italien sieht man am Beispiel der Artikel über Dostojewskij, die in La Voce erschienen, dass trotz der Absichten der Intellektuellen, die Kultur zu erneuern und philologische Genauigkeit wiederzuerlangen, der Umgang mit Dostojewksij einen deutlichen Beweis dafür liefert, wie schwierig es ist, sich mit Neuem auseinanderzusetzen.

Durch den Artikel Bacchellis wird auch klar, dass die Rezensenten von La Ronda eigentlich nicht bereit sind, Dostojewskij „das Wort zu überlassen“. Aus ihren kritischen Untersuchungen scheint eher zu resultieren, dass Fragen wie die Verschiedenartigkeit und die angeblich angeborene „Antiklassik“ des russischen Autors im Zentrum ihrer wissenschaftlichen Interessen stand.

Die schwierige Auseinandersetzung mit dem Neuen demonstriert oft eigene Inhaltslosigkeit. Man sucht auf beiden Seiten nach einem Dichter der starken Emotionen. Dostojewskij fordert vom Leser große Empathie, die bisher unbekannt war (Bierbaum, Carletti). In Italien wird behauptet, dass Dostojewskij die Literatur durch Schilderung unerhörter Emotionen aus ihrer Starre befreit habe (Cecchi), Bierbaum schätzt den Humor Dostojewskijs. Seine Exzesse und Übertreibungen werden immer mehr als Positivum gesehen (Zweig, Brückner). Auch in Italien erinnert Dostojewskij mit Nachdruck daran, dass das Tragische, das die emotionale Tiefe einer Existenz auszuleuchten weiß, nicht zu unterschätzen sei (Marussig).

Dostojewskij beeindruckt durch seine außergewöhnliche literarische Techniken: In der deutschen Frührezeption bringt er die Vorstellung der literarischen Figur als Person, die über sich selbst reflektiert und eine gewisse Selbständigkeit gegenüber seinem Schöpfer erlangt. Weitere Merkmale, die in der deutschen Frührezeption auffallen, sind: Das Sich-Zurücknehmen des Autors zugunsten der literarischen Figur, der Dialog als Ausdruck der Dramatik in der Handlung (Brandes, Ernst).

In Deutschland bezieht man sich sehr oft auf die literarische Produktion Dostojewskijs als Spiegel der neuen russischen Welt, in Italien wird er als Beispiel für Erneuerungen auf der literarischen Ebene allgemein herangezogen. Diesen Unterschied kann man zum Beispiel auch anhand der Überlegungen über Schillers Einfluss auf Dostojewskij beobachten, die aus deutscher und italienischer Sicht vollkommen verschieden klingen. In der Zeitschrift „Il Marzocco“ vom 9. Dezember 1923 wird ein anonymer Beitrag Schiller e Dostoevskij veröffentlicht, in dem der Autor betont, dass die Werke Schillers und Dostojewskijs in besonderer Weise Gemütsbewegung hervorrufen. ${ }^{5}$ Dostojewskij intensiviert, was Schiller schon gesagt hatte: die Prinzipien von Humanität und Freiheit stehen bei Schiller im Gegensatz zu seinem traditionellen Glauben - die X. Szene des V. Aktes aus Don

5 G., Schiller e Dostoevskij, Il Marzocco 9 dicembre 1923 Anno XXVIII n. 49. 
Carlos (die Ermahnung des Inquisitors Philipp gegenüber) wird zitiert - und bei ihm wird zusätzlich der schwierige Umgang mit der menschlichen Freiheit dargestellt. Der Inquisitor nimmt bei Dostojewskij Jesus fest und - die Übersetzung Polledros wird zitiert - „si tiene da quello religioso ancora su nel portamento, ha viso disseccato e occhiaie cave, ma in esse riluce ancora una scintilla". ${ }^{6}$ Schiller dagegen spricht zu Philipp wie zu einem Lieblingsschüler oder einem Kind.

Aus deutscher Sicht sei als Beispiel der Aufsatz August Scholzes (1857-1923, Lehrer, Dostojewskij-Übersetzer und Novellist aus Berlin) Schiller und Dostojewskij erwähnt: ${ }^{7}$ Die beiden Dichter werden als Vertreter zweier gegenseitiger Welten dargestellt; Schiller verkörpert die Freiheit (der im kühnen Hochflug des Gedankens frei über den Dingen schwebende Deutsche), Dostojewskij hingegen ist ein grübelnd in der Menschenseele wühlende Slawe. Der Autor verleiht dem russischen Schriftsteller eine nachgeordnete Position: Hervorgehoben wird, dass Dostojewskij unter Schillers Einfluss gestanden hat. Aus italienischer Sicht vertieft also das russische Vorbild die Motive der literarischen Tradition. Aus deutscher Sicht hingegen kommen Schiller und Dostojewskij aus zwei entgegen gesetzten Welten. Schiller als Vertreter des deutschen Geistes schreibt Werke, die große Emotionen wecken. Das russische Modell wird in Italien als ein rein literarisches Modell angesehen, das die Motive der bekannten literarischen Tradition vertieft. In Deutschland ist es eher ein Mittel, um die Gegensätzlichkeit zur eigenen Mentalität zu zeigen.

Was das Verhältnis Dostojewskijs zum Weiblichen betrifft, herrschen in der deutschen Rezeption Reflexionen vor, die einen direkten Bezug auf die Frau und auf die Sexualität nehmen. Brandes beklagt den Mangel an sexuellen Schilderungen in Dostojewskijs Werken und begründet sie mit den langen Zeiten der sexuellen Enthaltsamkeit im Leben Dostojewskijs. Im Text Rosa Luxemburgs befindet sich eine Reflexion über die prostituierte Frau als Herausforderung an die scheinheilige Moral der bürgerlichen Gesellschaft. Sonja wird als Frau idealisiert und zum Symbol religiöser Erlösung erhöht. Die Prostituierte ist keine Gefallene, sondern ein Mensch mit kranker Seele. Daraus schließt man auf eine größere menschliche Toleranz der Russen.

In Italien wird die Problematik stärker hinsichtlich ihrer literarischen Seite debattiert. Es wird der Mangel an Liebe bei Dostojewskij beklagt. Bei Ciampoli zum Beispiel wird sie nicht als literarisches Thema angesehen, sondern eher als konkretes Problem aus dem Leben Dostojewskijs. Im Gegensatz zum europäischen Roman, in dem Liebesgeschichten eine klar erkennbare Struktur haben, fehlt bei Dostojewskijs Beschreibungen die Aufmerksamkeit für körperliche und psychologische Aspekte. Mitte der zwanziger Jahre findet man in Italien keinesweg die

6 G., Schiller 1923, S. 3.

7 A. Scholz: Dostojewski und Schiller, in „Europa, Wochenschrift für Kultur und Politik“, 16. Heft, 1. Jg, Berlin 4. Mai 1905. 
Bereitschaft, Prostituierten wie etwa in Deutschland einem emanzipatorischen Charakter zu zugestehen. Die Frauenfiguren werden eher als absolut von den Männern abhängigen Wesen betrachtet. Dies geschieht sowohl in der literarischen Darstellung (Gasparini) als auch in der Schilderung der Gattin Dostojewskijs (Jannis).

In Italien fällt auf, dass die Aufmerksamkeit für Erinnerungen aus einem Totenhaus (Zapiski iz mërtvogo doma) wegen seiner klaren Anspielungen auf die persönlichen Erfahrungen des Autors besonders groß ist. Es wird auch der extreme Altruismus des Autors anerkannt (Ferri, Bacchelli), der in diesem Werk zutage tritt. Ausführliche Bewertungen von Einzelwerken gehören einer späteren Zeit an. Besondere Beachtung wird in der Frührezeption in Deutschland dem Werk Verbrechen und Strafen geschenkt. Man spricht vor allem von der Einschätzung der Figur Raskolnikov als eines Vertreters der russischen Gesellschaft. Brandes bezeichnet das Werk als repräsentativ für das „Russentum“. In dieser Welt sind die Widersprüche der Moral vorherrschend, die darin besteht, dass die bereits bestraften Taten als Wohltaten betrachtet werden. Raskolnikov zeigt außerdem die Fähigkeit und den Mut russischer Charaktere zu ehrlicher Selbstbetrachtung. Für Meyer ist dieser Roman, zusammen mit den Besessenen, ein Sieg des russischen Prinzips, was gleichzusetzen ist mit der Selbstbehauptung einer egoistischen Welt gegenüber. Die geschilderten Seelen sind durch einen Heilungsprozess gegangen und erlöst worden. Raskolnikov zeigt, dass er auf dem Rückweg zu gesellschaftlicher Kompatibilität ist. In der italienischen Rezeption werden am Anfang hauptsächlich die soziologischen Implikationen eines Verbrechens aufgenommen, nach und nach wird die Reflexion über die Zeit nach dessen Begehen immer wichtiger. Für Carletti vertritt Raskolnikov die These, dass es für den Verbrecher unmöglich ist, seine primitivsten Impulse zu beherrschen. Das erweckt Mitleid. Das Werk wird nach naturalistischen Maßstäben beurteilt, die Aufmerksamkeit richtet sich auf die Fähigkeit des Autors, die Welt des Verbrechers darzustellen. Ab der zweiten Hälfte der zwanziger Jahre wird Verbrechen und Strafen unter die großen Romane eingereiht (Galati). Raskolnikov ist nach Gasparinis Auffassung repräsentativ für die Besonderheiten in der Personendarstellung Dostojewskijs: Der Autor schildert ihn als entschlossenen Charakter, der seinem „io intellegibile“ nicht gerecht werden kann, seinem „io sensibile“ unterliegt und deshalb einen Mord begeht. Toffanin führt das religiöse Element ein: Raskolnikov muss wieder rein werden, um seinen Erlösungsprozess zu vollziehen.

Das Interesse für den Idiot (Idiot) entsteht in Deutschland zeitgleich mit den Reflexionen über die Krise der westlichen Gesellschaft. Eine vollständige Untersuchung der Figur des Idiot in der deutschen Rezeption liefert Hermann Hesse. Am Anfang wird dem Werk nur geringe Beachtung geschenkt. Kracauer stellt den Idiot als einen „Christusmenschen“, der „die Fackel des Guten in den Dirnen und Mördern entzünden will“, dem Übermenschen Nietzsches gegenüber. Hesses Aufsatz über den Idiot definiert die Konturen dieser eigenartigen Figur: Nach seiner 
Meinung besitzt der Idiot eine ganz andere Logik als andere Menschen. Da er so nah am Unbewussten lebt und seine Epilepsie ihm magische Kräfte verleiht, können Gut und Böse bei ihm zu einer Einheit verschmelzen. Die revolutionäre Bedeutung des Buches besteht darin, dass gerade ein Guter ein Feind der Ordnung ist. Der Mensch aus dem Westen muss wieder zu einem Zustand zurück finden, bei dem die Gegensätze sich vereinen können. In Italien gewinnt der Idiot ab Ende der zwanziger Jahre an Bedeutung. Marussig warnt davor, die Figur des Idioten zu banalisieren, weil er mehr denn je für den Kontrast zu dem rein rational denkenden westlichen Menschen steht.

Die Auseinandersetzung mit den Karamasow (Brat'ja Karamazovy) bedeutet für Deutschland die Auseinandersetzung mit der Frage nach dem Bösen im Menschen und akzentuiert die Kontraste zwischen der russischen und der westlichen Gesellschaft. Hesse betrachtet das Werk als Symptom für die Dekadenz einer Gesellschaft, in der das Chaos explodiert. Das Chaos kommt aus Russland; es ist der Zusammenprall von widersprüchlichen und sich gegenseitig ausschließenden Prinzipien. Die Karamasows verkörpern dieses Chaos, weil sie alle zusammen den russischen Menschen darstellen. Ein solcher Mensch vereint in sich die Charakterzüge des Hysterikers, des Säufers, des Verbrechers, des Dichters und des Heiligen. Das neue Ideal besteht darin, das Göttliche auch im Bösen zu sehen. Hesse sieht eine seelische Verwandtschaft zwischen Dostojewskij und Nietzsche. Dostojewskij, Prophet einer Krise, die sich im „Karamasow-Ideal“ artikuliert, ähnelt dem aufbegehrenden Nietzsche, der einen „amoralischen Menschen“ geschaffen hat.

Bäumer rechtfertigt das auffällige Verhalten der Karamasow-Figuren mit ihrer russischen Natur, die dem westlichen Menschen fremd ist. Die Ablehnung Gottes ist für den Mensch aus dem Westen Konsequenz aus einer rationalistischen, skeptischen Geisteshaltung; bei einer Figur wie Iwan hat das eher mit der Rebellion gegen die Kultur als begrenzende Form zu tun, mit einer Rebellion gegen normierte Werte, während die Russen doch nur fühlen können. Am Beispiel des Großinquisitors sieht man außerdem, dass bei Dostojewskij das Göttliche der absolute Gegensatz zum Menschlichen ist: Jesus hat die möglichen Formen der Vermenschlichung seines göttlichen Wesens abgelehnt, während die Kirche dem Menschen Gott als Illusion anbietet. Dostojewskij hat diesen tragischen Zwiespalt des religiösen Menschen gezeigt. Er zerstört die illusionäre Vorstellung einer ausgeglichenen Persönlichkeit auf der Welt und glaubt an die Idee eines asketischen Menschen wie Sossima, in dem sich Westen und Osten berühren. Bahr sieht in den Karamasow ein Werk, wo das Unheil so zerstörerisch wirkt, dass außer Gott nichts übrig bleibt. In Italien ist die Vorliebe für die stilistisch-literarisch orientierte Linie in der Rezeption durch den Roman die Brüder Karamasow bestätigt. Außerdem werden sie dort in der Regel nicht pessimistisch interpretiert. Die italienische Kritik setzt sich mit Borgese zum ersten Mal vollständig mit dem literarischen Wert dieses Werks auseinander. Die Karamasow werden als Beispiel für den Aufbau des Romans schlechthin genommen: Sie geben klare Antworten auf die großen Fragen 
der Menschheit, beweisen Symmetrie, Harmonie, Kohärenz in der Entwicklung der Personen (Entwicklung vom Verbrechen zur Läuterung). Sie zeigen, wie Kindlichkeit und Heiligkeit selbst höllische Leidenschaften überwinden können. Die Bewertung Borgeses ist auch eine Antwort auf die zu einseitige Vision des Bösen, die Gide in Frankreich entwickelt habe. Die Figuren werden denen von Dickens und den düsteren Charakteren der deutschen Dichtung gegenübergestellt: Während diese nur kopflastig sind, leben die russischen aus dem Bauch heraus. Er deutet auch auf Erneuerungen der Erzählkunst hin: Die Überraschungen und Unterbrechungen machen aus Dostojewskijs Romanen typische Abenteuer- und Urteilsromane. Während in Deutschland die Parallelen mit den Gedanken Nietzsches gezogen wurden, wird in Italien auf Ariost verwiesen, den Borgese als Meister in dieser Art Kunst bezeichnet. Interpretationen, die mehr auf eine explizite Diskussion über den Nationalcharakter verweisen, zeigen, wie positiv das Werk Dostojewskijs aufgenommen wird. Toffanin verweist auf die positiven Eigenschaften der Figuren, um sie in Katholiken zu „verwandeln“. Er als Vertreter der alten romanischen Welt findet auf diese Weise in dem jungen slawischen Herzen einen Verbündeten. Dagegen opponiert er gegen den düsteren, strengen germanischen Geist, der in der Figur des Parsifal verkörpert ist. Die optimistische Botschaft des Werkes wird auch von Gasparini bestätigt, der es für seine literarische Qualität lobt. Der Tod Sossimas, welcher auch als Danksagung an Gott für die Schöpfung verstanden werden kann, sei stilistisch hochgradig lyrisch.

Bei den Dämonen (Besy) fallen in Deutschland die Figuren Kirillow als Gottsucher und Stawrogin als zerrissene Gestalt, als Gewalt- und gleichzeitig Genussmensch besonders auf. In Italien gelten am Anfang die Dämonen als schwer zu deutendes Werk, vor allem aufgrund der negativen Bewertungen aus Frankreich (nicht zuletzt auch wegen der Dostojewskij-Satire gegen Turgenjew, welcher bei den Franzosen große Achtung als außergewöhnlicher Bewunderer des Westens genoss). Auch in weiteren Besprechungen werden die literarischen Figuren und die aufgeworfenen Fragen zu diesem Werk ganz besonders herausgearbeitet. Gasparini erläutert, wie Dostojewskij mit Stawrogin bewusst eine undurchschaubare Figur schaffen will. Nach Galati sieht man durch den Nihilismus Trofimows, dass Dostojewskij Erlösung für unmöglich hält. Borgese verweist auf die Zügellosigkeit der Figuren dieses Werks. Alle diese Besonderheiten sind aber nicht Bestandteil eines „russischen Charakters“, sondern werden als literarische Stärken eines neu entdeckten Autors anerkannt.

In der deutschen und italienischen Rezeption basiert die Diskussion über Dostojewskij zum Großteil auf der Gegenüberstellung mit Tolstoj. In den deutschen Texten ist die Polarisierung sehr stark: Dostojewskij gilt als Vertreter des russischen Andersseins, das sich einer „normalen“ „westlichen“ Art Literatur zu machen - eben der Art Tolstojs - konfrontiert. Dostojewskij kann den Leser in Spannung halten und geht in die Tiefe (Ernst), vertritt russische Demut (Bierbaum), kann echte Menschen beschreiben (Meyer), porträtiert die niedrigsten Klassen und gibt 
von Russland ein authentisches, unverfälschtes Bild, besitzt hochsensible Sinne (Brückner), vertritt authentisches Russentum (Lucka), schafft kranke statt gesunde Figuren (Bäumer) und predigt ein weltzugewandtes Christentum (Bahr).

Tolstoj und Dostojewskij ziehen in die italienische Literatur wie ein Wertepaar ein, das die neu entdeckte russische Welt vertritt. Eine radikale Gegenüberstellung mit Tolstoj so wie in Deutschland gibt es in Italien (bis auf einzelne längere Monographien einer späteren Zeit) nicht. ${ }^{8}$ Bacchelli verteidigt Tolstoj als Schriftsteller, der Literatur speziell für eine bestimmte Klasse, die Aristokratie, schafft. Mussi macht aus beiden zwei „Europäer“.

In Italien wird der Mangel an Naturbeschreibung nicht als Nachteil gesehen, in Deutschland hingegen wird die Schilderung der Natur als ein Teil des eigenen literarischen Vermögens seit der Romantik angesehen; hier fällt es durchaus negativ auf, dass sie bei Dostojewskij fehlt (Ernst, Brückner).

Ein Thema, mit dem sich beide Kulturen in Zusammenhang mit Russland und Dostojewskij beschäftigen, ist das Volk. Mit Dostojewskij entdeckt man den Dichter, der ein Volk besingt, das ein Bewusstsein von der eigenen Größe besitzt. Im deutschen Kontext wird seit dem Text Bierbaums die Komponente der Göttlichkeit des russischen Volkes unterstrichen. Viele Aufsätze betonen den missionarischen und erlösenden Wert des Volkes (Brandes, Bierbaum, Zweig, Brückner, Bahr), andere vertreten eine profanere Idee des Volkes in Zusammenhang mit der Reflexion über die russische Revolution. Kracauer zum Beispiel vertritt die Idee, dass tief im russischen Volk der Glaube an die Gleichheit der Menschen verwurzelt sei, Bäumer idealisiert das Element des Bauerntums im Volke, das zur Vertreibung der materialistisch gewordenen Intellektuellen beiträgt und das wahre, lügenhafte Gesicht des Bolschewismus entlarvt.

In Italien lassen sich verschiedene Tendenzen in Zusammenhang mit dem Thema Volk erkennen: das Volk als Diskussionsobjekt im soziologischen Sinn (Carletti spricht von Kriminalsoziologie des russischen Volkes) und das Volk mit beispielhafter Funktion in Bezug auf die Fähigkeit zum Glauben und zum Leiden (De Gubernatis und Lo Gatto). Nach der russischen Revolution wird das Element des Messianismus für die Erlösung der Menschheit (Zabughin und Toffanin) verstärkt. Die negative Meinung Gallettis über das russische Volk im Rahmen einer Verteidigung der westlichen Kultur fällt auf: Es mangele ihm an Traditionen und Ängsten, es sei apathisch. Mit Gramsci kommt man zu einem Punkt, an dem das Volk endlich als Gruppe wirklicher Menschen wahrgenommen wird. Das Thema Volk bietet Gelegenheit, über Verhältnisse zwischen den Klassen zu diskutieren. Die Intellektuellen haben in der russischen Gesellschaft eine Mission dem Volk

8 Eine ausführliche Gegenüberstellung findet man in einer späteren Phase, in den wenigen Dostojewskij-Monographien, und zwar bei Moscardelli (1935) und Donnini (1942). In den zwanziger Jahren, in der Dostojewskij-Monographie von Cuzzer (1925) stellt der Autor die zwei Schriftsteller nach den bekannten Chanones gegenüber, unterstreicht aber anschließend, dass beide Autoren das Märchen vom westlichen Fortschritt zerstören. 
gegenüber und stehen zu ihm nicht in einem „Diener-Herr-Verhältnis“. Daher solle man in Italien beachten, dass der Intellektuelle nicht von oben herab auf das Volk schauen, sondern es belehrend im Wandel begleiten solle.

In Deutschland wächst in den Jahren vor der Russischen Revolution die Idee eines „bösen Europa“, in dem der Mensch Gut und Böse nicht mehr unterscheiden kann. Die Thematik der krankhaften Wesenszüge der westlichen Gesellschaft ist in Deutschland ausgeprägt vorhanden und deckt sich mit Dostojewskijs schlechter Meinung über dieses Land. In zahlreichen Auszügen des Tagebuchs eines Schriftstellers, einem Werk das Anfang des XX. Jahrhunderts verbreitet wird, ist die Ansicht Dostojewskijs festgehalten, dass Deutschland ein arroganter Staat sei. Bei Kracauer und Meyer fällt besonders auf, wie sich die deutschen Rezensenten durch Dostojewskijs Kritik an Deutschland verletzt fühlen.

Sowohl in Deutschland als auch in Italien wird Dostojewskij oft mit der russischen Revolution in Verbindung gebracht, und zwar in Zusammenhang mit seiner angeblichen „Prophezeiung" einer blutigen Zeit für die russische Nation (Brückner). Hesse hebt die Dostojewskij-Prophezeiung zur Dekadenz der westlichen Gesellschaft hervor. Die Gestalt des Idioten verkörpert das Chaos als neue Existenzmöglichkeit für den Menschen, als Alternative zur bisherigen Einteilung der Welt in voneinander getrennte, um nicht zu sagen, gegensätzliche Bereiche.

In Italien ist es den Rezensenten wichtig, die Merkmale der eigenen Kultur zu definieren, indem sie eine Künstlergestalt entwickeln, die die veralteten und als oberflächlich empfundenen literarischen Theorien mit kraftvollen Konzepten bereichern. Die Literaturwissenschaft vollzieht ihren Prozess der deprovincializzazione durch die Befreiung aus einem accademismo in der Sprache und aus einem Begriff ästhetischer Theorien, die nicht nur die literarische Inspiration, sondern auch den Zusammenhang zwischen Biographie des Autors und seiner literarischen Produktion und schließlich die Experimentierfreude mit den literarischen Techniken mit einbezieht. Gleichzeitig ermöglicht die Konfrontation mit Dostojewskij, dass die Literaturwissenschaft ihre vertrauten Kriterien von Klassizität und Harmonie beibehalten kann.

In Deutschland definiert man sich selbst durch die Übernahme einer Künstlerfigur, die einem hilft, seine verlorene Welt wiederzuerlangen. Es ist, als spiegele sich in der russischen Welt die eigene, aber auf den Kopf gestellte. Dostojewskij repräsentiert die Möglichkeit einer Flucht aus der damaligen Welt sowie den Beginn einer neuen Welt, in der sich Rationales und Irrationales decken, die bürgerlichen Normen überwunden werden und Widersprüche sich vereinigen. 


\section{Bibliographie}

\section{Primärliteratur}

\section{A Ausgewählte Texte der Dostojewskij-Rezeption in Deutschland}

ATtEnTUS (R. WOLTERECK): Dante, Dostojewski und das Junge Deutschland, in: "Vivos Voco", Jg. II/6, Okt. 1921, S. 293-299.

G. BÄUMER: Dostojewski und der europäische Geist, in: “Die Frau”, Jg. 30, 1922/23.

H. BAHR: Der russische Christ, in „Hochland“, Jg. 18, 1921, S. 641 ff.

G. BRANDES: Fjodor Dostojewski, in: Menschen und Werke, Essays von Georg Brandes, Frankfurt, Literarische Anstalt, Rütten \& Loening, 1894.

O.J. BIRNBAUM: Dostojewski. Piper, München 1914.

A. BRÜCKNER: F. M. Dostojewskij 30 Okt 1821 - 28 Jan. 1881, in: Velhagen \& A. Klasings Monatshefte, Jg. 36/2, Okt. 1921.

Sir GALAHAD: Idiotenführer durch die russische Literatur, Langen, München 1925.

G. GESEMANN: Das goldene Zeitalter, Ein Kapitel über Dostojewski, in: “Dioskuren”, 1. Jg. (1922), S. 275-303.

H. HESSE: Dostojewski, in: Schriften zur Literatur. Eine Literaturgeschichte in Rezensionen und Aufsätze, ausgewählt und zusammengestellt von Volker Michels, XII Band, in: Gesammelte Werke in zwölf Bänden, Suhrkamp, Frankfurt 1970, S. 304-339.

W. HUECK: Dostojewski, der Psychologe des Irrationalen, in: "Das Literarische Echo" Halbmonatschrift für Literaturfreunde, Jg. 28, (1925/26) S. 199-201.

S. KRACAUER: Nietzsche und Dostojewski, in: "Vivos Voco". Zeitschrift für neues Deutschtum, Juli 1921, Jg. II/4/5, S. 211-225.

E. LUCKA: Dostojewski und der deutsche Geist, in: "Hellweg, Wochenschrift für deutsche Kunst”, Jg. 5/2, Essen, 14 Januar 1925, S. 17-18.

R. LUXEMBURG: Über Dostojewski, in: Die Aktion, 1921, S. 663-665.

R. LUXEMBURG: Die Seele der russischen Literatur, in: "Die weißen Blätter", 6/1929, Berlin, Cassirer, S. 56-75.

J. MEIER GRAEFE: Dostojewskij, in: "Die neue Rundschau”, Bd. 2 (1925), S. 811-820.

R. M. MEYER: Das russische Dreigestirn: Turgenjew, Dostojewskij, Tolstoi, in: Aufsätze literarhistorischen und biographischen Inhalts, II Band, Berlin 1912, S. 107-145.

A. SCHOLZ: Dostojewskij und Schiller, in: „Europa“, 1. Jg. (1905), S. 777-779.

T. SEGALOFF: Dostojewskys Krankheit, mit Portrait, in: „Grenzfragen der Literatur und Medizin in Einzeldarstellung“, Heft 5., hrsg. v. Dr. S. Rahmer, Reinhardt Verlagsbuchhandlung, München 1908.

\section{B Ausgewählte Texte der Dostojewskij-Rezeption in Italien}

A. ANILE: Il problema religioso in Dostoievsky, in: "Rivista d'Italia", a. VII n. 9 (15.9.1925), pp. 303-309.

R. BACCHELLI: Paradosso su Tolstoj e Dostojewsky, in: "La Ronda", n. straordinario (dicembre 1923), pp. 803-828. 
G. A. BORGESE: "Crotcaia" di Dostoievski, in: Studi di letterature straniere, Milano, Treves 1915, pp. 362-370.

G. A. BORGESE: Dostoievski secondo Gide, in: "Corriere della sera", a. XLVIII n. 310 (28.12.1923), p. 3.

G. A. BORGESE: I Karamazof, in: "Corriere della sera", a. XII, n. 129 (30.5.1924), p.3.

G. A. BORGESE: I Karamazov, in: "Corriere della sera", a. LII n. 35 (10.2.1927), p. 3.

G. A. BORGESE: Dostoievski minore, Gide e Dostoievski, I Karamazof, in: Ottocento europeo, Milano, Treves 1927, pp. 114-139.

L. CAPUANA: Gabriele D'Annunzio, in: Gli "ismi" contemporanei, Catania, N. Giannotta, 1898, pp. 83-111.

T. CARLETTI: Dostoevskij, in: La Russia contemporanea, Milano, Treves 1894, S. 371400.

E. CECCHI: Letteratura straniera. Dal giornale di Dostoiewski, ivi, a. I, n. 18 (27.3. 1904), pp. 9-12.

Cronache di letteratura. Le piccole foglie, in: "La Tribuna", a. XXX, f. VIII (25.4.1907), pp. 246-247.

D. CIAMPOLI: Saggi critici di letterature straniere, Lanciano, Carabba 1904, S. 189-201.

E. GASPARINI: Elementi della personalità di Dostojevskij, in: „Rivista di letterature slave“, I f. pp. 395-413; a. II f. (giugno 1927), pp. 240-250; III f. (settembre 1927), pp. 417-425; IV f. (dicembre 1927), 560-578.

A. DE GUBERNATIS: Schizzo sulla letteratura russa, in: "Gazzetta letteraria", a. III n. 18 (3-10.5.1879), pp. 138-142.

Necrologio, in: "Illustrazione italiana", a. IX, n. 20 (13.5.1881), p. 171.

E. JANNI: Dostojevski, in: "Corriere della sera", a. XLVI, n. 260 (30.10.1921), p. 3.

Dostojevski e le donne, ivi, a. XLVI, n. 266 (6.11.1921), p. 3.

E. LO GATTO: La Russia e il suo problema religioso secondo Dostoievskij, in: „Bilychnis“, Rivista di studi religiosi, edita dall facoltà della scuola teologica battista di Roma, Anno X - Fasc. VI, Roma, giugno 1921, Vol. XVII. 6, S. 373-381.

E. LO GATTO: Dostoievskij e l'Occidente, in: "I Libri del giorno", a. X n. 11 (novembre 1926), pp. 586-588.

G. MARUSSIG: Si torna a Dostoievschi?, in Scrittori d'oggi, Roma, Libreria di scienze e lettere, 1926, pp. 333-339.

A. SOFFICI: Dostojewski, in: "La Voce", a. IV, n. 4 (25.1.1912), p. 743.

A. SOFFICI: Dostojevskij, in: Statue e fantocci, Firenze, Vallecchi 1919, pp. 43-49.

G. TOFFANIN: Il nazionalismo di Dostoiewski, in: "Il Conciliatore", a. II, F. 2 (31.7. 1915), pp. 177-199.

A. FAGGI: Schiller e Dostoiewsky, in "Marzocco" a. XXIX n. 44 (2.11.1924), p. 1.

F. CAZZAMINI MUSSI: Di un libro su Dostojevskij, in: Uomini e libri: saggi critici, Palermo-Roma, Sandron 1927, pp. 220-247.

A. GALLETTI: Teorie di critici ed opere di Poeti: Berchet, Goethe, Hebbel, Wagner e D’Annunzio, in: La Russia e la civiltà occidentale. (La coltura dell'Italia contemporanea), L'Aquila 1930. S. 273-303. 


\section{Fëdor Dostoevskij in Spanien: Ein kurzer Überblick}

Fëdor Dostoevskijs geschichtliche Auffassung der politischen und religiösen Situation seines Zeitalters ${ }^{1}$ ermöglichte ihm, die verschiedenen Untergangserscheinungen der im Jahr 1789 geborenen europäischen Zivilisation wahrzunehmen². Dieses Verständnis der Realität zeigte sich in der historischen Rolle, die er den abendländischen Ländern zuschrieb ${ }^{3}$.

Während Polen keine Bedeutung für Dostoevskij hat ${ }^{4}$, liegt das Schicksal des protestierenden Lands ${ }^{5}$ Deutschland in der stetigen Verneinung des römischen Ideals

1 Vgl. Ludolf Müller: Dostojewski und Deutschland. In: Heinz Setzer, Ludolf Müller, RudolfDieter Kluge (Hg.): Fjodor Michailowitsch Dostojewski: Dichter, Denker, Visionär. Tübingen 1998, S. 235-254, hier S. 247: „Dostojewski denkt in großen geschichtlichen Zusammenhängen [...] Die Weltgeschichte wird letztlich bestimmt von großen Ideen, die miteinander ringen“, und Dagmar Herrmann: Die neue europäische Ordnung - eine Vision Dostojewskijs. In: Jahrbuch der Deutschen Dostojewskij-Gesellschaft (Dostojewskij und Europa), (2010) 17, S. 61122, hier S. 73: „Er [begriff] Geschichte als Geschichte von Ideen“.

2 Siehe dazu Michał Bohun: Fiodor Dostojewski i idea upadku cywilizacji europejskiej. Katowice 1996. Nicht umsonst wird es behauptet, dass lediglich Nietzsche - und nicht Marx oder Freud, die Dostoevskij als Vertreter der europäischen Dekadenz charakterisiert hätte - an seherischer Schärfe des Blicks mit Dostoevskij verglichen werden kann.

3 Siehe den politisch-programmatischen Artikel Dostoevskijs Drei Ideen (Januar 1877) in: Fjodor M. Dostojewski: Tagebuch eines Schriftstellers. Notierte Gedanken. München 2001, S. 287-294.

4 Polen wird nicht nur als das Land, wo der Katholizismus ein erhebliches Maß an Proselytismus erreicht hat, gekennzeichnet, sondern auch es ist für Dostoevskij „ein benachbarter katholischer Unruheherd, den es niederzuhalten und einzuverleiben gilt“. Vgl. Herrmann (2010), S. 103. Zu Dostoevskijs Bild von Polen, siehe Jacek Uglick: Polacy w powieściach i publicystyce Dostojewskiego, in: Przegląd Powszechny (2004) 121, 11, S. 194-206 (auf Russisch: Jacek Uglik: Obraz poljakov v romanach i publizistike F. M. Dostoevskogo, in: Toronto Slavic Quarterly (2011) 37, S. 136-149).

5 Siehe Die deutsche Weltfrage. Deutschland - das protestierende Land (Mai-Juni 1877) in: Dostojewski (2001), S. 354-360. Für Dostoevskij ist der Protestantismus, wie ebenfalls der Katholizismus, eine gefährliche Quelle des Atheismus in Europa. Siehe: Ich benütze die Gelegenheit. Vier Vorträge über verschiedene Themen anlässlich eines Vortrags, den mir Herr A. Gradovskij gehalten hat. Mit einer Ansprache an Herrn Gradovskij, in: Fjodor M. Dostojewskij: Winterliche Aufzeichnungen über sommerliche Eindrücke - Aufzeichnungen aus dem Kellerloch - Aus dem Tagebuch eines Schriftstellers. Übersetzt von S. Geier und A. Eliasberg. Mit einem Essay „Zum Verständnis der Werke“ und einer Bibliographie von Svetlana Geier. Hamburg 1963, S. 195. 
und nach einem eventuellen Sieg über den Katholizismus und den Sozialismus in seinem vollen Verschwinden aus der Weltgeschichte. Was das deutsche Volk betrifft, ist es aufgrund seines Hochmuts negativ charakterisiert ${ }^{6}$, Fürst Bismarcks Politik aber wird für seinen entschiedenen Kampf gegen Rom gelobt ${ }^{7}$.

Frankreich ist in Dostoevskijs Augen der Ursprung des Bösen, denn in diesem Land wurde die historische Perversion des echten Christentums, d.h. der Katholizismus, in all seinen Konsequenzen entwickelt. Auf diese Weise stellt Frankreich „die Verkörperung der katholischen Idee im Verlauf von Jahrhunderten “8 dar, die in der "schrecklichen Französischen Revolution“9 politisch mutierte und zugleich den Sozialismus (die Ideologie des sog. „vierten Stands“) verursachte ${ }^{10}$. Der Sozialismus bzw. der Nihilismus ${ }^{11}$ aber verbreitete sich nicht nur aus Frankreich, sondern auch aus der Schweiz. In „dem Hauptsitz der linken sozialistischen russischen Emigration"12, d.h. in Genf, fand im September 1867 die von Dostoevskij besuchte

6 Siehe z. B. Fëdor M. Dostoevskij: Zapiski k „Dnevniku pisatel’ja“ 1876: Iz rabočich tetradej 1875-1877gg. In: Fëdor M. Dostoevskij: Polnoe sobranie sočinenij v 30 tomach (= PSS). Leningrad 1972-1990; hier PSS XXIV:76; Winterliche Aufzeichnungen über sommerliche Eindrücke, I. Anstelle eines Vorworts. In: Dostojevskij (1963), S. 7-11; Vom kriegerischen Geist der Deutschen (Juli-August 1876). In: Dostojewski (2001), S. 235-239 oder Der Spieler (Igrok). Siehe ebenfalls dazu Herrmann (2010): S. 93ff

7 Dostoevskij schreibt: „Auffallend ist, daß Fürst Bismarck den Sozialismus nicht weniger als das Papsttum haßt [...] Fürst Bismarck, der Hauptfeind des Papsttums und der römischen Idee!“. Siehe den Aufsatz: Sie sind böse, aber auch stark, in: Dostojewski (2001), S. 369f. und ebenfalls: Wieder zum letztenmal ,Prophezeiungen“ (November 1877), in: PSS XXVI:89. Siehe dazu Herrmann (2010), S. 78ff. Zum Thema Dostoevskij und Deutschland, siehe den oben erwähnten Aufsatz von Lüdolf Müller.

8 Siehe Drei Ideen, in: Dostojewski (2001), S. 289.

9 Siehe Die deutsche Weltfrage. Deutschland - das protestierende Land, in: Dostojewski (2001), S. 356. Für Dostoevskij war die Französische Revolution nichts anderes „als die letzte Gestaltsveränderung oder Umverkörperung dieser selben altrömischen Formel der universalen Vereinigung“ (Ebd.). In der Schrift Winterliche Aufzeichnungen über sommerliche Eindrücke befindet sich eine detaillierte Schilderung des Siegers der Revolution, d.h. des Bourgeois. Siehe Dostojevskij (1963), S. 39-67. Zu Dostoevskijs Kritik an der Französischen Revolution siehe: Jordi Morillas: The Fight against the French Revolution. Dostoevsky as a Political Thinker, in: The Dostoevsky Journal. An Independent Review, (2007 [2010] - 2008 [2010]) vol. 8-9, S. 1-24.

10 Vgl. dazu nicht nur den Aufsatz Drei Ideen, sondern auch die von Karla Hielscher analysierte Rede des Fürsten Myschkins in Der Idiot (Fedor Dostojewskij: Der Idiot. Neuübersetzung von Swetlana Geier. Frankfurt am Main 2009, S. 786-790) in: Die ,russische Idee ${ }^{6}$ - made in Florenz. Dostojewskijs antiwestlich-russophile Ideologie in seinen Briefen aus Italien. In: Jahrbuch der Deutschen Dostojewskij-Gesellschaft (Dostojewskij und Europa), (2010) 17, S. 140-150; hier: S. 144-150.

11 Siehe dazu Ernst von Hippel: Dostoevskijs Kampf gegen den Nihilismus, in: Stimmen der Zeit (1951/1952), 150, S. 356-367.

12 Vgl. Hielscher (2010): S. 142. Siehe auch dazu Jordi Morillas: El valor de la política en la vida y en la obra de F. M. Dostoievski, in: La Torre del Virrey (Verano 2009) 6. Im Internet aufrufbar unter: http://www.estudiosculturales.es/libros/libros_verano09/pdf/125.pdf. 
Sitzung der Liga für Frieden und Freiheit statt, woraus die von dem russischen Schriftsteller genannten Genfer Ideen (Ženevskie idei) oder „die Tugend ohne Christus ${ }^{\text {"13 }}$ entstanden sind. England kommt die historische Rolle zu, das beste Beispiel für die grausamen sozialen Folgen des Kapitalismus („Baal“14) zu liefern, wie Winterliche Aufzeichnungen über sommerliche Eindrücke (Zimnie zametki o letnich vpečatlenjach) meisterhaft darlegen ${ }^{15}$. Dostoevskijs Bild der Vereinigten Staaten ist ebenso negativ angelegt, wie Verbrechen und Strafe (Prestuplenie i nakazanie) oder Die Brüder Karamasow (Brat'ja Karamazovy) beweisen ${ }^{16}$.

Im Gegensatz zu diesen Ländern erscheint Russland mit der religiös-historischen

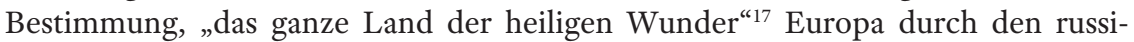
schen Christus vor Nihilismus und Untergang zu retten ${ }^{18}$.

Über Spanien hat Dostoevskij nie ausführlich gesprochen ${ }^{19}$. Die ersten bemerkenswerten Erwähnungen befinden sich in der Erzählung Onkelchens Traum

13 Vgl. Fjodor Dostojewskij: Ein grüner Junge. Aus dem Russischen von Swetlana Geier. Zürich 2006, S. 305.

14 Vgl. Dostoevskij (1963), S. 32-39.

15 Zum Thema Dostoevskij und Europa, siehe die folgenden Textsammlungen: Dostojevskij (1963) und die Ausgabe von Harry Harvest Dostojevski und Europa: Aus dem „Tagebuch eines Schriftstellers“. Zürich 1951. Ebenfalls wichtig sind die folgenden Studien: Joseph Frank: Dostoevsky: The Encounter with Europe, in: The Russian Review (1963) 22, S. 237-252; Malcolm V. Jones: Dostoevsky and Europe: Travels in the Mind, in: Renaissance and Modern Studies (1980) 24, S. 38-57; Kenneth Lantz: The Dostoevsky Encyclopedia. Westport 2004, S. 130-134 (s.v. „Europe“) und Andreas Guski: Die Konstruktion Westeuropas in Dostojewskijs Winteraufzeichnungen über Sommereindrücke. In: Jahrbuch der Deutschen DostojewskijGesellschaft (Dostojewskij und Europa), (2010) 17, S. 123-139.

16 Siehe Valentina Ivanovna Gabdullina: Rossia, Evropa i Amerika v paradigme avtorskogo diskursa F. M. Dostoevskogo. In: Prostranstvenno-vremennye perekrestki kultury. Sbornik statej i materialov vserossiiskoi naučnoi konferentsii s mezdunarodnym učastiem „Čelovek i mir čeloveka“, 30-31 oktjabrja 2008 goda. Barnaul - Rubtsovsk 2009, S. 173-180.

17 Dostojevskij (1963), S. 7. Dieser Ausdruck stammt aus dem Gedicht Mečta (1834) von A. S. Chomjakov.

18 Vgl. Der Idiot (Idiot) oder Puškin-Rede (Puškinskaja reč). In dem Aufsatz Erklärende Worte zu der unten abgedruckten Puschkinrede gibt Dostoevskij diesen Gedanken wie folgt wieder: „Ich sage nur ganz einfach, daß die russische Seele, der Genius des russischen Volkes vielleicht mehr als alle anderen Völker fähig sind, die Idee der allmenschlichen Vereinigung, der brüderlichen Liebe, der nüchternen Anschauung, die das Feindliche verzeiht, das Unähnliche unterscheidet und entschuldigt und das Widerspruchsvolle beseitigt, aufzunehmen“. Siehe Dostojevskij (1963), S. 172. Außerdem dazu Ludolf Müller: Der Kampf Dostojewskijs gegen den Westen. In: Jahrbuch der Deutschen Dostojewskij-Gesellschaft (1998) 5, S. 29-41, und Hielscher (2010), S. 140-150.

19 Das heißt aber nicht, dass Dostoevskij kein Interesse an Spanien hatte. Ganz im Gegenteil während der 30er und 40er Jahren des 19. Jahrhunderts war Spanien ein beliebtes Thema in Russland und Dostoevskij kannte die ganze Literatur, die damals über Spanien geschrieben wurde, wie z. B. die Werke von Timofej N. Granovskij (PSS 12:290) oder den Aufsatz über Spanien von K. P. Pobedonoszev veröffentlicht in Graždanin 1873 (PSS 21:536). In der Tat sprach Dostoevskij in diesem Jahr 1873 (und auch später) ständig über Spanien als Chef- 
(Djadjuškin son), in der der russische Schriftsteller Spanien als das Land der Liebe beschreibt:

„Wegen der Gesundheit des Fürsten fährt Sina ins Ausland, nach Italien, nach Spanien - nach Spanien, wo die Myrten blühen und die Zitronenbäume, wo der Himmel blau ist, wo der Guadalquivir fließt -, nach dem Lande der Liebe, wo man nicht leben kann, ohne zu lieben; wo Rosen und Küsse sozusagen in der Luft schweben! [...] Liebe und Jugend. Spanien - großer Gott! ${ }^{\text {(20 }}$

Spanische Motive kommen später in anderen Romanen, Erzählungen oder publizistischen Texten Dostoevskijs ${ }^{21}$ kurz vor, handelt es sich aber um die Rolle Spaniens in der geschichtlichen Weltanschauung des Dichters, so sind an erster Stelle Die Brüder Karamasow, vor allem das Kapitel „Der Großinquisitor“ zu erwähnen. Wie allgemein bekannt ist, platziert Dostoevskij die Handlung seiner Geschichte über die zweite Wiederkehr Christi auf Erden in Sevilla ${ }^{22}$, „in der schrecklichsten Zeit der Inquisition, als zum Ruhme Gottes im ganzen Land täglich die Scheiterhaufen loderten und man in purnkvollen Autodafés böse Häretiker verbrannte ${ }^{23}$ “"24

Redakteur dieser Zeitschrift und als politischer Kommentator (es ist sogar wahrscheinlich, dass Dostoevskij in den verschiedenen Konflikten des damaligen Spanien die Bestätigung, wenn nicht die Quelle seiner Theorie, dass der Papst sich mit den Kommunisten verbunden würde, um seine Macht nicht zu verlieren und die Welt zu beherrschen, gefunden hätte; siehe PSS 20:382). Eine für Dostoevskij mögliche Quelle zum Thema Spanien waren ebenfalls die berühmten Briefe über Spanien (Pis'ma ob Ispania, 1847-1851; als Buch 1857) von Wasilij P. Botkin.

20 Fjodor Dostojewski: Onkelchens Traum. Aus den Annalen der Stadt Mordassow. Deutsch von Günter Dalitz. Berlin 1987, S. 130.

21 Siehe z.B. Dostoevskijs Anwendung der Gestalt Poprischtschin von Gogols Aufzeichnungen eines Wahnsinnigen (Zapiski sumasšedšego, 1835), um die Politik seiner Zeit zu kritisieren, in Aufzeichnungen aus dem Kellerloch (Zapiski iz pod'polja) II.1; und die Aufsätze aus dem Tagebuch eines Schriftstellers (Dnevnik pisatel'ja) Träume und Phantasien (1873) und Plan zu einer anklagenden Novelle aus dem modernen Leben (Mai-Juni 1877).

22 Die Herausgeber der PSS (15:557) weisen auf das Werk von William H. Prescott History of the Reign of Philip the Second King of Spain (2 Bde.) hin als Quelle zur Komposition des Poems der Großinquisitor. Dostoevskij hatte das Buch auf Russisch gelesen (Ausgabe von Sankt Peterburg 1858). Siehe Leonid P. Grossman: Seminarij po Dostoevskomu. Materialy, bibliografija i komentarii. Moskva-Petrograd 1922, S. 38.

23 Wie im PSS (15:557) steht, stammen diese letzten zwei von Ivan Karamasow zitierten Verse von A. I. Poležaev mit dem Titel Koriolan (1834 geschrieben, aber 1857 veröffentlicht). Siehe dazu V. Bez’jačycnyj: Kogo zitiruet Ivan Karamasow, in: Ogonek (1969) 20, S. 7.

24 Fjodor Dostojewskij: Die Brüder Karamasow. Aus dem Russischen von Swetlana Geier. Zürich 2003, S. 400. Diese Identifizierung der Inquisition mit Spanien hat vielen Dostoevskij-Leser, besonders jene aus protestantischen Ländern, Anlass gegeben, ihre Vorurteile gegen den Katholizismus zu bestätigen. Spanien wurde dadurch als ein Land betrachtet, wo auf Grund der katholischen „Intoleranz" Menschen historisch verfolgt wurden. Dabei wird aber gern vergessen, dass die von Dostoevskij genannte „Ketzerei Luthers“ (siehe Drei Ideen, in: Dostojewski [2001]: S. 291), sowohl in ihrer kalvinistischen, als auch in ihrer anglikanischen oder evangelischen Form ebenso Blut an den Händen hat. 
Mit dieser Identifizierung der Inquisition mit Spanien enden Dostoevskijs Bemerkungen über das Mittelmeerland ${ }^{25}$. Welche Meinung haben aber die Spanier von Dostoevskij, d.h. wie war die Dostoevskij-Rezeption in Spanien?

Obwohl Dostoevskij viele Jahre in Europa verbrachte, waren sowohl er als auch seine Werke in den europäischen Ländern lange Zeit fast komplett unbekannt. Dostoevskijs Oeuvre findet erst seinen Weg nach Europa durch Deutschland und Frankreich, zwei Länder, die ihre politischen und kulturellen Beziehungen zu Russland historisch gepflegt haben. Auf diese Weise stammt die erste deutsche Dostoevskij-Übersetzung aus dem Jahr $1846^{26}$, die Französen mussten hingegen bis 1884 warten $^{27}$. Da aber die dominierende Sprache in den europäischen intellektuellen Kreisen bis zur Mitte des 20. Jahrhunderts Französisch war, machten nicht die deutschen, sondern die französischen Übersetzungen den europäischen Leser mit den Dostoevskij-Werken vertraut.

Seine Bekanntschaft in Europa verdankt Dostoevskij jedoch nicht nur den deutschen bzw. französischen Übersetzungen seiner Romane und Erzählungen, sondern auch der Studie von Vicomte Eugène-Melchior de Vogüé Le roman russe, die seine in Le revue des deux Mondes veröffentlichten Aufsätze zur russischen Literatur enthält ${ }^{28}$.

Dem russischen Dichter widmet de Vogüé ein ganzes Kapitel in Le roman russe („La religion de la souffrance - Dostoïevsky“; S. 203-278), in dem er Dostoevskijs Werk kritisch bewertet. Für de Vogüé ist Dostoevskij zwar ein großer Schriftsteller, aber „ein gebrechlicher, lebhafter und aufgeregter Nervenbündel, eine weibliche Seele in der Hülle eines russischen Bauern; egozentrisch, wild, voller Halluzinationen, mit Wellen tiefer Zärtlichkeit, die in seinem Herz ertranken, als er in die inneren Bereiche des Lebens hineinblickte“ (S. 208). Und obschon Dostoevskij ein großer Psychologe gewesen ist, wird er von de Vogüé als eine Person beschrieben,

25 Mit dem Dostoevskijs Bild von Spanien werden wir uns in einem zukünftigen Aufsatz ausführlich beschäftigen.

26 In der Veröffentlichung einer fragmentarischen Übersetzung von Arme Leute und Das todte Haus sagt W. Wolfsohn im Jahr 1863, dass er „kurz nach dem Erscheinen“ von Arme Leute (d.h. 1846) ein Bruchstück des Romans für eine Zeitschrift übertrug, deren Name er nicht gibt (Theodor Dostojewsky und seine sibirischen Memoiren, in: Russische Revue (1863), S. 136187, hier S. 143). Man weiß nicht, ob Wolfsohn damit seine lange Besprechung des Romans, die er in den Jahrbüchern für slawische Literatur, Kunst und Wissenschaft (F. M. Dostojewskis „Arme Leute.“, in: Jahrbücher für slawische Literatur, Kunst und Wissenschaft (1846), IV, S. 434-443) veröffentlichte, meinte oder nicht. Auf jedem Fall wurde ein Jahr später eine zweibändige Übersetzung von Aufzeichnungen aus einem Totenhaus publiziert (Th. M. Dostojewski, Aus dem Todten Hause. Nach dem Tagebuch eines nach Sibirien Verbannten, nach dem Russischen bearbeitet, Leipzig, 1864).

27 Die aus dem gleichen Jahr 1884 stammenden französischen Übersetzungen von zwei Dostoevskij-Romanen waren Humiliés et offensés (Traduit du russe par Ed. Humbert. Paris 1884), und Le Crime et le châtiment (Traduit du russe par V. Dérely. Paris 1884; 2 vol.).

28 Vicomte Eugène-Melchior de Vogüé: Le roman russe. Paris 1886. 
die „lediglich nachts gereist ist“ (S. 267). Was das Dostoevskij-Oeuvre angeht, ist de Vogüés Urteil nicht weniger nachsichtig. Während seine ersten Romane und Erzählungen eine relative positive Bewertung verdienen, sind die letzten Werke stark negativ charakterisiert ${ }^{29}$.

Dieses nicht sehr glückliche Dostoevskijs Bild verbreitete sich nicht nur in Frankreich ${ }^{30}$, sondern durch Gräfin Emilia Pardo Bazán, eine Schriftstellerin aus Galicien, auch in Spanien. Pardo Bazáns zufällige Entdeckung des Romans Verbrechen und Strafe im Jahr 1885 in Paris ${ }^{31}$ führte sie dazu, sich für die russische Literatur zu interessieren. Die Gräfin las hierzu all die damals in die französische Sprache übersetzten Werke der wichtigsten russischen Schriftsteller und nahm daneben Kontakt mit den russischen revolutionären Immigranten, die in jener Zeit in Paris residierten, wie zum Beispiel Isaak Jakovlevič Pavlovskij ${ }^{32}$ und Lev Aleksandrovič Tichomirov ${ }^{33}$. Außerdem befreundete sie sich mit französischen Intellektuellen, die sich mit der russischen Kultur und Sprache gut auskannten, wie Vicomte Eugène-Melchior de Vogüé ${ }^{34}$.

Obwohl die russische Literatur unter den spanischen gebildeten Kreisen damals weit verbreitet war $^{35}$ und der Name Dostoevskij bereits $1867^{36}$ aufgetaucht war, hatte die Gräfin Emilia Pardo Bazán das Verdienst, mit ihren aufgrund einer Einladung der kulturellen Institution Ateneo (Madrid) am 13., 20. und 27. April 1887 gehaltenen Vorlesungen mit dem Titel „Revolución y Literatura en Rusia“ dem spanischen Publikum mit der russischen Literatur und besonders Dostoevskij vertraut zu machen.

29 Vicomte de Vogüé beschrieb z.B. Die Brüder Karamasow als „diese endlose Geschichte“ (S. 266).

30 Vgl. André Gide: Dostoïevsky d'après sa correspondance (1908). In: André Gide: Dostoïevsky (Articles et causeries). Paris 1950 (1923 $3^{1}$ ), S. 1-46 (bes. 2ff).

31 In der oben genannten Version von Dérely, Paris 1884.

32 Sie las sein Werk En cellule. Impressions d'un nihiliste. Traduit du russe par A. N. Loukanina, préface et postface d'Ivan Tourguéniev, in: Le Temps (November, 1879) 12-25.

33 Sie kannte sein Werk La Russie politique et social. Paris 1886.

34 „Dona Emilia hatte sich in Paris wiederholt mit Vogüé unterhalten und dabei von dessen persönlichen Eindrücken und Erlebnissen in Rußland vermutlich mehr erfahren, als später ihr (freilich sehr umfangreiches) Buch [La revolución y la novela en Rusia. Lecturas en el Ateneo de Madrid. Anm. des Vf.] verriet“. Hans Hinterhäuser: Fin de siècle. Gestalten und Mythen. München 1977, S. 29.

35 Vgl. M. [sic!]: La literatura de los pueblos slavos [sic!], in: El Museo Universal (31. März 1867) 13, S. 100. Siehe dazu: Michail P. Alekseev: Očerki istorii ispano-russkich literaturnych otnošenij 16-19 vv. Leningrad 1964, und Julia L. Obolenskaja: Dialog kultur i dialektika perevoda. Sud'by proizvedenij russkich pisatelei 19 veka v Ispanii i Latinskoj Amerike. Moskva 1998.

36 Vgl. Leopoldo García Ramón: Cartas de París (20 de Setiembre de 1886), in: Revista Contemporánea (30. September 1886), S. 589-599, und Juan B. Pastor Aicart: La novela moderna. Cartas críticas. Con un epílogo postdata de D. Juan Barcia Caballero. Alcoy 1886, S. 235. 
In dem ersten Vortrag gab die Gräfin Pardo Bazán mit bewundernswerter Demut zu, dass sie lediglich einen einführenden Überblick über Russland, seine Geschichte und seine politische Gegenwart anbieten und die von ihr auf Französisch gelesenen russischen Autoren ${ }^{37}$ vorstellen könne, da sie die russische Sprache leider nicht beherrschte ${ }^{38}$ und ebenfalls nicht imstande war, nach Russland zu fahren (S. 11). Sie hoffte allerdings, die Neugier des Zuhörers zu wecken, sodass „jemand besser qualifiziert als ich diesen ersten und vorsichtigen Versuch aufnehmen und weiterführen könne" (S. 12). Unter den russischen Schriftstellern, die sie dem Publikum des Ateneo vorstellen wollte, hob sie „den atemberaubenden Psychologen Dostoevskij" hervor.

Wenn auch die Dostoevskij-Darstellung der Gräfin zum Teil auf dem Buch des Vicomte Eugène-Melchior de Vogüé beruhte ${ }^{39}$, so war ihre Interpretation sehr persönlich. Als Pardo Bazán in seiner Vorlesung enthüllte, war es dank der Lektüre des Romans Verbrechen und Strafe im Jahr 1885 in Paris, dass sie „in das Gebäude der russischen Literatur eingegangen "war (S. 374; vgl. S. 3). Dostoevskij wurde auf diese Weise von der Gräfin als ein „Visionär“ (S. 303) und als ein „Mystiker" (S. 425) gekennzeichnet, der die „Menschheit durch seine trüben Gedanken und verwirrten Geist sieht“" (S. 393). Mit Dostoevskij nimmt der Roman neue epische Dimension in der Weltliteratur ein, da er die klassische Harmonie nicht mehr suchte, sondern er „die fieberhafte, unvernünftige, morbide psychologische Intensität der kultivierten Geister seines Landes" zeigte (S. 356). Infolgedessen konnte Pardo Bazán über die Existenz einer „gefolterten, verdrehten, satanischen, aber intensiven, großen und dominanten Schönheit" in seinem Oeuvre sprechen (S. 379).

Beispiele für diese Welt, wo „das Schreckliche schön und die Hoffnungslosigkeit tröstlich ist, [und wo] das Unwürdige eine Aura der Erhabenheit besitzt" (S. 357), fand die spanische Schriftstellerin in Aufzeichnungen aus einem Totenhaus (Zapiski iz mertvogo doma), die sie - de Vogüés Auslegung folgend $-{ }^{40}$ mit Dantes Inferno verglich (S. 368). Als Pardo Bazán sich mit Verbrechen und Strafe beschäftigte, wies sie auf die Genialität und den tiefenpsychologischen Scharfsinn des russischen Schriftstellers hin, und behauptete, dass sogar E. A. Poe, „mit all seiner suggestiven Intensität und seiner fiebrigen Phantasie die enormen psychologischen Analysen“, die sich in diesem Werk befinden, nie erreicht habe (S. 377). Trotz dieser Be-

37 Die Gräfin hatte diese Werke während ihrer Winteraufenthalte in Paris und ihrer daraus folgenden Besuche der französischen Nationalbibliothek gelesen. Am Ende des Buches gab sie insgesamt 47 bibliographische Referenzen an.

38 Vgl. La revolución y la novela en Rusia (Lecturas en el Ateneo de Madrid). Madrid $1909^{4}$ (1887), S. 9. Es wird nach dieser Ausgabe mit eigener Übersetzung zitiert.

39 Und wie könnte anders gewesen sein, wenn die spanische Schriftstellerin nicht nur den Verfasser, sondern auch sein Werk persönlich kannte, ein Werk, das damals als die einzige ernste Studie zur russischen Literatur galt? Siehe Vsevolod Bagno: A propósito de las fuentes de $L a$ Revolución y la novela rusa de Emilia Pardo Bazán. In: José Carlos de Torres (Coord.): Estudios de literatura española de los siglos XIX y XX. Madrid 1998, S. 162-166.

40 Vgl. de Vogüé (1886), S. 237. 
wunderung für Dostoevskijs Kunst und Genie definierte die Gräfin das Wesen des russischen Dichters wie folgt: „Er war ein Nervenbündel, eine Harfe mit zu angespannten Streichern, er war ein Opfer von Epilepsie und Halluzinationen“ (S. 366).

Der Erfolg dieser Vorlesungen ${ }^{41}$ und ihrer sich daraus ergebende Veröffentlichung als Buch ${ }^{42}$ war der Ausgangspunkt der Übersetzungsgeschichte der Dostoevskij-Werke in Spanien. Auf diese Weise erschien der erste übertragene Text von Dostoevskij La centenaria (Die Hundertjährige) in der literarischen und politischen Zeitschrift La España Moderna im Juni 189043. Danach folgten andere Erzählungen wie Cálculo exacto (Christbaum und Hochzeit) ${ }^{44}$, El Mugik Marey (Der Bauer Marej) $)^{45}$, Alma de niña (Netotschka Neswanowa) ${ }^{46}$, und La mujer de otro (Der eifersüchtige Gatte $)^{47} .1891$ wurde die erste Übersetzung eines Dostoevskij-Romans La casa de los muertos (memorias de mi vida en la cárcel de Siberia) (Aufzeichnungen aus einem Totenhaus) mit einer einführenden Studie von Emilia Pardo Bazán veröffentlicht. Der zweite Teil mit dem Titel La novela del presidio. La vida plural. Segunda parte de La casa de los muertos wurde im folgenden Jahr publiziert.

Allmählich wurden weitere Werke des russischen Schriftstellers ins Spanische übersetzt: Apuntes del subsuelo (Aufzeichnungen aus dem Kellerloch; 1900), Crimen y castigo (Verbrechen und Strafe; 1901), El jugador (Der Spieler; 1902), Noches blancas (Weiße Nächte; 1902), La aldea de Stepánchik (Das Gut Stepantschikowo und seine Bewohner; 1910), Pobres gentes (Arme Leute; ca. 1910), Humillados y ofendidos (Erniedrigte und Beleidigte; 1918), El idiota (Der Idiot; 1920), El doble (Der Doppelgänger; 1920), El adolescente (Der Jüngling; 1922), Los hermanos Karamázov (Die Brüder Karamasow; 1923?), Los demonios (Die Dämonen; 1924) ${ }^{48}$, sowie andere Texte.

41 Vgl. Benito Pérez Galdós: Conferencias de Emilia Pardo Bazán en el Ateneo. Madrid, 15 de abril de 1887. In: Benito Pérez Galdós: Obras inéditas. Ordenadas y prologadas por Alberto Ghiraldo, Vol. II. Arte y crítica. Madrid 1923, S. 203-208.

42 Das Buch erschien mit dem Titel La revolución y la novela en Rusia. Lecturas en el Ateneo de Madrid in drei Bänden (Madrid). Das Werk war sofort vergriffen, sodass eine zweite Ausgabe, diesmal in einem Band im selben Jahr folgte.

43 Th. Dostoievsky: La Centenaria, in: La España Moderna (Juni 1890) 18, S. 167-174.

44 Th. Dostoievsky: Cálculo exacto. Cuento ruso, in: La España Moderna (Oktober 1890) 22, S. 25-33.

45 Th. Dostoievsky: El Mugik Marey. Recuerdo de Siberia, in: La España Moderna (August 1891) 32, S. 192-199.

46 T. Dostoiewsky: Alma de niña, in: La España Moderna (Februar 1906) 206, S. 122-160; (März 1906) 207, S. 135-165 und (April 1906) 208, S. 125-161. Die spanische Übersetzung von $\mathrm{Ne}$ totschka Neswanowa (Netočka Nezvanova, 1849) ist aber zuerst als Buch erschienen: H. [sic!] Dostoïewsky: Alma de niña. Trad. de Ramón Orts-Ramos. Barcelona 1900.

47 T. Dostoiewsky: La mujer de otro, in: La España Moderna (Februar 1907) 218, S. 149-166 und (März 1907) 219, S. 129-152.

48 Ein Jahr zuvor wurde das unveröffentlichte Kapitel „Die Beichte Stawrogins“, zusammen mit anderen Texten aus den Arbeitsheften übersetzt und publiziert: La confesión de Stavrogin y el plan de La Vida de un Gran Pecador, con notas explicativas. Madrid 1923. 
In den 1920er Jahren wurden einige Dostoevskij-Werke von in Spanien niedergelassenen russischen Emigranten übertragen. Diese Übersetzungen waren stilistisch nicht so gut wie die früheren, hatten aber den originalen russischen Text als Grundlage. In dieser Zeit wurde ebenfalls die erste Gesamtausgabe der Werke Dostoevskijs in dem Verlag Atenea / La Nave (Madrid) vorbereitet. Unter den wichtigsten Übersetzern sind Alfonso Nadal, Carmen Abreu, Ricardo Baeza und R. Z. Žukovskij zu nennen. Doch die erste vollständige Übersetzung seines Oeuvres direkt aus dem Russischen wurde von Rafael Cansinos Assens vollbracht. Diese Initiative des Verlags Aguilar erschien 1935 in zwei Bänden mit einem Essay über den russischen Dichter ${ }^{49}$.

Der Ausbruch des spanischen Bürgerkrieges und des Zweiten Weltkrieges brachte die Übersetzungen von Dostoevskij zu einem relativen Stillstand ${ }^{50}$. Mit der Rückkehr nach Spanien von den nach Russland geflohenen Spaniern befanden sich im Land Menschen, die sich mit der russischen Sprache und Kultur gut auskannten. Es war Augusto Vidal, ein ehemaliger kommunistischer Kämpfer im spanischen Bürgerkrieg und Professor an der Moskauer Universität, der eine Gruppe von Übersetzern (Juan Luis Abollado, Victoriano Imbert, Lidia Kúper und José Laín Entralgo) um sich sammelte, um im Auftrag von Jose María Boix, Inhaber des Verlags Vergara, Dostoevskij neu zu übersetzen. Diese Gesamtausgabe enthielt einen Essay von José Luis L. Aranguren und eine Studie über Dostoevskijs Leben und Werk von Augusto Vidal.

Andere spanische Kommentatoren oder Übersetzer von Dostoevskij sind z.B. Juan López-Morillas, Ricardo San Vicente, Isabel Martínez (jetzt: Bela Martinova), Selma Ancira, Natalia Ujánova, Fernando Otero oder José Ignacio López.

In die verschiedenen regionalen Sprachen Spaniens sind auch die wichtigsten Werke Dostoevskijs übersetzt worden. Unter diesen Übersetzern muss der Name von Josep Maria Güell hervorgehoben werden, der eine ausgezeichnete Version des Romans Der Idiot veröffentlicht hat ${ }^{51}$.

Was die spanische Dostoevskij-Forschung betrifft, so kann man sagen, sie begann im Jahr 1887 mit Biographien ${ }^{52}$ und Interpretationen, die Dostoevskij als Legalist und Soziologe betrachteten ${ }^{53} .1903$ schrieb der mit der russischen Sprache

49 Fedor M. Dostoyevski: Obras completas, Tomo I (1844-1870). Biografía, traducción y notas de Rafael Cansinos Assens. Madrid 1935, und Tomo II (1870-1881). Madrid 1935. Die vierte, revidierte und erweiterte Ausgabe stammt aus 1949 (diesmal in 3 Bände).

50 Es wurden trotzdem einige Übersetzungen veröffentlicht, wie z. B. die von Henrique Cuenca Granch für den Verlag Maucci (Barcelona).

51 Fiódor M. Dostoievski: L’idiota. Traducció de Josep Maria Güell. Barcelona 1982.

52 Anonymus: Las revistas rusas, in: El país (11 Oktober 1887), S. 2, und Zeda (pseud. Francisco F. Villegas): Dostoyuski, in: La Época (15 Juli 1900), S. 1-2.

53 Gabriel Tarde: La arqueología criminal, in: La España Moderna (Oktober 1893), S. 43-85, und Anatolij Fëdorovič Koni: Dostö̈evsky criminalista (traducido del ruso), in: Revista contemporánea (30 April 1899), S. 120-136. 
und Kultur gut vertraute Julián Juderías eine Besprechung ${ }^{54}$ über eine Studie von Minej Leont'evič Kheisin ${ }^{55}$, wo er einen der ersten Vergleiche zwischen Dostoevskij und Nietzsche herstellte. In den 1920er Jahren sind Beiträge von Ricardo Baeza $^{56}$, Gaziel ${ }^{57}$ und Corpus Bargas ${ }^{58}$ in Zeitschriften sowie Armando Donosos Buch Dostoievski, Renán, Pérez Galdós ${ }^{59}$ publiziert worden.

Diese Studien besagen aber nicht, dass Dostoevskij ein beliebter Schriftsteller für die spanischen Leser war. Wie in anderen Ländern Europas ist auch hier Tolstoj geschätzter als Dostoevskij. Der Dichter Antonio Machado zeigte diese spanische Bewunderung für Tolstoj in einem Vortrag im Jahr 1922, als er feststellte, dass es nicht Dostoevskij, sondern Tolstoj war, der „das Mitleid-Gefühl, das die ganze moderne russische Literatur durchdringt", am besten symbolisiert hätte (S. 93-94).

Erst nach dem Ersten Weltkrieg und vor allem nach der russischen Revolution 1917 wurde Dostoevskij unter den Spaniern zu einem berühmten Autor. Wie in Frankreich oder Deutschland ist der russische Dichter auch in Spanien als der Psychologe, als der Prophet, kurz gesagt, als der Politiker, betrachtet worden, der das Schicksal Russlands und Europas zusammen mit Friedrich Nietzsche vorausgesagt hatte.

War diese "Ostorientierung "60 in Deutschland von Ernst Niekisch und dem Nationalbolschewismus ${ }^{61}$ sowie, in gewissem Maße, von Arthur Moeller van den Bruck $^{62}$ vertreten worden, so gab es ebenfalls in Spanien Intellektuelle, die Dostoevskij als „den Führer“ ihrer Zeit feierten. Der Philosoph und Schriftsteller Miguel de Unamuno, der sich lange Zeit für einen Tolstojaner gehalten hatte, charakterisierte Dostoevskij bereits 1914 wie folgt:

54 Julián Juderías: Dostoiewsky y Nietzsche, in: La Lectura (September 1903), S. 157.

55 Minej L. Kheisin: Dostoevskij i Nietzsche, in: Mir Božii (1903) 6, S. 119-141.

56 Alle seine in der Zeitung El Sol veröffentlichten Aufsätze befinden sich in: Comprensión de Dostoiewsky y otros ensayos. Barcelona 1935.

57 Gaziel (pseud. Agustí Calvet): El misterio de Dostoiewsky, in: El Sol (28 Juni 1926), S. 1.

58 Corpus Bargas: Dostoïevski, dictador, in: Revista de Occidente (Oktober 1923), S. 132-135.

59 Armando Donoso: Dostoievski, Renán, Pérez Galdós. Madrid 1925. Dieses Buch sammelte die Dostoevskij-Beiträge, die Donoso in der Zeitschrift Nosotros bereits 1922 veröffentlicht hatte.

60 Siehe Wolfgang Wippermann: „Deutsche Drang nach Osten“. Ideologie und Wirklichkeit eines politischen Schlagsworts. Darmstadt 1981.

61 Siehe Ruth Fischer: Der Wanderer ins Nichts. Der Nationalbolschewismus am historischen Beispiel Ernst Niekischs, in: Frankfurter Hefte. Zeitschrift für Kultur und Politik (1959) 12, S. 871-880 und Louis Dupeux: „Nationalbolschewismus“ in Deutschland 1919-1933. Kommunistische Strategie und konservative Dynamik. München 1985.

$62 \mathrm{Zu}$ Arthur Moeller van den Bruck, siehe Volker Weiß: Moderne Antimoderne. Arthur Moeller van den Bruck und der Wandel des Konservatismus. Paderborn 2012. Zu seiner DostoevskijAusgabe, siehe Christoph Garstka: Arthur Moeller van den Bruck und die erste deutsche Gesamtausgabe der Werke Dostojewskijs im Piper-Verlag 1906-1919. Eine Bestandsaufnahme sämtlicher Vorbemerkungen und Einführungen von Arthur Moeller van den Bruck und Dmitrij S. Mereschkowskij unter Nutzung unveröffentlichter Briefe der Übersetzerin E. K. Rahsin. Mit ausführlicher Bibliographie. Geleitwort von Horst-Jürgen Gerigk. Frankfurt/M. u.a. 1998. 
„Meine Sicht von Russland, von meinem Russland, stammt aus der Lektüre der russischen literarischen Werke, vor allem der Werke von Gogol, Turgenew, Tolstoj, Gor'kij und besonders von Dostoevskij. Dostoevskij ist -ich muss es gestehenmeine Hauptquelle für Russland. Mein Russland ist Dostoevskijs Russland [...] Ich wünsche den Triumph der Philosophie, d.h. der Idee und des Lebens- und Weltgefühls von Dostoevskij [...] Ich habe es bereits ausgedrückt, indem ich mich auf Dostoevskijs Russland stütze, das Russland, das aus dem Geist seiner Aufzeichnungen aus dem Kellerloch, seines Idioten, und seines Raskolnikows geboren ist" " ${ }^{63}$

Und nach der russischen Revolution 1917 schrieb Unamuno aus Frankreich:

„Viele glauben auch, daß eine neue Religion im Entstehen ist, eine Religion jüdischen und zugleich tatarischen Ursprungs: der Bolschewismus, eine Religion, deren zwei Propheten Karl Marx und Dostojewski sind. Aber ist denn Dostojewskis Christentum kein Christentum? Sind denn die „Brüder Karamasow“ kein Evangelium?" 64

Unter den anderen Gelehrten, die sich mit Dostoevskij beschäftigten oder unter seinem Einfluss waren, heben sich José Ortega y Gasset ${ }^{65}$ und vor allem der Schriftsteller Don Pío Baroja ab, der sich sein ganzes Leben lang für einen DostoevskijVerehrer hielt ${ }^{66}$.

Bereits im Alter von 18 Jahren widmete Don Pío Baroja einen Artikel Dostoevskij ${ }^{67}$ und seitdem wird er ein ständiges Leitmotiv in allen seinen Werken, Aufsätzen und Vorträgen sein. Baroja beschrieb Dostoevskij als einen „Komödianten“68, als einen „Orientalen“69 und als einen „sentimentalen Wahnsinnigen“"70, der

63 Miguel de Unamuno: Un extraño rusófilo (veröffentlicht am 28. Oktober 1914 in La Nación), jetzt in: Miguel de Unamuno: Obras completas, IX. Discursos y artículos. Madrid 1971, S. 1246-1251, hier: S. 1248 und 1250. Die Übersetzung stammt von mir.

64 Miguel de Unamuno: Die Agonie des Christentums (1924). Deutsche Übertragung von Otto Buek. München 1928, S. 174. Aus dem literaturwissenschaftlichen Bereich sind noch zwei wichtige Beiträge von Unamuno erwähnenswert: Sobre el género novelesco (veröffentlicht am 3. September 1920 in Nuevo Mundo), jetzt in: Miguel de Unamuno: De esto y aquello: escritos no recogidos en el libro. Vol. 3. Libros y autores extranjeros (1898-1936); España y los españoles (1897-1932). Buenos Aires 1953, S. 440-443 und Dostoyeusqui sobre la lengua (veröffentlicht in September 1933 in Ahora), jetzt in: Unamuno (1953), S. 444-447.

65 Siehe z.B. José Ortega y Gasset: La voluntad del barroco, in: España (12 de agosto de 1915), S. 3-4. Jetzt in: José Ortega y Gasset: Obras completas. Madrid 1953 Bd. 1, S. 403-406.

66 Pío Baroja: Desde la última vuelta del camino. Memorias VII. Bagatelas de otoño. Madrid 1949, S. 314.

67 Pío Baroja: IX. El naturalismo: Dostoievsky, in: La Unión Liberal (17-III-1890), 12. Jetzt in: Pío Baroja: Escritos inéditos de Pío Baroja. Vol. 1: Hojas sueltas. Prólogo y notas de Luis Urrutia Salaverri. Madrid 1973, S. 69-73.

68 Pío Baroja: La caverna del humorismo (1919). In: Pío Baroja: Obras completas, V. Madrid 1948, S. 455.

69 Pío Baroja: Divagaciones apasionadas (1924). In: Baroja (1948), S. 501.

70 Pío Baroja: Intermedios (1931). In: Baroja (1948), S. 709. 
„wilde pessimistische“ Werke verfasste, in die er seine ganz „ruhelose und dionysische Seele“ setzte $^{71}$. Dabei wird er als ein "Genie“72 und als "großer Romanschriftsteller" ${ }^{\text {"73 }}$, aber mittelmäßiger Philosoph gekennzeichnet, der dem Volk eine wichtige Rolle in seinen Romanen verliehen hatte ${ }^{74}$. Baroja charakterisierte weiterhin Dostoevskij und Tolstoj als „die letzten großen Schriftsteller der Welt" ${ }^{\text {"75 }}$. Dostoevskijs politischer Kampf gegen die fortschrittlichen Ideale des 19. Jahrhunderts ${ }^{76}$ wurde von Baroja zuletzt als Eigenschaft jener Menschen interpretiert, „die ihren Turm erreicht haben, wo die Winde wehen". ${ }^{77}$

Barojas Auslegung von Dostoevskij begrenzte sich jedoch nicht auf diese Reihe von Kommentaren. Sie findet ihre Fortsetzung in einem zweiten dem russischen Schriftsteller gewidmeten Text. Dieser am 24. April 1938 mit dem Titel „El desdoblamiento psicológico de Dostoievski“ (Die psychologische Spaltung Dostoevskijs) veröffentlichte Aufsatz ${ }^{78}$ belegte nicht nur Barojas aufrichtige Bewunderung für Dostoevskij, sondern auch seine medizinische Interpretation des Dichters.

Bei Hervorhebung der „Schizophrenie“ nicht nur bei Dostoevskij, sondern auch bei seinen Helden, lässt Baroja (wahrscheinlich ohne ihn gelesen zu haben) Michail Bachtins Polyphonietheorie erahnen. Der Hauptunterschied zwischen Baroja und Bachtin liegt aber darin, dass der spanische Autor den polyphonischen Charakter der Werke Dostoevskijs seiner „schizophrenischen Erkrankung“ zuschrieb.

Nach dem spanischen Bürgerkrieg und dem Zweiten Weltkrieg wurde die Dostoevskij-Forschung auf Biographien ${ }^{79}$ und politische Interpretationen ${ }^{80}$ beschränkt. Die beste Studie aus dieser Zeit war El cristianismo de Dostoievski (1970) von José Luis López Aranguren.

Es gibt derzeit zwei Dostoevskij-Forschungsrichtungen in Spanien. Die erste wird von der Fakultät der Slawistik der Universität von Granada und der Zeitschrift „Mundo Eslavo“ repräsentiert. Ihr wichtigster Vertreter ist José Antonio Hita, der

71 Pío Baroja: Desde la última vuelta del camino. Memorias I. El escritor según él y según los críticos. Madrid 1952, S. 93.

72 Baroja (1952), S. 115.

73 Pío Baroja: Desde la última vuelta del camino. Memorias IV. Galería de tipos de la época. Madrid 1947, S. 46.

74 Vgl. Pío Baroja: Rapsodia (1936). In: Baroja (1948), S. 960, und Baroja (1947), S. 274.

75 Baroja (1947), S. 46.

76 Vgl. Pío Baroja: Desde la última vuelta del camino. Memorias (1944-1949). Madrid 1979, S. 689, und Baroja (1947), S. 214. Baroja beschrieb Dostoevskij sogar als ein „Anarchist“ (1952, S.137).

77 Baroja (1947), S. 81.

78 El desdoblamiento psicológico de Dostoievski. In: Pequeños ensayos (1943). In: Baroja (1948), S. 1066-1071.

79 Siehe z.B. Antonio J. Onieva: Bajeza y grandeza de Dostoievski. Barcelona 1954,

80 Siehe z.B. Ignacio Erizalde Armendariz: Se publica en Rusia la correspondencia de Dostoiewski, testimonio cristiano contra el comunismo, in: Razón y Fe (Dezember 1959) 160, S. 481489. 
zwei Dostoevskij-Monographien verfasst hat: Dostoievski y la crítica rusa (2002) und Nueva visión de la obra de Dostoievski (2003). Andere Forscher der Universität von Granada sind Natalia Arsentieva, die sich vorwiegend auf den metaphysischen und theologischen Charakter der Werke Dostoevskijs konzentriert; Leopoldo La Rubia, der die Ähnlichkeiten zwischen Dostoevskijs Der Doppelgänger (Dvojnik) und Kafka analysiert, und vor allem Benamí Barros, der die symbolische Aspekte der Dostoevskijs Werke ausgelegt und eine feine philologische Analyse einiger seiner wichtigsten Romane vollbracht hat. In dieser Forschungsrichtung befindet sich ebenfalls Luis Beltrán Almería, Professor an der Universität von Zaragoza, der die Frage nach Dostoevskijs Polyphonie im Dialog mit Bachtin und anderen Autoren untersucht hat.

Die zweite Dostoevskij-Forschungsrichtung werden von Isabel Martínez (jetzt: Bela Martinova), die eine kurze Biographie des Schriftstellers veröffentlichte und die Problematik des Nihilismus und des „Doppelgängers“ behandelte, und von Iván Iniesta, der Dostoevskij von einem medizinischen Standpunkt aus betrachtete, vertreten. Auch in diesem Zusammenhang soll Joan Pegueroles, S. I. erwähnt wer$\operatorname{den}^{81}$.

Im Jahr 2004 wurde in Spanien eine regionale Sektion der Internationalen Dostoevsky Society (IDS) (www.dostoevsky.org) ${ }^{82}$ gegründet. Die Eröffnung dieser spanischen Sektion der IDS in Genf ermöglichte zwei Jahre später, die erste nationale Dostoevskij-Konferenz in Barcelona zu organisieren. Diese Veranstaltung versammelte die wichtigsten spanischen Dostoevskij-Forscher mit Kollegen aus anderen Ländern wie Russland, Lettland, Polen, der Tschechischen Republik, Frankreich, Belgien, Holland oder Mexiko, die ebenfalls an der Konferenz tei$\operatorname{lnahmen}^{83}$. In diesem Kontext müssen an die fünf Seminare über Dostoevskij erinnert werden, die an der Universität Granada mit der Teilnahme von Forscher landesweit stattgefunden haben ${ }^{84}$.

Die Relevanz der spanischen Dostoevskij-Forschung lässt sich außerdem in der zunehmenden Präsenz von Wissenschaftlern an internationalen Kongressen wie zum Beispiel an dem Moskauer im Dezember $2006^{85}$ oder an den IDS-Konferenzen in Budapest ${ }^{86}$, Neapel ${ }^{87}$ oder Moskau ${ }^{88}$ erkennen.

$81 \mathrm{Zu}$ einer vollständigen bibliographischen Liste der Werke der spanischen DostoevskijForscher, siehe

http:/ $/$ www.agonfilosofia.es/index.php?option=com_content $\&$ view $=$ article\&id $=58 \% 3 \mathrm{Abibse}$ cdosto\&catid $=8 \&$ Itemid $=16$.

82 Siehe die Webseite der spanischen Sektion der IDS in www.ids.agonfilosofia.es.

83 Siehe http://www.dostoevsky.org/barcelona.pdf.

84 1. Seminar in Februar-März 2002 (Dostoievski y Kafka: Dos clásicos vigentes); 2. Seminar in März 2006 (Dostoievski y el siglo XX); 3. Seminar in März 2007 (Dostoievski y el siglo XX. El nihilismo); 4. Seminar in März 2009 (El pensamiento estético y político de Dostoievski en el mundo contemporáneo) und 5. Seminar in März 2012 (Dostoievski en España).

85 Siehe http://www.dostoevsky-fund.ru/page.php?id=36.

86 Siehe http://www.dostoevsky.org/Budapest/main.html. 
All diese seit den von Gräfin Emilia Pardo Bazán gehaltenen Vorlesungen im Jahr 1887 realisierten Aktivitäten zeigen, wie stark sich das spanische Interesse an der russischen Literatur entwickelt hat. Dostoevskijs Werke werden nicht nur in guten Übersetzungen veröffentlicht, sondern es entstehen auch wichtige Studien zu seinem Leben und Werk. Dabei sind die verschiedenen kulturellen Veranstaltungen zu erwähnen, die im ganzen Land stattfinden wie die im März 2011 von Réplika Teatro (Madrid) durchgeführte „Dostoievski confabulado“, in welcher der große russische Dichter mit einer Ausstellung, einer Reihe von wissenschaftlichen Vorträgen und einer brillanten Inszenierung von zwei seiner bedeutendsten Werke gefeiert wurde ${ }^{89}$. Dostoevskij hat angefangen, Spanisch zu sprechen - und fließend.

87 Siehe http://www.dostoevsky.org/programm.pdf.

88 Siehe http://dostoevsky.org/English/documents/Moscow_Symposium_Participants_2013_ English.pdf.

89 Die Werke waren Weiße Nächte und Der Großinquisitor. Siehe das Programm in: http://replikateatro.com/replika/2011/03/dostoievski-confabulado-marzo-de-2011/. 


\section{Übersetzungstheoretische Überlegungen zu den jüngsten deutschen Fassungen des Raskolnikow-Romans von F. Dostojewskij}

Deutschsprachige Verlage haben sich große Verdienste darin erworben, ihren Lesern nicht nur die aktuelle ausländische Literatur zugänglich zu machen, sondern daneben häufig auch Klassiker der europäischen Literatur neu übersetzen zu lassen. Dass dabei die Arbeit der literarischen Übersetzerinnen und Übersetzer heute stärker herausgestellt wird, als es früher der Fall war, ist sehr zu begrüßen. Man darf sich allerdings nicht täuschen. Der Hinweis auf eine besondere Qualität einer Neuübersetzung ist bei einem schon mehrfach übersetzten Klassiker ein wichtiges, ja notwendiges Verkaufsargument. Und offenbar reicht es nicht, eine neue Übersetzung als gelungen und z.B. der heutigen Sprache angemessen zu bezeichnen. Manchmal muss eine neu vorgelegte Übersetzung zum erstmals gelungenen Zugang zum Original erklärt werden ${ }^{1}$, womit alle älteren sowie die anderen zeitgenössischen Übertragungen implizit entwertet werden. Die Wendungen, mit denen eine Übersetzung geadelt wird, scheinen Moden unterworfen zu sein. Aktuell steht das Lob, eine „nicht glättende“ Übersetzung vorgelegt zu haben, hoch im Kurs, ein Dauerbrenner der letzten Jahre ist „als Sprachkünstler erschlossen“.

Große Beachtung fand das vor gut zwanzig Jahren (1993) begonnene Projekt des Züricher Ammann Verlags und seiner Übersetzerin Swetlana Geier, die Hauptwerke Dostojewskijs in neuen Übersetzungen herauszubringen. Es startete mit dem Raskolnikow-Roman², der im folgenden Jahr auch in einer neuen Übersetzung

1 So wurde zuletzt von Rezensenten eine Neuübersetzung der Madame Bovary gefeiert: „Dank der neuen ,Madame Bovary ' wird Flaubert erstmals auch auf Deutsch als Sprachkünstler erlebbar“ (Neue Zürcher Zeitung, 31.10.12); „Mit der großartigen Übersetzung von Flauberts ,Madame Bovary“ wird ein Meisterwerk neu entdeckt“ (Die Zeit, 6.12.12).

2 Fjodor Dostojewskij: Verbrechen und Strafe. Roman. Aus dem Russischen neu übersetzt von Swetlana Geier. Zürich 1993. Im Folgenden auch zitiert als „SG1993“. Im Copyright wird manchmal 1994 angegeben. - „Dostojewskij“ soll in diesem Beitrag gemäß den Gepflogenheiten dieses Jahrbuchs geschrieben werden. Ansonsten verwende ich für russische Namen, Ortsnamen usw. die gültige Duden-Transkription. In Zitaten werden die dort verwendeten Schreibweisen bewahrt. 
durch Margit und Rolf Bräuer erschien³. Eine von S. Geier selbst 1964 vorgelegte Übersetzung ist weitgehend vergessen. ${ }^{4}$ Die lieferbaren anderen deutschen Dostojewskij-Ausgaben stehen im Schatten der Aufmerksamkeit, die den Geierschen Übersetzungen in der Kultur-Öffentlichkeit zuteil wurde.

Beschränken wir unsere folgenden Überlegungen auf eine nähere Betrachtung allein des Raskolnikow-Romans in der (zweiten) Übersetzung durch S. Geier 1993. ${ }^{5}$ Bis heute liest man auf dem Umschlag der Taschenbuch-Ausgabe:

In der neuen Übersetzung von Swetlana Geier treten die Widerborstigkeit und die Härte, die oft archaische Begrifflichkeit der Sprache Dostojewskijs endlich deutlich hervor.

Die Übersetzerin selbst hat sich auch in etwas anderer Weise geäußert, wie unten noch ausgeführt werden soll. Verlockend ist das Versprechen allemal: Ein in sprachlicher Hinsicht bisher offenbar verschütteter Dostojewskij „endlich“ freigelegt - wie dankbar und erwartungsvoll muss der Buchkäufer eine solche Meldung lesen. Der im Raum stehende Anspruch, die ca. zwanzigste Übersetzung des Raskolnikow-Romans als erste eigentlich adäquate nach ca. neunzehn im Grunde also wertlosen zu deklarieren, wirft die Frage auf, worin denn das Besondere an der übersetzerischen Leistung in diesem Fall besteht und ob ein leitendes Übersetzungskonzept präziser namhaft gemacht werden kann, als es von Verlagsseite geschieht. Ziel der folgenden Analyse ist es ausdrücklich nicht, die Geiersche Übersetzung, etwa vergleichend mit der der Bräuers, als mehr oder weniger gelungen zu bewerten. Ausschließlich soll es um das Übersetzungskonzept des Geierschen Raskolnikow gehen, das, soweit es erkennbar ist, darstellungs- und diskussionswürdig ist. Dessen Implikationen und Konsequenzen scheinen nicht hinreichend im Bewusstsein der literarisch interessierten Öffentlichkeit zu sein. Dies mag auch daran liegen, dass es von der Übersetzerin selbst nirgends dezidiert formuliert wurde. Einzelne Ansichten über das Übersetzen scheinen umrisshaft in Interviews mit der Übersetzerin ${ }^{6}$ sowie in Rezensionen auf.

Aufschlussreich ist das indirekte Zeugnis in einer brieflichen Antwort auf die Beschreibung des Vorhabens einer neuen Übersetzung der Dämonen (Besy) durch

3 Fjodor Dostojewski: Schuld und Sühne. Deutsch von Margit und Rolf Bräuer. Berlin 1994 (Aufbau-Verlag). Ich benutze die 1. Auflage der Taschenbuch-Ausgabe, Berlin 2008, im Folgenden zitiert als „MRB“.

4 F. M. Dostojevskij: Raskolnikov. Schuld und Sühne. Übersetzt und mit einem Essay ,Zum Verständnis des Werkes‘ und einer Bibliographie versehen von Svetlana Geier. Reinbek 1964. Im Folgenden zitiert als „SG1964“.

5 Ich beschäftige mich ausdrücklich nur mit diesem, den ich nach der Ausgabe Fischer Taschenbuch Verlag, Frankfurt, 22.-26. Tausend: April 1998, zitiere. Die später vorgelegten Übersetzungen der übrigen Romane Dostojewskijs durch S. Geier habe ich nicht geprüft.

6 S. Geier: Ein Leben zwischen den Sprachen. Russisch-deutsche Erinnerungsbilder. Aufgezeichnet von Taja Gut, Dornach 2008. Das Buch enthält ein längeres neues sowie im Anhang drei weitere, ältere Interviews. 
die Übersetzerin, die sie dem Artemis und Winkler Verlag in München vorlegte. Das Schreiben der Verlagsmitarbeiterin Dr. Annalisa Viviani vom 19.3.1990 zeugt von einer sachkundigen Auseinandersetzung mit dem vorgeschlagenen Konzept und den eingereichten Übersetzungsproben. Im Anhang einer Vergleichsstudie zu deutschen Übersetzungen der Dämonen ist es nachzulesen. Dort heißt es u.a.7:

Bei Ihrer Übersetzung haben Sie sich auf die Dostojewskij-Poetik bzw. Philosophie, auf lexikalische Probleme konzentriert. Sie haben versucht, stilistische Eigenarten des Russischen im Deutschen, einer strukturell ganz anderen Sprache, zu reproduzieren. Die Unterschiede zwischen dem Russischen und dem Deutschen sind jedoch erheblich, und das Ergebnis dieses Neuansatzes hat uns doch nicht so überzeugt, daß wir uns zu einer Neuübersetzung entschließen können. Vom marktwirtschaftlichen Standpunkt aus ist es fraglich, daß dem Leser / Käufer geholfen ist, wenn in einer Neuübersetzung das Festhalten an jedem Ausdruck und jeder Formulierung des Originals zum Prinzip wird in dem Bemühen, mit dem Deutschen das Russische wiederzugeben. [...] Wir können uns nicht vorstellen, daß eine derart nach lexikalischen Gesichtspunkten gestaltete Neuübersetzung den Absatz dieses etablierten Romanciers erheblich steigern würde, da die traditionellen DostojewskijLeser durch eine gewisse Sprödigkeit der Sprache eher brüskiert wären.

Vom „marktwirtschaftlichen Standpunkt“ aus betrachtet dürfte sich die Lektorin fatal geirrt haben. Ihre Skepsis gegenüber dem geplanten Umgang mit dem russischen Original war allerdings berechtigt. Der Versuch, „mit dem Deutschen das Russische wiederzugeben“, wäre in der Tat ein problematisches Übersetzungskonzept. Von „Sprödigkeit“ spricht übrigens auch die Autorin der erwähnten Studie, die resümiert, bei S. Geier entstehe durch die „Treue gegenüber dem Original [...] häufig eine spröde Sprache, die zwar im Deutschen fremd wirkt, aber dem Duktus Dostoevskijs sehr nahe kommt“ (S. 193). „Treue gegenüber dem Original" kann übrigens auf verschiedenen Ebenen angesiedelt sein. Gemeint ist offenbar die lexikalische Ebene. Im Übrigen scheint die These von einer das Original reflektierenden „Sprödigkeit“ von der Kenntnis des Schriftwechsels von Frau Geier mit dem Winkler Verlag und vielleicht auch bereits von der Aura angeregt zu sein, die die Geierschen Übersetzungen in der Wahrnehmung von Publikum und Feuilleton alsbald umgab. Als Verbrechen und Strafe 1993 erschien, waren die dem Winkler Verlag vorgelegten konzeptuellen Überlegungen, also die Vorstellung, in der neuen Übersetzung „mit dem Deutschen das Russische

7 Marina Kogut: Dostoevskij auf Deutsch. Vergleichende Analyse fünf deutscher Übersetzungen des Romans Besy. Im Anhang Interviews der Autorin mit Swetlana Geier und Egon Ammann. Frankfurt u.a. 2009 (zuerst Dissertation Freiburg i. Br. 2005), S. 264f. Ich erlaube mir einen Abdruck, da der Brief dort hektografiert und damit frei zugänglich ist. Ich gehe davon aus, dass die Erlaubnis zum Abdruck bei Absenderin und Adressatin eingeholt wurde. 
wiederzugeben“, wohl nicht in die Öffentlichkeit gelangt. Früh kommuniziert wurden allerdings die Werbeaussagen über „Widerborstigkeit“ und „Härte“. 8

In den frühen Quellen zur Rezeption der Raskolnikow-Übersetzung von S. Geier zeichnen sich die folgenden Eigenschaften und konzeptuellen Aspekte ab, die im neuen Projekt erkannt oder ihm zugeschrieben wurden. An erster Stelle ist die Beibehaltung einmal gewählter Äquivalente der Zielsprache für dieselben Lexeme der Ausgangssprache zu erwähnen, die wiederholt als Vorzug der Geierschen Übersetzung benannt wurde. ${ }^{9}$ Dieser Übersetzungsgrundsatz ist uneingeschränkt zu begrüßen. Die das Original sprachlich vermeintlich verbessernde Operation der Synonymvermeidung ist in Übersetzungen des 19. Jahrhunderts anzutreffen, im 20. Jahrhundert ist man sich der Problematik bewusst. Dabei ist die motivischsemantische Seite der Wortverwendung bei Dostojewskij meist wichtiger als die stilistische. Viel Bedeutung kann in Wortmotive gelegt sein, die auch der Leser einer Übersetzung zu erkennen Gelegenheit haben sollte.

Der übersetzerische Umgang mit Wortmotiven ist nicht zuletzt auch ein wichtiger Gesichtspunkt bei der Wiedergabe von Figurenrede, sind die von einer Figur häufig verwendeten Ausdrücke doch ein Aspekt sprachlicher Idiosynkrasien. Das Konzept der ,Texttreue' (oder ,Textnähe') wird daher besonders als adäquater Zugang zu den Figurenstimmen in den Romanen Dostojewskijs gedacht. Hier liegt ein zweiter ihr wiederholt ausdrücklich zugebilligter Vorzug der Geierschen Übersetzung. Auch die Verlagswerbung hob (und hebt) darauf ab. Der oben zitierte Umschlagtext (über „Härte“ und „archaische Begrifflichkeit“) setzt unmittelbar fort:

Jede Gestalt spricht mit ihrer eigenen Stimme, ihrem eigenen Akzent, mit eigenen Gesten. Tonfälle offenbaren Charaktere, und in der Vielstimmigkeit des sich auf diese Weise bildenden Raums ist Dostojewski wohl am ehesten zu fassen.

Die Begriffsverwendung („Vielstimmigkeit“) lässt einen Einfluss der (nicht unproblematischen) These M. Bachtins von der „Polyphonie“ Dostojewskijscher Romane erkennen. Zu recht ist aber eingewandt worden, Bachtins Polyphoniebegriff bezeichne eine ideologische, nicht unbedingt eine stilistische Vielstimmigkeit. Im Gegenteil habe Bachtin bei Dostojewskij „sprachliche Vielfalt und Charakterisierung durch Redeweisen“ weniger konsequent gewahrt gesehen als bei Autoren wie Tolstoi. ${ }^{10}$ Die Postulate der Texttreue im allgemeinen und der stilistischen Variation entsprechend dem individuellen Sprechverhalten im besonderen sind

8 Die Ausdrücke zitiert bereits, ohne Quellenangabe, U. Heftrich: Ein neuer deutscher Dostojewski. Frankfurter Allgemeine Zeitung, 7.12.1993.

9 So Peter Urban: Kleinigkeiten, Kleinigkeiten! Die Zeit, 3.12.1993, der findet, dass Geiers Text „Wiederholungen nicht per Synonym-Lexikon eliminiert, sondern auf ihnen besteht“; vgl. später auch I. Rakusa (Glatt und fehlerfrei. Die Zeit, 10.3.1995).

10 Barbara Lehmann: Hypertrophie, Exzesse, Theatrum muni. Frankfurter Rundschau, 13.2. 1999 (Rubrik „Sport / Neue Bücher“). 
unabhängig von den Arbeiten Bachtins überaus berechtigt. Zumal in einem realistischen Roman sollten sie Leitlinien des Übersetzers sein. Richtig ist auch, dass viele Übersetzungen hier versagen und veraltet sind. ${ }^{11}$ Die Lösungen S. Geiers haben allerdings ebenfalls keinen uneingeschränkten Beifall der Rezensenten gefunden. ${ }^{12}$

$\mathrm{Zu}$ den genannten Leitlinien kommt schließlich das Verbot eigenmächtiger Insertionen im Sinne inhaltlicher Erweiterungen. ${ }^{13}$ Aus Geiers Auftritten vor Lesern wurde als ihr Credo zitiert: „Verboten ist jeder Eingriff - auch der wohlwollendste - in den Text“14. Der Übersetzerin helfe, nach eigener Aussage, „denkbar große Genauigkeit und die Vermeidung jeder Korrektur" ${ }^{\prime 15}$.

Was damit aus Kritikeräußerungen und einzelnen öffentlichen Bekundungen der Übersetzerin an Elementen eines Übersetzungskonzepts zusammenkommt, ist im modernen literarischen Übersetzen im Grunde selbstverständlich. Schließlich ist das Zeitalter der belles infidèles längst vorbei und das Bewusstsein für Stilprobleme lange schon geweckt. Neben den genannten sind einige weitere Äußerungen S. Geiers über ihre Auffassung vom Übersetzen dokumentiert. Letztlich nicht objektiv bestimmbar ist eine Formulierung, die die Übersetzerin offenbar über Jahre hinweg verwendete: „Den Atem des Textes erfassen“ habe sie ihre Arbeit genannt, wird vielfach überliefert. ${ }^{16}$ Kann man darin ein Konzept erkennen, und wie wäre es,

11 Ulrike Jekutsch: Auktorial-personal oszillierendes Erzählen in Dostoevskijs Prestuplenie i nakazanie und in der Wiedergabe durch frühe deutsche Übersetzungen. In: Dorothea Kullmann (Hrsg.): Erlebte Rede und impressionistischer Stil. Europäische Erzählprosa im Vergleich mit ihren deutschen Übersetzungen. Göttingen 1995, S. 137-178; Susanna Vykoupil: Erlebte Rede und verwandte Verfahren zur Bewußtseinsdarstellung in deutschen Übersetzungen von Prestuplenie i nakazanie. In: ebd., S. 179-220.

12 Vgl. U. Heftrich: „Zweifel regt sich indes, wo sie [S. Geier] das russische Radebrechen einer Deutschen in flottes Berlinerisch überträgt“ (a.a.O.). P. Urban schrieb, die Übersetzerin „bemüht sich (mit wechselndem Geschick) um eine stärkere Typisierung einzelner Sprechweisen und -haltungen der dramatis personae" (a.a.O.). Für I. Rakusa gelingt Frau Geier, anders als den Bräuers, „die so wichtige Figurencharakterisierung durch die Sprache [...] bis auf einige wenige, leicht outriert wirkende Stellen - überzeugend“ (a.a.O.). Rosemarie Tietze nahm, wie Heftrich, Anstoß am Berlinerisch der Kneipenwirtin (Dostojewski im Wettbewerb. Zu den beiden Neuübersetzungen des Raskolnikow-Romans. Süddeutsche Zeitung, 18.3. 1995).

13 Davon zu unterscheiden ist das Verfahren der Explikation (mittels einer hinzugefügten Erläuterung, Umschreibung), meist angewandt bei Realia, ausgangssprachlichen Begriffen usw. Es ist nicht nur zulässig, sondern oft genug geboten. Gelegentlich wurde kritisiert, dass S. Geier zu teilweise umfangreichen Anmerkungen griff, wenn sie eine Redensart oder einen Begriff in der Ausgangssprache beließ (u.a. U. Heftrich, a.a.O.).

14 Badische Zeitung, 27.9.2005. Die Übersetzerin sagte dies, so die Berichterstatterin, „im Hinblick auf die Tatsache, dass viele Übersetzer glauben oder glaubten, einzelne Sätze in ihrem Sinne, verschönern' zu wollen“.

15 Marion Pfordt: Man liest nie nur den Autor, Badische Zeitung, 26.6.2007. Präzision als Vorzug nennt auch K. Hielscher in ihrer Laudatio auf S. Geier zum Preis der Leipziger Buchmesse 2007, vgl. Jahrbuch der Deutschen Dostojewskij-Gesellschaft 14, 2007, S. 143 f.

16 Gemma Pörzgen: Der lebendige Atem der Sprache. Swetlana Geier berichtete im Literaturhaus von ihrer Dostoevskij-Übersetzung. Frankfurter Rundschau, 15.2.1995; Markus Böttin- 
entmetaphorisiert, wissenschaftlich zu beschreiben? Geht es um den Sprachrhythmus oder um Sprachmelodie, um Intonation? Oder etwa um Stilistik? Meint es dasselbe, was Peter Urban (a.a.O.) als seine zweite Eigenheit sah, als er, leider ohne weitere Erläuterungen und Belege, schrieb, Geiers Text lege „Wert auf Erhaltung der rhetorischen Strukturen und Elemente des Originals"? Gewiss nicht. Die Aussage Urbans führt eher zurück zum eingangs dargestellten Konzept der ,Wörtlichkeit'. Mit einer Aussage, es komme darauf an, den „Atem des Textes“ zu erfassen, bewegen wir uns auf dem diametral entgegengesetzten Ende der Möglichkeiten einer Beziehung zum Text, und zudem auf bereits mystifizierendem Boden. Das Publikum, das auf Leseabenden etwas vom „Atem des Textes“ (und von dessen Erfassen) vernahm, fühlte sich wohl an ein Mysterium und an seine Eröffnung herangeführt und stellte, soweit überliefert, keine Fragen, was es denn mit der seltsamen Vorstellung auf sich habe. Auch der berichtende Journalist fragte sich dies nicht, erklärte aber, Geier habe „nicht nur die russische Sprache, sondern auch ihre Seele ins Deutsche gebracht ${ }^{17}$. Allerdings sind Beispiele für ein sehr assoziatives Verhältnis von Frau Geier zum russischen Wortschatz überliefert, etwa ihre „kühne Verknüpfung der Geographie Russlands mit der Notwendigkeit, sich nicht mit zu viel Hab und Gut zu belasten, um jederzeit fliehen zu können“, was die Übersetzerin mit der sprachlichen Besonderheit in Verbindung bringe, dass es im Russischen kein direktes einfaches Äquivalent für das Wort „haben“ gäbe. ${ }^{18}$ Die Übersetzungstheorie in der Nachfolge Roman Jakobsons würde darauf erwidern, dass Aussagen über die Wirklichkeit in verschiedenen Sprachen strukturell unterschiedlich formuliert werden können (ein zusätzlicher Grund im Übrigen, weshalb sich ,wörtliches' Übersetzen verbietet). Die letzte Stufe der Mystifizierung des Übersetzens ist mit der Behauptung seiner Nonexistenz erreicht. S. Geier sagte in einem Interview ${ }^{19}$ :

[...] mich haben die Verluste interessiert. Mich hat das interessiert, was immer jenseits des Neuen, des Übersetzten bleiben muß. Übersetzen ist etwas, was es nicht gibt.

ger: „Den Atem des Textes erfassen“, Badische Zeitung 26.4.2003; ferner Badische Zeitung, 16.10.2003, u.a. Quellen.

17 Hagen Späth: Der Atem des Textes. Badische Zeitung, 16.10.2003.

18 Juliana Eiland-Jung: Die Literatur ist ihr Zuhause. Badische Zeitung, 2.11.2007. Für die Reporterin zeigt die Äußerung „wie weit für Geier das Thema ,Übersetzen“ gefasst ist“ - was vielleicht ebenfalls mit der Weite Russlands zusammenhängt, ist man versucht hinzufügen. Weitere Gedanken Geiers zur U-menja-Konstruktion im Russischen finden sich in S. Geier: Ein Leben zwischen den Sprachen, a.a.O., S. 112.

19 Uwe Pörksen: Das klebrige Blättchen einer jungen Birke. Swetlana Geier im Gespräch mit Uwe Pörksen über Dostojewskij und die neue Übersetzung der „Brüder Karamasow“. In: Die Drei. Zeitschrift für Anthroposophie in Wissenschaft, Kunst und sozialem Leben 2003, Nr. 10, S. 13-24, hier S. 23. Vgl. auch S. G.: Ein Leben zwischen den Sprachen, a.a.O., S. 156. 
Wo es im Lichte einer höheren Form von Sprach- oder Literaturbetrachtung Übersetzen nicht gibt, muss die ordinäre Übersetzungstheorie kapitulieren. Im vorliegenden Beitrag soll allerdings weiterhin von ihrem Boden aus analysiert und beurteilt werden.

Wie also sieht das Übersetzungskonzept S. Geiers aus? Die Vorstellungen darüber sind nicht präzise und nicht eindeutig. Konträre Merkmale wie Spiritualität („Atem des Textes“) und „archaische Begrifflichkeit“ vertragen sich anscheinend durchaus gut. Die uneindeutigen Beschreibungen möglicher Elemente eines Geierschen Übersetzungskonzepts waren der Aura, die das Dostojewskij-Projekt allmählich umgab, wahrscheinlich eher förder- als hinderlich. Es scheint gelungen zu sein, auf die Übersetzungen Geiers Eigenschaften zu projizieren, die der Leser immer schon im Original erwartete, bei einem Dostojewskij also, der tief im Zentrum der eigenartigen Russland-Schwärmerei der Deutschen steht. Den Prozess der Entstehung dieser Aura aufzuspüren, wäre reizvoll, ist aber kaum machbar. Erste Rezensenten begrüßten das Projekt wohlwollend, aber bar jeglicher Euphorie, und brachten auch kritische Bemerkungen vor. ${ }^{20}$ In späteren vergleichenden Rezensionen wurde die Schuld-und-Sühne-Übersetzung der Bräuers als ebenbürtig oder gar mindestens ebenbürtig bewertet. ${ }^{21}$ Den Erfolg der Geierschen Übersetzung beförderte entscheidend die Präsentation durch M. Reich-Ranicki im „Literarischen Quartett“ des Zweiten Deutschen Fernsehens am 31.3.1994. Der Verleger Ammann ${ }^{22}$ erinnert sich: „[...] von da an war das Eis gebrochen. Um Weihnachten 1994 herum haben uns die Leute das Buch Verbrechen und Strafe aus

20 Heftrich (a.a.O.) war, wie oben zitiert, nicht einverstanden mit dem „flotten Berlinerisch“, das für das „Radebrechen einer Deutschen“ genommen wird; andererseits sei die Übersetzung „der Vorlage fast bis zur Unverständlichkeit verhaftet“, der Kritiker moniert das „gleichzeitige Zuviel und Zuwenig an Texttreue“. Urban (a.a.O.) begründet, warum „der Jubel dennoch ein wenig verhalten klingt“, u.a. mit den Modernismen und allzu saloppen Ausdrücken im Text. In Rosemarie Tietzes Doppelrezension kam u.a. der Sprachfluss in Geiers Übersetzung im Vergleich zu dem bei den Bräuers nicht gut weg (a.a.O.).

21 Für P. Urban, der die Dostojewskij-Ausgabe des Aufbau-Verlags (13 Bände) recht kritisch besprach, haben Margit und Rolf Bräuer „für mein Empfinden, mit ,Schuld und Sühne den überzeugendsten Text zu dieser Ausgabe beigesteuert [...], einen, der den Vergleich mit Swetlana Geiers ,Verbrechen und Strafe“ wahrlich nicht zu scheuen braucht" (Ein Waschlappen erleidet Schiffbruch. Frankfurter Allgemeine Zeitung, 11.4.1995). R. Tietze (a.a.O.) legte ohne klaren Favoriten ausgewogen dar, wo sie Stärken und Schwächen beider Übersetzungen sah.

22 Ammann berichtete über frühe Werbemaßnahmen: „Wir versuchten im Vorfeld, das Erscheinen des Romans so gut wie möglich vorzubereiten, ich habe mit zahlreichen Kritikern und Buchhändlern gesprochen, bin herumgereist, um die neue Übersetzung anzupreisen und Aufmerksamkeit für sie zu schaffen" (Interview am 19.6.2001, Kogut, S. 278). Seine verlegerische Entscheidung für eine Übersetzung träfe Ammann nach dem sprachlichen Eindruck, den sie auf ihn macht, „wobei ich bei Sprachen, die ich nicht lesen kann, wie zum Beispiel das Russische, einen Gutachter oder eine Gutachterin meines Vertrauens beiziehe. Bei Frau Geier war dieses Prozedere aber nicht nötig, denn ich kannte sie ja als Übersetzerin, und ich habe ihr restlos vertraut, mit Recht und zum Glück“ (ebd., S. 277). 
den Händen gerissen“23. Vielleicht ist Zürich, der Sitz des Ammann-Verlags, das Epizentrum der alsbald einsetzenden Verklärung des dort erscheinenden Dostojewskij. Schon im November 1994 verwendete die Neue Zürcher Zeitung im Artikel „Swetlana Geier - Vermittlerin des originalgetreuen [!] Dostojewski“"24 ein Attribut, das übersetzungstheoretisch Unfug ist. Eine kritische Würdigung auch der möglichen Schwächen des Konzepts oder seiner Durchführung fand offenbar kaum noch statt. Eine seltene Ausnahme war Barbara Lehmanns Besprechung der Bösen Geister S. Geiers, in denen sie „zwei gravierende Mängel: eine stilistische Unsicherheit im Deutschen und eine allzugroße Ehrfurcht gegenüber dem russischen Original“" entdeckte. Für unseren Zusammenhang ist der zweite Aspekt von Interesse, den die Rezensentin konkretisierte. S. Geier tue „das, was sie an früheren Dostojewskij-Übersetzern wie E. Rahsin rügte: Sie hangelt sich so ehrfürchtig am Russischen entlang, daß der Text dadurch im Deutschen hausbacken und bieder gerät" ${ }^{25}$. Anzumerken ist, dass, was man für den Ausdruck eines Mangels an übersetzerischer Phantasie oder übersetzerischem Mut halten könnte, auch das Ergebnis des eingangs skizzierten Konzepts absichtlich gesteigerter Wörtlichkeit der Übersetzung sein kann.

Das Konzept der Wörtlichkeit erhielt eine späte theoretische Flankierung in der erwähnten Freiburger Dissertation. Die Autorin distanziert sich vom ihrer Meinung nach unbrauchbaren Äquivalenz-Begriff der Übersetzungstheorie (S. 49f.) und erstellt allen Ernstes eine „Quantifizierungstabelle“, in der sie „Ergänzungen“, „Auslassungen“ und „andere Abweichungen“ in fünf Übersetzungen ausgewählter Passagen der „Dämonen / Bösen Geister“ (Besy) zählt (S. 255ff.). Will man rechnerisch vorgehen, muss man sich in der Tat vorher vom Äquivalenz-Begriff trennen, bedeutet er doch, dass es beim Übersetzen unterschiedliche Hierarchien von Invarianz-Forderungen geben kann, und dass Äquivalenz wiederum durch unterschiedliche, einander bisweilen funktional substituierende oder kompensierende Verfahren hergestellt werden kann. ${ }^{26}$ Wo ein Übersetzer Sinn und Bedeutung im Original zu erfassen und alle möglichen semantischen und, nota bene, pragmatischen Aspekte in Ausgangs- und Zielsprache zu berücksichtigen hat, bemühte sich die Verfasserin der „Quantifizierungstabelle“ zu zeigen, „wie wenig Swetlana Geier

23 Kogut, S. 278. Ebenfalls breitenwirksam „schwärmte“ Jahre später (Oktober 2007) die Journalistin Elke Heidenreich in ihrer TV-Sendung von den Dostojewskij-Übersetzungen Geiers (lt. Badischer Zeitung, 2.11.2007).

24 Regula Heusser: Swetlana Geier - Vermittlerin des originalgetreuen Dostojewski. NZZ, 22.11.1994.

25 Barbara Lehmann, a.a.O. Den Verleger veranlassten diese und weitere Kritikpunkte („schlampiges Lektorat“, „verheddert sich oftmals in grammatikalischen Bezügen“, „Wenig schön sind auch die Russizismen“ u.a.) zu einem befremdlich unsachlichen Leserbrief (Ob die Rezensentin die Neuübersetzung der „Bösen Geister“ gelesen hat? Frankfurter Rundschau, 6.3.1999).

26 Siehe z.B. Michael Schreiber: Übersetzung und Bearbeitung. Zur Differenzierung und Abgrenzung des Übersetzungsbegriffs. Tübingen 1993. 
in ihrer Übersetzung vom Wortlaut und von der Syntax des Originals abgewichen ist" (S. 193), und bemerkte nicht, dass sie damit, wenn die These denn zutreffen würde, keinen Vorzug, sondern eine kapitale Schwäche in ihrem Untersuchungsobjekt ausgemacht hätte. Ein Rezensent verlor (aus Höflichkeit?) kein kritisches Wort über das methodisch Abwegige dieses Ansatzes, erklärte bei anderer Gelegenheit aber, Frau Geier übersetze „ja nicht Worte oder einzelne Phrasen“, sondern nach dem in der Ermahnung ihrer einstigen Lehrerin enthaltenen Prinzip „Nase hoch, d.h. nicht mit den Augen am Ausgangstext kleben, sondern ihn verinnerlichen und erst dann in der anderen Sprache wiedergeben" ${ }^{27}$. So wäre in der Tat gutes, übersetzungstheoretisch bewusstes Übersetzen $\mathrm{zu}$ beschreiben (wobei manch andere Anforderung selbstverständlich noch hinzukommt).

Präziser als es hier versucht wurde, ist ein die Übersetzerin möglicherweise leitendes Übersetzungskonzept nicht zu beschreiben. S. Geier gab auf die Frage „Würden Sie sagen, dass Sie eine Übersetzungstheorie haben?"“ die bemerkenswerte Antwort „Wahrscheinlich habe ich eine“28. Lassen wir die Frage, ob soz. gefühlt vorliegende Übersetzungsgrundsätze überhaupt als solche gelten können, beiseite, und wenden wir uns Aspekten der Übersetzungspraxis im Falle von Verbrechen und Strafe zu, um diese an die reklamierten bzw. zugeschriebenen Charakteristika des Geierschen Übersetzens, die oben zusammengetragen wurden, anzulegen. Das Bild, das sich ergeben wird, ist uneinheitlich. Auf der einen Seite ist eine Tendenz zur Texttreue im Sinne größtmöglicher Wörtlichkeit, wie sie am Beginn des gesamten Projekts als initiales Motiv für eine Neuübersetzung stand, sehr wohl erkennbar. Darüber soll im nächsten Kapitel (3.) gehandelt werden. Auf der anderen Seite fällt ein bisweilen recht freier Umgang mit dem Ausgangstext auf, eine also gegenläufige Tendenz. Diese passt in keiner Weise zu den Postulaten der Genauigkeit und des Verbots von Ergänzungen und Verbesserungen. Die Übersetzerin erlaubt sich Verfahren, die in der Übersetzungspraxis des späten 20. Jahrhunderts ungewöhnlich und fragwürdig sind. Die meisten der im folgenden zu konstatierenden Eigentümlichkeiten der Übersetzung von 1993 lagen in der von 1964 noch nicht vor.

Der erste hier anzuführende Komplex ist für die Wahrnehmung des Romans durch einen deutschen Leser gravierend, betrifft er doch ein für Verbrechen und Strafe eminent wichtiges Feld, das des Religiösen. Es sind eine Reihe Insertionen religiös gefärbten Wortmaterials an Stellen zu nennen, an denen das Original dafür

27 Rudolf Neuhäuser: (Rezension Kogut 2009). In: Dostoevsky Studies, New Series, vol. XIV (2010), S. 221-224; Ders.: Laudatio für Swetlana Geier. In: Geschichte eines Verbrechens. Über den Mord in der Romanwelt Dostojewskijs. München, Berlin 2010, S. 9-15, hier S. 13 (=Jahrbuch der Deutschen Dostojewskij-Gesellschaft, Jahrbuch 16, 2009).

28 S. Geier: Ein Leben zwischen den Sprachen, a.a.O., S. 158. 
keinen Anlass bietet. Besonders sticht die Szene des ungeplanten zweiten Mordes hervor, bei dem Raskolnikow das Beil gegen Lisaweta, die Schwester der Pfandleiherin, erhebt. Hier schreibt S. Geier: „Und so einfältig war diese unglückliche Lisaweta, so gottergeben, so ein für allemal eingeschüchtert, daß sie nicht einmal die Hand vor das Gesicht hielt [...]" (S. 109f.).29 Im Original findet sich kein Bezug zu Gott ${ }^{30}$, Frau Geier hat ihn in den Text hineingeschrieben.

In Kapitel I,2 setzt S. Geier für Ausdrücke mit den russischen Wörtern žal', žalet', die bei anderen Übersetzern in Wendungen mit den Vokabeln „Bedauern“ (Röhl), „Mitleid“ (Eliasberg), „leid tun“, „Mitleid“ (Rahsin) erscheinen und die 1964 auch von S. Geier selbst so wiedergegeben worden waren ${ }^{31}$, nun das religiös konnotierte Wort „Erbarmen“32. Die wichtige Stelle ist damit sachlich falsch übersetzt. Nicht zufällig reibt sich das falsche Substitut an der Umgebung, in der es vorkommt. Während „Ich habe kein Mitleid verdient!“ ein gebräuchlicher deutscher Satz ist, ist die Variante von 1993 „Ich habe kein Erbarmen verdient!“ zumindest ungewöhnlich. Erbarmen und verdienen sind im Deutschen nicht durch Kookkurrenz verbunden, was wohl daran liegt, dass eine solche theologisch fragwürdig wäre. An anderer Stelle schreibt S. Geier statt *,es ereignete sich“ oder *,es passierte“ (russ. slučilos') den Satz „Aber da begab sich etwas Seltsames“ (S. 474), und der Leser glaubt sich in die Welt des Neuen Testaments versetzt. ${ }^{33}$ Ähnlich verwendet Geier gegen Dostojewskij einen religiösen Terminus, wenn sie Sonja Lisaweta als „Gerechte“ bezeichnen lässt (S. 440). ${ }^{34}$ Wahrscheinlich aus dem gleichen Impuls eines religiös motivierten Übersetzens stammt die Wendung

29 In SG1964 noch: „Und so einfältig, so ergeben und so ein für allemal eingeschüchtert war diese unglückliche Lizaveta“ (S. 70).

30 „I do togo èta neščastnaja Lizaveta byla prosta, zabyta i napugana raz navsegda, čto daže ruki ne podnjala zaščitit' sebe lico [...]“ (F. M. Dostoevskij: Polnoe sobranie sočinenij v tridcati tomach. T. 6, Leningrad 1973, S. 65, nach dieser Ausgabe wird der russische Text im Folgenden mit einfacher Seitenangabe zitiert. Kursive stammen, wie auch bei den deutschen Zitaten, von mir.) Vgl. „Und diese unglückselige Lisaweta war so einfältig, so durch und durch verschüchtert und verschreckt, daß sie nicht einmal die Hände hob, um ihr Gesicht zu schützen“ (MRB, S. 105).

$31, \ll[\ldots]$ wer soll denn mit so einem wie mir Mitleid haben? Wie? Haben Sie etwa Mitleid mit mir $[\ldots] »[\ldots]$ «Warum sollte man auch noch Mitleid mit dir haben?» [...] «Mitleid, warum Mitleid mit mir haben!» [...]“ (SG1964, S. 23).

32 „Nun, wer soll schon mit einem Menschen wie mir Erbarmen haben? Wie? Haben Sie nun Erbarmen mit mir [...] hast du nun Erbarmen mit mir [...]“ [...] „Weshalb soll man Erbarmen mit dir haben?“ [...] „Erbarmen! Weshalb man Erbarmen mit mir haben soll? [...] Ich habe kein Erbarmen verdient!“ (S. 33). Für ,Erbarmen' gibt es im Russischen ein eigenes, eingeführtes Wort kirchenslavischer Herkunft, die Lehnübersetzung nach dem Griechischen miloserdie.

33 In SG1964 noch: „trat ein merkwürdiges Ereignis ein“ (S. 274).

34 Bei Dostojewskij steht spravedlivaja, nicht pravednaja. Die Bräuers schreiben „Sie war redlich und rechtschaffen" (S. 416). 
„neuer Weg“, wo es im Original um einen „Ausweg“ geht ${ }^{35}$, oder die schicksalhaftpathetischere Wendung „was ich jetzt zu tun habe“ (S. 599), wo es im Original einfach „was ich jetzt tun will“ heißt ${ }^{36}$.

Beim Umgang mit Leitmotiven zeigt sich in der neuen Übersetzung eine ähnliche Tendenz zur Überhöhung, wenn S. Geier mit dem Konkreten und Einfachen bei Dostojewskij eigenmächtig umgeht. Besonders bedauerlich ist das fast völlige Verschwinden des leitmotivisch verwendeten Wortes für ,Schmutz' (r. grjaz') im Eingangskapitel des Romans, in dem der Leser die Auseinandersetzung Raskolnikows mit seinem Mordplan miterlebt. Mit „Zu welchem Schmutz mein Herz doch fähig ist!" könnte der Original-Satz übersetzt werden ${ }^{37}$, bei S. Geier aber heißt er: "Wessen ist mein Herz nicht alles fähig!“ (S. 15). Der Sinn ist ins Ferne und Unbestimmte („wessen nicht alles") verschoben, und das zukünftige Leitmotiv ,Schmutz' (es kommt nicht nur an den hier zitierten Stellen vor) fällt heraus, es bleibt unübersetzt. Raskolnikow begibt sich, was psychologisch aufschlussreich ist, unmittelbar anschließend in den ,Schmutz' einer Spelunke. Wo dieser - wiederum mit dem Konkretum grjaz’ - benannt wird, überhöht ihn die Übersetzerin zu einer abstrakten Kategorie: „[...] ungeachtet aller ihn umgebenden Verkommenheit“ (S. 17). ${ }^{38}$ Von einer Reproduktion Dostojewskijscher "archaischer Begrifflichkeit" kann also nicht die Rede sein. Gegen die erklärte Maxime der Genauigkeit verstößt die Übersetzerin an wichtigen Stellen.

Nimmt man sich als Übersetzer den Raskolnikow-Roman vor, sollte man in jedem Fall mit allen schismatischen Bildern und Begriffen im Ausgangstext sorgsam umgehen. Der ungeplante Mord an Lisaweta erfolgt durch einen Schlag mit einem Beil „mitten auf den Scheitel“, und auch ein zweiter und ein dritter Schlag „mit dem Beilrücken“ gehen ,jedesmal auf den Scheitel“ (S. 106). Begriff und Bild vom „Scheitel“ (russ. temja) sind wichtig für den gesamten Roman. An allen Stellen, die sich auf den Mord beziehen, steht bei Geier das deutsche Äquivalent "Scheitel“ (S. 106, 110, 143, 375), nicht so aber in einer wichtigen inhaltlich verbundenen späteren Stelle. Im zweiten Dialog mit dem Untersuchungsrichter Porfiri schildert Raskolnikow die Verhörtaktik der Justiz. Der Verhörte werde durch abseitige Fragen abgelenkt, um ,ihn dann plötzlich, völlig überraschend, mit

$35,[\ldots]$ opjat' bor'ba - značit, našelsja ischod! - «Da, značit, našelsja ischod! [...]»" (S. 341). SG1993: „[...] wieder Kampf - also, ein neuer Weg! - »Ja, ein neuer Weg! [...]«“ (S. 603). SG1964 noch: „[...] neuer Kampf - es zeigt sich ein Ausweg! Ja, es zeigte sich ein Ausweg!“ (S. 376). Vgl. MRB: „[...] es würde wieder einen Kampf geben - das heißt, ein Ausweg war gefunden! Ja ein Ausweg war gefunden“" (S. 571).

36 „Čto že ty teper' chočeš’ delat'? - A tebe kakoe delo, čtó ja teper' choču delat'?“ (S. 339). SG1964 noch: „Was willst du denn jetzt tun - Was geht es dich an, was ich jetzt zu tun gedenke" (S. 374).

37 So bei den Bräuers (S. 13) für russ. „Na kakuju grjaz’ sposobno, odnako, moe serdce! Glavnoe: grjazno, pakostno, gadko, gadko!..." (S. 10).

38 „nesmotrja na vsju grjaz’ obstanovki“ (S. 11). Vgl. MRB: „trotz all des Schmutzes ringsum“ (S. $15)$. 
der verhängnisvollsten und allergefährlichsten ${ }^{39}$ Frage wie mit einem Schlag“ - und nun weicht S. Geier von der Wortwahl des Originals ab - „auf den Schädel zu treffen" (S. 451). Porfiri wird Raskolnikows spontan gefundenes, psychologisch verräterisches Bild dankbar aufgreifen und an zwei Stellen genüsslich zitieren (S. 455, 470). In diesen beiden Dialogpassagen ist für das russische Wort temja ,Scheitel" ebenfalls das deutsche Wort „Schädel“ gesetzt. Man kann sachliche Gründe haben und vom Sprachgefühl her meinen, dass in einer Übersetzung im angeführten Dialog besser "Schädel“ statt „Scheitel“ zu verwenden sei. Wenn aber das von S. Geier dem Winkler Verlag vorgelegte Konzept eines „Festhaltens an jedem Wort und Ausdruck" Berechtigung hat, dann sicherlich hier. Raskolnikow trägt das Schisma (russ. raskol) in seinem Namen, und Rasumichin hatte ihn beschrieben als Person, in der sich ständig zwei gegensätzliche Charaktere abwechseln (S. 290). Benutzt Raskolnikow selbst im Verhör mit Porfiri in einer deutschen Fassung nicht „Scheitel“, sondern „Schädel“, geht den Lesern ein wesentlicher Aspekt des Bild- und Begriffszusammenhangs des Romans verloren.

Im Übrigen hat das Konzept des „Festhaltens an jedem Wort und Ausdruck“ zwei Seiten. Das Postulat, nach Möglichkeit keine lexikalischen Eins-zu-zwei- oder Eins-zu-viele-Entsprechungen zuzulassen, kann letztlich nur wirksam sein, wenn auch Zwei- (oder Viele-) zu-eins-Entsprechungen vermieden werden. Bei S. Geier aber findet sich für russ. raz"edinenie ohne erkennbaren Grund die Übersetzung „Spaltung“40, die unnötig ist und einen auf Schlüsselbegriffe achtenden Leser verwirrt.

Solche Aufgabe lexikalischer Differenzierung ist dann besonders misslich, wenn es um Figurentext geht. So verwendet die Übersetzerin auf relativ kurzem Abstand das deutsche Wort „eindeutig“ für zwei verschiedene Adjektive im Ausgangstext: in ihrem Brief bezieht sich Pulcherija auf einen Brief Lushins, in dem dieser „einen Heiratsantrag machte und um rasche und eindeutige Antwort bat" ${ }^{41}$ (S. 49). Wenige Seiten später erregt sich Raskolnikow (in wörtlich zitierter Gedankenwiedergabe) gerade über diese von seiner Mutter berichtete Heiratsabsicht Lushins, und tut dies bei S. Geier mit den Worten „Weil es eine eindeutige Geschichte ist“42. Der Leser mag sich fragen: Zitiert Raskolnikow den Brief, oder sind seine Formulierungen unbewusst ,infiziert' von der Sprache Lushins, die in Pulcherijas Brief an dieser Stelle höchstwahrscheinlich wörtlich wiedergegeben worden war?

39 Zum Elativ siehe unten.

40 S. 737. MRB bieten hier „Kluft“ (S. 699). Es geht um die Distanz zu Gefängnisinsassen. Das Wort „Spaltung“ ist auch semantisch fragwürdig.

41, „... [ pis'mo, v kotorom ves'ma vežlivo is”'jasnil svoe predloženie i prosil skorogo i rešitel'nogo otveta“ (S. 31). MRB: „und am nächsten Tag einen Brief schickte, in dem er überaus höflich seinen Antrag machte und um eine rasche und endgültige Antwort bat" (S. 46).

42 S. 57, für „Potomu čto èto delo očevidnoe“ (S. 35), dafür MRB: „Die Sache ist doch sonnenklar“ (S. 54). 
Die Sprache Lushins ist eine gute Gelegenheit, nach der Wiedergabe sprachlicher Eigentümlichkeiten von Figurenrede - dem Vernehmen nach ein zentrales Anliegen der neuen Übersetzung - zu fragen. Das berechnende Wesen dieser Figur verrät sich in diversen Lexemen mit arithmetischer oder pekuniärer Grundbedeutung (,in Rechnung stellen / auf die Rechnung setzen', bzw. ,ankreiden'. ,verdoppelte sich' u.ä.). Markant ist die redundante Verwendung eines Adverbs bzw. Adjektivs kapital'no(e) (von ,Kapital'). An den drei Stellen, an denen sie vorkommt (alle in IV,2), setzt S. Geier aber jeweils Verschiedenes: „Zumal meine grundsätzliche und dringendste Bitte unerfüllt geblieben ist..." (S. 406, kapital’naja i ubeditel'nejšaja pros'ba, S. 230), ,und sie um die notwendige Aufklärung einer höchstlichst bedeutsamen und für mich ehrenrührigen Angelegenheit bitten" (S. 408, po odnomu ves'ma kapital'nomu i dlja menja obidnomu punktu, S. 231), „Angebote [...] die, wie ich sehe, für Sie eine kapitale und möglicherweise höchstlichst angenehme Bedeutung zu haben scheinen“ (S. 412, imejut dlja vas kapital'noe, a možet byt', i ves'ma prijatnoe značenie, S. 233). ${ }^{43}$ Nur im letzten Fall also ist das kapital'noe des Originals wiedererkennbar wiedergegeben. Vielleicht hat die Übersetzerin ihre Aufmerksamkeit ganz auf das redundante Modaladverb ves'ma (,sehr', ,äußerst') verlegt, für das sie ein veraltetes (und maniriert kleingendes) „höchstlichst" zu setzen sich entscheidet.

$\mathrm{Zu}$ den psychologisch verräterischen figuralen Fixierungen auf bestimmte Worte, die reproduziert werden sollten, gehört sicherlich Raskolnikows am Romananfang redundant verwendeter Ausdruck glavnoe, um den seine Gedanken vor der Ausübung der ersten Tat magisch kreisen. In einer wichtigen Stelle wiederholt ihn Raskolnikow im Abstand von nur drei Zeilen"4, doch findet die versprochene, von Rezensenten und Verlagswerbung gerühmte Bewahrung von Wortwiederholungen, deren Nicht-Beseitigung mit Hilfe von Synonymen, nicht statt:

Kein Mensch trägt einen solchen Hut [...] man erinnert sich an ihn ... das ist die Hauptsache [...] Kleinigkeiten, Kleinigkeiten, das ist das wichtigste. (S. 10)

Etwas später nimmt Dostojewskijs Raskolnikow, nicht aber Geiers, in der oben bereits angeführten Stelle das seine Gedankengänge charakterisierende Wortmotiv noch einmal auf:

Wessen ist mein Herz nicht alles fähig! Vor allem: schmutzig, ekelhaft, widerwärtig, widerwärtig! (S. 15)

43 In SG1964 erschien das verräterische Adverb in keinem der drei Fälle: „meine grundsätzliche und eindringlichste Bitte“ (S. 253), „in einer sehr grundlegenden und für mich äußerst kränkenden Angelegenheit“ (S. 255), „von einer grundsätzlichen und vielleicht sogar für Sie erfreulichen Bedeutung" (S. 257). Auch die Bräuers bringen es nicht.

44 „Nikto takich ne nosit [...] glavnoe, potom zapomnjat, an i ulika. Tut nužno byt' kak možno neprimetnee... Meloči, meloči glavnoe!“ (S. 7). 
Von den drei gewählten Varianten „Hauptsache“, „das wichtigste“ und „Vor allem“ ist die dritte zudem pragmatisch befremdlich, da sie sich nicht in die mündliche Äußerung einfügt. ${ }^{45}$

Das „Festhalten an jedem Ausdruck und jeder Formulierung des Originals“ (Dr. Viviani vom Winkler Verlag, Frau Geiers Programm wiedergebend) greift in der Praxis also gerade dort nicht, wo es unbedingt geboten wäre. Auf dem Feld, auf dem ihr Konzept vorrangig realisiert werden soll, dem lexikalischen, übergeht die Übersetzung Sachverhalte, die für das Hervortreten jeweils „eigener Stimmen“ von großer Bedeutung wären. S. Geier bleibt mehrfach selbst dort nicht beim Wortlaut der Vorlage, wo ein Zitat aus einer Figurenrede im Text selbst angezeigt wird, es also mit sich selbst identisch wiederzugeben gewesen wäre. So hatte Raskolnikow im Dialog mit Porfiri (IV,5) formuliert: „Es gibt doch, glaube ich, eine goldene Regel in der Juristerei, einen juristischen Kunstgriff" (S. 451). Diese Sätze hält ihm Porfiri später vor und zitiert dabei exakt. Bei S. Geier aber sagt Porfiri: „Und was unsere juristische Taktik anlangt, wie Sie sich so scharfsinnig ausdrückten[!]" (S. 455). ${ }^{46}$ Geiers Leser muss glauben, Porfiri verändere die Worte Raskolnikows (bewusst oder unbewusst). Ihm entgeht die Präzision in der Verhörführung des Untersuchungsrichters. Ein ähnliches Zitieren einer Figur durch eine andere liegt vor im Dialog zwischen Swidrigailow und Raskolnikow, den jener belauscht hatte (V.5). Wir lesen „Raskolnikow erblaßte [...], als er seine eigenen an Sonja gerichteten Worte zu hören bekam" (S. 589), erhalten die entscheidenden Zitate aber eben nicht genau übersetzt („Gemeinheit“ gegen „Gemeinheiten“ u.a.) und auch nicht, wie bei Dostojewskij, durch Anführungsstriche angezeigt, so dass die Stelle für deutsche Leser dunkel bleibt. ${ }^{47}$

Hier zu unterlassen, was jeder aufmerksame Leser aufgrund der expliziten Signale („wie Sie sich so scharfsinnig ausdrückten“, „seine eigenen Worte zu hören bekam") tut, nämlich zurückzublättern, ist nur eine der Nachlässigkeiten, von denen der Text der Übersetzung nicht wenige aufweist. Bekanntlich diktierte Frau Geier ihre Übersetzung einer Sekretärin, die an einer mechanischen Schreibmaschine saß. ${ }^{48}$ Mit einem befreundeten Musiker ging sie die Typoskripte später durch. Dieser Erstleser war, ebenso wie die Sekretärin, des Russischen nicht

45 Auch die Übersetzung der Bräuers (S. 8, 13) ist in Hinblick auf die Variation unbefriedigend, bringt aber im dritten Fall immerhin eine syntaktisch mögliche Lösung: ,Ja, das ist es: schmutzig, niederträchtig und widerlich, so widerlich“.

46 Bei Dostojewskij „priem juridičeskij“ bzw. „priemy-to naši juridičeskie“ (S. 256, 258). 1964 hatte S. Geier einheitlich den Ausdruck ,juristische Taktik“ verwendet (S. 282, 284).

47 Vgl. S. 551 und 589 (im russ. Original S. 313 und S. 334f., vgl. auch MRB, S. 523 und 559). Das von keiner der beiden Übersetzungen gelöste Problem der Notierung von Dialogwiedergabe (diskutiert schon von Urban 1993, a.a.O.) wird hier, wo eine Figur die Rede einer anderen zitiert, evident.

48 Die Arbeitsweise ist von S. Geier beschrieben in S. G.: Ein Leben zwischen den Sprachen, a.a.O., S. 139f., und filmisch festgehalten im Dokumentarfilm „Die Frau mit den 5 Elefanten. Swetlana Geier - Dostojewskijs Stimme“ von Vadim Jendreyko, 2010. 
mächtig. Die Übersetzung enthält Fehler, die sich mit dieser Arbeitsweise erklären lassen. ${ }^{49} \mathrm{Zu}$ monieren sind aber auch die eigene Form der Transkription, die bisweilen verschiedene Systeme mischt und dann für deutsche Leser undurchsichtig ist ${ }^{50}$, die Inkonsequenzen und Fehler bei der Eindeutschung von Ortsnamen ${ }^{51}$ und bei der Schreibung von Lehnwörtern ${ }^{52}$, die gelegentlich fehlerhafte Regelung von Groß- und Kleinschreibung ${ }^{53}$, lexikalische ${ }^{54}$ und syntaktische Fehler ${ }^{55}$, immer noch nicht beseitigte Druckfehler ${ }^{56}$ u.v.m.

Andere Eigenheiten der Geierschen Übersetzung stellen keine Fehler dar, sondern sind, allerdings nicht immer glücklich realisiert, Absicht. Die Übersetzerin erschafft ihr eigenes Deutsch, wo Dostojewskij die kirchenslavische Bibel zitiert: „und wer da lebet“ (S. 441), ,als Maria kam und sahe ihn...., „Als Jesus sie sahe

49 So sagt Porfiri: „(...) nehmen Sie es mir bitte nicht übel, daß ich so auf- und abgehe!“ (sic, S. 455). Auf einem Hörfehler während des Diktats dürfte auch der Schlusssatz des ersten Teils beruhen: „Fetzen, Bruchstücke, alle möglichen Gedanken schossen durch seinen Kopf“" (S. 119). Bei Dostojewskij schießen keine Fetzen oder Bruchstücke durch den Kopf der Figur, sondern Fetzen und Bruchstücke irgendwelcher (oder: aller möglichen) Gedanken. Übrigens kehrt der Ausdruck in Swidrigailows Theorie des Jenseitigen wieder (S. 390).

50 Z.B. „Eschenedelnaja“ (S. 348) gegen "Jekaterinen-Kanal“ (S. 148). Mit dem Apostroph in „Rod'ka“ (S. 600, 602) kann kein deutscher Leser etwas anfangen. Er bezeichnet in der wissenschaftlichen Transliteration die Weichheit des vorangehenden Konsonanten. In der (Duden-) Transkription kann es ihn nicht geben.

51 Geier gebraucht „Wassiljewskij-Insel“ (S. 56) neben, für Deutsche unverständlich, „WassiljewOstrow" (S. 152), richtig wäre "Wassili-Insel“. Die ,halbe’ Eindeutschung ist auch bei „Jekaterinen-Kanal“ (S. 148) falsch, da "-in-“ ja ein adjektivbildendes Suffix ist. Auch „Peterburgskaja“ (S. 217) kann der Leser nicht verstehen (gemeint ist die „Petersburger Seite“, ein Stadtteil). Extensiv ist die Übernahme russischer Bezeichnungen für Realia, bisweilen mit falschem Genus bzw. Numerus: Beguny (S. 615), Oklad (S. 77), der [!] Pirog (S. 75, 181), Sibirka (S. 16), der [!] Poddjowka (S. 17), ,in der [!] ,Moskowskie wedomosti“ (S. 221), inkonsequent steht „Chalat“ (S. 235) gegen „Schlafrock“ (S. 337). Einige der hier zitierten Beispiele entnehme ich der Magisterarbeit meiner ehemaligen Hörerin Elvina Prähofer, Würzburg 2011.

52 „Rendez-vous“ (S. 176) gegen „Rendezvous“ (S. 47).

53 Man begegnet einem „ermittelnden Staatsanwalt“ (S. 115), häufiger aber dem „Ermittelnden Staatsanwalt" (S. 451, 462, 610, 611).

54 „Aber ich kann doch Gottes Ratschlag nicht wissen“ (Sonja, S. 552, in SG1964 noch: „Gottes Ratschluß nicht kennen“, S. 345). Gott gibt keine Ratschläge. Da Raskolnikow „Wenn erst Gottes Ratschluß ins Spiel kommt" antwortet, reden Sonja und Raskolnikow bei S. Geier von verschiedenen Dingen. Bei Dostojewskij steht in beiden Repliken selbstverständlich ein und derselbe Ausdruck (božij promysl, S. 313). Ähnlich hat sich S. Geier im Wort vergriffen bei der Übersetzung von „tak prosto ot nevnimanija i naružnogo ravnodušija k svoej sud'be“ (S. 416) als „aus Unachtsamkeit und Gleichgültigkeit gegenüber seinem Schicksal“ (S. 733). Vgl. MRB: „aus Achtlosigkeit und äußerlicher Gleichgültigkeit gegenüber seinem Schicksal“ (S. 695).

55 „nicht nur schlechter, sondern vielleicht weit besser“ (S. 511) statt „nicht nur nicht schlechter“, vgl. SG1964: „nicht auch nur im mindesten etwas Schlechteres, sondern vielleicht etwas weit Besseres war“ (S. 319). Unglücklich klingt „auf dem Wege zur Besserung“ (S. 739, für „Uže vyzdoravlivaja“, S. 419).

56 „Profirij“ (S. 259). 
weinen ..." (S. 442). Ein pseudo-archaisches Phantasie-Deutsch zu konstruieren, gehört sicher zu den schlechteren möglichen Lösungen der Aufgabe, ein deutsches Äquivalent für das Kirchenslavische zu finden. Auch sei angemerkt, dass das (keineswegs ungeteilte, s.o.) Rezensenten-Lob für S. Geiers Wiedergabe von Figurensprache fast immer der Sprache von Figuren wie der deutschen Bordellbesitzerin Luisa Iwanowna oder des jüdischen Feuerwehrmanns (Dialog mit Swidrigailow) gilt. ${ }^{57}$ Geht es darum, Lösungen für defekte Figurenrede zu finden (beide genannten Figuren sprechen inkorrektes Russisch), ist S. Geier mutiger und phantasiereicher als andere. Das ist anzuerkennen, auch wenn Berlinerisch bei Dostojewskij zu lesen nicht nach jedermanns Geschmack ist. Defekte Kommunikate sind allerdings ein Spezialfall der Übersetzung. Die Qualität einer Übersetzung hängt nicht von der Lösung solcher eher peripherer Probleme ab.

Ganz im Widerspruch zur Eigenwerbung und zum Mythos, der sich um die Geiersche Übersetzung von 1993 gebildet hat, muss deren Neigung zu Gallizismen und zu Fremdwörtern sowie zum Amplifizieren, zur periphrastischen Ausdrucksweise, zum stilistischen Glätten und ,Aufhübschen' festgestellt werden. Einige Ausführungen und Beispiele, die sowohl die Figuren- als auch die Erzählersprache betreffen, mögen zur Illustration genügen.

Auffallig ist der übermäßige Gebrauch französischer Ausdrücke, den die Übersetzerin der Erzähler- und auch verschiedenen Figurenstimmen spendiert. Man trifft, wenn Dostojewskij einfache russische Worte verwendet, bei S. Geier auf „Malheur" (S. 606, Porfiri, für beda) oder auf „Bagatellen“ (S. 97, für meloči). Aus einem einfachen „in Klammern“ (russ. $v$ skobkach) wird „en parenthèse“ (S. 22, 277, Erzählerrede) ${ }^{58}$, Swidrigailow fällt ins Französische („keinerlei spécialité!“, S. 635) ausgerechnet in dem Moment, in dem er beklagt, keinem Beruf (russ. special'nost'), d.h. „keiner eigenen Tätigkeit“ (Röhl) nachzugehen. Pulcherija Alexandrowna berichtet, von Lushin ein „Billet“ erhalten zu haben.59 Ein solcher Gallizismus in ihrem ansonsten unprätentiösen Redetext ist problematisch. Lushin dagegen „Sie [...] in ihrem Logis aufzusuchen“ (S. 295, für russ. kvartira) sagen zu lassen, ist als Ersatzverfahren zur Redecharakterisierung eher zulässig.

Auch Lehnbildungen nach dem Französischen müssen nicht ins Französische transferiert werden, wenn Dostojewskij dies vermieden und eine russische Variante gewählt hatte. Den Ausdruck „nepodvižnaja mysl'“ (S. 159, ,unbewegter / unbeweglicher Gedanke') sollte man mit "fixe Idee“ übersetzen (die Fremdwörter sind unvermeidlich). S. Geier aber schreibt „eine idée fixe“ (S. 279). Dem Milieu wird eine russisch-französischsprachige Diglossie untergeschoben, die so nicht vorliegt, die Sprecher werden als sprachlich prätentiös hingestellt. Übrigens stellen

57 So etwa I. Rakusa (a.a.O.).

58 In SG1964 noch „fügte er erläuternd hinzu“ (S. 16), bzw. „Wir wollen in Klammern hinzufügen" (S. 172).

59 S. 294, zweimal. Der Erzähler spricht danach allerdings von einem „Brief“ (S. 295). Im Original verwendet er russ. zapiska wie vorher Pulcherija Alexandrowna auch (S. 167f.). 
Lehnbedeutungen nach dem Französischen ein Problem der Übersetzung dar, das nicht ungelöst ignoriert werden darf. Dass nach frz. object im Russischen seit der Puschkin-Zeit (belegt im Jewgeni Onegin) das Wort predmet für eine angebetete Schöne verwendet wird, ist einem deutschen Leser nicht ohne Weiteres bekannt. Swidrigailows Ausdrucksweise „Denn als ich meinen Gegenstand zu einer gemeinsamen Flucht nach Amerika oder in die Schweiz zu bewegen suchte [...]" (S. 380) muss daher irritieren. 1964 hatte S. Geier auf das hier gebotene Verfahren der Explizierung zurückgegriffen („Gegenstand meiner Verehrung“, S. 236). Der offenbar der Idee einer vollkommenen Wörtlichkeit verpflichtete Verzicht darauf richtet in der neuen Übersetzung nur Schaden an.

Auffällig ist auch die Neigung zum Fremdwort. Als Bestandteil der deutschen Sprache ist ein Fremdwort ein sinnvolles und oft das einzig mögliche Mittel der Übersetzung, auch wenn im Ausgangstext ein eigensprachliches, hier also russisches Wort steht. So ist nichts gegen „Delirium“ (S. 739, für russ. bred), gegen „Krisis seines Lebens“ (S. 505, perelom v žizni, bei MRB: „Umwälzung“, S. 698), wenig gegen „Ekstase“ für russ. vostrog (S. 568, eigentl. ,Begeisterung", entspricht oft aber eher ,Furor ${ }^{c}$ als ,Ekstase') zu sagen. Nicht zu empfehlen aber ist das Fremdwort, wenn durch seine Verwendung eine ungebräuchliche Verbindung entsteht, so in „blindes Fatum“ (S. 734, statt einfaches „blindes Schicksal“, russ. slepaja sud'ba). Wie hier die gängige redensartliche Verknüpfung verloren geht, geht mit einem anderen fremdwörtlichen Äquivalent die Alternanz bei Dostojewskij verloren: S. Geier verwendet „Lazarett“ sowohl für „Krankenhaus“ (S. 739, bol’nica) als auch für „Hospital“ (S. 741, gospital'nyj dvor, MRB: „Hospital“).

Nicht glücklich wirkt sich die Tendenz zum Fremdwort aus, wenn die Figurenrede dadurch stilistisch überhöht wird. So setzt S. Geier z.B. „Du brauchst dich nicht zu inkommodieren" (S. 283, Rasumichin) für einen einfachen russischen Ausdruck im Original. ${ }^{60}$ Richtig ist, dass Rasumichin häufig Gallizismen verwendet. Auch darf der Übersetzer gelegentlich kompensieren, d.h. ein Verfahren verwenden, obwohl es im Original an der betreffenden Stelle nicht vorliegt, weil er es vielleicht an anderer Stelle nicht anwenden kann. Hier aber wird wohl des Guten zuviel getan, und in Hinblick auf den Erzähler und andere Figuren ohnehin. Deshalb ist auch, als Eingriff in die Charakteristik der Figurenrede, die Lösung „ein bestimmtes ,Problem' (wie Herr Lushin sich auszudrücken pflegte)“ fragwürdig, wenn im Original russ. vopros ,Frage‘ steht. Der Fall gehört zu den auch von Rezensenten kritisierten Modernismen ${ }^{61}$ im Geierschen Text.

Zum selbst postulierten Anspruch, Wortwiederholungen zuzulassen und sie nicht ,mit dem Synonymwörterbuch' aufzulösen, müsste, sollte man annehmen,

60 „Ne trevožsja i ty osobenno“ (S. 161), in SG1964 noch: „Mach Du dir keine besonderen Umstände“ (S. 176).

61 Urban (Die Zeit, 3.12.1993) führt noch an: „realisierbar“ (für ,durchführbar’), „kombinieren“ (für ,scharf nachdenken’). In die Reihe gehört auch „Momente“ (S. 726, für ,Umstände’, obstojatel'stva, S. 412). 
ganz vorzüglich gehören, gleichlautende figurale Fremdcharakteristiken in der Identität eines einzigen Äquivalents zu belassen. Das im gesamten Roman häufig verwendete Adverb nizko bzw. die entsprechenden Adjektiv-Formen sind im Kapitel V,3 (bes. S. 534-542) Beleidigungswort zweier Figuren für Lushin. „du gemeiner Mensch“ sagt Katerina Iwanowna zu ihm (S. 534, nizkij čelovek), Lebesjatnikow, der im Original dasselbe russische Wort wie Katerina verwendet, greift in Geiers Übersetzung dagegen zum Fremdwort „infam “: „wie infam “, „Was für eine Infamie“ (S. 537), „Ach, wie infam“ (S. 538, dort dann, das einzige Mal "gemein“: „Sie gemeiner Mensch“). Auch im Satz „Warum hat er dieses infame Spiel riskiert?! Oh, dieser jämmerliche, gemeine Mensch!“ (S. 542) ersetzt „infam“ das redundante russische nizkij (nizkij postupok), der "gemeine Mensch“ ist allerdings an dieser Stelle Vertretung für russ. podlyj - eine unglückliche Variante, die zu schwach wirkt ${ }^{62}$ und die Systematik der Äquivalente, die durch das Fremdwort „infam“ bereits vom Original abwich, zusätzlich stört.

Eine unzulässsige Anreicherung der Figurenrede im Original ist der (im übrigen, wenn Fontane ins Bewusstsein kommt, anachronistische) Gebrauch des geflügelten Wortes „Ja, ja, das ist ein weites Feld ...“ (S. 396), wo man schlicht z.B. „Nun, das ist eine weitreichende Frage ...“ übersetzen sollte ${ }^{63}$. Falsche, in dieser Kriminalgeschichte unangebrachte und von Dostojewskij gewiss nicht intendierte gedankliche Verknüpfungen entstehen durch die Redensart „er träumt den Schlaf eines Gerechten", die S. Geiers Rasumichin in Bezug auf Raskolnikow verwendet ${ }^{64}$.

Was Stilfragen betrifft, sollte man nicht annehmen, die Geiersche Übersetzung biete stilistisch niedrigere, im Zweifel gar vulgäre Sprache, wenn dies angezeigt ist, und stehe darin Dostojewskij möglicherweise näher als ältere Versuche, die den erforderlichen Mut nicht aufbrachten. Eine solche Projektion auf die Geiersche Übersetzung scheint im Raume zu stehen, geht aber fehl. P. Urban (1993, a.a.O.) äußerte sich unzufrieden über „111 Jahre“ deutsche Dostojewskij-Rezeption. Der deutsche Leser sei „mit dem ,Stilgefühl“ seiner deutschen Übersetzer bedient worden, und dies berief - und beruft sich bis heute - meist auf seinen ,guten Geschmack', auf die Duden-Vorschriften und Regeln des ,gepflegten Ausdrucks“". Als Beispiel bringt der Kritiker eine monologische Aussage Raskolnikows während des ersten Verhörs, die stilgetreu übersetzt lauten sollte: „sie spucken mir ganz offen in die Fresse!“ Ältere Übersetzungen böten aber „Sie speien mir ganz offen ins Gesicht“, jüngere gingen bisweilen immerhin zum Verb „spucken“ über, beim

62 Vgl. MRB: „Wieso hat er eine solche Gemeinheit riskiert! Ach, was für ein erbärmlicher, niederträchtiger Mensch!“ (S. 514). Im Original: „dlja čego on risknul na takoj nizkij postupok! O žalkij, podlyj čelovek!“ (S. 308).

63 So die Bräuers (S. 375) für den Satz „Nu, èto vopros obširnyj“ (S. 224).

64 S. 278. „Er schläft den Schlaf der Gerechten“ auch schon SG1964, S. 173. Im Original steht die nicht wörtlich wiederzugebende Redensart „spit vo vsju ivanovskuju“ (S. 158), übersetzt z.B. mit „wie ein Murmeltier“ (schon Eliasberg, dann MRB, S. 264), „wie ein Bär, fest und ruhig“ (Röhl), „wunderbar, tief, ruhig“ (Rahsin). 
"Gesicht“ allerdings „bleiben alle“. Urban kommt an dieser Stelle seiner ausführlichen allgemeinen Einleitung noch nicht auf S. Geiers Verbrechen und Strafe zu sprechen und hat die Stelle dort nicht geprüft. Bei Geier lautet sie: „Sie speien mir ganz offen ins Gesicht" (S. 342).65

Solches sprachliches ,Verbessern' ist in der Geierschen Übersetzung keine seltene Ausnahme. Legion sind die Fälle hinzugefügter Epitheta und anderer nichtmotivierter Verstärkungen. Auf Schritt und Tritt ${ }^{66}$ stößt man auf Verfahren sprachverliebter elocutio, auf Ausschmückung, Erweiterung, Amplifikation. Man liest „Er hatte übrigens die reinste Wahrheit gesagt [...]“ (S. 277), wo im Original nur von „Wahrheit" die Rede ist ${ }^{67}$, wird dort etwas „mit Beweisen belegt" (MRB, S. 688), wird es bei Geier „mit Beweisen hinlänglich belegt“68. Aus „Armut“ (so auch MRB, S. 687) wird bei Geier eine „aussichtslose Armut“ (S. 725), gibt es keine Zweifel, so gibt es bei Geier „nicht die geringsten Zweifel“ (S. 747), ist Raskolnikows Gesundheit „zufriedenstellend“ (so MRB, S. 694, zdorov'e udovlitvoritel’no), so gibt bei Geier "seine Gesundheit [...] keinen Anlass zur Sorge“ (S. 732), aus "Raskolnikow konnte das nicht so sehen“ (MRB, S. 699, ne mog tak smotret') wird „Raskolnikow konnte diese Anschauung aber nicht teilen“ (S. 737), wird bei Dostojewskij berichtet, dass Raskolnikow "ganze Tage lang schweige" (MRB, S. 695), liest man bei Geier, „dass er tagelang kein Wort über die Lippen brächte“ (S. 733), aus ,achten, schätzen“ wird „einen weit höheren Wert beimessen“ (S. 737), die „dünne Kohlsuppe mit den Schaben darin“ (MRB, S. 696, pustye šči s tarakanami, S. 416) erscheint als „wässrige Kohlsuppe, in der statt Fleisch Küchenschaben schwammen“ (S. 734), aus Besuchen „sooft es ging“" (vozmožno) werden „Besuche im Gefängnis sooft es erlaubt war“ (S. 729).69

65 Dagegen die Bräuers: „Sie spucken mir ganz offen in die Fresse“ (S. 326). - Generell ist der Übersetzung Geiers die Wahl der stilistisch höher stehenden Variante nicht fremd, vgl. z.B. „»Nun, sprich doch, sprich doch «. [...] »Nun, warum, warum, warum sprichst du nicht? «" (S. 606) für „«Nu, govori že, govori že [...] čto že, čto že, čto že ty ne govoriš?» “ (S. 342). Dagegen MRB: „So rede doch, rede [...] warum sagst du denn nichts?“ (S. 573).

66 Viele der folgenden Beispiele stammen aus dem Epilog, wo sie auffällig häufig auftreten.

67 „On, vpročem, pravdu skazal“ (S. 158), in SG1964 noch: „Er hatte übrigens die Wahrheit gesagt“ (S. 172). Es geht tatsächlich nur darum, ob die Figur gelogen hatte oder nicht, eine Modulation des Begriffs Wahrheit (,reinste W.“) ist fehl am Platze.

68 S. 726. Im selben Absatz kommt dasselbe Adverb in Geiers Erzählertext ein zweites Mal vor: „Diese Aussage wurde [...] von mehreren Zeugen hinlänglich bestätigt“, und diesmal steht es für Wortmaterial im Original („dovol'no chorošo zasvidetelstvovali“). Durch die eigenmächtige Erweiterung im ersten Fall entsteht der Eindruck sprachlicher Monotonie, die im Original nicht vorliegt.

69 Trotz solcher sprachlicher Bemühungen bietet die Übersetzung SG1993 oft genug schlechtes Deutsch. Die Lösung „Was trieb ihn zum Mord, und was führte ihn zum Raub“ (S. 725) ist eine „Härte’, die nicht auf Dostojewskij zurückgeht („čto imenno moglo sklonit’ ego k smertoubijstvu i čto probudilo ego soveršit' grabež“, S. 411). Vgl. „was ihn letztendlich zum Mord verleitet und zu dem Raub veranlaßt habe“ (MRB, S. 687). 
Die Grenze zur eigenmächtigen Texterweiterung, und damit zum inhaltlichen Eingriff, ist bei den zitierten Beispielen hier und da bereits erreicht, in vielen anderen Fällen wird sie überschritten. Wenn Raskolnikow nichts weiter will als eine Filzdecke (MRB: „weiter wolle er nichts haben“, S. 695, drugogo ničego ne chočet sebe ustroit', S. 416), kann man daraus nicht konstruieren, er „habe sich geweigert, etwas anderes anzunehmen“ (S. 733); die Aussage „ließ ihn begraben“ (MRB, S. 688, pochornil ego, S. 412) darf nicht weiterentwickelt werden zu „übernahm [...] die Kosten für die Beerdigung" (S. 726). Auch wenn es in der fiktionalen Wirklichkeit so war, sollte man sich doch an das halten, was Dostojewskij schreibt. Der Leser sollte sich darauf verlassen können, dass Details, die psychologisch interessant und wichtig sein können, richtig übersetzt werden. Der Held bei Geier aber „begeht zwei Morde und vergißt dabei, die Tür zu schließen“ (S. 725), der Raskolnikow des Originals „vergißt, dass die Tür offensteht!“ (MRB, S. 687, „čto dver' stoit otpertaja“, S. 411). Bei Geier (S. 737) liest man über Raskolnikow „Er hatte gleichsam mit niedergeschlagenen Augen gelebt:" und könnte sich über die widersinnige Fortsetzung nach dem Doppelpunkt „Alles, was er sah, war ihm widerwärtig und unerträglich" wundern ${ }^{70}$. Bei Dostojewskij ${ }^{71}$ ist die Stelle keineswegs widersinnig, sie könnte übersetzt lauten: „Er lebte sozusagen mit niedergeschlagenen Augen: Es war ihm widerwärtig und unerträglich, um sich zu blicken" (MRB, S. 699).

Somit ist zu konstatieren: Die reklamierte und ihr oft zugeschriebene Bewahrung von (motivisch oder stilistisch wichtigen) Wortwiederholungen im Original ist in der Geierschen Übersetzung an durchaus entscheidenden Stellen nicht durchgeführt, die Ankündigung von sprachlicher „Härte“, „Widerborstigkeit“ und „archaischer Begrifflichkeit“ wird nicht eingelöst. Im Gegenteil variiert, amplifiziert und überhöht Frau Geier an vielen Stellen frei nach gusto und in einem Maße, wie es sich in neuer Zeit wohl kaum ein anderer Prosa-Übersetzer erlaubt. Das Dostojewskijsche Wort verschwindet oft infolge der Neigung der Übersetzerin, interpretierend den Sinn zu verschieben (ins Religiöse), das Konkrete ins Abstrakte zu überhöhen („Weg“ für „Ausweg“, „Verkommenheit“ für „Schmutz“), Gallizismen, Fremdwörter oder auch unpassende Redensarten (,ein weites Feld“, „Schlaf des Gerechten“) zu verwenden, zu glätten und stilistisch aufzuhübschen.

Wie die vorstehenden Ausführungen zeigen, hat sich in der Praxis des Übersetzens in Geiers Verbrechen und Strafe das eingangs dargestellte Konzept gesteigerter Wörtlichkeit, d.h. der Versuch der Wiedergabe des Russischen mit den Mitteln des Deutschen, gewiss nicht auf breiter Front durchgesetzt. In der mühsamen täglichen

70 Und übrigens auch über die unterschiedlichen Tempus-Formen.

71 „On žil, kak-to opustiv glaza: emu omerzitel'no i nevynosimo bylo smotret" (S. 418). 
Arbeit dominierte anscheinend ein spontanes, offenbar weitgehend auf Intuition vertrauendes, von keiner „Übersetzungstheorie“ geleitetes Übersetzen, das, wie gesehen, stellenweise eigenen inhaltlichen und stilistischen Vorstellungen nachgab. Und doch hat das Konzept der Wörtlichkeit Spuren in Geiers Text hinterlassen. Es begründete immerhin das Vorhaben, nach 1964 eine weitere, eine andere Übersetzung vorzulegen. Diesen Spuren soll nun nachgegangen werden.

Von Roman Jakobson stammt die Aussage, dass sich Sprachen weniger darin unterscheiden, was man in ihnen ausdrücken kann, als darin, was man in ihnen ausdrücken muss. Dies hat weitreichende Konsequenzen für das Übersetzen. Begibt man sich in ein linguistisches System, hat man sich dessen Zwängen zu stellen. Man kann mit grammatischen Kategorien (z.B. Genus, Aspekt, Tempus, Artikel) zu tun bekommen, die in der Sprache des Ausgangstextes nicht oder anders gegeben sind als in der Sprache des Zieltextes, und hat, wohl oder übel, Entscheidungen zu treffen. Man spricht von grammatischer Asymmetrie. Die Unterschiede im grammatischen Bau des Russischen und Deutschen sind groß. Sie zu ignorieren, geht nicht an. Neben der Grammatik halten auch die Lexika der beiden beteiligten Sprachen Asymmetrien in Bezug auf Bestand und Gebrauch bereit.

Über weite Strecken hält S. Geier die erforderliche Distanz zum Ausgangstext. Die ersten häufig geforderten Operationen bei der Sprachübersetzung (nicht nur der literarischen), der Wortartwechsel (Transposition) und der Perspektivenwechsel (Modulation), werden, wenn sie nötig sind, und also hundertfach, durchgeführt. In ihrer nach der von 1964 zweiten Übersetzung des Raskolnikow-Romans schlägt allerdings in einem nicht unerheblichen Maße das Programm durch, das oben aus den Projektbeschreibungen rekonstruiert wurde. Es gründet in der Vorstellung, man könne das Original in der Übersetzung gleichsam durchscheinen lassen, man könne es mittels großer (lexikalisch-semantischer und grammatischstruktureller) Nähe reproduzieren, um „mit dem Deutschen das Russische wiederzugeben“ durch ein „Festhalten an jedem Ausdruck und jeder Formulierung des Originals" (so die Worte Dr. Vivianis, die als Wiedergabe der Projektbeschreibung durch S. Geier gelesen werden können, s.o.). Es ist indes irrig zu glauben, der Sachverhalt der Asymmetrie der Sprachen könne (wenigstens momentweise) vernachlässigt oder suspendiert werden.

Dazu ein Beispiel aus dem Gebiet der Syntax. Haben wir es mit einer Exklamation zu tun, ist auch im Deutschen ein Prädikat entbehrlich. ${ }^{22}$ Anders

72 Der Verzicht auf Ausfüllung solcher Sätze wurde verschiedentlich gefordert, die Lösungen bei S. Geier gelobt, z.B. von Urban (vgl. Weiteres unten) und Rosemarie Tietze, die Geiers „Alles Unsinn“ (S. 16) dem „Das ist ja alles Unsinn“ der Bräuers (S. 14) vorzieht (a.a.O.). Allerdings wird derselbe russische Satz „Vse ėto vzdor“ (S. 10, und 289) von Geier anderenorts auch einmal mit Prädikat übersetzt („Das ist alles Unsinn“, S. 508). Man hat halt nach dem Kontext zu entscheiden, ob eine Exklamation oder ein (verbloser) Aussagesatz vorliegt. - Das Thema der Modalität, das durch die Modalpartikel „ja“ in der Version der Bräuers aufgeworfen wird, 
verhält es sich bei einem Aussagesatz. Das Kapitel III,3 beginnt in der neuen Übersetzung S. Geiers:

»Gesund! Gesund! « rief Sossimow den Eintretenden munter entgegen. Er war vor etwa zehn Minuten gekommen und saß wie gestern in seiner Sofaecke. (S. 299)

Rasumichin, Raskolnikows Mutter und Raskolnikows Schwester werden in der Wohnung Raskolnikows von Sossimow mit den zitierten Worten empfangen. Was will Sossimow mit ihnen ausdrücken? Wünscht er Gesundheit?73 Bezieht er sich auf Raskolnikow? Spricht die Geminatio für Euphorie? Oder für ein Insistieren? Die Aussage Sossimows im gebotenen Wortlaut ist für Deutsche unverständlich. Es dürfte kaum eine Situation geben, in der sie unter deutschen Muttersprachlern ein erfolgreich eingesetztes Kommunikat darstellen könnte. Vor Geier 1993 hat denn auch kein Übersetzer (von den herangezogenen) Sossimows Worte - im russischen Original »Zdorov, zdorov!« (S. 170) - nach der Wort-für-Wort-Methode wiedergegeben, auch Geier selbst (1964) nicht. Mögliche Übersetzungslösungen sind: „»Er ist gesund, er ist gesund!« empfing Sossimow die Eintretenden fröhlich“ (MRB, S. 284) oder „»Er ist gesund, er ist gesund « rief Zosimov den Eintretenden fröhlich entgegen" (SG1964, S. 187). Im Russischen ist ein verbloser Aussagesatz möglich, im Deutschen in diesem Falle nicht. Wo der Russe auf Subjekt und Prädikat verzichtet (bzw. beides ins Prädikatsnomen steckt), muss der deutsche Sprecher beides nennen.

Laufend kann so wie in der besprochenen Stelle natürlich nicht übersetzt werden. Der Fall ist ein extremer. Allein steht er aber nicht. Auch an anderen Stellen meint die Übersetzerin, gegen die Syntaxregeln des Deutschen auf das Verb verzichten zu können. Unter Umständen bleibt das Gemeinte erfassbar, mindestens aber ergeben sich Holprigkeiten. Das Replikenpaar „Pravda èto-s? - Net, daže nelepost'“ zum Beispiel gibt Geier 1993 wieder mit: „Ist das wahr?“ - „Keineswegs,

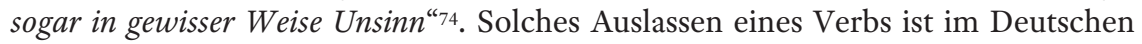
nicht recht möglich. Bezeichnend ist übrigens, dass S. Geier in der ersten Replik mit dem Wort „wahr“ die Wortwurzel des im Original verwendeten Wortes (pravda, Wahrheit') aufnimmt. In der Übersetzung von 1964 tat sie dies noch nicht, und auch bei den Bräuers beendet die Figur (Sonja) ihre Fragen - es geht darum,

ist hochkomplex und soll in diesem Beitrag nicht behandelt werden. Das Deutsche verfügt bekanntlich über äußerst viele Modalpartikel und weitere Möglichkeiten des Ausdrucks der Modalität. Auch dies ist ein Aspekt der Asymmetrie zwischen Russisch und Deutsch. Die anerkannt gute Lesbarkeit der Bräuerschen Übersetzung liegt auch daran, dass die Übersetzer diesem Umstand Rechnung tragen und u.a. durch ,hinzugefügte‘ (Modal-) Partikel in ,wirkliches' Deutsch, besonders bei gesprochenen Partien, übertragen.

73 So verstanden es einige befragte deutsche Test-Leser.

74 S. 505. 1964 schrieb Geier noch „Nicht im geringsten, es ist in mancher Hinsicht sogar absurd." (S. 316) 
dass Lushin eine bestimmte Aussage gemacht haben soll75 - mit den Worten:

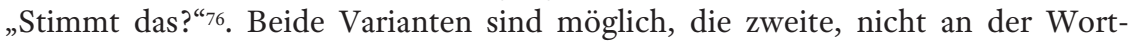
wurzel im Ausgangstext hängende Variante klingt indes natürlicher, denn es geht im Kontext des Dialogs nicht darum, ob eine Feststellung wahr ist, sondern ob sie richtig ist. Eine gebräuchliche phraseologische Wendung dafür lautet im Deutschen „stimmt das?“. Es sind eben nicht Worte und auch nicht Sätze zu übersetzen, sondern Kommunikate in konkreten Situationen. Die zielsprachliche Entsprechung in der kommunikativen Verwendung hat hier eine hohe Position in der Hierarchie der Invarianz forderungen. Das nicht nur semantisch, sondern auch pragmatisch bedingte Äquivalent in der Zielsprache greift auf anderes Wortmaterial zurück, als es in der Ausgangssprache vorliegt. Die durch die Grundbedeutung der Wortwurzel veranlasste Vertretung („wahr“ wg. russ. pravda) ist die schlechtere Lösung, denn sie ist prätentiöser, weniger umgangssprachlich und an der Opposition wahr - unwahr, nicht an der Opposition richtig - falsch ausgerichtet. Eine unwahre Aussage kann gelogen sein, eine falsche trifft schlicht nicht $\mathrm{zu}$.

Illustrieren wir den kritischen Umgang mit verblosen Sätzen im Russischen noch mit dieser verbalen Auseinandersetzung zwischen Lushin und Katerina Iwanowna. Zuerst spricht Lushin:

- Uderžite ètu sumasšedšuju! - zakričal on. [...] - Kak! Sumasšedšuju? Ėto ja-to sumasšedšaja? Durrak! [sic] - vzvizgnula Katerina Ivanovna. - Sam ty durak [...]. (S. 303)

»Halten Sie diese Wahnsinnige zurück!« rief er aus. [...] »Was? Wahnsinnige? Bin ich etwa diese Wahnsinnige? Dummkopf! « kreischte Katerina Iwanowna. »Du bist selbst wahnsinnig [...]«(S. 533f.)

Im Deutschen ${ }^{77}$ kann die Sprecherin, anders als im Russischen des Originals, nicht den Akkusativ aus Lushins Ausruf („diese Wahnsinnige“, ètu sumaš̌edšuju) ohne jegliche Einfügung in ein wie auch immer geartetes Syntagma aufnehmen („Wahnsinnige?"), was auch daran liegt, dass im Deutschen, anders als im Russischen, ein Artikel (bestimmt oder unbestimmt) gefordert wäre. Das bedeutet nicht, dass es nicht auch Lösungen ohne Prädikat geben kann. ${ }^{78}$

Mit der Diskussion der Varianten Ist das wahr vs. Stimmt das? war bereits das Gebiet der Lexik berührt. Wie der grammatische Bau ist auch der lexikalische

75 Vgl. in der Übersetzung von 1964: „«Sie sagte mir nämlich gestern, Sie hätten es übernommen, diese Pension für sie zu erwirken. Stimmt das?»" (S. 316)

$76 »$ Stimmt das?«»Durchaus nicht, in gewissem Sinne ist das sogar absurd. [...]« (MRB, S. 479). Im zweiten Satz verwenden die Bräuers natürlich ein Prädikat.

77 Mit den letzten vier Worten weicht S. Geier übrigens eigenmächtig (oder irrtümlich?) vom Original ab. Katerina sagt ein zweites Mal durak (dt. ,Dummkopf“ o.ä., MRB: „Idiot“, S. 506), "Du bist selbst wahnsinnig" sagt sie bei Dostojewskij nicht.

78 Vgl. MRB: „»Wie! Ich und verrückt? Ich soll verrückt sein? Idiot!«“(S. 506). 
Bestand von Sprachen asymmetrisch. Die Lexem-Relationen Eins-zu-Null oder Eins-zu-viele, solche Fälle also, bei denen in der Zielsprache kein Äquivalent oder aber mehr als eines gegeben ist, sind ein auffälliges Anzeichen der Asymmetrie, indes vergleichweise leicht zu erkennen und zu bewältigen. Tückischer wird es bei vermeintlichen Eins-zu-eins-Entsprechungen, da die Anwendungsfelder von Wörtern mit gleicher Grundbedeutung nicht immer deckungsgleich sind. Unter Umständen wird man auf ein in der Zielsprache im speziellen Kontext gebräuchlicheres Lexem zugreifen müssen. Das Übersetzen, das allein mit den Grundbedeutungen, d.h. den lexikografisch erstnotierten Bedeutungen arbeitet, kann fehlerhaft geraten. Auch dazu ein Beispiel aus Verbrechen und Strafe. Im Kapitel III, 3 sagt Raskolnikow zu seiner Schwester, als das Gespräch auf Swidrigailow kommt:

»Also ist er gar nicht so schrecklich, wenn er es sieben Jahre ausgehalten hat? Ich glaube fast, du möchtest ihn rechtfertigen, Dunetschka? « (S. 308)

Im Original heißt der zweite Satz: „Ty, Dunečka, kažetsja, ego opravdyvaeš ?“ (S. 175). Die Grundbedeutung von russ. opravdyvat' ist zwar, rechtfertigen', aber nicht in allen möglichen Kontexten wird das deutsche Äquivalent verwendet, so etwa nicht, wenn das Akkusativ-Objekt eine dritte Person ist. Man kann sich rechtfertigen oder eine Sache, eine Haltung, ein Verhalten, eine Tat u.dgl. Kann man aber jemanden, kann man einen Menschen rechtfertigen (außer sich selbst)? Das Verb hat keine personalen Akkusativ-Korrelate in der dritten Person. Es hat seinen Grund, dass alle (eingesehenen) Übersetzungen das deutsche Wort, das die Grundbedeutung von opravdyvat' stellt, meiden. Die Bräuers schreiben „in Schutz nehmen“ (S. 292), ferner liest man "Ich glaube, du verteidigst ihn, Dunjetschka“ (Eliasberg) und wieder „Du scheinst ihn in Schutz zu nehmen, Dunja?“ (Röhl). Geier selbst schrieb 1964 noch „Du scheinst ihn zu entschuldigen, Dunetschka“ (S. 192). Die Übernahme der Grundbedeutung des Verbs schafft in der Übersetzung von 1993 einen Defekt, den es im Original nicht gibt.

Ein etwas anders gelagerter Fall betrifft dasselbe Problem asymmetrischer Valenz des Verbs. Im Epilog heißt es im russischen Original über den inhaftierten Raskolnikow: „Vsmatrivajas' dal'še, on videl primery, ešče bolee neob”jasnimye“ (S. 418). Wo eine gute Übersetzung lauten könnte: „Je mehr er sich umschaute, desto unerklärlichere Beispiele sah er" (MRB, S. 699), liest man bei Geier "Je länger er beobachtete, desto häufiger entdeckte er [...]“ (S. 737). „Beobachten“ ist aber ein transitives Verb, das zwei obligatorische "Argumente" benötigt (Subjekt und Objekt). Das Akkusativ-Objekt kann nur dann fehlen, wenn „nur die Handlung des Beobachtens betont wird“79, etwa in einem Satz wie * "Er wollte beobachten, und selbst nicht gesehen werden“. Eine solche Sicht ausschließlich auf den Akt des Beobachtens selbst ist in unserem Beispiel durch die Angabe der Länge des

79 Institut für deutsche Sprache (Mannheim): Das elektronische Valenzwörterbuch deutscher Verben, Eintrag „beobachten“. 
Beobachtens („Je länger er ...“) aufgehoben, ein Gebrauch ohne Objekt daher nicht mehr möglich.

Es gibt weitere Gründe, warum eine wörtliche Übersetzung nicht empfehlenswert oder gar falsch sein kann. So können kulturell bedingte Unterschiede in der Pragmatik des Wortes wichtig werden. Bei Schimpfwörtern tritt dies sichtbar hervor. Der Rezensent Urban kritisierte an älteren deutschen Übersetzern die Neigung, Ein-Wort-Aussagen zu ergänzen (vgl. oben, Anm. 72). Sein Beispiel stammt aus der Welt der Beleidigungen: Wo Rasumichin zu Raskolnikow im Original einfach „Svinja“ sagt (Teil III, Kap. 4 und 5), habe man bisher mindestens ein „Du“ davorgesetzt „oder gar einen ganzen Satz“ dazugedichtet („Du bist ein Schwein“). Lassen wir den oben bereits angesprochenen syntaktischen Aspekt beiseite und schauen wir auf das Lexikalische. Schimpfwörter werden in unterschiedlichen Kulturen unterschiedlich verwendet. Gerade bei Schimpfwörtern aus der Tierwelt wird es diffizil. Das Wort „Schwein“ hat eine zoologische Grundbedeutung über die Sprachgrenzen hinaus. In der Regel ist das Hausschwein (sus scrofa domestica) gemeint. Als Schimpfwort wird „Schwein“ metaphorisch verwendet. Dabei aktivieren sich verschiedene Assoziationen. Im Deutschen steht, aber nicht in allen Kontexten, das Merkmal des Unreinen (Schmutzigen, Dreckigen) im Vordergrund, dahinter dürften Merkmale wie moralisch verwerflich / unanständig, dumm, gemein usw. rangieren. S. Geier verwendet die naheliegende Lösung „Schwein“, teilweise so ohne Satzerweiterungen, wie es der genannte Rezensent empfahl (S. 336, vgl. aber S. 334). Wenn die Bräuers (übrigens mehrfach ebenfalls mit einer Ein-Wort-Wiedergabe ohne Ergänzungen, S. 319, vgl. S. 317) in der gesamten Szene nicht „Schwein“, sondern stets „Schweinehund“ verwenden, haben Sie offenbar das Merkmal der Niedertracht im Original dominant gesehen. $\mathrm{Ob}$ es Gründe gibt, die zoologische Grundbedeutung beizubehalten (weil sie evtl. im künstlerischen Aufbau des Werkes eine Rolle spielt) oder ob besser ein pragmatisch äquivalenter Ausdruck in der Zielsprache zu wählen ist, hat der Übersetzer zu entscheiden. Mit der Wahl des Äquivalents der Grundbedeutung ist er jedenfalls nicht automatisch auf der sicheren Seite.

Kommen wir damit zu Problemen der Wortbildung. Ein folgenreicher Fall sprachlicher Asymmetrie ergibt sich durch die Möglichkeit des Deutschen, Komposita zu bilden. Im Russischen fehlt diese Möglichkeit, Substantive sind hier mit Hilfe von Adjektiven zu attribuieren. Adjektive tragen (in beiden Sprachen) qualifizierende oder relationale (seltener quantifizierende) Bedeutung. Sowohl bei der Ersetzung einer ausgangssprachlichen Adjektiv-Substantiv-Verbindung durch ein Kompositum als auch bei deren struktureller Beibehaltung kann es passieren, dass in der Zielsprache die jeweils andere grammatische Bedeutung gegeben ist. Die Asymmetrie birgt auch hier Fallen der Übersetzung.

Frau Geier bleibt oft bei der Struktur vorgefundener Adjektiv-SubstantivVerbindungen, während sie Komposita eher zu meiden scheint. Im folgenden Fall hat dieses Vermeidungsverhalten keine ernstere Auswirkung: Eine Übersetzung 
„Statt aller Versuche, auf seine Gemütsverfassung oder überhaupt auf sein inneres Leben einzugehen“ (S. 731f.) ist ebenso möglich wie „oder überhaupt sein Innenleben zu erklären“ (MRB, S. 693, für vsej vnutrennej ego žizni, S. 415). In beiden Varianten ist die relationale Bedeutung, wie im Original, gegeben. Schwierig wird es dagegen bei anderen Adjektiven. S. Geier übersetzt Raskolnikows Gedankenwiedergabe:

Stoit tol'ko posmotret' na delo soveršenno nezavisimym, širokim i izbavlennym ot obydennych vlijanij vzgljadom, i togda, konečno, moja mysl' okažaetsja vovse ne tak... strannoju. (S. 417)

Wenn man die Sache nur mit einem völlig unabhängigen, von den alltäglichen Einflüssen ungetrübten Blick ansieht, dann, dann erscheint meine Idee keineswegs so ... sonderbar! (S. 735)

Das Adjektiv obydennyj im russischen Original kann als Qualitäts- wie auch als Bezugsadjektiv aufgefasst werden. Wenn man innerhalb der gleichen Wortart bleiben möchte und es mit dem deutschen Adjektiv „alltäglich“ übersetzt, engt es sich auf die Bedeutung eines Qualitätsadjektivs ein (es fällt praktisch mit der Form "täglich“ zusammen), die relationale Bedeutung tritt zurück. Beim Kompositum („Alltags-“) steht dagegen die relationale Bedeutung im Vordergrund. Das Verfahren der ,Wörtlichkeit" - hier im Sinne der Nachbildung der grammatischen Struktur Adjektiv + Substantiv - schränkt die Option grammatischer Bedeutungen ein. Sind denn aber "alltägliche Einflüsse“ gemeint, d.h. täglich, Tag für Tag wirksame Einflüsse? Oder nicht vielmehr Einflüsse aus dem Alltag, durch den Alltag. Für Letzteres spricht, dass Raskolnikow im Original den „Blick“ mit drei komplementären, ähnlich gerichteten Attribuierungen charakterisiert: Ein Blick, vor dem für Raskolnikow seine Idee nicht mehr als "sonderbar“ erscheint, ist danach 1. ,unabhängig', 2. ,weit' (širokij, von Geier eigenartigerweise nicht wiedergegeben) sowie 3. ,befreit / frei von ...'Einflüssen, die offenbar aufgrund ihrer Enge (vs. ,weit', širokij) und Gewöhnlichkeit, nicht deren Frequenz schädlich wären. Der unabhängige, weite Blick ist einer, der auch von Einflüssen des Alltags (oder: Alltagseinflüssen) befreit ist. ${ }^{80}$ Auch dieser Fall zeigt, dass der Übersetzer um eine Interpretation des sprachlichen Sachverhalts im Original nicht herumkommt und keineswegs immer richtig liegt, wenn er das Original lexikalisch oder, wie hier, in der Kategorie der Wortart möglichst identisch reproduziert.

Kommen wir zu einer weiteren grammatischen Kategorie, die im Russischen und Deutschen unterschiedlich vertreten ist. Das Prinzip der äußerlichen Nachbildung der Sprache des Ausgangstextes greift in S. Geiers Übersetzung von 1993 auffällig oft, wenn im Original der Elativ vorliegt. Der Elativ existiert im Russischen

80 Vgl. MRB: „Man muß die Sache nur einmal ohne Vorurteile, großzügig und frei von Alltagseinflüssen betrachten, dann erweist sich meine Idee durchaus nicht als so ... sonderbar." (S. 697) 
wie im Deutschen. Durch verschiedene sprachliche Mittel, darunter Modalwörter, Präfixe, aber auch formal superlativische Adjektiv- oder Adverbformen wird ein allgemein hoher Grad eines Merkmals bezeichnet. Die Asymmetrie der beiden Sprachen liegt wiederum vor allem auf dem Feld der Pragmatik. Im Russischen wird der Elativ sehr viel häufiger gebraucht als im Deutschen. Für die Sprache unseres Dostojewskij-Romans trifft dies allemal zu.

Es ließen sich viele Stellen anführen, bei denen Superlativ-Formen im Original durch ebensolche in der Übersetzung wiedergegeben werden, obschon die russischen Formen besser als Elative aufzufassen sind. Die unbeirrte Wiedergabe eines russischen Superlativs durch einen deutschen ist in Verbrechen und Strafe mehr oder weniger die Regel. Oben wurde bereits Raskolnikows Beschreibung der Verhörtaktik der Justiz zitiert. Der Verhörte werde durch abseitige Fragen abgelenkt, um „ihn dann plötzlich, völlig überraschend, mit der verhängnisvollsten und allergefährlichsten Frage wie mit einem Schlag [...] zu treffen" (S. 451). Für die Adverbien „plötzlich, völlig überraschend“ steht im Original übrigens ebenfalls formal ein Superlativ. ${ }^{81}$ Auch Erzähler-Sprache (die freilich durch Interferenz mit Momenten der Figurenrede, infiziert' sein kann) ist betroffen. Man stößt auf „die allerentscheidendste und allerendgültigste Wirkung auf sein ganzes Schicksal“82. An anderer Stelle vermitteln die zuerst als „trocken und unbefriedigend“ empfundenen Briefe Sonjas Dunja und Rasumichin dann doch „die vollständigste und genaueste Vorstellung von dem Schicksal ihres unglücklichen Bruders“. Denn: „Sonjas Briefe waren erfüllt von der alltäglichsten Wirklichkeit, von unübertroffen schlichten und klaren Schilderungen [...]"83 (S. 731). In den beiden letzten Fällen gebraucht die Übersetzerin (vielleicht wegen der eingetretenen Häufung) keine Superlativ-Formen mehr, sondern eine Wendung, die als sog. Exzessiv aufzufassen ist („unübertroffen schlicht“) und damit in eine dem Elativ entgegengesetzte Richtung geht. Fasst man, wie die Bräuers, alle Formen als Elative auf, ergibt sich eine etwas andere Interpretation des Gemeinten. ${ }^{84}$

Die quantitativen Unterschiede im Ausdruck des Elativs im Russischen und Deutschen erlauben es, von einer Asymmetrie in einem pragmatischen Aspekt zu sprechen, die nicht unberücksichtigt bleiben darf. Etwas anders verhält es sich mit

81 „i potom vdrug, neožidannejšim obrazom ogorošit' ego v samoe temja kakim-nibud' samym rokovym i opasnym voprosom“ (S. 256). Die Bräuers deuten alle Formen als Elative: „und ihn dann plötzlich, aus heiterem Himmel mit einer äußerst verhängnisvollen und gefährlichen Frage“ (S. 427). Geier selbst hatte 1964 sogar ,nur“ den Positiv verwendet: „um ihn dann plötzlich unversehens mit einer verhängnisvollen und entscheidenden Frage“ (S. 282).

82 S. 84, für „samoe rešitel'noe i samoe okončatel'noe dejstvie“ (S. 51), vgl. MRB: „eine äußerst entscheidende und endgültige Wirkung auf sein ganzes Schicksal“ (S. 80).

83 „[...] samoe polnoe $i$ točnoe predstavlenie o sud'be ich nesčastnogo brata. Pis’ma Soni byli napolnjaemy samoju obydennoju dejstvitel'nost'ju, samym prostym i jasnym opisaniem“ (S. 415).

84 „Sonjas Briefe erschöpften sich in Details aus der ganz alltäglichen Wirklichkeit, in einer ganz schlichten und klaren Schilderung [...]“ (MRB, S. 693). 
einer Erscheinung wie der nominalen Ausdrucksweise. Die Verwendung derselben Wortart, die im Original verwendet wird, ist ein Spezialfall der Geierschen „nachbildende(n) Nähe zum Ausgangstext" (Kogut, S. 276) und vor allem in einer gewissen Tendenz zum nominalen Stil erkennbar. Es stellt sich die Frage, ob die Neigung zum Nominalen ein Stilmerkmal Dostojewskijs (oder seines Erzählers oder seiner Figuren) ist, oder ob das Russische generell diese Ausdrucksmöglichkeit mehr nutzt als das Deutsche - dann wäre eine Verschiebung der Proportionen der Wortarten und Ausdrucksverfahren legitim, wenn nicht gar geboten. Der Versuch, nominalen Stil nachzubilden, mag dennoch nicht von vorneherein unzulässig sein. An zwei zufällig ausgewählten, aber doch charakteristischen Beispielen soll im Folgenden aber gezeigt werden, dass der Verzicht auf Transposition (Wortartwechsel) einige Tücken birgt. Bleibt man, wie die Übersetzerin in einer Reihe von Fällen, bei der nominalen Ausdrucksweise des Ausgangstextes, kann man dies nicht für alle Satzteile durchhalten und bekommt sekundär doch mit asymmetrischen grammatischen Kategorien zu tun: mit dem im Deutschen in der Regel notwendigen Artikel (incl. der Wahl zwischen dem bestimmten und dem unbestimmten Artikel) und oft mit einer präpositionalen Rektion, wo im Russischen Objektbeziehungen auch synthetisch ausgedrückt werden können.

Gleich der vierte Absatz des Romans lautet:

Vpročem, na ètot raz strach vstreči s svoeju kreditorščej daže ego samogo porazil po vychode na ulicu. (S. 6)

Dieses Mal übrigens war er, als er auf die Straße hinaustrat, sogar selbst verblüfft über die Furcht vor einer Begegnung mit seiner Gläubigerin. (SG, S. 8)

Als er diesmal auf die Straße hinaustrat, wunderte er sich, daß er vor einer Begegnung mit seiner Gläubigerin Angst gehabt hatte. (MRB, S. 6)

Die Emotionen ,Furcht' und ,Verblüffung' (oder, Verwunderung') existieren nicht gleichzeitig: Das bei Dostojewskij Gemeinte erschließt sich im Zusammenhang mit der Darstellung zwei Absätze zuvor, wonach Raskolnikow jedesmal, wenn er die Treppe hinunterging, befürchtete, seiner Vermieterin zu begegnen. Dieses Mal war es anders. Der Satz bezieht sich also auf zwei Zeitebenen, ein Früher und ein Jetzt, markiert dies aber nur schwach - der Autor setzt auf das Textgedächtnis des Lesers. Während das Subjekt des Originalsatzes, die „Furcht vor einer Begegnung“ (strach vstreči), auch in der Übersetzung Geiers nominal wiedergegeben wird, hat die Übersetzerin das Hinaustreten auf die Straße zwar verbal ausgedrückt, dabei aber die temporale Präposition po ,nach' unterschlagen. Deshalb suggeriert der temporale Nebensatz mit der Konjunktion ,als' und einfachem Präteritum (,heraustrat') leicht eine Gleichzeitigkeit mit dem im Hauptsatz genannten Gefühl der ,Furcht'. Der Subjekt-Objekt-Wechsel („war verblüfft über ..., statt * „die Furcht verblüffte $i h n^{\prime \prime}$ wie im Original) ist, neben dem Austausch des Nomens durch ein Verb („trat hinaus“ statt * „nach dem Hinaustreten“), ein weiterer Beleg, 
dass eine ,wörtliche' Übersetzung unter Bewahrung grammatischer Strukturen schwerlich aufrechtzuhalten ist. Strukturell erhalten bleibt, ohne sichtbaren übersetzerischen Gewinn, im Grunde nur die Verbindung „Furcht vor einer Begegnung“. Diese gerade transponieren die Bräuers ins Verbale, wobei ihr Plusquamperfekt zum Signal der Vorzeitigkeit wird: ,Furcht“ (bei ihnen: „Angst“) stellte sich bisher jedesmal ein.

Abschließend sei eine Stelle vom Anfang des sechsten Teils betrachtet:

no kak rad by on byl osvobodit'sja i ubežat' ot inych zabot, zabvenie kotorych grozilo, vpročem, polnoju i neminuemoju gibel'ju v ego položenii. (S. 335)

aber wie froh wäre er erst gewesen, jene Sorgen abschütteln und ihnen entfliehen zu können, deren Verdrängung einen Menschen in seiner Lage mit dem endgültigen und unausweichlichen Untergang bedrohte. (SG, S. 593)

wie gern hätte er sich mancher Sorgen entzogen und sich von ihnen befreit, aber sie zu vergessen hätte in seiner Lage den vollständigen und unvermeidlichen Untergang bedeutet. (MRB, S. 561)

Lassen wir die Fragen beiseite, ob es „jene Sorgen“ oder „manche Sorgen“ heißen sollte, und ob das Wörtchen vpročem lediglich vergessen wurde (in beiden Übersetzungen). Während die Bräuers gleich in einen finiten Konjunktiv wechseln, bleibt S. Geier bei den Infinitiven des Originals, muss aber am Ende ein Hilfsverb („können“) ergänzen. Interessant ist dann die nominale Wiedergabe des Nominalen bei Dostojewskij. Der Versuch, die grammatische Struktur des Satzes zu reproduzieren, ist auch in diesem Falle nicht durchzuhalten. Er wird bezahlt mit einer nicht unerheblichen (im Grunde nicht zulässigen) semantischen Verschiebung von einem ,Vergessen“ (zabvenie) im Original zu einer „Verdrängung“ in der Übersetzung. Diese Verschiebung mag durch den Umstand erzwungen sein, dass im Deutschen kein echtes Substantiv zur Verfügung stand, sondern nur das substantivierte Verbum „das Vergessen“, das im gegebenen Satz schlecht zu verwenden war. Für das Vorhaben, die nominale Ausdrucksweise des Ausgangssatzes nachzubilden, stand also das entsprechend benötigte Wortmaterial in der Zielsprache nicht zur Verfügung. Hinzu kommt, dass in der Geierschen Übersetzung das Objekt „einen Menschen“ („... bedrohte") offenbar zwingend zu ergänzen war. In der Summe ist somit keine größere Textnähe erzielt. Im Gegenteil: Ein Hilfsverb („zu können“), ein hilfsweise ergänztes Objekt („einen Menschen“) und eine lexikalisch-semantische Verschiebung („Verdrängung“) sind nötig, um die Konstruktion des Satzes um den zentralen nominalen Ausdruck herum zu retten. 
„Swetlana Geiers Ruf verdankt sich der PR. Ihre Übersetzungen sind lebendig; korrekt und sinnvoll sind sie nicht immer" schrieb ein Leser der NZZ. ${ }^{85}$ Dass mit der (zweiten) Prestuplenie-i-nakazanie-Übersetzung S. Geiers ein Unternehmen das Licht der Welt erblicke, das einen bisher gleichsam unübersetzt gebliebenen Dostojewskij für deutsche Leser erstmals ,authentisch` zugänglich mache („S. Geier - Vermittlerin des originalgetreuen Dostojewski“ u.ä.) - diese Mitte der 1990er Jahre aufkommende Vorstellung ist selbst ein bemerkenswertes Faktum der deutschen Dostojewskij-Rezeption.

Ein neues durchdachtes, übersetzungstheoretisch bewusstes und konsequent realisiertes Konzept steht den landläufigen Annahmen über Spezifik und Qualität der neuen Übersetzung nicht gegenüber. Verbrechen und Strafe ist vielmehr ein doppelgesichtiges Übersetzungswerk. Einerseits sind Auswirkungen eines Plans spürbar, der vor dem Beginn der Arbeiten zumindest in Umrissen vorlag: der Plan, den Raskolnikow-Roman in erhöhter wörtlicher Textnähe zu übertragen, das Russische des Originals in Lexik und grammatischen Strukturen nachzubilden. Er ist, wie gezeigt, nicht zu Ende gedacht, wo er sich über die Asymmetrie sprachlicher (lexikalischer, grammatischer) Strukturen der beteiligten Sprachen hinwegsetzt. Im übrigen ist er während der Arbeit an der Übersetzung offenkundig (und zwangsläufig) in den Hintergrund getreten, so dass bisweilen nur noch der Eindruck bestimmter Vorlieben, etwa die für die Bewahrung nominaler Ausdrucksweisen, übrig bleibt, ein Eindruck also ähnlich dem einer Rezensentin eines anderen Romans der Serie, die schrieb, die Übersetzerin „hangelt sich ehrfürchtig am Russischen entlang" (s.o.). An der veröffentlichten deutschen Version zeigt sich einmal mehr, dass ,Textnähe' nur bedingt durchzuführen ist und das Streben danach (bzw. ein Sich-nicht-lösen-Können) meist doch nur schlechtes Deutsch hervorbringt.

Andererseits überrascht Geiers Verbrechen und Strafe an vielen Stellen mit dem genauen Gegenteil von Textnähe. Keine andere auf dem Markt verfügbare Übersetzung dürfte so oft so ungenau sein wie diese, keine andere erlaubt sich, ein Wort wie "gottergeben“ zu verwenden, wo bei Dostojewskij nichts dergleichen steht. Die Übersetzerin hat im Zweifelsfall keine Bedenken, den Text nach eigenen Vorstellungen anzureichern und auch stilistisch zu,verbessern`. Gleichzeitig mangelte es vielfach an übersetzerischer Konsequenz und Aufmerksamkeit für den Text. Dies spiegelt sich schon in aufschlussreichen Details wie den Inkonsequenzen bei der Transkription oder der Wiedergabe von Ortsnamen. Ein Nebeneinander von "Wassiljewskij-Insel“ und „Wassiljew-Ostrow" zeigt in nuce, wie wenig Bewusstsein

85 Hans Werner Müller aus Winterthur, NZZ 21.11.2010. Anlass war der Nachruf auf S. Geier, ebd. 14.11.2010. 
für translatorische Probleme mit am Werke war, und dass keine Konsequenz bei deren Lösung aufgebracht wurde.

Vielleicht wirkte das Bild, das Publikum, Literaturkritik und akademische Russistik von der Persönlichkeit Swetlana Geiers hatten, dabei mit, dass man dieser Übersetzerin den Zugang zu Dostojewskij und die Umsetzung einer adäquaten Übertragung ins Deutsche zutraute. Wie es scheint, dachte Geier selbst ähnlich von sich und sah sich in besonderer Weise für das Übersetzen der großen Autoren ihrer Muttersprache, des Russischen, prädestiniert. Kurz vor Abschluss der Dostojewskij-Übersetzungen sagte sie über Nikolai Gogol:

Er ist eigentlich unübersetzt und wartet, dass ich nach Dostoevskij ihn übersetze. (Kogut, S. 271)

Dem ist zu widersprechen. Gogol war zum Zeitpunkt der Aussage (2000) seit langem und auch immer wieder gut übersetzt worden, und manch sorgfältige Neuübersetzung ist in jüngerer Zeit noch hinzugekommen. 


\section{Christoph Garstka}

\section{Starker Staat oder Bürgergesellschaft? Dostoevskijs politische Visionen im Reiche Putins}

Dostoevskijs Bedeutung für das heutige Russland - dieses Thema begleitet die Tagungen der Deutschen Dostojewskij-Gesellschaft seit ihrer Gründung. Im ersten Jahrbuch bereits finden wir zwei Beiträge von Wolf Schmid und Karla Hielscher, beide unter dem Titel „Dostojewskij - Perspektive oder Gefahr?“, die der Frage nachgehen, welche Rolle vor allem Dostoevskijs politisches Denken in der postsowjetischen Gesellschaft spielen kann und soll, welche Ideen und Vorstellungen vielleicht als Modell für die ideologische Positionierung der jungen Russischen Föderation geeignet sein könnten?' Doch schon 1992 überwogen in beiden Beiträgen die Bedenken darüber, ob sich Dostoevskij als Lehrmeister eignen könne, das ideologische Vakuum nach dem Untergang des Kommunismus auszufüllen. Diese Skepsis blieb bestehen in allen weiteren Essays mit der Überschrift „Dostoevskij segodnja“ - Dostoevskij heute, seien sie im Jahrbuch oder an anderer Stelle publiziert worden. Stets lautete das Fazit, die künstlerische Größe des „Meisters aus Russland" stehe außer Frage, seine publizistische Prosa allerdings, so wie wir sie vor allem in seinem Tagebuch eines Schriftstellers (Dnevnik pisatelja) finden, tauge keinesfalls als Programm zu einer nationalen Identitätsbildung im gegenwärtigen Russland.

Bei aller gebotenen Skepsis muss man jedoch gleichwohl feststellen, dass die Popularität gerade der politischen Überzeugungen Dostoevskijs im heutigen Russland ungebrochen ist, und die Begründung dafür ist relativ leicht zu finden: Auch nachdem der Systemwechsel bereits über 20 Jahre zurückliegt und das gesellschaftliche und politische System der Russischen Föderation bereits verschiedene Phasen der Transformation durchlaufen hat, dauert das postulierte ideologische Vakuum immer noch an. Der Übergang von einer marktorientierten Reformphase in der El'cin-Zeit in den 90er Jahren zu einer autoritären Machtstruktur seit dem

1 Vgl. Wolf Schmidt: Dostojewskij - Perspektive oder Gefahr für die heutige politische und kulturelle Entwicklung in Russland. Einführung in die Tagung am 23. November 1991 in Hamburg. In: Ellen Lackner, Maria Schumann (Hg.): Jahrbuch der Dostojewskij-Gesellschaft 1992. Band 1. Flensburg 1992, S. 56-65; Karla Hielscher: Dostojewskij - Perspektive oder Gefahr? Der Streit um das Erbe des Schriftstellers in den aktuellen politisch-ideologischen Debatten Rußlands. In: Ebd., S. 80-89. 
Jahr 2000 hat an dieser Tatsache nichts geändert. ${ }^{2}$ Es fehlt auch dem Putin-Regime eine identitätsstiftende nationale Idee, die dem russischen Staatssystem eine tiefere Bestimmung zu geben vermag als allein die eines Ordnungshüters und Wohlstandsmehrers. Verschiedene programmatische Ansätze sind bereits diskutiert worden, so z.B. das Konzept einer "souveränen Demokratie“ durch Vladislav Surkov, das enge Zusammengehen von Kirche und Staat, die Umwertung der Sowjetgeschichte - besonders des Stalinismus - als heroischen Abwehrkampf oder seit Neuestem die Umwertung der russischen Volkskultur durch den neuen Kulturminister Vladislav Medinskij. Sie alle haben es aber nicht vermocht, dass die Frage Gogol's am Ende des ersten Teils der Toten Seelen (Mërtvye duši), „Russland, wohin fliegst Du?" beantwortet werden könnte. Von einem besonders skurrilen Versuch, dieses ideologische Vakuum auszufüllen, berichtet der britische Historiker Simon Sebaq Montefiore. Als er in Russland für sein Buch über Katharina und Potemkin recherchierte, ${ }^{3}$ sei ein Spitzenfunktionär der Putin-Regierung zu ihm gekommen und habe ihm berichtet, der Präsident sei auf der Suche nach historischen Vorbildern für den russischen Staat. Und er habe gefragt, ob nicht Fürst Potemkin, der als Staatsmann eine Verbindung von Autoritarismus und Humanität darstelle, ein geeignetes Modell für den russischen Präsidenten im 21. Jahrhundert sein könne. ${ }^{4}$ Doch der dekadente Lebensstil des Geliebten der Zarin Katharina II., mehr aber noch seine enorme Habgier, die Vetternwirtschaft und Korruption begünstigten, machten den Fürsten des 18. Jahrhunderts zu einem denkbar ungeeigneten Vorbild für einen Präsidenten des 21. Jahrhunderts.

Die Suche nach historischen Leitbildern ist noch nicht beendet. Und genau deshalb bleibt die Popularität Dostoevskijs ungebrochen, auch wenn er kein Staatsmann und Politiker war. Gerade in den beiden letzten Jahren, in denen es durch Putins Ankündigung und Übernahme einer dritten Amtszeit als Präsident zu einer umfangreichen gesellschaftlichen Diskussion darüber gekommen ist, welches staatliche System für Russland das geeignetste sein soll, kann man beobachten, dass neben dem dichterischen Werk auch die Biographie und besonders das politischpublizistische Schreiben Dostoevskijs in den verschiedenen Debatten präsent ist. Die Spannweite der Bezugnahmen auf den Autor des 19. Jahrhunderts ist dabei keineswegs einseitig auf ein enges klerikal und nationalchauvinistisches Umfeld beschränkt, sondern reicht, wie im Titel dieses Beitrags angedeutet, von den Anhängern einer autoritären, durch Orthodoxie und Volkstümlichkeit geprägten Überzeugung bis zu den Streitern für eine nach westlichen Maßstäben ausgebildete liberale Bürgergesellschaft. Zwei aktuelle Beispiele mögen das verdeutlichen: Der Prozess um die Moskauer Punk-Band Pussy Riots nach ihrer „Punkandacht“ in der

2 Vgl. dazu Lev Gudkov, Victor Zaslavsky: Russland. Kein Weg aus dem postkommunistischen Übergang? Aus dem Italienischen von Rita Seuß. Berlin 2011, S. 11-14.

3 Vgl. S. S. Montefiore: Potemkin: Catherine the Great's Imperial Partner. New York 2005.

4 Vgl. Ders.: "An Affair to Remember". In: The New York Review of Book, February 24, 2005, S. 33. Siehe auch Gudkov/Zaslavky (2011), S. 108. 
Christ-Erlöser-Kathedrale ist weltweit aufmerksam beobachtet worden. Angeklagt waren die drei jungen Frauen wegen „Hooliganismus aus Gründen des religiösen Hasses" (chuliganstvo po motivam religioznoj nenavisti). In ihrer Verteidigungsrede nennt das Gruppenmitglied Nadja Tolokonnikova drei Namen von historischen Persönlichkeiten, die wegen Gotteslästerung angeklagt und zum Tode verurteilt wurden: den biblischen Diakon Stephanus, den griechischen Philosophen Sokrates und den russischen Dichter Dostoevskij. ${ }^{5}$ In allen drei Fällen ging es um politische Prozesse, in denen die herrschende Macht die religiöse Anklage nur vorgeschoben hat, um mit unbequemen Denkern und Aktivisten abzurechnen. In einer Gesellschaft mit dem Erzmärtyrer und Christusbekenner Stephanus und mit dem Sophistenbekämpfer Sokrates hätte sich Dostoevskij nicht unwohl gefühlt -, ob er aber in einem Atemzug mit den sich hinter Strickmützen verbergenden Punkfrauen hätte genannt werden wollen, die in ihrem Punkgebet die Muttergottes aufgefordert haben, Feministin zu werden, sei dahingestellt.

Es beziehen sich jedoch ebenso autoritätshörige, die zentrale Macht unterstützende Künstler auf Dostoevskij und versuchen damit aktiv Wahlhilfe für Putin zu betreiben. So tauchten beispielsweise im September 2011 in den Straßen Petersburgs seltsame Graffiti an den Wänden auf. Es handelte sich um Zeichnungen des "Streetartkünstlers" Daniil Tichonov, die im Kleinformat auch als Postkarten verteilt wurden. Sie zeigten Putin und Dostoevskij im freundlichen Gespräch über Probleme der Gegenwart vereint. Einige Beispiele dieser befremdlichen Wahlwerbung, die im russischen Internet zu einem der umstrittensten Themen des letzten Jahres wurden, seien hier kurz vorgestellt ${ }^{6}$ : Zunächst Putin und Dostoevskij, die über den Roten Platz spazieren, und dabei natürlich über die „ewige Frage" diskutieren, wohin Russland steuern wird (Abb. 1: - Womit wollen wir uns beschäftigen, Vladimir Vladimirovič? - Womit wir uns immer beschäftigen, Fëdor Michajlovič!!!). Doch anscheinend haben sich die Zeiten seit dem Zarenreich geändert, denn in Putins Russland hätte der russische Schriftsteller weniger Grund gehabt, so missmutig in die Zukunft zu blicken (Abb. 2: - Und du, warum warst du so traurig?" - Die Zeiten, Volodja, es waren schwere Zeiten ...). Die Menge der Demonstranten und Protestierenden gegen das Putinsystem ist nur als entindividualisierte Silhouette im Hintergrund zu sehen und wird von den beiden Passanten als dumm und egoistisch belächelt (Abb. 3: - Was, denkst du, ist in den Köpfen der Unzufriedenen (nicht Zustimmenden)? - WO?!!). Die Zahl „31“ steht

5 So in ihrem Abschlussplädoyer am 8. August 2012 vor der Urteilsverkündung, siehe das Stenogramm der Sitzung auf http://www.novayagazeta.ru/news/58826.html - letzter Zugriff 01.03.2013.

Alle Übersetzungen aus dem Russischen in diesem Beitrag stammen, so weit nicht anders gekennzeichnet, vom Verfasser.

$6 \mathrm{Zu}$ finden sind die Zeichnungen auf der Internetseite der „Künstlergruppe des Wandels" (Gruppirovka Peremen, s.u.) http://groupper.livejournal.com/ - letzter Zugriff 01.03. 2013, und an zahlreichen anderen Orten im russischen Internet. 
für die Nummer des Artikels der Verfassung der russischen Föderation, der das Recht auf Demonstrations- und Versammlungsfreiheit festhält. Eine russische Bürgerrechtsbewegung (Strategija-31) versucht seit Juli 2009 an jedem 31. eines Monats in Moskau eine Demonstration zu organisieren, die die Beachtung dieses Artikels fordert. ${ }^{7}$ Und auch das Werk des Romanciers wird zum Gegenstand der Gespräche zwischen Putin und Dostoevskij. Die Dämonen (Besy) stellen dabei ein drohendes Menetekel für Chaos und Terror dar, das allein durch die Ordnungsmacht Putins verhindert werden kann (Abb. 4: - Bist Du Dir sicher, dass es nicht eintreten wird? - Ich strenge mich an ...). Der Künstler wollte Putin und Dostoevskij als das neue Machttandem Russlands installieren, und deshalb musste der alte Tandempartner, der damals noch amtierende Präsident Medvedev, abdanken. Dies wird in einer Szene aus dem Arbeitszimmer des Untersuchungsrichters aus Verbrechen und Strafe (Prestuplenie i nakazanie) verdeutlicht. Genau diese Worte, „aber Sie haben sie doch getötet“ (Vy i ubilis'), hatte Porfirij Petrovič dem Mörder Raskolnikov an den Kopf geworfen (Abb. 5: - Wer nur hat unsere Beziehung getötet? - Aber, mein lieber Herr, Sie haben sie doch getötet!!!). Eine nationalchauvinistische Note schließlich hat die folgende Zeichnung, in der Dostoevskij das historische Leid des jüdischen Volkes mit dem des russischen vergleicht. (Abb. 6: (auf dem Schild: Zchinwal) - Man kann nun wirklich nicht behaupten, dass das russische Volk weniger Unglück und Böses in seiner Geschichte erdulden musste als die Juden, wo auch immer es gewesen sei.) Zchinval ist die Hauptstadt der völkerrechtlich umstrittenen Republik Südossetien. Georgien besetzte die Stadt am 8. August 2008, woraufhin russische Verbände die Georgier zurückschlugen. Bei den Kämpfen wurden Teile der Stadt zerstört.

Der Zeichner dieser Karten gehört zu der Petersburger „Künstlergruppe des Wandels“ (Gruppirovka Peremen), deren Mitglieder sich selbst auch die „zornigen Künstler" nennen. Die Gruppe will nach eigener Aussage die eigenständige demokratische Entwicklung Russlands fördern und baut deshalb auf die einzige zentrale Macht, die Ordnung und Sicherheit für einen stabilen Aufbau garantieren könne, nämlich auf Vladimir Putin. Dass es sich hierbei nicht um ein postmodernes ironisches Spiel zur Dekonstruktion politischer Strukturen handelt, sondern um ein bewusstes Eintreten von Künstlern für die Macht, wird aus den weiteren Aktionen der besagten Gruppe ersichtlich. Am 4. November 2011, dem Tag der „Nationalen Einheit“, erschien eine weitere Zeichnung, die Putin und Dostoevskij vor einer Landkarte zeigt und als Werbebanner im Internet massenhaft verbreitet wurde (Abb. 7: 4. November - Tag der Nationalen Einheit! - Wir müssen uns vereinigen, Vladimir Vladimirovič! Daran arbeite ich, Fëdor Michajlovič!). Die

7 Im Wortlaut: „Die Bürger der Russländischen Föderation haben das Recht, sich friedlich und ohne Waffen zu versammeln, Versammlungen, Kundgebungen, Demonstrationen und Umzüge durchzuführen sowie Streikposten aufzustellen.“

(http://www.constitution.ru/de/part2.htm - letzter Zugriff 01.03.2013). 
Aussage ist simpel: allein Putin garantiert die staatliche Einheit der Russischen Föderation. Am 4. Dezember 2011 konnte die Petersburger Bevölkerung schließlich Zeuge eines Theater-, Pantomimen- und Mysterienspiels werden, das die Gruppe auf dem Isaaksplatz unter freiem Himmel aufführte. Es stand unter dem Titel „Anti-Dämonen“ (Antibes') und baute auf Motiven aus Dostoevskijs Revolutionsroman auf. ${ }^{8}$ In den Tagen zuvor hatten mit Dostoevskijmasken verkleidete Freiwillige die Ankündigungen verteilt. Sie standen während der Aufführung vor hunderten von Zuschauern auch mit diesen Masken in der Menge. Einer der Initiatoren betonte in einer Stellungnahme die Aktualität gerade dieses Romans Dostoevskijs: „Wir haben diese Aufführung nach Motiven von Dostoevskijs Roman Dämonen veranstaltet, um zu zeigen: es gibt immer Menschen, die bereit sind unsere Gesellschaft zu provozieren, die zu Gewalt, Chaos und Erschütterung aufrufen. Diese Aktion hier ist dagegen eine Warnung und Ermahnung." "9 Zum Abschluss der Veranstaltung wurden auf der Bühne von den Akteuren Blätter aus Sergej Nečaevs Revolutionärem Katechismus (Katechizis revoljucionera, 1869) zerrissen und die alte russische Zarenhymne gesungen.

Bei all diesen Aktionen ist es nicht verwunderlich, dass sich die Künstlergruppe mit anderen Putintreuen Organisationen zusammenschloss und aktiv den Wahlkampf des Bewerbers unterstützen wollte - auch dies wieder im Zeichen Dostoevskijs. Am 21. Dezember 2011 luden Vertreter der Gruppen „Junges Russland“ (Rossija Molodaja), der „Ansässigen/Lokalen“ (Mestnye), „Neue Menschen“ (Novye ljudi) und eben der "Gruppierung Wandel“ die Presse zu einer Ankündigung ein, ausgerechnet vor dem Dostoevskij-Denkmal an der Russischen Staatsbibliothek in Moskau. Verkündet wurde die Gründung eines „Stabes einheitlicher Tätigkeiten“ (Štab edinych dejstvij), der die vielfältige Unterstützung des Präsidentschaftsbewerbers durch Aktionen, Meetings und Demonstrationen landesweit koordinieren wollte. ${ }^{10}$ Zum Zeichen dieser Vereinigung wurden weiße Handschuhe und der abgespreizte Zeige- und Mittelfinger erkoren, das „V“ steht für „Vladimir Vladimirowitsch Putin“. Alle diese Gruppierungen verstehen sich als Sprecher der jungen russischen Generation, die für Putin plädiert, weil er allein Ordnung, Stärke und Größe Russlands garantieren könne. Dostoevskij ist von ihnen als geistige Leitfigur auserkoren, weil er ihrer Meinung nach genau diese Forderungen bereits im 19. Jahrhundert am vehementesten formuliert habe. Dass der Dichter dabei zu einer Ikone im Stil der Popart wird, wirft ein bezeichnendes Licht auf die spezifisch russische Rezeption der Postmoderne. Die „zornigen Künstler" verkaufen T-Shirts mit dem Bild Dostoevskijs entweder im Stile Andy Warhols oder mit folgendem Dostoevskij zugesprochenen Slogan versehen: „Die

8 Zahlreiche Fotos zu dieser Veranstaltung findet man unter

http://groupper.livejournal.com/10115.html - letzter Zugriff 01.03.2013.

9 Vgl. ebd.

10 Vgl. http://and-tatarinov.livejournal.com/27222.html - letzter Zugriff 01.03.2013. 
Freiheit liegt nicht darin, dass man sich nicht zügeln muss, sondern darin, dass man sich selbst beherrscht" (Svoboda ne v tom, čtob ne sderživat" sebja, a v tom, čtob vladet' soboj).

Gegen diese Art der Vereinnahmung kann sich der Dichter nicht mehr wehren, allein, eine solche Vereinnahmung Tolstojs, Turgenevs oder gar Čechovs ist in der Gegenwart undenkbar. Mit Dostoevskijs Roman Dämonen ist bereits ein Schlüsselwerk genannt, das sich durch seinen ideologischen Gehalt hervorragend zur Übertragung in die gegenwärtige Politik eignet. Doch während Alexander Krinicyn 1998 noch feststellte, dass Dostoevskij im damals gegenwärtigen Russland vor allem als Schriftsteller der "Krise“ geschätzt wurde, der in seinen literarischen Figuren, in seinen asozialen Helden, wichtige und gerade damals aktuelle Fragen beschrieb, wie z.B. die nach dem Reichtum und wie man an ihn gelangt, ${ }^{11}$ so geht es in Putins dritter Amtszeit als Präsident vor allem darum, was Dostoevskij zur russischen Idee, zur nationalen Eigenständigkeit, zur Frage nach dem Verhältnis zum Westen und zur Spezifik des russischen Wesens vorgebracht hat. Und hier rückt ein anderes Werk des Schriftstellers in den Vordergrund der Aufmerksamkeit, ein Werk, das man aus literaturwissenschaftlicher Sicht als „gattungsgeschichtliches Skandalon" bezeichnen könnte, das aber gleichwohl Dostoevskijs Ruf als herausragenden Denker und Intellektuellen seiner Zeit erst begründet hat: Das Tagebuch eines Schriftstellers. Für den Literaturwissenschaftler ist es, wie betont, ein nur schwer zu deutendes Werk. Man könnte provokant fordern, dass ein solcher ganz die Finger von diesem Werk lässt, vielleicht mit Ausnahme der eingestreuten fiktionalen Erzählungen und der Puschkinrede. Gleichwohl hat das Tagebuch mit der sich darin offenbarenden politischen Haltung seines Autors immer schon auch die Lesart der Romane Dostoevskijs bestimmt. Nur nebenbei sei bemerkt, dass der erste Herausgeber des Gesamtwerks des russischen Dichters in Deutschland, Arthur Moeller van den Bruck, seine eigenen Interpretationen Dostoevskijs, die er in Vorworten zur Ausgabe, eigenen Artikeln und Büchern kundgab, fast ausschließlich auf diese Publizistik stützt. Doch zum Tagebuch später mehr.

Vladimir Putin äußert sich nur sehr selten zu Fragen des geistigen Fundaments Russlands, der spezifischen russischen Idee und der ideologischen Ausrichtung. Die meisten seiner großen Reden gehen fast ausschließlich auf sozioökonomische Kriterien ein. Man muss deshalb genau beobachten, welche offiziellen Stimmen aus dem Umkreis des Kreml's zu ideologischen Problemen Stellung nehmen und in wie weit diese dann von der Zentrale - zumeist durch Schweigen - akzeptiert und verbreitet werden. Trotz dieser an die alte Sowjetastrologie erinnernden Schwierigkeiten lassen sich einige strategische Grundzüge aus den Äußerungen des Präsidenten und seiner „stillen“ Zustimmung zu anderen Positionen herausfiltern, die

11 Vgl. Alexander Krinicyn: Dostojewski in Russland heute. In: Heinz Setzer, Ludolf Müller, Ludolf, Rolf-Dieter Kluge (Hg.): Fjodor Michailowitsch Dostojewski. Dichter, Denker, Visionär. Tübingen 1998, S. 217-233, hier S. 221/222. 
sein Weltbild zumindest skizzieren können. Im Folgenden sollen nun einige Punkte dieses Bildes herausgestellt und die offensichtliche Ähnlichkeit mit Dostoevskijs Verlautbarungen in seinem Tagebuch belegt werden. Es gilt dann aber gleichwohl davor zu warnen, die Verbindungen zwischen „Putinismus“ und den politischen Ideen des Dichters zu eng zu ziehen. Ich möchte sogar behaupten: im Kern ihrer Überzeugungen haben der Präsident des 21. Jahrhunderts und der Schriftsteller des 19. Jahrhunderts nichts gemeinsam.

Die erste und bis heute gültige Aussage Putins zu den geistigen Grundlagen Russlands stammt aus dem Anfang seiner Regierungszeit und ist deutlich als „Programmartikel“ gekennzeichnet. Unter dem Oberpunkt „Staatlichkeit“ heißt es hier Ende 1999:

\begin{abstract}
„Russland wird nicht so bald, wenn es das überhaupt wird, eine zweite Ausgabe, sagen wir, der USA oder Englands sein, wo die liberalen Werte eine große historische Tradition und Bedeutung haben. Bei uns spielten der Staat, seine Institutionen und Strukturen immer schon eine außerordentlich wichtige Rolle im Leben des Landes und des Volkes. Ein starker Staat (krepkoe gosudarstvo) ist für einen Russländer keine Anomalie, nicht etwas, gegen das man kämpfen muss, sondern ganz im Gegenteil die Quelle und der Garant für Ordnung, der Initiator und die wichtigste treibende Kraft eines jeden Wandels. " ${ }^{\text {12 }}$
\end{abstract}

Schon Anfang des Jahrtausends offenbarte sich damit die antiliberale Haltung und die Vorstellung der Inkompatibilität des westlichen Demokratieverständnisses mit dem russischen. Die historische Verankerung der Vorstellung vom „starken Staat“ in Russland wird auch von wissenschaftlicher Seite mit Argumenten unterlegt, die an Dostoevskij erinnern. So vergleicht das Akademiemitglied Valerija Spiridonova 2011 in einem Artikel den "grausamen“ (žestkoe) amerikanischen mit dem „starken“ (sil'noe) russischen Staat. ${ }^{13}$ Zwar solle sich dem amerikanischen Verständnis nach der Staat so weit wie möglich aus den öffentlichen Belangen zurückziehen und die Administration auf ein Minimum reduzieren. Aber die Tatsache, dass Amerika dieses Modell als heilbringend für die ganze Welt ansehe und es zum Teil mit Militärgewalt fremden Nationen und Kulturen aufzwingen wolle, mache es eben zu einer grausamen Staatsform. Das russische Staatsverständnis dagegen sei anders: „[...] im russischen Bewusstsein stellt der Staat nicht allein und ausschließlich den Staatsapparat dar. In einer bestimmten Beziehung [...] stellt der Staat im synkretistischen Sinne die Gesellschaft dar, er ist das Subjekt des ,kollektiven Unbewussten‘. Er ist das konzentrierte Bild der nationalen Identität.

12 Vgl. Vladimir Putin: Rossija na rubeže tysjačeletij: Programmnaja stat'ja predsedatelja pravitel'stva Rossii, 30.12.1999 (Russland an der Jahrtausendwende: Programmartikel des russischen Regierungsvorsitzenden), http://www.ng.ru/politics/1999-12-30/4_millenium.html letzter Zugriff 01.03.2013.

13 Vgl. Valerija Spiridonova: Dve versii ,sil'nogo gosudarstva (Zwei Versionen eines ,starken Staates'), http://politvektor.ru/glavnaya-tema/5687/ - letzter Zugriff 01.03.2013. 
Demnach vereinigt er potentiell in sich die moralische Autorität der Gesellschaft. "14 Damit ist der Staat aber auch, und das wird weiter ausgeführt, die Verkörperung der eigentlichen Idee des Volkes. Leicht erkennt man hinter diesen Aussagen die Vorstellung der "Sobornost“", einer mystischen Gemeinschaft im Gegensatz zu einer vertraglich fundierten Gesellschaftsordnung. Das Streben und die geistige Bestimmung eines Volkes und einer Nation finden im Staatswesen ihren unmittelbaren Ausdruck. Umgekehrt könnte man sagen, wer sich gegen die Staatsmacht stellt, stellt sich gegen den Volkswillen. Und mehr noch: er schließt sich bewusst aus der Gemeinschaft aus. So wie im strengen Sinne ein Christ nicht ohne Kirche sein kann, kann demnach auch ein Russe nicht ohne den russländischen Staat sein.

Warum ist aber nun der Staat nicht als "grausam“ zu bezeichnen? Ohne den Namen Dostoevskijs zu erwähnen, begründet Spiridonowa dies mit der Fähigkeit der Russen zur friedlichen Symbiose mit fremden Völkern, letztlich also mit der Fähigkeit zum „Allmenschentum“. Russland musste zwar als kolonialer Staat vor allem im Osten Asiens notwendigerweise stark sein, aber eben nicht brutal und grausam. Es heißt: „Im Zuge der Ausdehnung des Staates nach Osten haben die Russen die ansässige Bevölkerung nie mechanisch und aggressiv verdrängt und unterdrückt, sondern haben ganz im Gegenteil ihre eigenen Sitten und Gewohnheiten ganz leicht verändert, sich in die neue Umgebung hineinversetzt (vživalis') und dabei gleichzeitig die dortigen Bewohner an ihre eigene Kultur herangeführt. Diese ,Missionierung hatte einen symbiotischen Charakter. ${ }^{\text {"15 }}$ Dass diese Fähigkeit zur „friedlichen Symbiose“ zum Beispiel im Kaukasus an ihre Grenzen gestoßen ist, liegt sicherlich am schlechten Charakter der dort ansässigen Bevölkerung.

Aber Putin selbst geht noch weiter und nutzt die Idee Dostoevskijs von der russischen Fähigkeit zum Allverständnis in einer kühnen Umdeutung zur Begründung seiner Vorstellung eines „russländischen“ Staatsvolks, indem er sich explizit auf den Schriftsteller bezieht. Im Januar 2012 publizierte der (damals noch) Präsidentschaftsbewerber einen programmatischen Artikel zur nationalen Frage in der Russischen Föderation. ${ }^{16}$ Putin erläutert hier konzentriert sein zuvor schon entwickeltes Konzept vom russischen Staat als einer multinationalen Gesellschaft, die gleichwohl ein einziges Staatsvolk darstelle. Im Laufe seiner tausendjährigen Geschichte habe der russische Staat niemals eine nur auf eine einzelne Ethnie bezogene Gemeinschaft präsentiert, sondern vielmehr die ideale Vereinigung unterschiedlichster Stämme und Nationen. So sei Russland eine weltweit einzigartige Zivilisation: „Wir sind eine multinationale Gesellschaft, aber wir sind ein Volk“. Der Kern aber, das „verbindende Gewebe“ dieser einzigartigen Zivilisation, wie es heißt, sei das russische Volk, die russische Kultur. Denn dieses russische

14 Ebd.

15 Ebd.

16 Vgl. Vladimir Putin: Rossija: nacional'nyj vopros (Russland: die nationale Frage), http://www.ng.ru/politics/2012-01-23/1_national.html - letzter Zugriff 01.03.2013. 
Volk, diese russische Kultur sei durch eine einzigartige Fähigkeit ausgezeichnet, die Dostoevskij bereits erkannt habe: die Fähigkeit zu umfassender Einfühlung, zu tiefstem Mitgefühl, zur Allversöhnung, kurz, zum Allmenschentum. Putin weist auf die interessante Tatsache hin, dass Russen, wo auch immer sie in der Emigration waren, niemals eine widerstandsfeste nationale Diaspora gebildet hätten (man könnte böswillig ergänzen, „wie die Polen“). Und er begründet dies wie folgt:

„Weil wir in unserer Identität einen anderen kulturellen Code besitzen. Die Russen sind ein staatsbildendes Volk allein bezogen auf die Existenz Russlands. Die große Mission der Russen liegt in der Vereinigung, im Verbinden der Zivilisationen. Über Sprachen und Kulturen hinweg sind die russischen Armenier, die russischen Aserbajdschaner, die russischen Deutschen, die russischen Tataren durch diese ,weltweite Offenheit und Versöhnungsbereitschaft' [vsemirnaja otzyvčivost', ein direktes Zitat aus Dostoevskijs Puschkinrede], nach der Festlegung Fëdor Dostoevskijs untereinander verbunden. Verbunden in einem Typ von staatlicher Zivilisation, die keine Nationalisten mehr kennt, sondern in der die Anerkennung von Eigenem und Fremden einen allgemeinverbindlichen kulturellen Wert darstellt. Eine solche zivilisatorische Identität ist auf dem Bewahren der russischen kulturellen Dominante gegründet, und ihre Träger sind nicht allein ethnische Russen, sondern unabhängig von der Nationalität alle Träger dieser Identität. ${ }^{\text {"17 }}$

Nach dem Willen Putins also haben sich Dostoevskijs panslavistische, paneuropäische Visionen und Utopien auf dem Territorium der Russischen Föderation, weiter noch auf dem Gebiet der ehemaligen Sowjetunion, bereits verwirklicht.

Der Kern der Kultur bleibt russisch, aber weil russisch gleich allmenschlich ist, ist jede andere ethnische Identität freudig bereit, sich ihr anzuschließen. Der russische kulturelle Kern aber lässt sich nicht säkularisieren, er ist untrennbar mit der Orthodoxie verbunden. Und deshalb ist auch Putins Staatsverständnis durch die slavophile Vorstellung der „Sobornost““ gekennzeichnet. „Sobornost““ ist im orthodoxen Verständnis eine ideale Gemeinschaft in Christo. Man sollte zwar keinesfalls denken, dass Putin den Staat in eine Kirche verwandeln will wie der Starez Sosima aus den Brüdern Karamasow (Brat'ja Karamazovy). Auffällig ist jedoch der betonte Schulterschluss mit der Russisch-Orthodoxen Kirche, deren Werte der Präsident mehrfach als Grundlage der russischen Kultur bezeichnet hat. So wird ab dem am 1. September 2012 beginnenden Schuljahr das Fach „Grundlagen der orthodoxen Kultur" nach mehreren Probeläufen landesweit in allen Schulen der Russischen Föderation gelehrt, denn, so die Logik der Putinschen Programmatik, diese Grundlagen bilden den Kern auch aller anderen nichtrussischen Kulturen auf dem Gebiet des russischen Staates. Und der Präsident lässt keinen Zweifel daran aufkommen, dass die Wiedergeburt des orthodoxen Glaubens untrennbar mit dem Wiedererstarken des russischen Staates verknüpft ist. Im Jahr 2005 besuchte Putin beispielsweise die Mönchsrepublik auf dem Berg Athos.

17 Vgl. ebd. 
Dort begrüßte ihn der Abt eines Klosters mit den Worten: „Die Stärke des russischen Volkes liegt vor allem in seiner Liebe zu Gott, von der der russische Autor Dostoevskij so erbaulich geschrieben hat." Man überreichte dem Präsidenten eine Ikone der Gottesmutter mit der Inschrift, „Allerheiligste Gottesmutter, bitte für Deinen Diener Vladimir.“ Putin antwortete darauf: „Sie haben recht, die Stärke Russlands liegt in seiner Spiritualität." Und er fügte hinzu, dass die Wiedergeburt des Glaubens die Grundlage sei für die gegenwärtige Wiedergeburt der Größe Russlands. ${ }^{18}$

Wenn nun schon zwei Säulen des - nach slavophilem Verständnis - idealen russischen Staatsaufbaus im heutigen Russland wiederentdeckt werden konnten, Autokratie und Orthodoxie, dann fehlt noch der Nachweis der dritten Säule, der „Volkstümlichkeit“. Dafür sei an dieser Stelle zunächst ein kurzer Rückblick auf Dostoevskijs Tagebuch gestattet. Man kann in ihm nämlich einen polemischen Stil entdecken, der Dostoevskijs „Volksnähe“ belegen soll, der aber in Wahrheit eine argumentative Strategie darstellt, mit der Andersdenkende gnadenlos diffamiert werden. Eine solche Strategie ist dann auch bei Putin zu finden. Das Tagebuch eines Schriftstellers ist in seinen nichtfiktionalen Teilen weitgehend dialogisch aufgebaut, d.h. Dostoevskij erweckt den Anschein, als würde er mit seinen Lesern eine Unterhaltung führen, ihre Gegenargumente aufnehmen und sie wie in einer mündlichen Diskussion widerlegen. Doch bleibt dieser Leser oder essayistische Gesprächspartner über weite Strecken anonym, er ist ein Konstrukt, hinter dem sich das Ideal eines gebildeten russischen Zeitschriftenlesers der 70er Jahre des 19. Jahrhunderts verbirgt. In die Augustnummer des Jahres 1880 nimmt Dostoevskij allerdings einige Artikel auf, in denen er einen seiner Kritiker direkt anspricht und dessen Vorwürfe widerlegen will. Diese Auseinandersetzung ist als „DostoevskijGradovskij-Polemik“ bekannt. Der Rechtshistoriker und Professor an der Petersburger Universität, Aleksandr D. Gradovskij, hatte in der Zeitschrift Golos (Die Stimme) eine Kritik der Puschkinrede Dostoevskijs veröffentlicht, in der er dem Dichter letztlich vorwirft, er denke allein an die moralische Vervollkommnung des Individuums, habe aber von der politischen Gestaltung eines Staatswesens überhaupt keine Ahnung. Die wütende Antwort des Dichters stellt eine Essenz seines gesamten politischen Denkens dar, wie er es in den Jahren zuvor im Tagebuch entwickelt hat. Darüber hinaus zeigt sie ebenso, anders als die Puschkinrede, in konzentrierter Anschaulichkeit Dostoevskijs Talent zur polemischen Rhetorik, zeigt ihn als Meister einer hinterhältigen und subversiven Argumentationsstruktur, vor der ein seriöser und sachlicher Gesprächspartner die Waffen strecken muss. Hier nur ein kurzes Beispiel, das uns in Deutschland nicht fremd sein dürfte: Für Dostoevskij ist Gradovskij ein europäisierter Liberaler. Zum wiederholten Male erzählt er die Geschichte von jenem Feldjäger, den er in seiner

18 Siehe „President Vladimir Putin Visits Holy Mount Athos”. In: Europaica Bulletin 75 (5. Oktober 2005); http:/ / orthodoxeurope.org/page/14/75.aspx - letzter Zugriff 01.03.2013. 
Jugend auf einer Poststation gesehen hatte und der den Kutscher schlug, der wiederum das Pferd besinnungslos peitschte. Den Feldjäger nennt er einen „europäisierten Russen“, dessen Europäertum nicht mit der Aufklärung, sondern mit den Ausschweifungen begonnen habe, nur um dann zu erklären: „Der Sohn eines solchen Feldjägers wird vielleicht ein Professor, also bereits ein patentierter Europäer geworden sein. “19 Ab sofort bekommt der Begriff „Professor“ und „Gelehrter" in den folgenden Ausführungen einen üblen Beigeschmack, der an den erinnert, den der damalige Bundeskanzler Gerhard Schröder dem „Professor aus Heidelberg" mitgegeben hatte.

Dostoevskij wirft Gradovskij vor, er trenne das staatlich-gesellschaftliche Leben vom individuell-religiösen. Für ihn wäre der Bürger eines Staates demnach in zwei Hälften aufgeteilt, privates Christentum und offizielles Bürgertum. Das aber sei unmöglich. Gradovskijs Thesen werden vom Dichter zitiert. Der „Professor“ sage, persönliche und soziale Sittlichkeit seien nicht ein und dasselbe, der einzelne Mensch mag sich vervollkommnen, dadurch entstehe aber noch kein besserer Staat. Vereinfacht glaube er also: auch schlechte Christen können einen guten Staat bilden, auch gute Christen können einen schlechten Staat bilden. Dazu sagt Dostoevskij deutlich „Nein“, das sei ganz unmöglich. Und er führt das Beispiel der geizigen alten Gutsbesitzerin Korobočka aus Gogol's Toten Seelen an. Wenn sie eine wahre Christin geworden wäre, hätte sie die Leibeigenschaft aufgehoben und, so Dostoevskijs Pointe, die Bauern wären trotzdem bei ihr als Diener geblieben. Dostoevskij sieht hier auf der Mikroebene ein Idealbild, zu dem der ganze Staat auf der Makroebene werden soll. Er kann erst zu einer Kirche werden, wenn auch die kleinsten gesellschaftlichen Einheiten sich im Sinne Christi vervollkommnet haben. Regiert auf allen Ebenen die brüderliche Liebe und das Allverzeihen, dann werden hierarchische Strukturen zwar nicht aufgehoben, Herr und Knecht gibt es weiterhin, ihre Beziehung aber ist durch das Vorbild Christi durch Freiwilligkeit und den Aspekt des gegenseitigen Dienens gekennzeichnet.

Der Staat ist in dieser Konzeption keine Organisation freier Individuen, die sich etwa durch einen Vertrag zusammenschließen. Am Anfang einer Entwicklung eines Volks zu einem Staatswesen, meint Dostoevskij, stehe immer zunächst eine sittliche Idee, die dann zum Gesetz geworden sei. Das heißt: die mystische Idee steht über dem Individuum, das sittliche Gesetz geht voll im Staat auf, womit aber dem Individuum in einem solchen Staat genauso jede Möglichkeit zur persönlichen Einmischung genommen ist. Es würde dann ja gegen das sittliche Gesetz der Nation verstoßen. Damit ist aber auch jeder Argumentation über öffentliche Angelegenheiten der Grund entzogen. Es fehlt in ihnen nämlich der rechte „innere“ Zusammenhang der Kritiker zum Gemeinwesen. Das Punkgebet der Pussy Riots

19 Die Polemik findet sich als drittes Kapitel unmittelbar nach dem Abdruck der Puschkinrede in der Augustausgabe des Tagebuchs von 1880, der einzigen Nummer, die in diesem Jahr herauskam. 
war demnach nicht nur eine Tat der Erregung öffentlichen Ärgernisses, sondern ein sichtbares Zeichen dafür, dass sie diesem mystischen Staatsverbund nicht angehören. ${ }^{20}$

Es sind vor allem zwei Punkte, die diese Konzeption Dostoevskijs für die gegenwärtige russische Staatsvorstellung so attraktiv machen: die „russländische Zivilisation" ist demnach keine heterogene Gesellschaft, sondern eine durch das Netz der russischen Kultur zusammengehaltene mystische Gemeinschaft, aufbauend auf der genuin russischen Idee. Hierin liegt auch der Kern der Konzeption einer „souveränen Demokratie“, wie sie der "Chefstratege Putins" (so die Bezeichnung des Spiegels, 20.06.2005), Vladimir Surkov, in den letzten Jahren in mehreren Artikeln und Reden entwickelt hat. ${ }^{21}$ Ohne hier ausführlicher darauf eingehen zu können, sei nur festgehalten, dass Surkovs Modell ganz bewusst in Abgrenzung zum westlichen Demokratieverständnis entwickelt wurde. Er geht davon aus, dass in den liberalen Demokratien die spezifischen Eigenarten der einzelnen Nationen redundant geworden seien. Demokratie sei im Westen nicht mehr an die Nation gebunden, sondern ein allgemein austauschbares Modell, das die nationalen Eigenarten unberücksichtigt lässt. Dagegen müsse man die souveräne Demokratie als Verbindung von „Heimat und Freiheit“ sehen, einer natürlichen „Freiheit“, die aus dem Selbstverständnis „Brüder“ zu sein, entstamme. Es ist die Freiheit, die Korobočkas entlassene Leibeigene gleichwohl auf dem Gut der Alten hält, weil sie eine gute Christin geworden ist. Eng mit diesem ersten Punkt verbunden ist die in Dostoevskijs Tagebuch durchgängig aufzufindende strenge Dichotomisierung, die strikte Unterteilung in „Wir“ und „Ihr“ als argumentative Taktik. Das „Wir“ ist das Volk bzw. die Gebildeten, die den wahren Willen des Volkes, das immer nur eine rätselhafte und geheimnisvolle Größe bleibt, kennen. Das „Ihr“ sind die durch europäische Bildung und Zweifel vom russischen Volk Entfremdeten. Blickt man in dieser Fokussierung allein auf Dostoevskijs Polemik mit Gradovskij, dann wird man feststellen müssen, dass Dostoevskij in geradezu impertinenter Weise behauptet, als einer der ganz wenigen Gebildeten seiner Zeit das Volk zu kennen, und dass er seine Lagererfahrungen als einzigartige Lehrschule im Erkennen des Volkswillen stilisiert. Eine solche Argumentations-

20 Als kleine Miszelle sei darauf verwiesen, dass der zeitgenössische Dichter Andrej Rodionov eine interessante Verbindung zwischen Putin, den Pussy Riots und Dostoevskij in seinem Gedicht „Die Mädchen sangen maskiert im Kirchenchor“ (Devočki peli v maskach v cerkovnom chore) herstellt. Rodionov bezieht sich dabei auf Aleksandr Bloks berühmtes Gedicht aus dem Jahr 1905, „Ein Mädchen sang im Kirchenchor“ (Devuška pela v cerkovnom chore), in dem am Ende das Jesuskind weinend auf das schreckliche menschliche Schicksal blickt. Im Text aus dem Jahre 2012 ist es Dostoevskij, der aufmerksam auf den still im Kreml ' weinenden Putin blickt.

21 Vgl. Vladislav Surkov: Nacionalizacija buduščego: paragrafy pro [sic] suverennuju demokratiju (Die Nationalisierung der Zukunft: Paragraphen für eine souveräne Demokratie), http:// gtmarket.ru/laboratory/expertize/2006/597 - letzter Zugriff 01.03.2013. 
struktur ist nicht auf Konsens und Kompromiss, sondern auf Stigmatisierung und Ausgrenzung hin angelegt. Natürlich ist diese perfide Rhetorik keine genuin Dostoevskijsche Erfindung. Wenn von hier aus trotzdem die Beziehung zu aktuellen Putinreden hergestellt wird, dann geht es eher um einen typologischen Vergleich. Es soll keine inhaltliche sondern eine formale Kontinuität gezeigt werden, die für das Diskussionsniveau der politischen Debatten um die Zukunft Russlands im 19. ebenso wie im 21. Jahrhundert typisch ist.

Einen seiner umstrittensten, mittlerweile muss man sagen, berüchtigtsten Wahlkampfauftritte hatte Putin in einem Moskauer Stadion zehn Tage vor der Präsidentschaftswahl am 23. Februar 2012. Die relativ kurze Rede ist auch in den westlichen Medien beachtet und ungläubig kommentiert worden. ${ }^{22}$ Putin baut hier die Illusion auf, dass seine Wähler die wahren Verteidiger des gesamten Vaterlandes sind. ${ }^{23}$ Der Staat ist demnach kein „Apparat“, sondern eine Familie, die durch die Liebe der sich zu ihr Bekennenden zusammengehalten wird. ${ }^{24}$ Putin wirkt wie ein Vater, der die bösen Kinder der Familie mahnend davon abhalten muss, den Familienfrieden zu stören. ${ }^{25}$ Ein Höhepunkt der Rede ist sicherlich die Kennzeichnung der Russen als Siegervolk: „Wir sind ein Siegervolk. Das liegt bei uns in den Genen, in unserem genetischen Code. Das wird bei uns von Generation zu Generation weiter getragen. Und so werden wir auch jetzt siegreich sein." Und als „Beweis“ für die Richtigkeit dieser in biochemischer Hinsicht äußerst gewagten Hypothese zieht Putin die Schlacht von Borodino heran. Im Jahre 2012 ist dem Sieg der Russen über die Armee Napoleons besonders gedacht worden, denn er jährte sich zum 200. Mal, am 8. September war der offizielle Feier- und Erinnerungstag. ${ }^{26}$ Der Präsidentschaftsbewerber bezieht sich jedoch nicht direkt auf das Ereignis, sondern fragt seine Zuhörer, ob sie sich an die Verse des russischen

22 Siehe z.B. den Artikel „Wir sind ein Siegervolk, das haben wir in den Genen“, http:// www.zeit.de/politik/ausland/2012-02/russland-putin-praesidentschaft-wahl - letzter Zugriff 01.03.2013.

23 Zitate (auch die Folgenden) nach http://www.1tvnet.ru/content/show/rech-putina-v-lujnikahrasshifrovka-.html - letzter Zugriff 01.03.2013. Der gesamte Auftritt auf youtube: http://www. youtube.com/watch?v=mWUxcGCfdiI - letzter Zugriff 01.03.2013.

24 „Ich werde euch jetzt etwas fragen und bitte euch mir einmütig mit dem einfachen und kurzem Wort , Ja' zu antworten: Lieben wir Russland? Natürlich lieben wir Russland [...] Wir rufen alle dazu auf, sich vereint um unser Land zu scharen, natürlich alle die, die Russland als ihre ureigene Heimat ansehen, die bereit sind sie zu hüten, die sie wertschätzen und die an sie glauben."

25 „Wir bitten alle nicht aufs Ausland zu schauen, sich nicht auf die Seite zu stellen oder wegzulaufen und seiner Heimat untreu zu werden, sondern stattdessen mit uns zu sein, mit uns an der Heimat und ihren Völkern zu arbeiten und sie genauso zu lieben, wie wir es tun - von ganzem Herzen."

26 „Der Tag der Schlacht von Borodino zwischen der russischen Armee unter dem Kommando von M. I. Kutuzov und der französischen Armee 1812, der Tag des militärischen Ruhms für Russland“, so lautet die offizielle Bezeichnung im staatlichen Feiertagskalender. 
Romantikers Lermontov erinnern, die dieser in seinem berühmten Gedicht „Borodino“ von 1836 verfasst habe. Putin sagte: „Erinnern wir uns seiner [= Lermontovs] Worte? ,Sterbt vor Moskau, so wie unsere Brüder gestorben sind, und wir haben versprochen zu sterben, und den Schwur der Treue haben wir in der Schlacht bei Borodino gehalten'. Der Kampf um Russland hält an. Der Sieg wird unser sein." An dieser Stelle allerdings hätte Putin einen Literaturwissenschaftler um Rat fragen sollen, denn blickt man auf den gesamten Text von Lermontovs Gedicht, erkennt man, dass er die Strategie des Wahlkämpfers, das „russische Wir“ zu stärken, untergräbt. In dem Gedicht fragt ein junger Russe einen alten Veteranen über die Zeit der napoleonischen Kriege und die Heldentaten der damaligen Soldaten aus. Der Alte aber meint nur: „Ja, zu unserer Zeit gab es solche Leute, nicht solche, wie die heutige Generation. Das waren Helden - nicht wie ihr!" Es ergibt sich hier also ein genau umgekehrter Sinn: Lermontovs eigene Generation ist abgelebt und müde, die Jugend wird keine Helden mehr aus ihren Reihen hervorbringen. Putins verzückter Siegesrausch offenbart sich als hohle Phrase. Der angerissene typologische Vergleich verweist vor allem auf die Aktualität der polemischen Strategie Dostoevskijs, wie er sie im Tagebuch verfolgt hat. Demnach ist der Andersdenkende kein gleichwertiger Gesprächspartner in einem rationalen Diskurs, seine Argumente sind kein ebenbürtiger Beitrag in einer auf Konsens ausgerichteten Diskussion von Wahrheitssuchenden. Vielmehr belegt allein schon der kritische Gestus eines Individuums das grundsätzliche Nicht-Dazugehören zur Volksgemeinschaft. Ein solcher Kritiker ist ein existentieller Feind der eigenen Weltordnung, seine Widerlegung muss notwendigerweise umfassend sein und zielt letztlich auf seine Vernichtung.

Doch habe ich bereits davor gewarnt, die Vergleiche zwischen dem Denken eines Schriftstellers aus dem 19. Jahrhundert und der aktuellen gesellschaftlichen Situation in Russland im 21. Jahrhundert zu weit zu treiben. Dostoevskij bleibt gerade in seinen politischen Schriften immer der "Gesinnungsethiker“ im Sinne Max Webers, er geht von der Unteilbarkeit der Moral aus. Seine politischen Überlegungen kennen die auf die tatsächliche politische Situation zugespitzte Verantwortungsethik nicht. Dazu sagt einer der Vizepräsidenten der „International Dostoevsky Society“, Igor Volgin: „Das Gewissen ist [bei Dostoevskij] das einzige Kriterium der Lebensführung, sei es bei einem Individuum oder in einem Staatswesen. Das heißt nichts anderes als die Übertragung des christlichen Bewusstseins in die Sphäre der praktischen Politik. ${ }^{27}$ Putin dagegen ist ein pragmatischer Machtpolitiker. Wie weit seine Verantwortung für das Allgemeinwohl dabei durch seinen unbedingten Machtwillen beschädigt wird, kann erst von einem Historiker der Zukunft beantwortet werden.

27 Vgl. das Interview mit Igor Volgin von Vladimir Poljakov: Pisatel` Igor Volgin: ,Glavnaja strast' Dostoevskogo - èto Rossija ( Der Schriftsteller Igor Volgin: ,Die wichtigste Leidenschaft Dostoevskijs - das ist Russland'), http:// file-rf.ru/analitics/460 - letzter Zugriff 01.03. 2013. 
Für einige russische Intellektuelle allerdings ist diese Beschädigung bereits jetzt so eklatant, dass sie einen direkten Bezug zwischen Putinismus und Stalinismus herstellen. So ist das wohl interessanteste auf die Politik bezogene Literaturprojekt der vergangenen zwei Jahre im russischen Internet durch eine bezeichnende Aktion und einen nachdenkenswerten Text abgeschlossen worden. Der Dichter Dmitrij Bykov und der Staatsschauspieler Sergej Efremov haben bereits im Februar 2011 unter dem Titel „Graždanin poèt“, (Bürger Dichter) ein Projekt gestartet, bei dem wöchentlich ein neues politisches Gedicht auf der Basis klassischer Vorlagen vorgetragen wurde. Damit kommentierten sie die aktuellen politischen Ereignisse in Russland auf zum Teil äußerst ironische und witzige Art und Weise. Die Namensgebung bezieht sich ausdrücklich auf das Vorbild des Dichters Nekrasov und seinen berühmten Vers: „Ein Dichter brauchst Du nicht zu sein, / Aber ein Bürger zu sein bist Du verpflichtet. ${ }^{“ 28}$ Abgeschlossen wurde dieses Projekt allerdings mit einem beunruhigenden Auftritt am 5. März des Jahres 2012, einen Tag nach der Präsidentenwahl und gleichzeitig der Todestag Stalins. In der Uniform Stalins, mit Pfeife und Schnurrbart erscheint hier Efremov und fragt nach dem Rummel, der in letzter Zeit in Russland vor sich ginge. Dieser sei ja nun mit der Wahlentscheidung endgültig beendet und jetzt werde wieder Ordnung herrschen, so wie er, Stalin, sie damals auch habe durchsetzen können. Das Gedicht verdeutlicht in lakonischer Präzision das Empfinden vieler oppositioneller Intellektueller in Russland nach den für Putin gewonnenen Wahlen: Die Bürgergesellschaft hat abgedankt, nun wird wieder ein starker Staat entstehen, der einzig und allein die Machtposition des Präsidenten und seiner Klientel absichern soll. ${ }^{29}$

Как ваш бесстыдный балаган, Я умер в пятый день весны, И, в общем, я бы полагал, Что вы почтить меня должны. Когда мне было двадцать лет, Свистя от голода в кулак, Я тоже был большой поэт И сочинял примерно так: «Вот жаворонок всех смелей Поднялся выше облаков, А вдохновенный соловей Пел детям песню из кустов». В стихах немного красоты, И сам я это понимал.
Was ist das für ein Rummel da bei Euch, Ich starb am 5. Tag des Frühlings, Und außerdem schlage ich Euch vor, Ihr solltet mich verehren. Als ich zwanzig Jahre alt, Und vor Hunger in die Fäuste pfiff, War ich auch ein großer Dichter Und habe etwa folgendes geschrieben: ,Dort erhob sich die allermutigste Lerche Höher als die Wolken Und die beseelte Nachtigall Sang den Kindern aus den Büschen zu. An den Versen ist wenig Schönes, Ich wusste das selber ganz genau.

28 So in seinem Gedicht „Poèt i graždanin“ (Der Dichter und der Bürger) von 1856.

29 Siehe den russischen Text auf http://f5.ru/pg/post/396473 - letzter Zugriff 01.03.2013. Das Video auf youtube: http://www.youtube.com/watch?v=FwJBz3LghsU\&hl=ru - letzter Zugriff 01.03.2013. 
Плох перевод, заметишь ты?

Но хуже был оригинал.

Я пел о розах, о луне

И о поэзии святой,

И о любви к моей стране,

Что типа стонет под пятой.

В моих стихах, по ходу, нет

Ни ярких мыслей, ни картин.

Я был посредственный поэт, Зато хороший гражданин.

Как символично, видит Бог, Что все у нас наоборот, Что ваш проект сегодня сдох, А мой, напротив, восстает! Сегодня, в пятый день весны, Хотим мы или не хотим, Не только контуры ясны, Но даже запах ощутим. Прошла волна лихих годин, Десятилетий череда, А я, поэт и гражданин, Опять не делся никуда. Идет сопливая весна, Уже недолго до травы... А что страна? Да что страна! Ей все смешно - что я, что вы.
Sie meinen, schlechte Übersetzung?

Das Original war noch viel schlechter. Ich sang von Rosen, von dem Mond Und über die heilige Dichtkunst, Und über die Liebe zu meiner Heimat, Was man eben unter Druck so stöhnt. In meinen Versen sind keine klaren Gedanken, keine Bilder. Ich war ein durchschnittlicher Dichter, Aber dafür ein guter Staatsbürger. Und das ist doch, weiß Gott, symbolisch, dass es nun bei uns umgekehrt ist, Dass Euer Projekt heut endet, Und sich meins, im Gegenteil, erhebt! Heute, am fünften Tag des Frühlings, Ob wir es wollen oder nicht, Sind nicht nur die Konturen schon ganz klar, Auch der Geruch ist spürbar. Es vergingen schlechte Jahre, Eine Reihe von Jahrzehnten, Aber ich, Dichter und Bürger, Bin nicht verloren gegangen. Es kommt der junge Frühling, Nicht mehr lange, bis es grünt... Und das Land? Ach, was soll schon sein! Es ist doch alles lächerlich, mal ich, mal ihr.

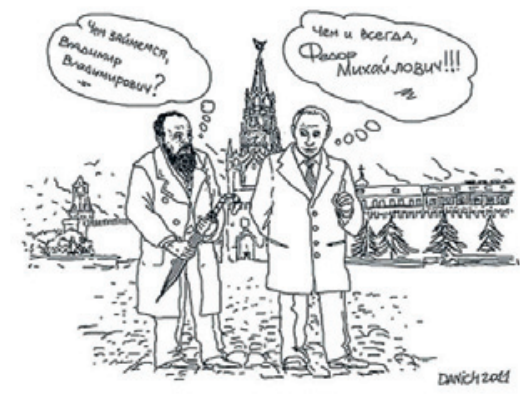

Abbildung 1 


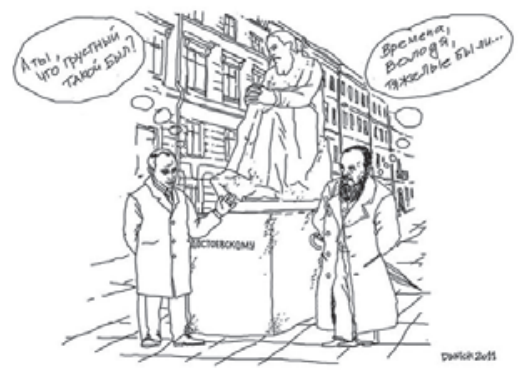

Abbildung 2

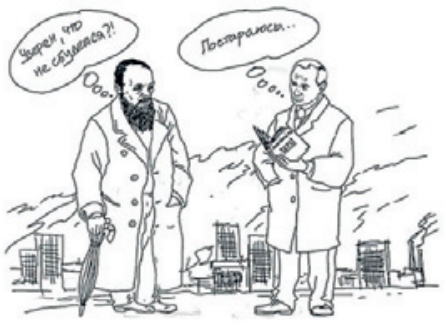

Abbildung 4

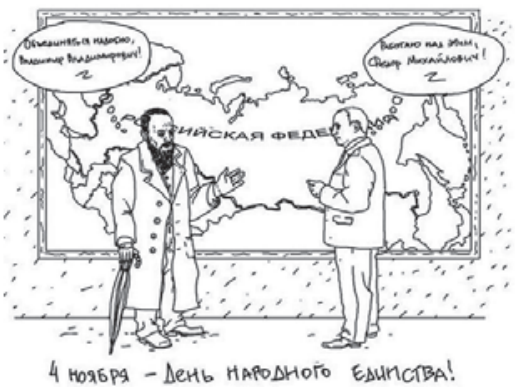

Abbildung 6

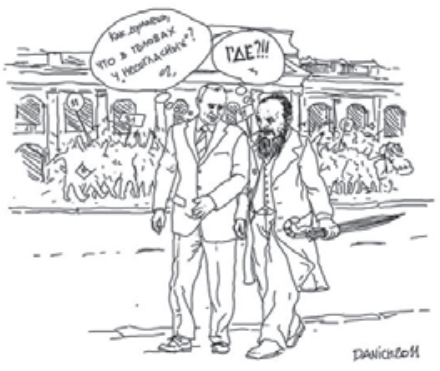

Abbildung 3

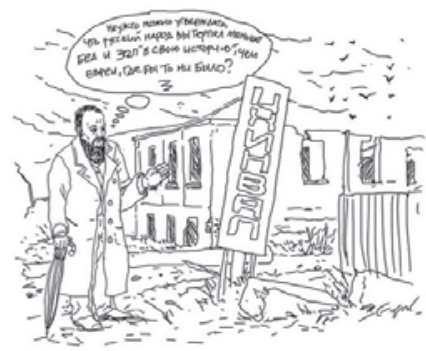

Abbildung 5

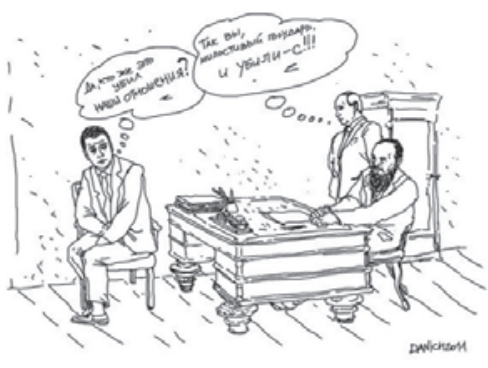

Abbildung 7 


\section{Henrike Schmidt}

\section{Dostoevskij digital. Zum virtuellen Nachleben eines Klassikers im Internet ${ }^{1}$}

Im Jahr 2001 stellt der russische Medienkünstler Aleksroma aka Aleksandr Romadanov ein Dostoevskij gewidmetes Netzkunstwerk vor. Das Konzept dazu umreißt er in wenigen Zeilen: ${ }^{2}$

„Das vorliegende Projekt präsentiert den gesamten Text des Romans von F. Dostoevskij „Der Idiot“ in Form einer „laufenden Zeile“, eines sogenannten Tickers. Das Nachrichtenformat der Textpräsentation unterstreicht die Aktualität des Romans, die Reproduktion des Texts in lateinischer Schrift - seine globale Bedeutung in der Gegenwart.“

Die buchstäbliche Gesamtlaufzeit des Werks beträgt 24 Stunden. Und so wird sich wohl kaum eine Leserin oder ein Betrachter finden, der den Text in ganzer Länge an sich vorbeiziehen lässt. Romadanov fasst denn auch gleich andere Möglichkeiten einer mobilen Lektüre ins Auge, die noch stärker auf den Alltag der heutigen Leser-Nomaden zugeschnitten ist. Literarische Texte sollen häppchenweise auf Werbetafeln projiziert werden. Wer dann beispielsweise mit dem Auto von der Neva an die Moskva reise, könne Radiščevs klassischen Travelogue Reise von St. Petersburg nach Moskau (Putešestvie iz Peterburga v Moskvu) aus dem Jahr 1790 gleichsam im Vorbeifahren rezipieren, ohne Zeit zu verlieren und dabei die beißende Sozialkritik des Reformers aus der Zarenzeit ins Verhältnis setzen zur postsozialistischen Realität am Straßenrand.

Aleksromas halb ernste, halb ironische Hommage an die Meister der russischen Klassik $^{3}$ impliziert aber nicht nur eine Sozial- sondern auch eine Medienkritik: „Die Verbindung von Kunst und Massenmedien [wird] problematisiert, indem auf-

1 Der Beitrag stellt die verschriftlichte und überarbeitete Fassung eines Vortrags bei der Deutschen Dostojewskij-Gesellschaft, Arbeitskreis Hamburg, am 3. September 2012 dar.

2 Aleksroma (Aleksandr Romadanov): F. Dostoevskij. IDIOT, in: Setevaja slovesnost', 04.05.2001, http://www.litera.ru/slova/alexroma/idiot.htm. Online nicht mehr zugänglich. Kopie in Internet Archive, http://web.archive.org/web/20040123170327/http://www.russianwriter.com /flash/idiot/idiot.swf (20.03.2009).

Hier wie im Folgenden stammen alle Übersetzungen von der Verfasserin.

3 Die Bezeichnung „Klassik“ bezeichnet hier keine historische, stilistische Strömung, sondern verallgemeinernd einen innerhalb der Gesellschaft kanonisierten Korpus von Werken und Autoren. 
gezeigt wird, in welch absurder Weise die Massenmedien (der Ticker) genutzt werden, um die Ästhetik der klassischen Kunst in die Sphäre der Medien-Kunst zu übertragen." Aleksroma kritisiert hier im bewusst verklausulierten Jargon der Medienwissenschaft die vulgär-materialistische Übertragung künstlerischer Inhalte aus einem Medium in das andere: hier konkret vom gedruckten Buch in den elektronischen Nachrichtenticker, ohne die Funktionalitäten der Lektüre mitzudenken. ${ }^{4}$ Über die verfremdende Zuspitzung seines Projekts sensibilisiert er für die grundsätzliche Frage nach den Möglichkeiten sowie den gewollten und ungewollten Konsequenzen des Medienwechsels. Aus seinem „idiotischen“ Kunstprojekt lassen sich zwei Fragen ableiten, die für diesen Artikel über das digitale Nachleben eines Klassikers wie Dostoevskij im (russischen) Internet relevant sind: Erstens die Frage nach der Anschlussfähigkeit seiner Erzählstoffe und Erzählverfahren an die digitale Gegenwart. Und zweitens die globalere Frage nach dem Schicksal des am Buch geschulten Lesens in Zeiten elektronisch-digitaler Vervielfältigung der Lektüre-Modi. Im Folgenden sollen beide Fragen anhand einiger Beispiele in den Blick genommen werden, auch wenn sich insbesondere letztere nach der Veränderung des Lesens in der Ära des Digitalen so global nicht beantworten lässt.

\section{„Im feuchten Keller" der Netz-Literatur. Dostoevskij digital lesen}

Wer die Zeit nicht mitbringt, Aleksromas digitalisierten Idioten in Tageslänge an sich vorbeitickern zu sehen, findet im Internet reichlich alternative Lektüremöglichkeiten. Dies gilt insbesondere für die russischen Originaltexte. Wer in deutscher Übersetzung lesen will oder muss, verfügt über ein begrenzteres Textkorpus, kann aber immerhin auf einige gemeinfreie Übersetzungen der Romane im Projekt Gutenberg oder der nach Zenodot, dem Begründer der legendären Bibliothek von Alexandria, benannten Internet-Bibliothek Zeno zurückgreifen. Schuld und Sühne / Verbrechen und Strafe (Prestuplenie i nakazanie) etwa findet sich auf projekt.gutenberg.de in der Übersetzung von Hermann Röhl, erschienen im Jahr 1956 im Aufbau Verlag, oder auf zeno.org in der älteren Übertragung durch Alexander Eliasberg aus dem Jahr 1924 (Gustav Kiepenheuer Verlag). Beide Projekte bieten die Texte kostenfrei zur Lektüre am Bildschirm an, verlangen für den Download jedoch eine Gebühr oder vertreiben die digitalisierten Inhalte über CD-Rom. ${ }^{5}$ Projekt Gutenberg digitalisiert sein Textkorpus mit der Hilfe von Freiwilligen. Das Redaktionsteam ist nach eigenen Aussagen bestrebt, im Zuge der

$4 \mathrm{Zu}$ Begriff und ästhetischen Funktionen des Medienwandels siehe Jay D. Bolter; Richard Grusin: Remediation: Understanding New Media. Cambridge, Mass. 2000.

5 Beide Projekte setzen programmatisch auf die kostenfreie Publikation von gemeinfreien Inhalten, kombinieren betriebswirtschaftlich kostenfreie und zahlungspflichtige Bereitstellungen der Materialien. Vgl. dazu die Informationen der Websites selbst unter http://www.pro jekt.gutenberg.de/information und http://www.zeno.org/Zeno/-/Nutzungsbedingungen. 
Digitalisierung entstehende Fehler in den Texten zu korrigieren. Eine Paginierung gibt es nicht. Die Texte sind also literaturwissenschaftlich nicht zitierfähig. Zeno .org legt mindestens prinzipiell größeren Wert auf philologische Standards. Die Seitenzahlen der zitierten Ausgabe werden angegeben, in manchen Fällen sind die digitalisierten Texte im HTML-Format sogar mit Scans der Faksimiles verlinkt. Für die drei Romane Dostoevskijs, neben Schuld und Sühne / Verbrechen und Strafe noch Der Idiot (Idiot) und Die Dämonen (Besy) plus Auszüge aus den Brüdern Karamazow (Brat'ja Karamazovy), ist dies jedoch noch nicht der Fall.

Digitalisierte E-Book-Ausgaben deutscher Dostoevskij-Übersetzungen gibt es zu günstigen Preisen von wenigen Euro in den einschlägigen Internet-Shops, beispielsweise bei Amazon, zu kaufen. Die Preise variieren in Abhängigkeit von der Aktualität der Übersetzung. Die elektronische Wiederauflage vergriffener, gemeinfreier Texte entwickelt sich in Deutschland wie in Russland zu einem einkömmlichen Geschäft, da die Texte der Klassiker in der Regel keinem Autorenrecht mehr unterliegen. Zumeist handelt es sich bei diesen Texten jedoch um nicht-wissenschaftliche Lese-Ausgaben. „Bezahlt“ werden die kostenfreien Angebote durch die Daten, welche die Leser hinterlassen, durch Empfehlungen, die sie in sozialen Netzwerken geben und dadurch auch auf die „Bezahlprodukte“ der Anbieter aufmerksam machen.

Wer Dostoevskij hingegen im russischen Original digital lesen will, hat die Qual der Wahl zwischen einer Vielzahl von Bibliotheken unterschiedlichster Couleur und zwischen Formaten verschiedener philologischer Qualität und Lese-Komforts. Da wäre zunächst einmal die „Volksbibliothek“ lib.ru von Maksim Moškov, im Hauptberuf Programmierer, zu nennen. Diese „älteste“ Bibliothek des Runet, wie das russische Internet von seinen Protagonisten bisweilen abgekürzt wird ${ }^{6}$, ist die bis heute wohl bekannteste Sammlung russischsprachiger Belletristik, klassischen wie zeitgenössischen Profils (sie umfasst darüber hinaus esoterische Schriften, Liedermacher-Songs, Prosa von Afghanistan-Veteranen und andere wissenschaftliche oder halb-literarische Textsorten). Nach Problemen bezüglich der Wahrung von Autoren-Rechten und einem Copyright-Prozess im Jahr 2004 veränderte der bekennende Hobby-Bibliothekar seine Publikationspolitik und veröffentlicht aktuell nur noch literarischen „Samizdat“, d.h. auf Eigen-Initiative der Autoren freigegebene Texte, sowie klassische Werke, für die kein Copyright mehr existiert. ${ }^{7}$

6 Der Terminus „Runet“ bezeichnet in diesem Sinn manchmal das russischsprachige, manchmal das in der Russischen Föderation „produzierte“ Internet. Beide Facetten des Begriffs sind als Phänomene einer globalen Netzkultur realiter nicht deutlich voneinander zu unterscheiden. Für den gegebenen Kontext ist diese Unterscheidung in ihren auch politischen Implikationen jedoch nicht von zentraler Bedeutung, weshalb der Begriff „Runet“ hier als Sammelbegriff russischsprachiger Internet-Ressourcen verwendet wird. Vgl. Karina Alexanyan; Olessia Koltsova: Blogging in Russia Is not Russian Blogging. In: Adrienne Russell (Hg.): International Blogging: Identity, Politics and Networked Publics. New York 2009, S. 65-84.

7 Vgl. Aleksandr B. Antopol'skij: Spasi i sochrani. Ėlektronnye biblioteki Rossii: problemy i 
Letzteres Projekt wird durch staatliche Fördergelder unterstützt. Es wird seit dem Jahr 2004 vorangetrieben und enthält mit Stand 15. Juni 2013 1.679 Rubriken russischer und 353 Rubriken ausländischer Autoren. In der Dostoevskij-Rubrik finden sich die Romane und Erzählungen des Schriftstellers, seine Tagebücher und die Briefkorrespondenz sowie umfassende Sekundärliteratur. Die Texte stehen kostenfrei zur Verfügung, zur Lektüre am Bildschirm oder zum Download. Die verwendeten Quellen werden korrekt ausgewiesen: Der Publikation von Schuld und Sühne / Verbrechen und Strafe ist beispielsweise die 15-bändige Gesamtausgabe, Band 5, Leningrad: Nauka, 1989 zugrunde gelegt. ${ }^{8}$ Die im HTML-Format aufbereiteten Texte weisen allerdings keine Paginierung auf und sind somit nicht zitierfähig.

Ein weiteres, seit vielen Jahren existierendes und renommiertes Projekt des russischen Internet ist die Russländische Virtuelle Bibliothek (Rossijskaja Virtual'naja Biblioteka RVB). Im Unterschied zur Biblioteka Moškova wird die RVB von Philologen betrieben (u.a. Igor' Pil'ščikov, Evgenij Gornyj), die bestrebt sind literaturwissenschaftliche Standards einzuhalten und zitierfähige Textgrundlagen zu bieten. ${ }^{9}$ Entsprechend findet sich auf den Seiten der RVB eine digitale Reproduktion der 15-Bände umfassenden Kleinen Akademischen Ausgabe (Maloe akademičeskoe izdanie Polnoe sobranie sočinenij Dostoevskogo $v 15$ tomach. Leningrad: Nauka, 1988-1995, $t$ 1-15). Die Annotationen sind hypertextuell verlinkt, die Seitenzählung bleibt erhalten. Gleichzeitig wird für eine bequeme Navigation durch den Text gesorgt.

Die RVB will damit eine von ihr konstatierte Lücke schließen. In der Dostoevskij-Rubrik der Homepage heißt es: „Der Mangel an Werken Dostoevskijs im Netz wird bereits seit langem bemerkt [...]“. In der Tat weist die zweite große und staatlich geförderte elektronische Bibliothek, die Fundamentale Elektronische Bibliothek Russische Literatur und Folklore (Fundamental'naja Ėlektronnaja Biblioteka Russkaja Literatura i Fol'klor FĖB) bezüglich Dostoevskijs eine überraschende Lücke aus. Die Bibliothek, die durch verschiedene Förderprogramme finanziell unterstützt wird, setzt sich zum Ziel zentrale Autoren und literarische Werke der russischen Literatur digital in ihrer Gesamtheit zur Verfügung zu stellen. Sie arbeitet zu diesem Zweck mit sogenannten digitalen Gesamtausgaben (Ėlektronnye naučnye izdanija ĖNI), in denen das Gesamtwerk einzelner Literaten, oder im Falle der Folklore Genres, in den verschiedenen existierenden Ausgaben und in-

perspektivy, in: Novaja Gazeta, 22.05.2005, http://www.ng.ru/internet/2005-04-22/10_biblio teki.html (09.02.2009).

8 Es wird darauf verwiesen, dass diese digitalisierte Version des Texts im „Original“ aus einer anderen Bibliothek des Runet stammt, nämlich der Russländischen Virtuellen Bibliothek (Rossijskaja Virtual'naja Biblioteka RVB). Nicht nur in diesem Fall werden digitalisierte Texte von einer Website auf die andere transferiert, nicht immer unter korrekter Nennung der Quelle.

9 Evgenij Gornyj; Konstantin Vigurskij: Razvitie èlektronnych bibliotek: mirovoj i rossijskij opyt, problemy, perspektivy. In: Il'ja Semenov (Hg.): Internet i rossijskoe obščestvo. Moskva 2002. Online unter http://www.zhurnal.ru/staff/gorny/texts/dlib.html (26.04.2004). 
klusive einschlägiger Sekundärliteratur zusammengestellt wird. Während bereits elektronische Gesamtausgaben (ĖNIs) solcher Autoren wie Puškin, Tolstoj, Lermontov, Gogol' oder Čechov vorliegen, bleibt der Link hinter Dostoevskijs Namen noch leer. ${ }^{10}$

Dennoch berührt die von den literarischen Profis der RVB konstatierte Lücke primär die Frage wissenschaftlich zuverlässiger, kritischer Textausgaben. ${ }^{11}$ Bezieht man nämlich die Laien-Bibliotheken und privaten Websites mit ein, auf denen einzelne oder auch mehrere Werke Dostoevskijs publiziert werden, so ergibt sich ein vielfältiges, buntgemischtes Bild. Beispielhaft zu nennen wären etwa die Seiten der Bibliothek von Aleksej Komarov (ilibrary.ru), des Neuen Literarischen Netzwerks (Novaja literaturnaja set', fdostoevsky.ru) oder anderer individueller Dostoevskij-Liebhaber. Komarov definiert in seinem Mission-Statement in aufschlussreicher Weise die Unterschiede seiner Bibliothek gegenüber den erwähnten RVB und FĖB: Im Gegensatz zu den Betreibern letzterer sei er kein Philologe. Vorrang vor der akademischen Vollständigkeit habe für ihn die Bequemlichkeit und die Ästhetik der Lektüre am Bildschirm. Die Bibliothek formiere sich entsprechend den Interessen seiner Leser/innen, die er u.a. über die Suchabfragen ermittelt. Der Befriedigung „brennender“ Leser-Bedürfnisse werde Vorrang gegeben vor dem Prinzip der Vollständigkeit und bibliographischer Konsequenz. ${ }^{12}$

Neben solchen Privat-Bibliotheken, in denen wie bei Komarov Werke verschiedener Autoren gesammelt werden, existiert eine Vielzahl von dezidiert Dostoevskij gewidmeten Liebhaber-Seiten. Bei diesen handelt es sich um private Aneignungen eines kanonisierten Autors, wie etwa auf der Seite des Neuen Literarischen Netzwerks zu sehen. Hier werden die Biografie, eklektisch ausgewählte Bilder, Fotografien und Werke präsentiert, oftmals ohne Quellen-Angaben.

Die Art und Weise, wie diese Texte auf den Websites präsentiert werden, mag wissenschaftlichen Standards nicht entsprechen, dafür illustrieren diese die individuellen Lektüre-Vorlieben ihrer Initiatoren. Diese Form der Privat- und LaienBibliotheken findet oft eine eher skeptische Bewertung, sowohl unter anderen User/innen als auch in der Forschung. Als Vasja-Pupkin-Websites, also als die literarischen Jedermann-Projekte, wurden sie insbesondere in der Frühzeit des Runet verspottet. Sie privatisieren und verkitschen Lektüre-Erfahrungen, so die häufig geäußerte Kritik, und nutzen zwecks Nobilitierung ihrer eigenen literarischen Ergüsse das symbolische Kapitel klassischer Autoren. ${ }^{13}$ Ein Zitat von der

10 Nach Angaben der RVB ist eine Publikation der Großen Akademischen Dostoevskij Ausgabe in 30 Bänden sowie der Dostoevskij-Ausgabe der Petrozavodsker Universität geplant.

11 Hier findet sich auch eine Übersicht über weitere digitale Editionen der Werke Dostoevskijs oder literaturwissenschaftliche Hilfsmittel wie Konkordanzen, etwa auf der Homepage der Universität von Petrozavodsk.

12 Aleksej Komarov: O biblioteke, http://www.ilibrary.ru/aboutilibrary/ (09.09.2013).

13 Mirza Babaev (Evgenij Gornyj) (o.J.): Apologija choum pejdža, in: InterNet magazine 14, http://www.gagin.ru/internet/14/30.html (07.07.2013). Für eine Beschreibung der Ästhetik 
Privat-Homepage eines Users mit dem Nickname Alex-Astra aus dem Jahr 2002, im typisch dilettantischen Design mit Laufzeile „Danke, dass Sie diese Seite besucht haben“, mag dies verdeutlichen (dostoevsky.df.ru):

„Aber viele, wenn sie von Dostoevskij sprechen, meinen den Autor von „Schuld und Sühne“ und dem „Idioten“. Ich möchte aber von ihm erzählen als von einem interessanten Menschen mit einem schwierigen Charakter und genau so schwierigen Gedanken, dessen Schicksal selbst wie eine spannende, gespannte Erzählung ist ...".

Im Zuge der rapiden Verbreitung des Internet und der damit verbundenen Abkehr von avantgardistischen Erwartungen an das „neue“ Medium finden die massenhaften literarischen Praktiken in ihrer literatursoziologischen und ästhetischen Bedeutung jedoch zunehmend Beachtung. Der Literaturwissenschaftler Shillingsburg bezeichnet diesen Sektor der selbstgebastelten Bibliotheken als den „feuchten Keller" (dunk cellar) des akademischen Internet, in dem zwar keine Literaturwissenschaft betrieben wird, in dem aber sozusagen der Humus generiert werde, aus dem sich in der Folge die literarischen Vorbilder der Nation im Ganzen generieren ließen. ${ }^{14}$ Für den hier vorliegenden Kontext ist die Metapher Shillingsburgs vom „feuchten Keller" eine ungewollte, aber hübsche Reminiszenz auf einen der berühmtesten Texte Dostoevskijs, nämlich die Aufzeichnungen aus dem Untergrund (Zapiski iz podpol'ja, 1864), die gerne für die metaphorische Beschreibung der "Schatten-Seiten“ des Internet herangezogen werden.

Neben der philologischen und textkritischen Adäquatheit der Text-Reproduktion spielen zunehmend Fragen der technischen Bequemlichkeit der Lektüre eine Rolle (die unterschiedlichen Bezahl-Modelle des elektronischen Buchmarkts sind für Werke, die keiner Rechtebindung mehr unterliegen, weniger zentral als für die zeitgenössische Prosa). Die Lektüre verlagert sich zunehmend von den ComputerBildschirmen auf die mobilen Lese-Geräte, inklusive der Smartphones. Dieser Entwicklung tragen auch diverse kommerzielle Angebote im russischen Internet Rechnung, die neben zeitgenössischer Belletristik klassische Literatur in allen gängigen E-book-Formaten vorrätig halten, etwa der elektronische Buchhändler Litres (litres.ru). Zu erwähnen wären hier auch die elektronische Plattform für den Vertrieb von digitalem Content Ajmobilko (imobilco.ru) oder der russische virtuelle Buchklub Bookmate (bookmate.com). Bei allen drei Anbietern „bezahlt“ man für die kostenlosen Ausgaben der Klassiker, indem man seine persönlichen Daten und Netzwerke zur Verfügung stellt, etwa indem man „seinen LieblingsDostoevskij“ über den persönlichen Facebook-Account empfiehlt und damit auch auf das Bezahl-Angebot des jeweiligen Portals aufmerksam macht. Im Mittelpunkt

dieser Laien-Websites siehe Olia Lialina: A Vernacular Web, The Indigenous and The Barbarians, in: Teleportaica.org, 2005, http://art.teleportacia.org/observation/vernacular/ (30.06. 2013).

14 Peter L. Shillingsburg: From Gutenberg to Google: Electronic Representations of Literary Texts. Cambridge 2006, S. 138ff. 
steht in allen der erwähnten Fälle nicht die philologische Korrektheit des Texts, sondern der Lese-Komfort und der Austausch mit anderen Leser/innen in einem sozialen Netzwerk. Besonders charakteristisch ist in diesem Zusammenhang ein Zitat der Userin „ilala“ (Zeichensetzung wie im Original): ${ }^{15}$

„Ich lese diesen Roman zum zweiten Mal. Das erste Mal in der Schule,ohne darüber nachzudenken,das zweite Mal auf dem Telefon. Ein unglaublicher Roman. Kann umsonst runtergeladen werden. In seinem Helden verkörpert der Autor seine Weltanschauung, seine Emotionen, sich selbst...“

Ob groß oder klein, akademisch oder amateurmäßig betrieben, „trocken“ oder "feucht" - die (Netz-)Bibliotheken stellen nie nur neutrale Textsammlungen dar. ${ }^{16}$ Durch die Kriterien ihrer Auswahl, die Navigation, das Design, die Paginierung etc. generieren sie den Rahmen, durch welchen die einzelnen Texte wahrgenommen werden. Der norwegische Literaturwissenschaftler Kåre J. Mjör untersucht am Beispiel der FĖB, wie über solche editorischen Vorentscheidungen und technologischen Voreinstellungen implizit kulturelle und literaturwissenschaftliche Normen und Kanones transportiert werden, etwa durch die unkommentierte Reproduktion von Sekundärliteratur aus der Sowjetzeit. ${ }^{17}$ Für die kleinen Krauter unter den NetzBibliotheken, die zumeist unsortierte Textsammlungen oder lediglich Link-Listen darstellen, konstatiert der britische Kulturwissenschaftler Vlad Strukov hingegen ein subversives, den Kanon potenziell dekonstruierendes Potenzial: ${ }^{18}$

15 Kommentar zu Schuld und Sühne / Verbrechen und Strafe im Leser-Forum von imobilco.ru von Userin ilala, 17.04.2013, http://www.imobilco.ru/books/-/619579/\#comments (09.09. 2013).

16 Das Internet ist nicht nur ein Textrepositorium. Oder im Rückgriff auf die unterschiedlichen populären Metaphorisierungen des Internet: Dieses ist nicht nur Bibliothek, sondern auch Museum (Gedenkort). So finden sich im Runet zahlreiche Dostoevskij und seinem Werk gewidmete Erinnerungs- und Gedächtnisorte. Neben virtuellen Repräsentanzen offizieller Institutionen, wie dem Dostoevskij-Museum in St. Petersburg, kann man sich etwa auf Youtube private Videos anschauen, in denen die auratischen Orte aus dem Leben Dostoevskijs und seiner Figuren gezeigt werden. So nimmt eine Studentin mit dem Nutzernamen MrsAnitaMalik den Besucher mit auf einen virtuellen Rundgang durch Dostoevskijs St. Petersburg, und reproduziert dabei doch weitestgehend in der Schule oder dem Studium angelesenes kanonisches Wissen.

17 Kåre J. Mjør: The Online Library and the Classic Literary Canon in Post-Soviet Russia: Some Observations on „The Fundamental Electronic Library of Russian Literature and Folklore“, in: Digital Icons: Studies in Russian, Eurasian and Central European New Media, Vol. 1, No. 2 (2009), S. 83-99, http://www.digitalicons.org/wp-content/uploads/2009/12/Kare-JohanMjor-DI-2.6.pdf (10.12.2010)

18 Vlad Strukov: Digital (After-)Life of Russian Classical Literature, in: kultura. Russland-Kulturanalysen 1 (2009): Notes from the Virtual Untergrund. Russian Literature on the Internet. Forschungsstelle Osteuropa an der Universität Bremen, S. 9-10, http://www.kulturarus.de /kultura_dokumente/artikel/englisch/k1_2009_EN_Strukov.pdf (10.04.2009). 
"To some extent, new technologies help to pass the power of aesthetic judgments over the literary canon from the authority of the state to the commonality of the reader. [...], the Internet has enabled desacralisation of Russian classical literature, whereby the hierarchal structure of literary history has been replaced by the searchable environment of the web.“

\section{Dostoevskij „raten“.}

\section{Leser-Bewertung und Kommentierung in Foren und Netzwerken}

Dies gilt zumal, wenn nicht nur die Form der Textpräsentation in den Blick genommen wird, sondern auch ihre interaktive Kommentierung in den LeserForen der jeweiligen Bibliotheken und elektronische Buchhändler. Bezüglich der Möglichkeit einer solchen Kommentierung unterscheiden sich im Übrigen die „professionellen“ deutlich von den „Laien-Bibliotheken“. Die RVB verfügt über gar kein Forum, die FĖB hat ein allgemeines Gästebuch, in dem primär technische und editorische Fragen, also Tippfehler oder nicht funktionierende Links, besprochen werden. In einigen Fällen wird auch die Textauswahl (kritisch) kommentiert. Dabei wird insbesondere das Fehlen einer Werkausgabe Dostoevskijs als editorische „Sünde" hervorgehoben (etwa von Davidus Orlovskij im Forum der FĖB am 22.01. 2013). Die Bibliothek Maksim Moškovs hingegen erlaubt eine Kommentierung jedes einzelnen Werks. Zu Schuld und Sühne / Verbrechen und Strafe finden sich hier mit Stand August 2013 rund 300 Leser/innen-Kommentare. Jenseits editorischer Spezialfragen werden persönliche Leseempfindungen und -interpretationen wiedergegeben. Dabei wird unter den Leser/innen kräftig polemisiert, bis hin zur Forderung nach Streichung inadäquat formulierter Beiträge, welcher der Moderator des Forums offensichtlich auch nachgekommen ist. Darüber hinaus besteht die Möglichkeit, die Werke einer Punktewertung zu unterziehen, auf einer Skala von 1 bis 10. Schuld und Sühne / Verbrechen und Strafe erreicht in diesem Rating einen Mittelwert von 6,3 Punkten, d.h. die Leser/innen bewerten diesen Klassiker der Weltliteratur als Lektüre mittlerer Qualität („normal'no“). Dasjenige Werk Dostoevskijs, das unter Leser-Bewertungen den höchsten Wert erreicht, ist im übrigen Der Idiot (8,8 Punkte = sehr gut; Platz 14. der beliebtesten Werke). Aufgrund seiner höheren moralischen Qualitäten wird er, anders als Schuld und Sühne / Verbrechen und Strafe, auch als kanonische Schullektüre empfohlen.

Es sind besonders diese Formen der unverblümten, nicht-philologischen Kommentierung der Klassiker, die oftmals kulturpessimistische Reaktionen hinsichtlich des kulturellen Niveaus der Lesekultur im Internet hervorrufen. Dennoch erfordert auch diese niedrigschwellige Diskussionskultur explizite Textkenntnis und will andere User/innen zur individuellen Lektüre motivieren - und durchaus auch zum richtigen Schreiben. Dies zeigt etwa ein Blick in das Leser-Forum der sogenannten „Piraten-Bibliothek“ lib.rus.ec. Librusek, initiiert von dem Programmierer Il'ja Larin und basiert in Südamerika, ist vom Textumfang her die aktuell wohl größte russischsprachige Textsammlung im Internet. Dies liegt u.a. daran, dass Larin lange 
Zeit eine dezidierte Copyleft-Politik vertrat und Werke ungeachtet existierender Autorenrechte (und -meinungen) publizierte. ${ }^{19}$ Aufgrund legislativen und technischen Drucks (Hacker-Angriffe) wurde dieses Bibliotheks-Modell mittlerweile modifiziert und in eine Status überführt, der legal weniger angreifbar sein soll. Die Bibliothek bietet nun Abonnement-Modelle und kooperiert mit digitalen Buchhandlungen (und ähnelt damit immer mehr den oben erwähnten kommerziellen Content-Anbietern Litres, Ajmobilko oder Bookmate.ru). Sie bietet eine kostenfreie Lektüre ausgewählter Texte am Bildschirm oder einen Download der Texte in gängigen E-book-Formaten gegen eine Monatsgebühr an. Dostoevskij ist auch hier mit zentralen Werken vertreten, die im Forum vielfach kommentiert werden, allerdings nicht nach einzelnen Werken unterschieden, wie in Maksim Moškovs Netz-Bibliothek. Im Forum gibt eine Leserin eine glühende Lese-Empfehlung ab: ${ }^{20}$

Julia Abr: „Die Brüder Karamazov: Mein liebstes Buch von Dostojewski. Empfehle ich jedem!“

Solcher Art emphatischer Mini-Rezensionen finden sich hier, wie in den anderen Leser-Foren der nicht-philologischen Bibliotheken und Plattformen, en masse. Dabei werden nicht nur als kanonisch gesetzte Werke zur Lektüre empfohlen, sondern gelegentlich auch energisch auf die Einhaltung der Normen von Rechtschreibung und Syntax gepocht (eine Mahnung, die im Übrigen mit Fug und Recht auch an die oben zitierte Userin ilala gerichtet werden könnte): ${ }^{21}$

Astrowalk: „Das war wohl nicht Dostoevskij, der Dir beigebracht hat, nach einem Satzzeichen kein Leerzeichen zu setzen?“

\section{Fan Fiction: Dostoevskij digital weiterschreiben}

Dostoevskij kann im (russischen) Internet nicht nur gelesen und kommentiert, sondern auch weitergeschrieben werden. ${ }^{22}$ Als Fan Fiction wird die narrative Fortführung erzählerischer Welten literarischer, aber auch filmischer Provenienz durch die Fans bezeichnet, in der Regel ohne kommerzielle Intentionen. In Foren

19 Zur Entwicklung der elektronischen Bibliotheken im Runet vgl. auch Henrike Schmidt: Russische Literatur im Internet. Zwischen digitaler Folklore und politischer Propaganda. Bielefeld 2011 , insb. S. $167 \mathrm{ff}$.

20 Kommentar im Leser-Forum von Librusek von Userin Julia Abr vom 19.02.2012, http:// lib.rus.ec/a/18736 (01.09.2012).

21 Ebd. Kommentar von User Astrowalk vom 21.04.2012. Für Analysen zur linguistischen Kultur und der sprachkritischen Debatten im Runet siehe Ingunn Lunde; Martin Paulsen: From Poets to Padonki. Linguistic Authority and Norm Negotiation in Modern Russian Culture. Bergen 2009.

22 Eine Sammlung mit weiteren Links zu Netzprojekten, Comics, Verfilmungen findet sich auf der Dostoevskij Website von K. Trost http://www.dostojewski.eu/18_LINKS/Links_ Freaks.html sowie auf der Website des Dostoevskij-Museums in St. Petersburg http://www. md.spb.ru/dostoevsky/Dostoevsky_links/. 
auf der ganzen Welt werden von Jane Austen bis Harry Potter oder, für den russischen Kontext, von Fëdor Dostoevskij bis zu den Brüdern Strugackij Hunderttausende solcher „alternativer Geschichten“ verfasst, wobei der Schwerpunkt deutlich im Bereich massenkultureller Literatur, Filme oder Fernsehserien liegt. Ursprünglich eine Nischenkultur, die in der vordigitalen Ära in Fanzines gepflegt wurde, verbreitete sich diese Form der Laien-Literatur mit der Massenmedialisierung des Internet rasant. ${ }^{23}$ Ins breitere Bewusstsein ist die Fan Fiction mit dem Erfolg der Skandal-Trilogie Fifty Shades of Grey von E. L. James (Erika Leonard) eingetreten. Die Autorin hatte ihre Geschichten um die fatale Liebe der Protagonistin zu ihrem sie quälenden Liebhaber in einem Fan-Forum zu Stefanie Meyers Vampir-Saga erprobt und war von ihren virtuellen Fans zu deren Publikation ermuntert worden.

Die Amateur-Schriftsteller der ersten Stunde hatten in der Kritik einen schweren Stand. ${ }^{24}$ Sie galten als graphomanische Dilettanten, die selbst schreiben wollten, anstatt "gute Literatur" zu lesen. Mit dem Internet verbanden sich zunächst Hoffnungen auf avantgardistische Nutzungsweisen, die nicht-traditionelle Erzählverfahren voranbringen sollten anstatt Sequels der Trivial-Literatur zu propagieren..$^{25}$ Mit der Zeit verschob sich die Aufmerksamkeit jedoch von den avantgardistischen auf massenkulturelle Nutzungsformen, zu denen auch die Fan Fiction zu zählen ist. Die amerikanische Erzähl-Forscherin Marie-Laure Ryan sieht in dieser Form der massenhaften Textproduktion eine Interaktivität am Werk, die in ihren komplexen Vernetzungen die digressiven Narrationen des technisch arrangierten Hypertexts übertreffe ${ }^{26}$. Sie fasst diese Form der kollektiven (Weiter-) Erzählung fiktionaler Stoffe, die einzelne Werke übergreift, in den Begriff der Transfiktionalität: ${ }^{27}$

"Transfictionality expresses the reader's desire to free the fictional world from the control of the author and to see it live and evolve independently of the text that originally brought it to life."

23 Vgl. Linor Goralik. Kak razmnožajutsja Malfoi. Žanr „fènfik“: potrebitel' masskul'tury v dialoge s media-kontentom, in: Novyj mir 12 (2003), S. 131-147. Online in Žurnal'nyj zal, http:// magazines.russ.ru/novyi_mi/2003/12/goralik.html (27.03.2007).

24 Für eine prominente Kritik der Amateur-Kultur im weiteren Sinne siehe Andrew Keene: The Cult of the Amateur: How Today's Internet Is Killing Our Culture. New York 2007.

25 Vgl. etwa die Darstellungen in Christine Scheucher: Figuren des Unmittelbaren: zur Fortschreibung der Avantgarden im digitalen Raum. Berlin 2007.

$26 \mathrm{Zu}$ digressiven Erzählverfahren und der Utopie des Hypertexts siehe etwa George Landow: Hypertext 3.0: Critical Theory and New Media in an Era of Globalization. Baltimore 2006; Roberto Simanowski; Jörgen Schäfer; Peter Gendolla: Reading Moving Letters: Digital Literature in Research and Teaching. A Handbook. Bielefeld 2009. Zu einer Kritik des hypertextuellen Paradigmas Stephan Porombka: Hypertext. Zur Kritik eines digitalen Mythos. München 2001.

27 Marie-Laure Ryan: Fictional Worlds in the Digital Age. In: Ray Siemens; Susan Schreibman (Hg.): A Companion to Digital Literary Studies. Malden, M.A 2007, S. 250-266. 
Insbesondere die Arbeiten von Henry Jenkins haben die Debatte um die Fan Fiction und ihre Nobilitierung weiter befördert. ${ }^{28}$ In ihrer Studie zu Harry-PotterFan Fiction fasst Sigrid Sindhuber die zehn Verfahren zusammen, die laut Jenkins für die Transformationen narrativer Stoffe durch die Laien-Literaten zum tragen kommen: „Recontextualization“, „Expansion of the Series Timeline“, „Moral realignment", „Refocalization“, „Genre Shifting“, „Cross overs“, „Character dislocation“, „Personalization“, „Emotional intensification“, „Eroticization“.$^{29}$ Die genannten Verfahren lassen sich auch in der Dostoevskij Fan Fiction wiederfinden. Als kleine Fallstudie sollen einige Bearbeitungen von Schuld und Sühne / Verbrechen und Strafe im russischen Fan-Fiction Forum ficbook.net Berücksichtigung finden. Besonders prominent sind im Rahmen dieses Samples von 38 Bearbeitungen $^{30}$ Interpretationen, die eine zeitliche Fortsetzung des Plots offerieren. Das offene Ende des Romans fordert zu einer Ausweitung des Erzählhorizonts offensichtlich geradezu heraus. Die Dostoevskij Fans nehmen diesen Impuls dankend auf und offerieren verschiedene Versionen einer Zukunft für Raskolnikov und Sonja, die zwischen sentimentalistischen und tragischen Storylines schwanken. So lässt der User mit dem Nickname „Brr“ beide Selbstmord begehen, nachdem Rodion, im Wahn von der toten Pfandleiherin verfolgt, in der sibirischen Verbannung einen erneuten Mord begeht und eine Nachbarin erschlägt. ${ }^{31}$ Im Sinne einer Refokalisierung (refocalization) wird der Akzent in anderen Fan-Fortsetzungsromanen auf Nebenfiguren der Erzählung verschoben, oftmals mit der erwähnten emotionalen Intensivierung (emotional intensification) oder moralischen Umwertung (moral realignment). Wie in der Fan Fiction allgemein ist schließlich das Element der Erotisierung besonders stark, gattungsmäßig unterschieden danach, ob heterosexuelle (het) oder homosexuelle Beziehungen (slash) überwiegen. Auch die Figuren Dostoevskijs werden einer solchen expliziten Sexualisierung unterzogen. So wird etwa die dramatische Bekenntnisszene in der Dachstube zwischen Sonja und Rodion in eine erotische Liebesszene unter dem Titel Sünder (Grešniki) überführt. ${ }^{32}$ Homosexuelle Liebesbeziehungen werden sowohl zwischen Raskolnikov und Razumichin ${ }^{33}$ als auch zwischen Raskolnikov und Svidrigajlov inszeniert. ${ }^{34}$

28 Henry Jenkins: Textual Poachers. Television Fans and Participatory Culture. New York 1992; Henry Jenkins: Convergence Culture: Where Old and New Media Collide. New York 2006.

29 Sigrid Sindhuber: Slashing Harry Potter: the phenomenon of border-transgression in fanfiction. Wien 2010, http://othes.univie.ac.at/9666/1/2010-05-11_0400588.pdf (09.09.2013).

30 Fanfiki po fẻndomu „Dostoevskij F.M. „Prestuplenie i nakazanie““, in: Kniga fanfikov, http://ficbook.net/fanfiction/books/dostoevskij__prestuplenie_i_nakazanie (09.09.2013).

31 User „Brr“: Prodolženie romana „Prestuplenie i nakazanie“, in: Kniga fanfikov, http:// ficbook.net/readfic/839680 (09.09.2013).

32 User „KesToreador“: Grešniki, in: Kniga fanfikov, http://ficbook.net/readfic/754107 (09.09. 2013).

33 User „Ore.sama :3“: Poterjano navsegda, in: Kniga fanfikov, http://ficbook.net/readfic/ $843363(09.09 .2013)$. 
Die starke Erotisierung in der Fan Fiction dürfte als provozierende Profanierung der Klassik die stärksten kulturkritischen Reaktionen auf den Plan rufen. ${ }^{35}$ Die Fans sind sich der Ambivalenz ihres Unterfangens selbst durchaus bewusst. „Dostoevskij möge mir verzeihen“, kommentiert etwa User „Tindin“ sein Slash-Drama in drei Teilen und im Umfang von immerhin neun Seiten. ${ }^{36}$ Auffällig ist andererseits die besonders starke Anbindung der pornographischen Profanierung an die etablierten literarischen Kanones, wie bereits die russische Kulturkritikerin und Netzliteratin Linor Goralik in ihrer Studie zur Fan Fiction konstatiert. ${ }^{37}$ Der „Dark room“ der Klassik reproduziert in seiner Textauswahl den offiziell etablierten Kanon, auch wenn er diesen radikalen Transformationen unterwirft.

\section{\#Dostoevskij twittern. Mediales Genre Shifting}

Eine besondere Form der Fan Fiction in Form eines Genre Shifting stellen Twitter-Adaptionen der Texte und der Autor-Persona Dostoevskijs dar. Die Werke werden hier nicht aus einer literarischen Gattung, sondern aus einer medialen Umgebung in eine andere versetzt. Ein prominentes Beispiel ist die Publikation von Auszügen aus Dostoevskijs Briefen im Twitter-Format unter@ @Fedor. Dostoevsky, in der gebotenen Kürze der zulässigen 140 Zeichen. Immerhin mehr als 22.000 Follower verfolgen diese Kurznachrichten von Dostoevskijs twitterndem Wiedergänger. Aktualisiert wird der Tweet in lockerer Regelmäßigkeit mehrmals wöchentlich. Die ausgewählten Zitate beziehen sich primär auf Dostoevskijs Kommentare zum Wetter, zu seinem Gesundheitszustand, seiner finanziellen Lage sowie seinen (Schreib-)Hemmungen. Es sind dies also Themen, mit denen sich der typische Twitter-Nutzer zwischen Netz-Bohème und digitalem Prekariat leicht identifizieren kann. Anders als in der klassischen Fan Fiction werden hier also keine literarischen Stoffe weiterentwickelt und Plots weitergeschrieben, sondern Dostoevskij-Zitate durch Überführung in eine andere mediale Umgebung rekontextualisiert und dadurch - ganz im Sinne Aleksromas - in einen neuen globalen Zusammenhang gesetzt.

34 User „Besfamil'naja“: Rodnye duši, in: Kniga fanfikov, http://ficbook.net/readfic/748149 (09. 09.2013).

35 Bei einer strikten Anwendung des neuen russischen Gesetzes, das die Propaganda von Homosexualität vor Jugendlichen unter Strafe stellt, müssten diese Seiten im Übrigen geschlossen werden.

36 User „Tindin“: Spasëš menja?, in: Kniga fanfikov, http://ficbook.net/readfic/1158511 (09.09. 2013).

37 Goralik 2003. 


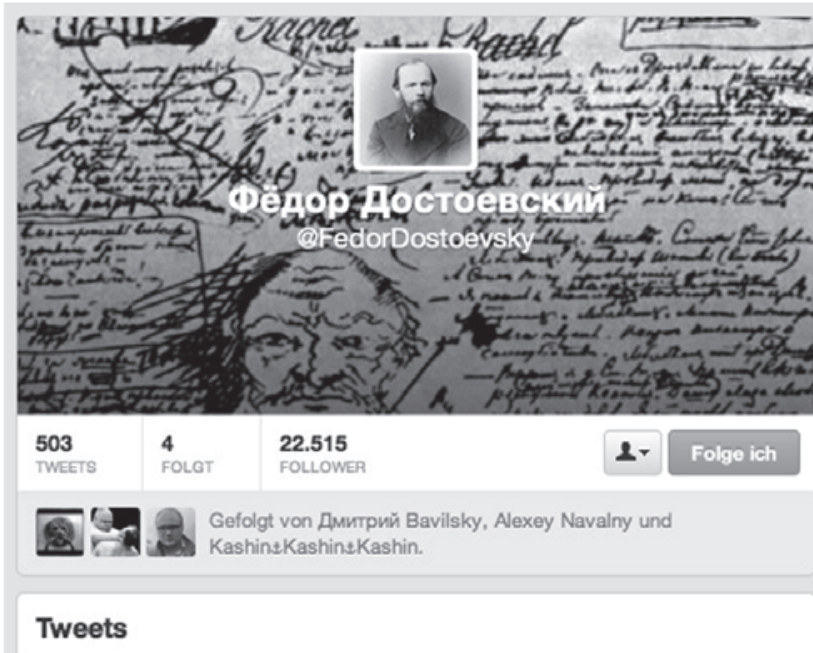

Фёдор Достоевский еFedorDostoevsky

27 Aug

Полагаю, что в сырость я простудился.

Öfnen

Фёдор Достоевский

19 Aug

Но бог выручал нас доселе, и бывали времена и хуже.

Otfnen

Фёдор Достоевский еFedorDostoevsky

Ужасно смущает меня мысль ежедневная: как-то мы устроимся осеныю и на какие средства!

Offnen

Фёдор Достоевский

Чувствую себя несравненно здоровее прежнего: силы, сон, anпетит - все это превосходно.

Offnen

Фёдор Достоевский өFedorDostoevsky

9 Aug

Здоровье мое чрезвычайно укрепилось, хоть я и не потолстел вовсе.

Offnen

Фёдор Достоевский еFedorDostoevsiky

Хватит ли сил и здоровья для таких каторжных занятий, какие я задавал себе до сих пор? Романы оканчивал, а здоровье все-

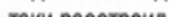

Abbildung 1: Screenshot des Twitter-Accounts @Fedor.Dostoevsky, 03.09.2013 
Ein ähnlicher Dostoevskij-Twitter-Account existiert in englischer Sprache. Hier werden allerdings Text-Splitter aus unterschiedlichen Werken des Autors gepostet. Zudem werden diese explizit als Zitate markiert, unter Angabe der jeweiligen Quelle. Bei den ausgewählten Stellen handelt es sich, in markantem Kontrast zum russischen Mikro-Blog, um besonders deutungsschwere, philosophisch aufgeladene Zitate. Während der englische Twitter-Dostoevskij also das kanonische Werk im Blick hat, lässt seine russische Entsprechung die Autoren-Persona in ihrer rührenden, bisweilen komischen oder melancholischen Menschlichkeit aufscheinen. Mit rund 1.200 Followern weist der englischsprachige Mikro-Blog als gezwitscherte Aphorismen-Sammlung im Vergleich zum russischen Äquivalent mit seiner zeitgenössischen Individualisierung der Dichter-Persona eine deutlich geringere Popularität auf.

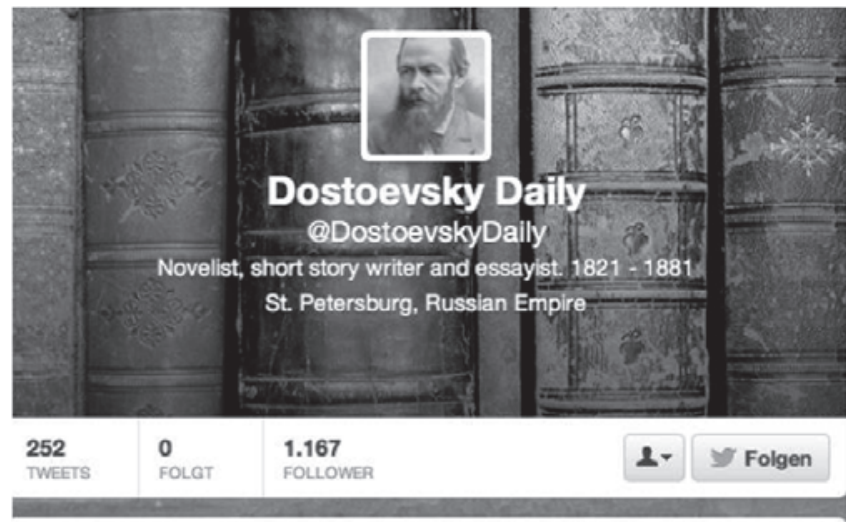

\section{Tweets}

Dostoevsky Daily eDostoevskyDaly

"They have succeeded in accumulating a greater mass of objects, but the joy in the world has grown less." Fyodor Dostoyevsky \#LaborDay

Otfnen

Dostoevsky Daily eDostoevshyDally

"We have all lost touch with life, we all limp, each to a greater or lesser degree."

- Fyodor Dostoyevsky, Notes from Underground

Offnen

Abbildung 2: Screenshot des Twitter-Accounts @DostoevskyDaily, 03.09.2013 
Die Tagebuch- und Briefkultur des 19. Jahrhunderts erweist sich dann als erstaunlich anschlussfähig an die Netzwerkkultur des 21. Jahrhunderts. Eine vergleichbare Intention weist auch das Projekt pismoteka.ru auf: Hier werden Briefe russischer Schriftsteller des 19. Jahrhunderts auf einer Homepage hypertextuell arrangiert, um deutlich zu machen, wie soziale literarische Netzwerke der vordigitalen Ära funktionierten.

\section{Dostoevskij animiert. Intermediales Crossover}

Fan Fiction beziehungsweise künstlerische Adaptionen des Dostoevskijschen Werks und Wirkens sind gerade im Internet keinesfalls allein Text basiert. Sie umfassen Bildbearbeitungen von Fotografien und Grafiken, eigens erstellte Bilder, Comics, Animationen oder Videoclips. Sie können von Amateuren erstellt werden, wie die klassische Fan Fiction, oder aber auch von ausgewiesenen ComputerSpezialisten und Künstlern. Strukturell und terminologisch bewegt sich diese digitale Rezeption eines Klassikers zwischen Amateur-Kunst und Folklore ${ }^{38}$, Netzkunst und Internet-Memen ${ }^{39}$, mit unterschiedlich starken Markierungen von Autorschaft und Anonymität ${ }^{40}$, individuellem Schaffen und kollektiver Kreativität, künstlerischer Intention und kommerzieller Vermarktung. Im Folgenden sollen einige Aspekte einer solchen visuellen Fan Fiction und netzkulturellen DostoevskijRezeption an ausgewählten Beispielen aufgezeigt werden.

Kirill BADMAN Kalandgis humoreske Video-Clips sind ein typisches Beispiel für die Amateur-Kultur im Netz. Unter der charakteristischen Mischung von Pseudonym und Klarname veröffentlicht BADMAN auf diversen Homepages und Video-Kanälen (Youtube, Viteo) Anekdoten und Witze im Clip-Format. Eines dieser Videos ist explizit dem Roman Schuld und Sühne / Verbrechen und Strafe gewidmet. Es ist angelehnt an die frühe Videospiel-Ästhetik. Der Clip reproduziert diese nicht nur visuell, sondern basiert in seinem Mini-Narrativ und seinem Witz auf der Grundidee der interaktiven Netzkultur, alternative Verläufe einer Geschichte erzählen zu können. Gemäß dieser Vorstellung von spielerischer Netzliteratur, von Espen Aarseth als „ergodic literature“ bezeichnet ${ }^{41}$, wird der Leser

$38 \mathrm{Zu}$ Definition, Abgrenzung und Ausprägungsformen von Folklore und Amateur-Kultur im Internet vgl. Dagmar Burkhart; Henrike Schmidt: „Geht ein Bär durch den Wald“: Zu Status und Varietät der russischen Internet-Lore, in: Zeitschrift für Slavistik 1 (2009), S. 20-43; Mariann Domokos: Folklore and Mobile Communication. SMS and Folklore Text Research, in: Fabula. Zeitschrift für Erzählforschung 48/1-2 (2007), S. 50-59; Folk-art-net. Novye gorizonty tvorčestva: Ot tradicii - k virtual'nosti. Moskva 2007; sowie das Kapitel zur Folklore in Schmidt 2011, S. 248-265.

39 Im Sinne von sich viral verbreitendem Content in Form von - zumeist bearbeiteten - Bildern und Fotografien, Animationen, Video-Clips oder auch sprachlichen Floskeln, die innerhalb kürzester Zeit globale Aufmerksamkeit erreichen.

40 Zur Frage der Autorschaft in der Netzliteratur siehe u.a. Florian Hartling: Der digitale Autor: Autorschaft im Zeitalter des Internets. Bielefeld 2009.

41 Espen J. Aarseth: Cybertext. Perspectives on Ergodic Literature. Baltimore, London 1997. 
zum Mit-Gestalter und hat auf den unterschiedlichen Leveln des als Spiel konzipierten Narrativs die Möglichkeit, verschiedene Handlungen auszuwählen. Kirill BADMAN stellt diese Wahlfreiheit im Umgang mit einem klassischen literarischen Narrativ der russischen Literatur dar. Dabei stehen in seinem Clip Optionen zur Verfügung, die der zugrunde liegende Roman gar nicht enthält, etwa die Flucht vor der eigenen Tat, wie in der Abbildung gezeigt.
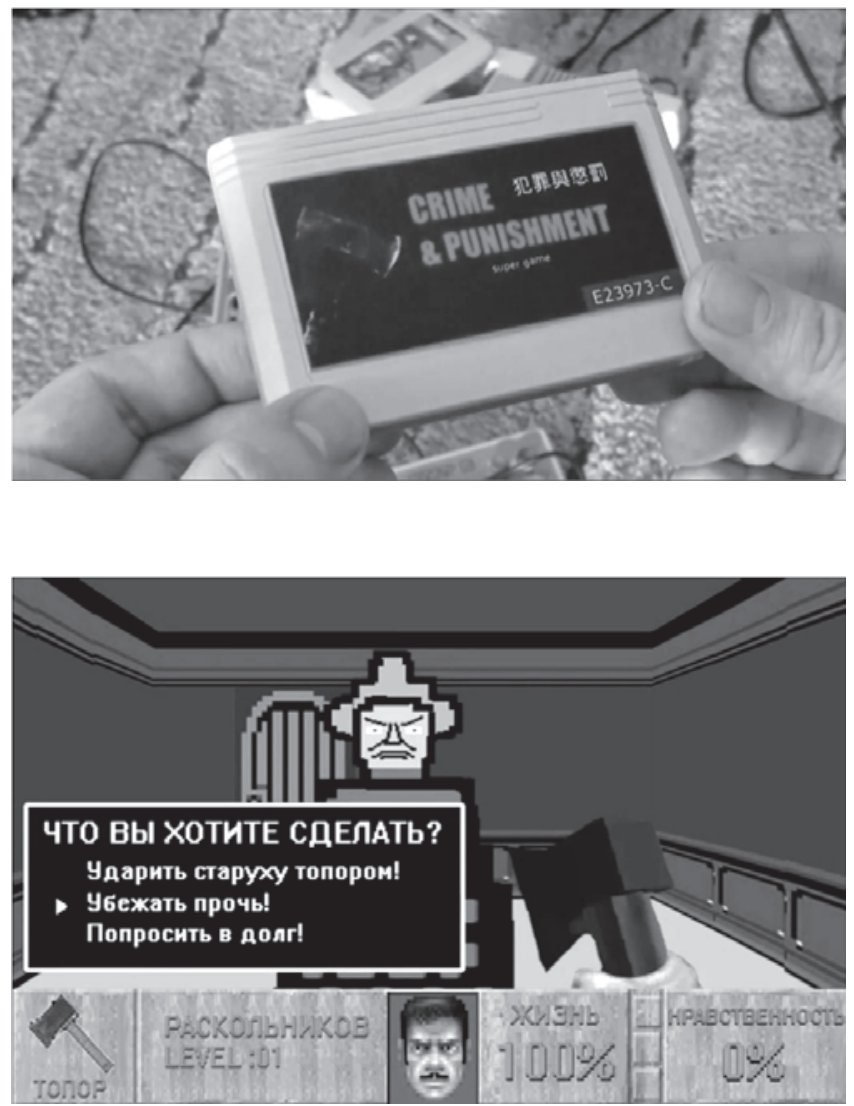

Abbildungen 3 und 4: Stills aus dem Video-Clip Schuld und Sühne auf Dandy (Prestuplenie i nakazanie na Dendi) von Kirill BADMAN Kalandgi, 03.09.2012

In den Clip sind aber nicht nur vom Roman abweichende Handlungsoptionen eingebaut, sondern auch die Personencharakterisierungen und Settings unterscheiden sich vom Original. Die Intention des Videos scheint sich damit im Kon- 
text der „alternativen Geschichte“ zu bewegen, der Lust am narrativen Austesten variabler Erzählverläufe. Umso überraschender kommt daher der Schluss-Appell Kirill BADMANs an den Zuschauer, die Klassik doch lieber im Original zu lesen, um den authentischen Handlungsverlauf kennenzulernen. Es handelt sich also um eine als Computerspiel verkleidete didaktische Geste zur Popularisierung des "guten alten Buchs“. Und als solche widerspricht sie populären Befürchtungen einer Verdrängung der Buchkultur durch die sogenannten neuen Medien. Der „Autor" BADMAN nimmt auf seiner Homepage dazu Stellung und erklärt den ihm selbst offensichtlich leicht befremdlichen Impuls - seinerseits als Form der Kulturkritik. Bei seinen Fahrten in der Metro sehe er nur noch Menschen, die Krimi-Trash à la Darja Doncova läsen, was ihn zu seinem aufklärerischen SpaßVideo inspiriert habe. ${ }^{42}$ Es ist hier gerade das Internet, das die Hochkultur vor dem Trash rettet - eine ungewohnte Allianz.

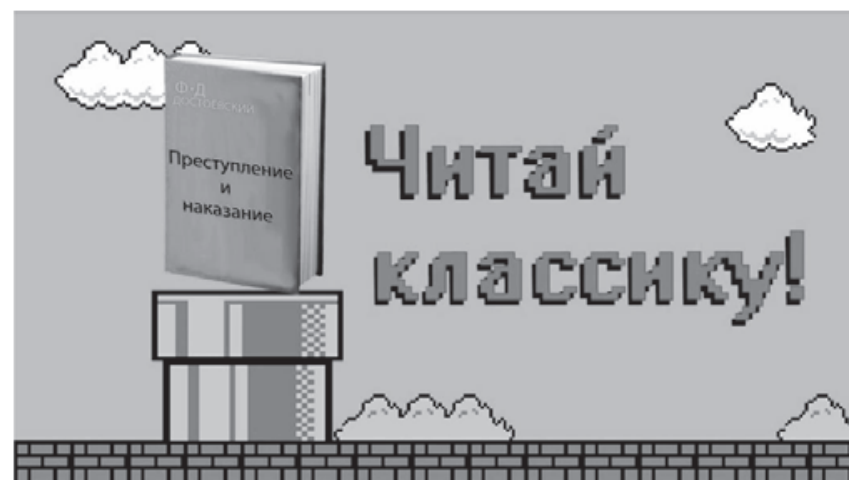

Abbildung 5: „Lies’ die Klassik“. Still aus dem Video-Clip Schuld und Sühne auf Dandy (Prestuplenie i nakazanie na Dendi) von Kirill BADMAN Kalandgi, 03.09.2012

Das Prinzip der „alternativen Geschichte“ kennzeichnet nicht nur diesen Clip oder die schriftliche Fan Fiction. Es liegt auch der Dramaturgie einer weiteren filmischen Umsetzung des gleichen Romans von Fëdor Dostoevskij im Format der Animation zugrunde. Der von den Toonbox Good Animation Studios präsentierte Clip erzählt die Geschichte des Romans zunächst in aller Kürze, aber stringent in seinen Kernszenen nach. ${ }^{43}$ Neben der Tat selbst werden atmosphärische Details

42 Kirill BADMAN Kalandgi, Kommentar zum Video-Clip Schuld und Sühne auf Dandy http:/ / www.badmanhumor.ru/index.php?option=com_content\&view=article\&id=61:1-r-\& catid=2:2010-09-06-13-35-19\&Itemid=5 (09.09.2013).

43 Die Serie umfasst (http://www.toonbox.ru/movies/6) insgesamt sechs animierte Video-Clips, aus dem russischen Kontext treten neben Dostoevskijs Raskolnikov die Figuren A.S. Puškin und Čapaev in alternativen Geschichtsverläufen auf. 
wie auch Seitenstränge der Erzählung in präziser Raffung und in ästhetisch überzeugenden Bildern dargeboten. Zu erwähnen wären etwa die delirierenden Fieberfantasien Raskolnikovs, insbesondere aber die Episode des Pferdchen-Traums, in dem Rodion sein als Kind erlittenes Trauma einer unmenschlichen Gewalttat am Tier wiederträumt.

Neben diesen präzis in Anlehnung an das Original wiedergegebenen Szenen finden sich in der visuellen Gestaltung Anklänge an die Gegenwartskultur, insbesondere über Fußball-Graffiti in den morbid gestalteten, für den Roman so charakteristischen Treppenaufgängen. Im visuellen Detail kommen das literarische Narrativ und die zeitgenössische Realität zueinander. In der Schlussszene des Mords, hier am Ende des Clips positioniert, wird dann eine überraschende Wende vorgenommen: Die hilflose alte Pfandleiherin entpuppt sich nämlich in dem Moment, in dem sie den tödlichen Schlag empfängt, als durchaus wehrhaft. Sie schlägt zurück und den „Hacker“ Raskolnikov in die Flucht. „Die Geschichte hätte auch anders enden können“, lautet der programmatische Slogan in der Abblende.

Dreierlei ist an diesem Clip bemerkenswert: Erstens die visuelle Ästhetik, die das Dostoevskijsche Petersburg adäquat in die Welt der Animation und des Comics transponiert. Zweitens das erzählerische Prinzip der „alternativen Geschichte“, das für die Fan Fiction generell von zentraler Bedeutung ist beziehungsweise ihre Entstehung genuin motiviert. Bei diesem künstlerisch gestalteten Clip handelt es sich allerdings um ein professionell produziertes, kommerzielles Werbe-Produkt der russischen Firma für Anti-Viren-Schutz Kaspersky. Damit kommen wir zum dritten zentralen Punkt: nämlich der inhaltlichen Überblendung des Narrativs des Romans und seines zentralen Protagonisten mit der digitalen und der Netzkultur. Der nihilistische Raskolnikov gilt in der Tat in manchen feuilletonistischen Kommentaren zum Internet als Projektionsfigur für jugendliche Hacker, die ihre Allmacht im ,virtuellen Untergrund' erproben wollen. Diese Überblendung ist weniger durch die Handlung des Romans motiviert, als vielmehr durch die Psychologisierung der Figur sowie den semantischen Kern des sprechenden Namens Raskolnikov. Die Idee des Spaltens und Zerschlagens ist anschlussfähig an die Semantik des „Hackens“ im Sinne des Knackens von Computercode. 

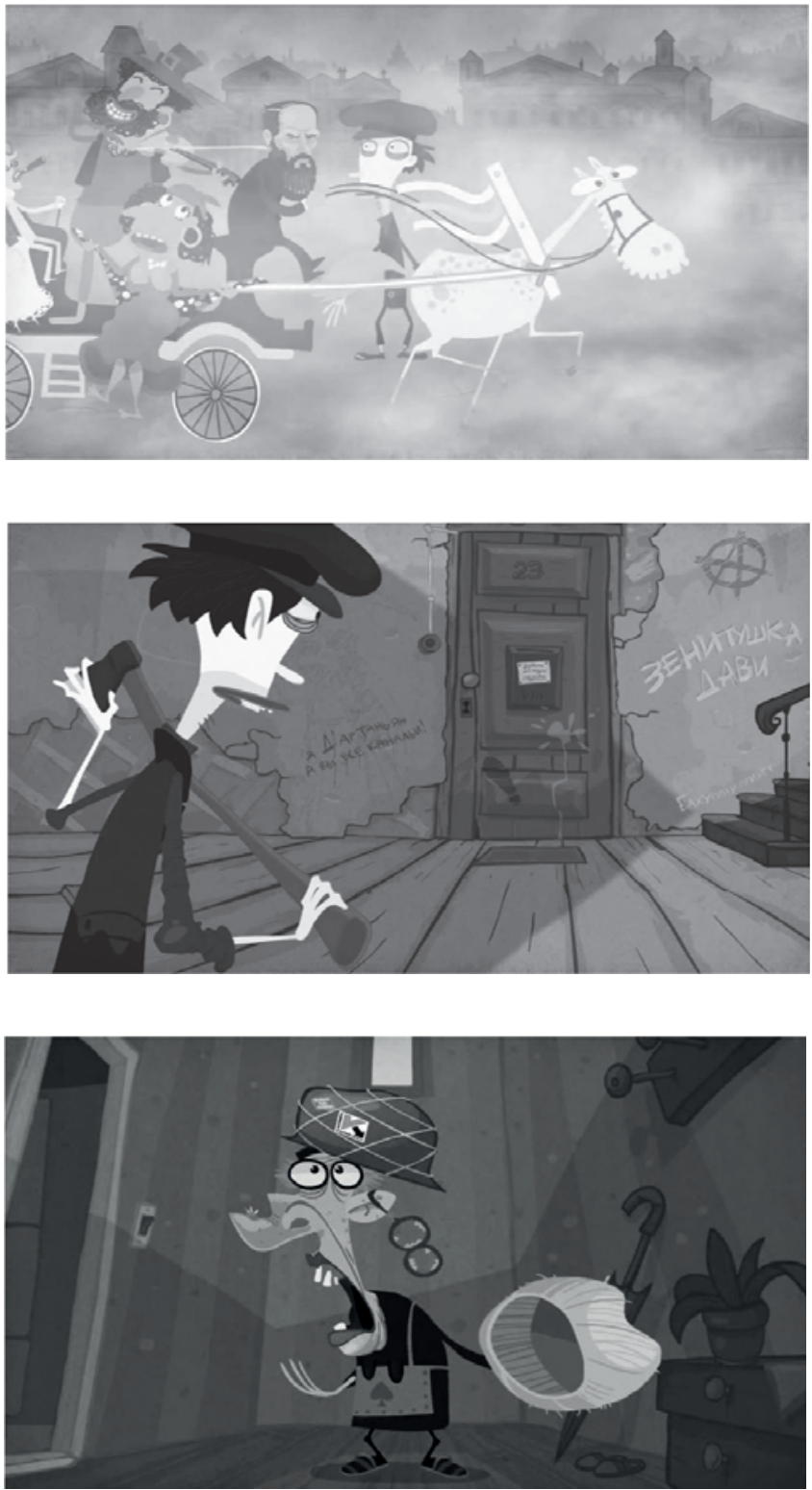

Abbildungen 6 bis 8: Stills aus dem Video der Toonbox Animation Studios Alternative Geschichte. Raskolnikov (Alternativnaja istorija. Raskolnikov), 03.09.2013 
Eine explizit künstlerische Bearbeitung von Dostoevskijs Leben und Werk in ihrer spezifischen Überblendung stellt das Projekt des Animationskünstlers Ėduard Časovitin dar, der auf seiner Website Dostoevkij-Cartoons, Animationen und schließlich auch einen Fanartikel-Shop beherbergt. ${ }^{44}$

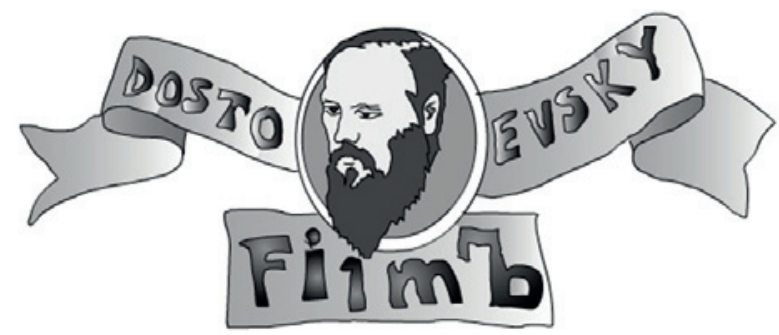

Abbildung 9: Logo der Website des Animationskünstlers und Regisseurs Ėduard Časovitin mit Dostoevskij-Cartoons, Animationen und Fanartikel-Shop http://www.adiart.spb.ru/, 03.09.2013

Hier finden sich Comic-Strips und kurze Animationsfilme, die Dostoevskij in zeitgenössischer Umgebung u.a. beim Arbeiten am Plot eines zukünftigen Romans zeigen. In einem gewagten Crossover von Leben und Werk setzt der Künstler Autor und Werk zueinander in Bezug und positioniert sie im Umfeld des zeitgenössischen Underground der kleinen Dealer und Prostituierten. Er schickt den Romanautor des 19. Jahrhunderts auf diverse Reisen durch die heutige Welt Russlands (nach Suzdal, auf eine Wolga-Kreuzfahrt) wie des europäischen Auslands (London, Brügge, Venedig). Und dokumentiert diese Expeditionen in die Gegenwart in Form von Bild-Geschichten, die in sehr freiem Anklang an Dostoevskijs eigene Reisetagebücher stehen. Er lässt den Autor sozusagen seinen historischen ,Trip“ nach London aus dem Jahr 1861 wiederholen, dessen düstere Eindrücke in den Winteraufzeichnungen über Sommerereignisse (Zimnye zametki o letnych vpečatlenijach, 1862) niedergelegt sind. Zwei „Stationen“ dieser Bilderreise Dostoevskijs nach London sollen genauer in den Blick genommen werden: ${ }^{45}$

44 Ich verdanke diesen Hinweis auf das Dostoevskij-Projekt Časovitins dem Artikel von Vlad Strukov (2009), in dem auch erste Interpretationsansätze vorgestellt werden, die ich hier fortsetze. Vgl. auch Anna Aslanyan: A Contemporary Classic, in: Russia Profile.org, 09.06.2011, http://russiaprofile.org/culture_living/44717/print_edition/ (09.09.2013); R.N. Morris: The day I met Dostoevsky, in: Bloody Blog, 08.08.2011, http://rogernmorris.co.uk/the-day-i-metdostoevsky/ (09.09.2013).

45 Ėduard Časovitin: Dostoevsky \& Banksy, The London Trip, in: Dostoevskij Film, http:// www.adiart.spb.ru/london/index.html (09.09.2013). 


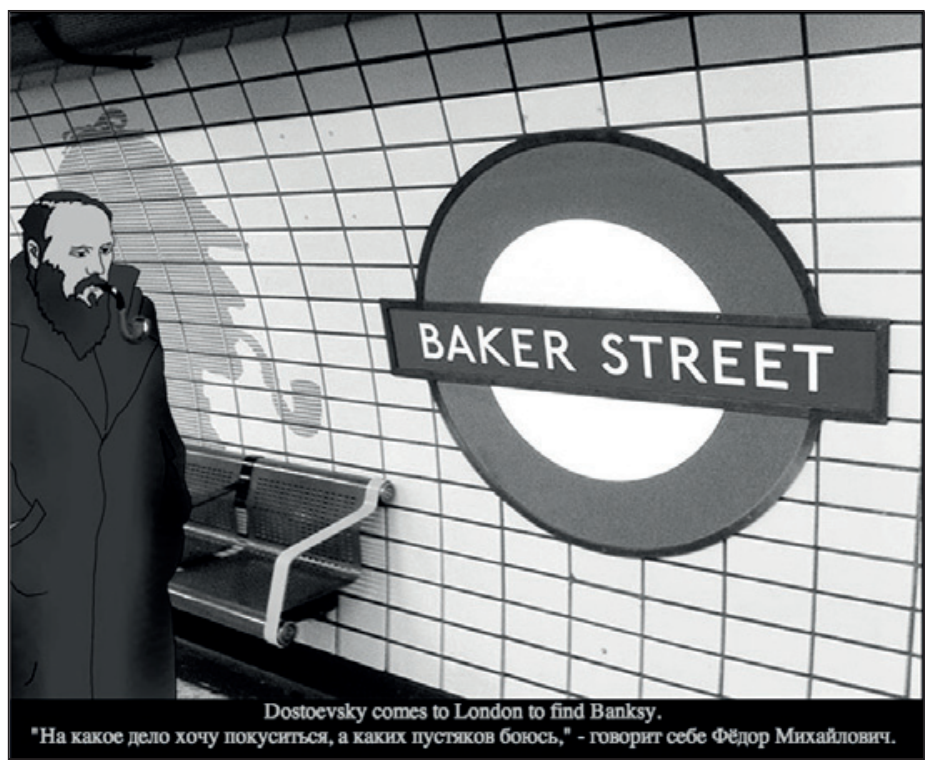

Abbildung 10: Station aus der Bild-Geschichte „Dostoevskij in London“ des Animationskünstlers und Regisseurs Ėduard Časovitin http://www.adiart.spb.ru/, 03.09.2013

In der ersten hier abgebildeten Collage steht die Trick-Figur Dostoevskij in der Londoner Tube an der Station Baker Street. Über seine literarischen Darstellungen der Abgründe des urbanen Frühkapitalismus sozusagen mit „street credibility“ ausgestattet, will der Literat hier an der Themse den mysteriösen zeitgenössischen Street-art-Künstler Banksy treffen. Im Hintergrund ist der Schatten Sherlock Holmes an der Wand zu sehen (im Übrigen eine Lieblingsfigur der Fan Fiction, deren Kriminal-Fälle in unzähligen Varianten weitergeschrieben werden). Unterlegt ist die Collage mit einem Raskolnikov-Zitat aus Schuld und Sühne / Verbrechen und Strafe, das hier aber dem Autor Dostoevskij in den Mund gelegt wird. Časovitin nimmt hier mithin einen bemerkenswerten Crossover vor zwischen Werk und Leben, empirischem Autor und Autor-Persona, Romancier und Street-art-Künstler, russischer und englischer Literatur, der Gattung des Reisetagebuchs und des Kriminalromans. 


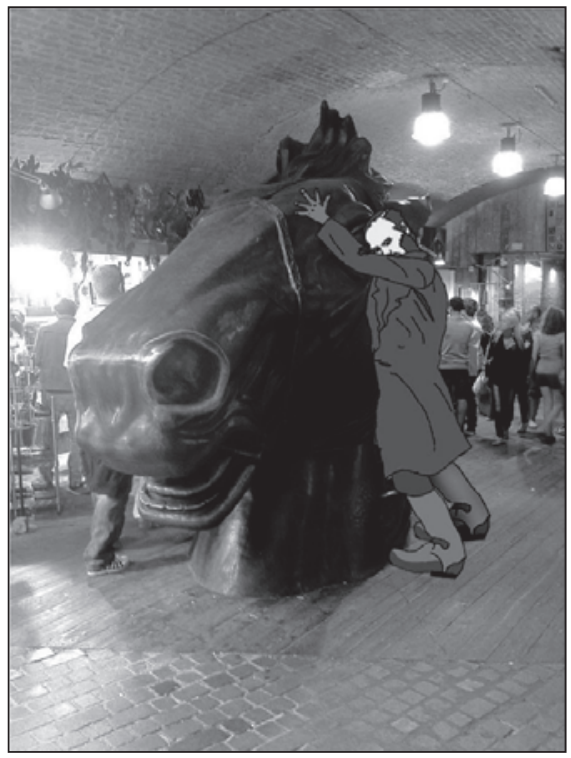

Abbildung 11: Station aus der Bild-Geschichte „Dostoevskij in London“ des Animationskünstlers und Regisseurs Ėduard Časovitin http://www.adiart.spb.ru/, 03.09.2013

In der zweiten Bild-Collage wird der Comic-Dostoevskij in ein Foto der HorseMarket-Tunnels in Camden, London, montiert. Die so verzweifelte wie mitleidende Geste hin zum Pferdekopf ruft das Motiv des Pferdchen-Traums aus Schuld und Sühne / Verbrechen und Strafe erneut auf. Weitere intertextuelle Referenzen sind denkbar, etwa auf das Turiner Pferd, also die weithin kolportierte Anekdote von Nietzsches Nervenzusammenbruch in Turin angesichts eines gequälten Kutschpferds. Das Ergebnis ist eine reizvolle Mischung diverser intertextueller Verweise, eine schöne motivische Reminiszenz auf die literarischen Beziehungen zwischen zwei Autoren, über deren kontaktologische wie geistesgeschichtlich-motivische Verbindungen viel geschrieben und spekuliert worden ist. ${ }^{46}$

Die einzelnen Sujets und visuellen Adaptionen bleiben dabei in ihren Bezügen immer rätselhaft, lassen sich nicht im Detail entschlüsseln und bilden so in ihrer Gesamtheit einen neuen Dostoevskij-Kosmos. Časovitin will nach eigener Aussage die Aktualität des Dostoevskijschen Werks und insbesondere seiner ethischen Maximen an der Gegenwart überprüfen ${ }^{47}$, wie dies auch Aleksroma in seiner

46 Vgl. etwa Renate Müller-Buck: „Der einzige Psychologe, von dem ich etwas zu lernen hatte“:

Nietzsche liest Dostojewskij, in: Dostoevsky studies. New Series, 6 (2002), S. 89-118.

47 In R.N. Morris 2011. 
„Nachrichten-Ticker“ Version des Idioten angekündigt hatte. Interessanterweise beschäftigen sich beide Künstler auch mit der buchstäblichen Grundlage des Dostoevskijschen Schaffens, in dem sie nämlich mit dem Wechsel zwischen kyrillischem und lateinischem Alphabet spielen. Für Aleksroma steht die latinisierte Variante des Romans für dessen Globalität. Časovitin erprobt das Verfremdungspotenzial im Spiel mit den unterschiedlichen Alphabeten in Titeln und ComicSprachblasen. So betitelt er einen Mini-Clip, in dem Dostoevskij nach dem Thema eines neuen Romans sucht, als „The New Roman“ und mixt dabei die englische und die russische Bedeutung des Worts (Roman), überblendet also die Frage nach einer neuen Gattungsästhetik mit typografischer Satztechnik. ${ }^{48}$ Oder er legt seiner Dostoevskij-Animation den grammatikalisch verfälschten Slogan „I am gratefool“ in den Mund, in dem die Ethik des Romans Der Idiot - als in seiner Naivität und Aufrichtigkeit "großem Narren“ - komprimiert enthalten ist. Schließlich überprüft Časovitin auch praktisch den aktuellen Marktwert des Klassikers, indem er in einem Online-Shop Dostoevskij-Shirts, Tassen und Postkarten verkauft. ${ }^{49}$ Die visuellen Motive setzen den intertextuellen, visuellen Crossover fort, wenn Dostoevskij á la Warhol vervielfältigt wird oder á la Magritte seine Filzstiefel in den Himmel steigen.
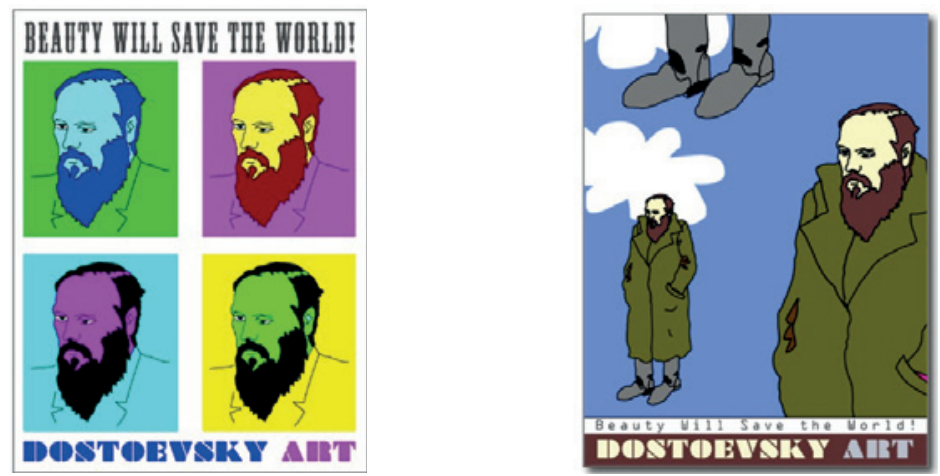

Abbildung 12 und 13: Screenshots des Internet-Fanartikel-Ladens des Animationskünstlers und Regisseurs Ėduard Časovitin http://www.adiart.spb.ru/, 03.09.2013

48 Ėduard Časovitin: THE NEW ROMAN, in: Dostoevskij Film, http://www.adiart.spb.ru/d_ roman.html (09.09.2013).

49 Ėduard Časovitin: Dostoevsky Art Shop, http://www.zazzle.com/dostoevsky_by_magritte_ postcard-239332927513253418 (09.09.2013). 


\section{Polyphonie im Roman - Vielstimmigkeit im Netz?}

Der hier dargestellte eher kursorische als systematische Durchgang durch virtuelle Interpretationen des Werks Dostoevskijs macht eines deutlich: Die Adaptionen erfordern solide Textkenntnisse, bei Schreibenden wie Lesenden. Die porträtierten Projekte haben (mindestens) zwei Intentionen und Effekte:

Erstens reinszenieren sie das Werk und Wirken Dostoevskijs in neuen Kontexten, entweder durch eine narrative Fortschreibung oder durch eine neue mediale Rahmung. Im Sinne Aleksromas testen sie damit die Anschlussfähigkeit des Dostoevskijschen Oeuvres an die Gegenwart, sei es in Hinblick auf die Stoffe und Figuren in der Fan Fiction im engeren Sinn, sei es in Hinblick auf die Schrift- und Kommunikationskultur im Zeitalter des Digitalen. Die medialen Genre-Wechsel weisen im Vergleich zur literarischen Fan Fiction ein höheres Reflexionsniveau auf und einen stringenteren konzeptionellen Ansatz. Sie sind zumeist weniger kitschig, sentimentalistisch, romantisch oder obszön. Wie auch immer man jedoch im Einzelnen zu den jeweiligen Formen der Fan Fiction stehen mag: Sie erfordert in ihren naiven wie selbstreflexiven Ausprägungen ein hohes Maß an Text- und Werkkenntnis, unter Schreibenden/Gestaltenden wie Lesenden/Rezipierenden. Eine kulturpessimistische Position, gemäß derer die digitalen Medien das Ende der Literatur im klassischen Sinne bedeuten, lässt sich in dieser Plakativität nicht halten. Charakteristisch ist in diesem Sinne der Amateur-Clip von Kirill BADMAN, der den Video-Clip nutzt, um für das Buch zu werben.

Zweitens wird die Verfügungsmacht über den Kanon von den zentralen staatlichen und kulturellen Instanzen auf den individuellen Leser übertragen. Strukov unterstreicht diesbezüglich die subversiven Elemente einer Kanon-Dekonstruktion. Der Blick in die "feuchten Keller" des Internet (Shillingsburg) macht jedoch deutlich, dass sich hier vielfach auch kanonische Lesarten manifestieren, die in ihrer Naivität bestehende kulturelle Normen eher stützen als dekonstruieren. Eine eindimensionale Bewertung der Impulse, die das Netz für eine (Re-)Lektüre der Klassik geben $\mathrm{kann}^{50}$, lässt sich also schwerlich formulieren. Während das Projekt, Dostoevskijs Romane im Ticker-Format zu medialisieren, bewusst „idiotisch“ bleibt, erweist sich das Twitter-Format als ausgesprochen passend für eine Aktualisierung der Gattung des Epistolarischen und erreicht mit über 20.000 Followern beeindruckende Leser-Zahlen. Festhalten lässt sich in jedem Fall, dass sich ein Forschungsfeld auftut, das bis dato weitgehend vernachlässigt worden ist. Eine empirisch basierte Studie etwa der Kommentare der Leser/innen in den virtuellen Bibliotheken verspricht wichtige literatursoziologische Einsichten. Selbiges

50 Siehe zur Fan Fiction Forschung mit Bezug auf die russische Kultur aktuell das Themenheft Digital fandom and media convergence. Edited by Sudha Rajagopalan and Ksenia prasolova. Digital Icons. Studies in Russian, Eurasian and Central European New Media, 10 (2013), http://www.digitalicons.org/issue10/editorial/. 
gilt für die Fan Fiction und die kreativen künstlerischen Adaptionen des Dostoevskijschen Oeuvres.

Fan Fiction und Netzkunstwerke schreiben nicht nur die Werke Dostoevskijs fort. Auch andere russische Klassiker bevölkern das Runet, seine Bibliotheken, privaten Homepages, Video-Portale, Blogs und sozialen Netzwerke. Eines der frühesten russischen Netzkunstwerke stammt von der bekannten Medientheoretikerin Olia Lialina und ist Lev Tolstojs Roman Anna Karenina gewidmet. ${ }^{51}$ Ließe sich dennoch mindestens hypothetisch eine besondere Beziehung zwischen dem Internet und der Poetik der Werke Dostoevskijs annehmen? Der Literat und künstlerische Netz-Aktivist Dmitrij Bykov scheint dies zu vermuten, wenn er im Jahr 2005 schreibt: „Es wäre keine große Übertreibung zu sagen, dass es Fëdor Michajlovič war, der das Rulinet [das russische literarische Internet, H.S.] bereits 150 Jahre, bevor es entstanden ist, erfunden hat" ${ }^{\text {". }}$ In den blassen Bloggern, die in den zahlreichen Web-Foren ihre zynischen Kommentare hinterlassen, sieht er würdige Nachfolger des Untergrund-Menschen. Die Journalistin Sonja Margolina hat bereits in den 1990er Jahren zur Charakterisierung russischer Hacker auf die literarische Figur des Raskolnikov zurückgegriffen. ${ }^{53}$ Es gibt also wenigstens in feuilletonistischen Darstellungen eine gewisse Neigung, das Internet als „kulturellen Untergrund" zu sehen, dessen Funktionsweisen sowie die Psychologien seiner Protagonisten sich im Rückgriff auf Dostoevskij erhellen ließen. Soweit zur Ebene der Beschreibung und der Metaphorik. Bezüglich der Ebene der Textproduktion und ihrer Poetik lässt sich die These aufstellen, dass Fan Fiction eine motivische und stoffliche Offenheit der adaptierten Werke erfordert, wie sie gerade dem Roman-Werk Dostoevskijs in seiner Bachtinschen Polyphonie eignet. Mit einem gewissen Grad an Zuspitzung ließe sich also formulieren: Die Vielstimmigkeit und Polyphonie, die Michail Bachtin in seiner berühmten Studie für die Prosa Dostoevskijs konstatiert, ${ }^{54}$ harmoniert mit der Vielstimmigkeit des heterogenen Internet. Die von Bachtin gleichfalls konstatierte Emanzipation des literarischen Helden von seinem Autor ist vielleicht eine ästhetisch-poetische Eigenschaft, die gerade Dostoevskij für die Fan Fiction, sei sie nun literarisch oder visuell, so besonders anschlussfähig macht.

51 Siehe Sylvia Sasse: „Anna Karenina goes to Paradise“ neben anderen Illusionen von der „Elektrifizierung des ganzen Landes“, in: Diss.cetera / OstWEB 2001, http:/www.dis sense.de/km/sasse.html (20.03.2009).

52 Dmitrii Bykov: Dostoevsky and the Psychology of the Russian Literary Internet, in: Russian Studies in Literature, v. 41, no. 2 (2005 Spring), S. 64-74, hier S. 64-65.

53 Sonja Margolina: Dostojewskis Erben. Raskolnikow knackt den Microsoft-Code: Rußlands junge Elite, in: Frankfurter Allgemeine Zeitung, 14.11.2000, Nr. 265, S. 56.

54 Michail Bachtin: Problemy poètiki Dostoevskogo. In: Ders.: Sobranie sočinenij v semi tomach. Tom 6. Moskva 2002. [1963] 


\section{Jörg Pottbeckers}

\section{Die Spielerin, der Verführer und der Mann, der die Welt verkaufte. Zur Dostojewskij-Rezeption im zeitgenössischen Film ${ }^{1}$}

Die zugegebenermaßen etwas unklare Formulierung der ,Dostojewskij-Rezeption im Titel ist durchaus bewusst so gewählt worden und zwar aus zwei Gründen: Zum einen, um dem uferlosen definitorischen Exkurs, was denn nun eine Literaturverfilmung eigentlich genau sei, aus dem Weg zu gehen. Und zum anderen, da es im Folgenden auch um solche Filme gehen soll, die nicht direkt auf einem Text von Dostojewskij basieren (oder von einem solchen inspiriert wurden), nach konventionellem Verständnis also keine Literaturverfilmungen sind, bei denen die Person Dostojewskij oder sein Werk dennoch im wahrsten Sinne des Wortes eine Rolle spielen. Ich versuche eine Präzisierung, inhaltlich wie definitorisch: Bereits der Begriff ,Literaturverfilmung ' impliziert ein gewisse Negativwertung, wird er doch häufig als Ausdruck eines alten bildungsbürgerlichen Vorurteils verstanden, ein literarisches Werk könne in seiner filmischen Version nur verfälscht oder bestenfalls verstümmelt erscheinen. Insbesondere im Dostojewskij-Kontext erscheint der Terminus ohnehin völlig deplatziert, suggeriert er doch, man könne die enorme Vielschichtigkeit seiner Texte quasi eins zu eins in ein alternatives Medium transportieren. Möglicherweise liegt hier (und zwar nicht nur auf Dostojewskij bezogen) auch eine Ursache für die immer noch recht weit verbreitete Einstellung im literaturwissenschaftlichen Umgang mit Verfilmungen, ihnen eine grundsätzliche Minderwertigkeit im Vergleich zum Buch zu unterstellen. Es verwundert daher kaum, dass Studien unter dieser Prämisse oft zu wertenden Vergleichen mutierten, die in den meisten Fällen zu Ungunsten der Filmversion ausfallen. Der recht konservativ klingende Begriff der Werktreue - der heutzutage wissenschaftlich kaum noch laut ausgesprochen wird - steht hier als Bewertungskriterium eigentlich immer noch im Raum; und sei es lediglich auf Rezeptionsebene durch Kommentare wie „Das war im Buch aber ganz anders“.

An die Stelle des Werktreue-Begriffs sind inzwischen andere getreten: Adaption, Transformation und Aktualisierung, um nur die drei gängigsten zu nennen. Unproblematisch ist allerdings keiner dieser Begriffe - der fachterminologische

1 Der Vortrag wurde am 08. September 2012 auf der Tagung der Deutschen DostojewskijGesellschaft in Loccum gehalten. Die nachträglich eingefügten Fußnoten im Vortragstext sind als bloße Literaturhinweise zu verstehen, nicht als wissenschaftlicher Apparat. 
Gebrauch von Adaption ist beispielsweise durch die Alltagssemantik mitbestimmt: die Adaption eines Werkes der Kunst durch eine andere Kunstgattung oder eine andere Kunstform läuft immer Gefahr, lediglich als Anpassung missverstanden zu werden, was zugleich Hochschätzung der Vorlage und Abwertung der Adaption impliziert. ${ }^{2}$ Auch der Terminus ,Transformation' stiftet latente Verwirrung, suggeriert er doch die Möglichkeit einer Veränderung lediglich des Mediums bei Beibehaltung des Inhalts. Tatsächlich wird in der Forschungsliteratur zur Transformationsanalyse mit dem schillernden Begriff der ,Botschaft ${ }^{\star}$ eines literarischen Werkes argumentiert, die es in das filmische Medium zu transformieren gelte. Die Verfilmung kann, vereinfacht gesagt, die „analoge Wiedergabe [...] einer bereits bestehenden literarischen Botschaft“ anstreben oder „selbst eine originäre Botschaft" formulieren. ${ }^{3}$ Der Terminus ,Botschaft' ist allerdings ebenso problematisch wie sein Pseudo-Synonym ,Autorintention' und wirft natürlich grundsätzlich die Frage auf, was denn nun die Botschaft beispielsweise eines Dostojewskij-Romans sein mag.

Neutraler, weil vielschichtiger tritt der Terminus ,Aktualisierung auf, der lediglich als Oberbegriff für eine potentielle Vielfalt an Änderungen im Vergleich zur literarischen Vorlage fungiert - und Zeit wie Ort ebenso meinen kann wie Kostüme, Musik oder die Figurenkonstellation. Gemeinsam ist allen Begrifflichkeiten aber der Versuch, eine Skala unterschiedlicher Relationen zwischen Vorlagentext und Film abzudecken, ohne damit zwangsläufig eine wie auch immer geartete qualitative Wertung vorzunehmen. Diese Skala reicht, grob gesprochen, von einer lediglich die Literatur illustrierende, also bebildernden Funktion des Films, über eine mehr inspirierende Kausalbeziehung zwischen beiden Medien bis hin zum Konzept der filmischen Eigenständigkeit, bei dem zumeist die Hinweise auf den literarischen Bezugtext im Vor- oder Abspann fehlen. Kurz gesagt: Die Skala geht von ganz nah am Text bis ganz weit weg.

Wie aber wurde Dostojewskij bisher überhaupt verfilmt? Und wie sieht die filmische Dostojewskij-Rezeption heute aus? Man kann zunächst und grob vereinfachend zwei Ausrichtungen unterscheiden. Die meisten Filme belassen die Handlung im originären historischen Kontext (in der zweiten Hälfte des 19. Jahrhunderts) und rekonstruieren die "Originalschauplätze" der Romane, also Petersburg, das russische Provinzstädtchen oder ähnliches. Damit ist aber natürlich noch nichts über den Umgang mit dem Vorlagentext ausgesagt, der jeweils unterschiedlich verändert, gekürzt, ergänzt werden kann. Die zweite Gruppe von Filmen versetzt das Sujet in eine andere Zeit oder an einen anderen Ort, zumeist beides. Diese Gruppe macht nicht zuletzt durch ihre divergierende Vielfalt terminologisch

2 Vgl. Wolfgang Gast: Grundbuch. Einführung in Begriffe und Methoden der Filmanalyse, Frankfurt am Main 1993, S. 45.

3 Vgl. Michaela Mundt: Transformationsanalyse. Methologische Probleme der Literaturverfilmung, Tübingen 1994, S. 38. 
die größten Schwierigkeiten, sie enthält zugleich aber die vielschichtigsten Filme. Wie also soll man sie nennen?

Ein kurzer Blick auf die jüngsten Publikationen zum Thema Dostojewskij und Film soll auch die einführende Problematik illustrieren, die die Rede von der Literaturverfilmung und verwandten Begriffen mit sich bringt. Als eine „Pionierleistung ersten Ranges“ bezeichnete Hans-Jürgen Gerigk (zweifellos zu Recht) die wohl jüngste Publikation im deutschsprachigen Raum, nämlich Dunja Brötz 2008 erschienene Untersuchung „Dostojewskijs ,Der Idiot‘ im Spielfilm. Analogien bei Akira Kurosawa, Sasa Gedeon und Wim Wenders. ${ }^{" 4}$ Der recht vage Begriff der ,Analogien' im Titel verdeutlicht bereits, dass Brötz sich weniger den traditionellen filmischen Dostojewski-Adaptionen widmet, sondern vielmehr den kaum offensichtlichen, oder anderes formuliert: den Dostojewskij-Verfilmungen, die nach konventionellem Verständnis gar keine sind. Über den Wim Wenders-Film The Million Dollar Hotel bemerkt Brötz in ihrer Einleitung programmatisch: „Wim Wenders Film hat keinerlei direkten Bezug zu Dostojewskijs Roman. Dies wurde mir, auf meine Nachfrage bei Wenders Images GmbH ausdrücklich versichert." ${ }^{\text {" }}$ Welchen Sinn macht es dann aber, so könnte man fragen, trotzdem nach Analogien zwischen Roman und Film suchen zu wollen? Hierfür muss eine zentrale These der Autorin herangezogen werden, die da lautet: „Parallelen zwischen zwei unterschiedlichen, in verschiedenen Medien entstandenen Kunstwerken müssen nicht notwendigerweise auf direkten nachweisbaren Kontakten beruhen, sondern können auch auf die unbewusste Verwendung ähnlicher, narrativer Basiselemente zurückzuführen sein. “6 Was bedeutet das? Das bedeutet beispielsweise, dass sowohl bei Dostojewskij als auch bei Wenders eine ungeklärte Anfangsszene erst am Ende aufgeklärt wird und bei beiden ein unzuverlässiger Erzähler auftritt, der „nie ganz die Wahrheit sagt und dessen Glaubwürdigkeit bezweifelt werden darf"

Ich möchte keineswegs den Wert der Untersuchung schmälern oder gar in Frage stellen, sondern lediglich auf zwei Probleme hinweisen. Die Rede von der „unbewussten Verwendung ähnlicher narrativer Basiselemente" ist viel zu vage. Werden bei allen unglücklichen Liebesgeschichten dann auch unbewusst narrative Basiselemente aus Romeo und Julia verwendet? Auch die Analogien zwischen Text und Film an der Glaubwürdigkeit des Erzählens selbst festmachen zu wollen, erscheint als viel zu allgemein - oder ist jeder Film, in dem ein unzuverlässiger Erzähler auftritt oder der mit einer ungeklärten Anfangsszene beginnt, gleich eine Dostojewskij-Adaption? Brötz gelingt es zwar durchaus, eine Vielzahl von ihren titelgebenden Analogien aufzuspüren, ohne aber den Eindruck auszuräumen, dass man

4 Dunja Brötz: Dostojewskijs „Der Idiot“ im Spielfilm. Analogien bei Akira Kurosawa, Sasa Gedeon und Wim Wenders, Bielefeld 2008.

5 Ebd., S. 16.

6 Ebd.

7 Ebd., S. 17. 
ähnliches mit ähnlichen (oder vielleicht auch ganz anderen) Filmen ebenso hätte nachweisen können.

Von der gleichen Autorin erschien im vergangenen Jahr ein Aufsatz über Dostojewskijs Roman Schuld und Sühne in jeweils zwei filmischen Adaptionen (The Machinist und Nina); die populärste hiervon ist sicherlich Brad Andersons The Machinist mit Christian Bale in Hauptrolle. Beide Filme, so die Autorin, können "nicht als Literaturverfilmungen im herkömmlichen Sinne bezeichnet werden "8, da sie sich weder an die räumlich-zeitliche Verortung des Romans halten, noch an dessen Handlungsaufbau orientieren und schon gar nicht als bloße Bebilderung der schriftlichen Vorlage fungieren. Mit welchem Terminus aber lassen sich diese Filme dann adaptionstheoretisch verorten? Mit Rekurs auf die Adaptionstypologien von Michaela Mundt kommt Brötz zu dem Schluss: mit dem Konzept der „Eigenständigkeit" ${ }^{\text {"9 }}$, womit gemeint ist, dass der literarische Vorlagentext nur einen Bezugspunkt unter vielen darstellt, Hinweise in Vor- oder Abspann meist fehlen und damit eigentlich kaum noch von einer Literaturverfilmung gesprochen werden kann - wofür man natürlich den Begriff, Literaturverfilmung' auch erst definieren müsste. Einen konkreten Bezugspunkt führt Brötz allerdings sehr wohl auf: der Regisseur des Films, Brad Anderson, bezeichnete in einem Interview Dostojewskijs Werke als wichtigste Inspirationsquelle - freilich nicht für sich selbst, sondern für seinen Drehbuchautor. Dies ist richtig, aber auch verkürzt: tatsächlich nennt der Drehbuchautor Scott Kosar in den DVD-Specials durchaus seinen Haupteinfluss nämlich Dostojewskijs Der Doppelgänger. Entsprechend dünn fallen die Parallelen zu Schuld und Sühne aus, die Brötz herausarbeitet. Wieder wird das unzuverlässige Erzählen bemüht, als handele es sich dabei um etwas Dostojewski-Exklusives. Etwas vage erscheinen auch die Analogien im Hinblick auf die Schuld, die beide Protagonisten auf sich geladen haben. Überzeugend sind allenfalls die Analysen und Parallelisierungen der Traum- bzw. alptraumhaften Sequenzen in Roman und Film. Die beiden Arbeiten verdeutlichen vielleicht aber in erster Linie die Schwierigkeiten, die nicht nur im terminologischen Bereich auftreten, wenn Filme und ihre literarischen Ausgangspunkte in ein Bezugsystem gesetzt werden. Entsprechend vorsichtig werde ich mich zunächst in eine bewusste Unschärfe begeben, lediglich von einer filmischen Dostojewskij-Rezeption sprechen, um erst ganz am Ende diese Thematik nochmals hoffentlich erhellend aufzugreifen - und damit auch den definitorischen Aspekt zugunsten einführender Worte beiseitelegen werde.

Ganz allgemein formuliert ist Dostojewskij, wenn es um die filmische Rezeption seines Werkes geht, ein äußerst präsenter Autor. Allein der Roman Schuld und

8 Dunja Brötz: Dostojewskijs „Schuld und Sühne“ (Prestuplenie i nakazanie, 1866) als filmischer Albtraum bei Heithor Dhalia („Nina“ 2004) und Brad Anderson (The Machinist“ 2004). In: Gudrun Goes (Hg.): Dostojewskij intermedial. Jahrbuch der Deutschen Dostojewskij-Gesellschaft, Jahrbuch 18, München, Berlin 2012, S. 114-135, hier S. 115.

9 Michaela Mundt (1994), S. 39. 
Sühne wurde in den vergangenen zehn Jahren (auf diesen Zeitraum werde ich mich nachfolgend konzentieren) mehrfach verfilmt: am populärsten ist vielleicht die ebenso hochgelobte wie opulent ausgestatte BBC Mini-Serie aus dem Jahr 2002, die sich (abgesehen vom abweichenden Ende) eng an die Romanvorlage orientiert. ${ }^{10}$ Sieht man von zahlreichen Kurzfilmen ab, bleiben eine Vielzahl abendfüllender Spielfilme, die rund um den Globus produziert wurden, unter anderem auch in Deutschland. Ich nenne kurz einige wenige, aber hoffentlich signifikante Beispiele: Frank Castorf, der an der Berliner Volksbühne in den letzten Jahren diverse Werke Dostojewskijs für das Theater adaptierte, hat mit dem Ensemble der Volksbühne zwei Werke - Die Dämonen und Der Idiot - auch filmisch realisiert. Interessant ist vor allem Castorfs Dämonen-Interpretation, die keine bloße Theaterabfilmung, sondern vielmehr ein eigenständiger, auf seiner Theater-Inszenierung beruhender Film ist, der aber an Schauplätzen außerhalb des Theaters gedreht wurde. Genauer gesagt: ein Erholungsheim der Volksbühne, eine Art Forsthaus, diente als Kulisse für Castorfs Regie-Erstling, der neben dem Dostojewskij-Roman auch Camus' Die Besessenen und improvisierte Texte verarbeitet. Dies stellt ein spannendes Experiment dar und übrigens auch eine der wenigen filmischen Dostojewkij-Rezeptionen aus jüngerer Zeit, von der die DVD überall im Handel erhältlich ist.

Von den großen Dostojewskij-Romanen wurden die Brüder Karamasow jüngst gleich zwei Mal verfilmt: 2009 als Fernseh-Mehrteiler (eine russische Produktion ${ }^{11}$ ) und unter dem Titel "The Karamazovs" als eine tschechisch-polnische Koproduktion aus dem Jahr 2007, die eine hochinteressante Mischung aus Theaterperformance und Spielfilm ist und fast komplett in einem Stahlwerk spielt. ${ }^{12}$ Dostojewskij wurde verfilmt in Israel (eine recht freie Schuld und Sühne-Adaption ${ }^{13}$ ) und in der Türkei (eine fast noch freiere Umsetzung der Aufzeichnungen aus dem Untergrund $\left.^{14}\right)$.

Auffällig ist jedoch eine relative Fokussierung der Filmschaffenden in den letzten Jahren auf einige wenige Werke Dostojewskijs - neben den bereits erwähnten sind es vor allem zwei: Der Spieler und Weiße Nächte. Die filmische Rezeption dieser beiden Werke ist so erstaunlich vielfältig, in ihren jeweiligen Umsetzungen teils schon abwegig, dass sie im Fokus der nachfolgenden Ausführungen stehen werden. Zudem soll mit ihnen eine paradox klingende These diskutiert werden: Dostojewskij, so könnte man nämlich sagen, ist ständig präsent, wird aber entweder gar nicht oder nur am Rande genannt. Was bedeutet das? Das bedeutet, dass Werke Dostojewskijs für eine Vielzahl zeitgenössischer Filme Pate gestanden haben (ich benutzte auch hier diese unscharfe Formulierung ganz

10 „Crime and Punishment”, UK 2002, Regie: Julian Jarrold.

11 „Bratya Karamazovy“, RUS 2009, Regie: Juri Moroz.

12 „The Karamazovs“, CZ 2008, Regie: Petr Zelenka.

13 „Melah Ha'arets“, ISR 2006, Regie: Uri Barbash.

14 „Yeralti“, TUR 2012, Regie: Zeki Demirkubuz. 
bewusst), die Titel der jeweiligen Filme aber diese Patenschaften verschleiern sprich: die Filmtitel sind nicht mit den Werktiteln identisch. Diese Titelverfremdung oder Titelverschleierung ist aber durchaus symptomatisch für die Dostojewskij-Rezeption im zeitgenössischen Film, die sich dennoch oder gerade deswegen als bemerkenswert vielfältig entpuppt. Dostojewskijs Werk taugt nämlich zu weit mehr als zu Arthaus-Filmen, die vermeintlich anspruchsvoll und verkopft daherkommen, sondern durchaus auch zu Mainstream-Hollywood-Komödien, indischen Bollywood Schmachtfetzen mit Gesangs- und Tanzeinlagen oder zu filmischen Zukunftsvision aus Afrika. Das mag vielleicht ein wenig absurd klingen, passt aber häufig erstaunlich gut zusammen.

Tatsächlich tauchte Dostojewskij in den vergangen zehn Jahren an ungewöhnlichen, fast schon skurrilen filmischen Schauplätzen auf - nicht unbedingt namentlich, aber dennoch gut sichtbar. Beispielsweise im Film Alex \& Emma $a^{15}$, einer Hollywood-Komödie aus dem Jahr 2003, inszeniert vom Regie-Veteranen Rob Reiner, der unter anderem für Blockbuster wie Harry und Sally verantwortlich war. Titel, Regisseur und Besetzung (Kate Hudson, Luke Wilson) lassen ein filmisches Leichtgewicht vermuten - humorig, locker, belanglos (und tatsächlich ist der Film ganz genau so wie man ihn erwartet). Kaum ein Kontext also, in dem man Dostojewski anzutreffen vermutet. Und man trifft ihn auch nicht. Allerdings kommt dem Dostojewskij-Affinen schon der überschaubare Plot merkwürdig bekannt vor: ein Schriftsteller in Geldnot muss, um seine Schulden begleichen zu können, innerhalb von 30 Tagen einen neuen Roman fertigstellen. Ärgerlicherweise zerstören zwei mafiöse Schuldeneintreiber seinen Computer, auf dem der auch noch an einer Schreibblockade leidende Autor normalerweise seine Werke verfasst. Was also tun? Als Dostojewskij-Biographie-Kenner ahnt man es: statt einfach einen neuen Rechner zu kaufen (oder ein Diktiergerät), engagiert der Schriftsteller eine Stenographistin, der er seinen neuen Roman zu diktieren gedenkt (das mit der Schreibblockade hat sich zwischenzeitlich auf geradezu wundersame Weise erledigt). Eine geeignete Kandidatin der Kategorie jung, hübsch und ungebunden ist nach den obligaten Schwierigkeiten auch recht schnell gefunden. Der Autor diktiert also seinen neuen Roman, der als Film-im-Film-Handlung in den zwanziger Jahren des vergangenen Jahrhunderts spielt und von einem Hauslehrer handelt, welcher von einer alleinstehenden Frau (namens Polina) mit zwei Kindern angestellt wird. Diese Polina wiederum steckt in argen finanziellen Schwierigkeiten, hat aber eine vermögende, kurz vor dem Ableben stehende Großmutter, die sich mit dem Sterben aber ärgerlich viel Zeit nimmt. Als dann auch noch eine Madame Blanche auftritt, wird spätestens hier klar, dass Dostojewskijs Roman Der Spieler für diesen Film in zweierlei Hinsicht rezipiert wurde. Zum einen wird seine Entstehungsgeschichte lose adaptiert, zum anderen finden sich in der Film-im-Film-Handlung diverse Parallelen zum Roman. Unschwer ist also zu

15 „Alex \& Emma“, USA 2003, Regie: Rob Reiner. 
erraten, was nachfolgend geschieht. Der Hauslehrer, natürlich verliebt in seine Chefin Paulina, versucht im nächstgelegenen Casino sein weniges Geld zu vermehren - vergeblich, ebenso wie das Hoffen Polinas auf die reiche Erbschaft. Auch die Rahmenhandlung des Filmes ist wenig überraschend, denn natürlich werden Autor und Stenographistin am Ende der Geschichte ein Paar. Der Film folgt hier also nicht nur einer typischen Hollywood-Dramaturgie, sondern ebenso der Dramaturgie der Biographie Dostojewskijs.

Erstaunlicherweise (wenn man bedenkt, um was für eine Art von Film es sich hier handelt) findet also eine Dostojewkij-Rezeption auf gleich zwei Erzählebenen statt. Thema und vor allem die Besetzung des Films richten sich aber sicherlich an eine Zielgruppe, die, vorsichtig formuliert, wahrscheinlich keine exzessiven Dostojewskij-Leser sind. Anders ausgedrückt: Von den meisten Rezipienten dieses Filmes werden die zahlreichen Dostojewskij-Anspielungen wohl überhaupt nicht erkannt, zumal weder im Vor- noch im Abspann noch sonst irgendwo auf der DVD-Hülle oder dem Filmplakat der Name Dostojewskij erwähnt wird. Zweifellos eine bemerkenswerte, weil kenntnisreiche Art der Dostojewskij-Rezeption, die aber dann natürlich die Frage aufwirft, warum denn der Name des Autors keinerlei Erwähnung findet? Hier kann nur spekuliert werden: Möglicherweise weil er eher eine vom Kinobesuch abschreckende Wirkung hätte - schließlich sind Dostojewskij-Romane nach gängiger Meinung keine leichte Lektüre, der Filmtrailer aber leichte Unterhaltung verheißt. Oder soll der Film zwei völlig unterschiedliche Zielgruppen ansprechen? Sind also merkantile Gründe auch hier die Motivation, durch die neben der juvenilen, einen Romantik-Comedy-Film erwartende Hauptzielgruppe noch eine intellektuelle, sich mit russischen Klassikern auskennende angesprochen werden soll, die sich über jede gefundene Anspielung freut? Eine eher abwegige These, gegen die bereits Regisseur und Besetzung spricht. Vielleicht ist der Film auch einfach nur als Hommage zu verstehen, die die Zeitlosigkeit der Dostojewskij-Sujets illustriert, ohne sich gleich mit dem Autornamen schmücken zu wollen.

Die Frage, wie sich Zielgruppe und Autor miteinander vertragen, stellt sich noch nachdrücklicher bei einem anderen Film. Dostojewskijs Weiße Nächte als eine indische Bollywood-Produktion mit diversen Gesangs- und Tanzeinlagen ist offensichtlich eine recht krude Kombination, so könnte man meinen, nichtsdestotrotz versucht der 2007 erschienene Film Saawariya ${ }^{16}$ (dt. etwa „Meine Liebe“, oder „Geliebte") genau das - Dostojewskij nach Indien zu transportieren. An exponierter Position im Vorspann, der außerdem lediglich die Namen des Produzenten und Regisseurs nennt, erfährt der Rezipient, dass das nun Folgende „based on Dostojewskys White Nights" sei. Hat man die ersten indischen Lieder überstanden, folgt der Film erstaunlich genau der Novelle Dostojewskijs: Ein junger Mann (im Film ein Musiker und Sänger, auch deshalb wird ständig gesungen) trifft zufällig an

16 „Saawariya“, IND 2007, Regie: Sanjay Leela Bhansali. 
einem Fluss auf eine weinende Frau. In bewusst märchenhaft-artifiziellen und farbintensiven Kulissen, angesiedelt in einer fiktiven indischen Stadt, entspinnt sich die wohlbekannte Liebesgeschichte, die allerdings an emotionalem Pathos Ihresgleichen sucht. Dazu tragen nicht nur die schmachtvollen Gesangseinlagen bei, sondern auch der ständige Einsatz von Zeitlupen, durch den jede noch so kleine emotionale Regung maximal ausgedehnt wird. Aber selbst in Details stimmen der Plot der literarischen Vorlage und der filmische Umsetzung überein, trotz aller Skurrilität. So berichtet beispielsweise die Protagonistin, die übrigens den Namen Sakina trägt, dass Ihre Großmutter, bei der sie wohnt, sie - ebenso wie Dostojewskijs Heldin - mit einer Nadel an sich gebunden hat. Allerdings macht die Angebetete kaum einen Hehl daraus, wem ihre Liebe gehört: nicht dem anwesenden namenlosen Träumer, mit dem sie, neumodisch formuliert, allenfalls ein wenig flirtet, sondern dem seit einem Jahr Abwesenden, dessen Ankunft sie herbeisehnt. Nicht nur hier bleibt der Film recht eng an Vorlage, auch in seiner finalen Handlungsstringenz: der grundsymapthische, aber auch naive, weltfremde Träumer wird buchstäblich im Regen stehen gelassen, sobald der seit einem Jahr Herbeigesehnte plötzlich auftaucht.

Der Film ist eine Schmonzette, zweifellos, aber eine bemerkenswerte, da erstens Bollywood und Dostojewskij scheinbar so gar nicht zueinander passen und zweitens, weil in der filmischen Umsetzung Bollywood und Dostojewskij sehr wohl zueinander passen. Was, so könnte man nämlich etwas ketzerisch fragen, hat Dostojewskij mit seinen Weißen Nächten denn anderes geschrieben als einen sentimentalen Tränendrücker in Novellenform? Bemerkenswert ist diese Art der Dostojewskij-Rezeption, da sie die latent elitären, akademischen oder Bildungsbürgertum-Bahnen (wie auch Alex \& Emma) verlässt, den Namen Dostojewskij aber nachdrücklich in einen neuen Rezipienten-Kreis einführt. Oder ist es anmaßend zu behaupten, dass auch Bollywood-Liebensschnulzen-Konsumenten nicht unbedingt Dostojewskij Leser sind? Im Gegensatz aber zu Alex und Emma scheint die indische Produktion das Schmücken mit dem Namen Dostojewskij als Adelung zu verstehen - und vielleicht auch als Exklusivmerkmal, um sich von diversen ähnlich daherkommenden Produktionen abzugrenzen.

Nur schwerlich vom Titel auf die literarische Vorlage schließen lässt sich auch bei John Kochs 2009 veröffentlichtem Film The Seducer ${ }^{17}$, einem kleinen Film, der auf einigen weniger bekannten Independent-Festivals mit recht beachtlichem Erfolg lief, trotz oder gerade wegen seiner mit geringem Budget erfolgten Realisierung. Koch bezeichnete seinen komplett in Schwarz-weiß gedrehten Film als eine „adaptation and present-day re-imagination of Fyodor Dostoevsky's 1848 short story, White Nights'. Through this tragic tale of love and loss the questions and consequences of seduction are explored 163 years after the story's original publication, the fundamental conflict between masculine and feminine energies

17 „The Seducer“, USA 2009/2012, Regie: John Koch. 
within it remains universal and as relevant as ever in contemporary life." 18 Interessant ist zunächst der Titel des Films, der so gar nicht zu der literarischen Vorlage zu passen scheint, denn schließlich handelt es sich bei Dostojewskijs Helden um alles andere als einen Verführer. Der Titel verwundert umso mehr, als die namenlose Hauptfigur bei Koch keineswegs ein Draufgänger oder gar ein Verführer ist, sondern ein umherschweifender Träumer wie in der Vorlage. Tatsächlich scheint bereits der Titel eine Interpretation von Dostojewskijs Novelle zu sein, schließlich kann man in dem so harmlos scheinenden Träumer durchaus auch einen Verführer sehen. Aber erst mit dem Abspann des Films löst sich das kleine Titel-Rätsel: Der Verführer ist keineswegs der Träumer, sondern sein abwesender Rivale.

Worum geht es in dem Film? Es geht um einen jungen Mann, beruflich wohl ein Kameramann, der in einer schmalen Dachkammer wohnt und scheinbar ziellos durch eine amerikanische Großstadt läuft oder mit dem Fahrrad erkundet. Er trifft zufällig auf eine junge Frau namens Sophia (die auch wieder mit ihrer leicht tyrannischen Großmutter zusammenlebt) und an einer bestimmten Stelle eines Flusses auf die Rückkehr ihres Geliebten wartet. Die Handlungsstruktur wird also zunächst größtenteils von Dostojewskijs Novelle übernommen und lediglich zeitlich aktualisiert in das heutige Amerika transportiert. Auch der weitere Plot ist Dostojewskij analog - der Träumer und Sophia lernen sich in dialogreichen Nächten kennen und mindestens schätzen, mit der beidseitigen Tendenz zu einer tieferen emotionalen Bindung. Schließlich taucht der seit einem Jahr abwesende Verführer wieder auf und Sophia lässt ihren Träumer auch hier wieder buchstäblich im Regen stehen.

Bemerkenswert abweichend ist lediglich die nachfolgende Handlungsentwicklung inklusive dem Ende - nach gut 75 Minuten Film spricht der Protagonist eine letzte Botschaft für Sophia in seine Webcam, die wortgleich mit dem letzten Satz in Dostojewskijs Novelle ist. Er befindet sich wieder in seiner Dachkammer, verständlicherweise enttäuscht und frustriert. Doch dann geschieht Erstaunliches: Der Held findet sich nicht mit seinem Schicksal ab. Der Träumer sucht seinen Rivalen auf und macht im klar, dass er durchaus nicht bereit ist, ihm Sophia widerspruchslos zu überlassen. Auch Sophia nähert er sich mit einer Mischung aus Vorwürfen und Erwartungen erneut an. Das Ende ist dramatisch - Sophia stirbt nach exzessivem Alkoholgenuss, wobei die Frage, ob sie Selbstmord begangen hat oder nicht, unbeantwortbar bleibt. Akzentuiert wird aber, dass sie eine emotionale Ausnahmesituation durchlebt, für die es keine Lösung zu geben scheint. Der eigentliche Konflikt auf weiblicher Seite, der bei Dostojewskij, wenn überhaupt thematisiert, dann nur angedeutet wird, rückt in den filmischen Fokus und erzählt gleichzeitig den Dostojewskij-Text ein Stück weiter. War es für Nastenka denn tatsächlich so einfach, sich zwischen den beiden Männern zu entscheiden, die

18 http://johnkoch.org/the-seducer.html 
sie doch angeblich beide liebt? Diese Leerstelle im Text füllt der Film mit einer Weitererzählung aus.

Betrachtet man vorsichtig resümierend die beiden Weiße-Nächte Adaptionen, die ja auf den ersten Blick unterschiedlicher kaum sein könnten (farbenfrohes BigBudget-Bollywood Kino auf der einen, schwarz-weißes Low-Budget-IndependentKino auf der anderen Seite), so fallen doch signifikante Gemeinsamkeiten auf. Erstens: Der Verzicht auf den Originaltitel. Zweitens: Die Plot-Analogien. Drittens: Die explizite Hervorhebung Dostojewskijs als Autor der literarischen Vorlage.

Eine Liebesgeschichte, eigentlich ein Liebesdrama, ist auch Dostojewskijs Erzählung „Ein schwaches Herz“ oder „Das schwache Herz“, das unter dem Titel The man who sold the world ${ }^{19}$ verfilmt wurde und 2010 als offizieller Beitrag aus Marokko auf der Berlinale lief. Ähnlich wie im Seducer wird auch in dieser filmischen Dostojewskij-Rezeption die Handlungsstruktur der Vorlage übernommen, in eine andere Zeit und an einen anderen Ort transportiert - und implizite, bei Dostojewskij aber kaum thematisierte Aspekte stärker fokussiert. Der Titel des Films assoziiert zunächst natürlich nicht Dostojewskij, sondern David Bowie, der sein drittes, 1970 erschienenes Album The man who sold the world nannte, das auch auf Rezeptionsebene ungleich bekannter sein dürfte als die DostojewskijErzählung. Vor allem das Albumcover sorgte seinerzeit für Aufsehen. Bowie, mit langem lockigem Haar, ein geblümtes Kleid und derbe Lederstiefel tragend, liegt lasziv auf einem mit blauem Satin bedeckten Divan. Mit der einen Hand streicht er sich durch das Haar, mit der anderen hält er eine französische Spielkarte. Das Bild war Bowies erstes Kokettieren mit einem androgynen Image, das in den siebziger Jahren typisch für ihn wurde. Damit suggeriert bereits der Filmtitel also etwas, dass der Dostojewskij Vorlage völlig fehlt - Homoerotik. Tatsächlich verbindet auch die beiden männlichen Protagonisten im Film eine latent homoerotische Beziehung, ohne dass im Film allerdings explizite Eindeutigkeit herrscht: homoerotische Sexualität findet nicht statt.

Wovon handelt der Film? ' $\mathrm{X}$ ' - so heißt seine Hauptfigur - müsste eigentlich ein zufriedener Mann sein. Seinen Lebensunterhalt verdient er sich mit einem zwar eintönigen, aber sein Ein- und Auskommen sichernden Beruf. Sein zufriedener Gönner, der kafkaesk unerreichbare 'Mister M.', scheint große Stücke auf ihn zu halten. Sein Freund Ney umhegt ihn und ist stets für ihn da - und dann steht auch noch die Verlobung mit der ihn aufrichtig liebenden Lili an. Sein vordergründig intaktes Leben findet jedoch in einer Parallel- oder Alternativwelt statt, einer Welt, in der Krieg herrscht, in der Mütter und Väter jeden Tag ihre Kinder verlieren. Und er, ' $X$ ', arbeitet für die Regierung, die für diesen Krieg Soldaten rekrutiert.

Das eigentlich Verblüffende an dem Film der regieführenden Brüder Noury ist, dass selbst die haarsträubendsten Prämissen funktionieren. Dass ein wasserstoffblond verstrubbelter, immer etwas verknittert und zerknautscht wirkender Mann

19 „The man who sold the world”, MAR 2009, Regie: Swel und Imad Noury. 
im Kriegsministerium arbeitet - wieso nicht? Dass sich eine blendend schöne, graziöse Tänzerin in den körperlich behinderten und ergo unbeholfenen Dahinstolpernden verliebt - durchaus glaubwürdig. In einer Welt, in der Computer von der Regierung abgeschafft wurden, militärische Uniformen aus blauen BaumwollOveralls mit weißer Krawatte bestehen und für eine Hochzeit die Erlaubnis des zuständigen Ministeriums beantragt werden muss, ist vieles möglich. Die Dialoge, oft eins zu eins aus Dostojewskijs Erzählung Ein schwaches Herz übernommen, wirken in diesem Kontext keinesfalls anachronistisch, sondern (und das ist das eigentlich erstaunliche) völlig zeitlos, unverkrampft und authentisch. Die beiden marokkanischen Regisseure meistern ihre und damit auch Dostojewskijs große Themen - Liebe, Schuld und das, was man früher "geistige Umnachtung" nannte mit erstaunlicher Virtuosität. Gegen Ende verstummen die latent eifersüchtigen Zwischentöne genauso wie das homoerotische Knistern, und 'Mister M.' hält noch ein überraschendes Statement zu der von ' $\mathrm{X}$ ' als so bedeutsam wahrgenommenen Arbeit bereit, die sich als belanglose Beschäftigungstherapie entpuppt. In einem der letzten "Kapitel" sieht man Ney, der auf einem offenen Strand seinem Freund ' $X$ ' durch eine rote Tür zu folgen versucht. Diesen führt die rote Schwelle ins Nichts, während Ney sich nur wieder auf dem offenen Strand befindet - die Geschichte driftet ins Parabolisch-Rätselhafte ab.

Am Ende bleibt das Staunen - auch darüber, dass eine solch widersprüchlichradikale Dostojewskij-Rezeption gedreht wurde, ohne dass der Eindruck entsteht, der literarischen Vorlage wurde Unrecht angetan. Denn tatsächlich wird der Plot beibehalten, die Dialoge (wie gesagt) partiell übernommen und dennoch ein im hohen Maße eigenständiger Film realisiert. Ist dieser Film also ein Beispiel dafür, dass die Dostojewskij'schen Handlungsstrukturen eine zeit- und ortunabhängige Relevanz besitzen, sie also überall und jederzeit funktionieren? Es scheint fast so, vor allem, wenn man die beiden Weiße-Nächte-Adaptionen mit hinzuzieht, denen etwas durchaus Ähnliches gelingt.

Vom Filmtitel auf die literarische Vorlage zu schließen ist im Falle eines Films namens Die Spielerin ${ }^{20}$ sicherlich nicht übermäßig schwer. Tatsächlich basiert der Film, eine deutsche Fernsehproduktion aus dem Jahr 2005, die unter der Regie von Erhard Riedelsperger entstand, auf dem Roman Der Spieler. Im Vor- und Abspann des Films fällt der Name Dostojewskij aber erstaunlicherweise, bedenkt man die offensichtliche Namensähnlichkeit der Titel, nicht.

Der Film spielt in Hamburg, Hannelore Elsner spielt die Titelrolle, die den erkennbar an Dostojewskis Vorlage erinnernden Vornamen Paulina trägt. Diese Pauline, eine ebenso wohlhabende wie kultivierte Frau, residiert standesgemäß in einem Hamburger Nobelhotel, in dem sie von einer Zufallsbekanntschaft gebeten wird, genau eine halbe Stunde am Roulettetisch zu spielen. Analog also zu Dostojewskis Helden findet der erste Kontakt mit dem Spiel im Auftrag eines

20 „Die Spielerin“, D 2005, Regie: Erhard Riedelsperger. 
anderen statt. Wenig überraschend ist auch hier, bei Kenntnis der literarischen Vorlage, der weitere Fortgang der Geschichte: Die Spielerin gewinnt bei ihrem Debüt im Casino, bei dem sie sich übrigens wundert, warum denn niemand auf die Null setzt (der Dostojewskij geschulte Leser wird sich hier an die Generalin erinnern), rund 20.000 Euro. Natürlich entspinnt sich noch eine unglückliche Liebesgeschichte zwischen dem Anstifter und der Spielerin, die natürlich auch die Motivation zum Spiel ist. 2,1 Millionen Euro soll der Geliebte der Spielerin veruntreut haben, die selbstredend erfolglos versucht, über das Roulette Geld zu beschaffen. Der Abstieg folgt rasant, von den Hamburger Nobelcasinos in billige Spielhallen und illegale Spielhöllen, von der zwangsversteigerten Designerwohnung in eine heruntergekommene Pension in ca. 15 Filmminuten. Erstaunlich ist auch (wie bereits erwähnt) die völlige Absenz des Namens Dostojewskijs, der weder im Voroder Abspann noch auf der Hülle der DVD erscheint. Lediglich aus alternativen Informationsquellen (Film-Datenbanken wie der Internet Movie Database beispielsweise $^{21}$ ) erfährt man, dass das Drehbuch nach Motiven aus dem Roman Der Spieler entstand.

Tatsächlich ist die Spielerin eine eigentümliche Verfilmung: Die Analogien im Titel, in der Namensgebung der Figur und im Plot verweisen eindeutig auf Dostojewskij. Manche Passagen sind sogar mehr oder weniger wörtlich übernommen. Beispielsweise schildert die Spielerin eine Begebenheit, in der sie, nach einer langen Verluststrecke im Casino schon auf dem Heimweg, zufällig fünf Euro in ihrer Manteltasche findet, umkehrt, das Geld setzt und schließlich mit 170 Euro das Casino wieder verlässt. Mit einer analogen Schilderung beendet Dostojewskij seinen Roman, nur dass es nicht 170 Euro, sondern 170 Gulden sind. Paradoxerweise positioniert sich der Film aber in weitem Abstand zur literarischen Vorlage. Von dem psychologisch vielschichtigen Personengeflecht der Vorlage bleibt nahezu nichts mehr übrig, stattdessen konzentriert sich der Film ausschließlich auf zwei Personen - die Spielerin und ihren unter Anklage stehenden Geliebten. Der Film wird so zu einem moralinsauren Lehrstück über die Gefahren der Sucht und gleichzeitig über die heilende Kraft der Liebe nach dem Motto: die wahre Liebe überwindet alle Hindernisse. Das Spielen und die Spielsucht erscheinen im Film fast als beliebiges Motiv, die durch jede andere Sucht ersetzt werden könnte. Natürlich geht es auch bei Dostojewskij um Spielsucht oder Spielleidenschaft, aber die Motivation der Figuren und vor allem das Beziehungsgeflecht der Personen untereinander ist weitaus vielschichtiger. Das Spielen beeinflusst, forciert und radikalisiert die Interaktion der Dostojewskij-Figuren, ohne aber ihre grundsätzliche Disposition zueinander grundsätzlich zu verändern. Um was für eine Rezeption handelt es sich hier also? Es scheint fast so, als würde auf die Nennung des Autors der literarischen Vorlage ganz bewusst verzichtet werden, eben weil der Film trotz seiner offensichtlichen Nähe zum Buch so wenig mit ihm gemein hat.

21 www.imbd.com 
Der Film, so könnte man etwas abfällig resümieren, kokettiert dezent mit einer intellektuellen Tiefe, die ihm eigentlich fehlt. Entsprechend deplatziert scheint hier auch die Rede von einer Literaturverfilmung zu sein - wie aber sonst lässt sich ein solcher Film definitorisch verorten? Und ebenso weiterführend wie anschließend gefragt: Gibt es überhaupt einen Begriff, unter dem die vorgestellten Filme sich potentiell subsumieren bzw. definitorisch verorten lassen?

Auf jeder neuen Dostojewskij-Verfilmung lastet eine doppelte Tradition: nicht nur der subjektive Erwartungshorizont des von seiner Dostojewskij-Lektüre vorgeprägten Kino- bzw. Fernsehzuschauers, sondern auch das unterschiedlich umfangreiche Arsenal bereits existierender filmischer Adaptionen. Potenziert wird diese Last immer dann, wenn es sich mit den ganz Großen zu vergleichen gilt: Wer kann schon eine zeitgenössische Weiße-Nächte-Verfilmung anschauen, ohne nicht an die Visconti-Verfilmung aus dem Jahre 1957 zu denken, die übrigens auch den Titel Weiße Nächte trug? Möglicherweise liegt hier auch der Grund für die recht auffällige Nichtübernahme der Titel. Zeitgenössische Filmemacher können sich emanzipieren, einerseits von der filmischen Tradition und andererseits von einer rezeptiven Erwartungshaltung, die allzu leicht in eine schnöde ,Das war im Buch ganz anders'-Haltung mündet. Die Titel-Veränderung betont die Eigenständigkeit des filmischen Werkes, dass sich vielleicht auch dann viel weniger mit solchen überholten Kriterien wie der Werktreue auseinandersetzen muss. Versucht man aber, diesen Begriff trotz aller Vorbehalte nutzbar zu machen, dann bietet sich für die hier kurz besprochenen Filme genau jener Adaptionstyp an, den Wolfgang Gast in seiner Typologie der Adaptionsformen als ,Aneignung von literarischem Rohstoff $^{\natural}$ bezeichnet. ${ }^{22}$ Was heißt das? Das bedeutet, dass der Film die Figurenkonstellation und die Handlungsführung der literarischen Vorlage übernimmt, ohne beidem aber sklavisch zu folgen. In allen erwähnten filmischen Beispielen verweist der Plot, das Handlungsgerüst also immer recht deutlich auf die literarische Vorlage. Damit ist natürlich noch nichts über die inhaltliche Füllung der Adpationskonzepte gesagt - gibt es also doch so etwas wie eine ,Botschaft ${ }^{`}$ der Dostojewskij'schen Werke, die wiederum irgendwie in das Medium Film transportiert werden können? Ja, wenn man - wie John Koch, dem Macher von The Seducer - die Quintessenz der Weißen Nächte - simplifizierend im fundamentalen, also quasi zeitlosen Konflikt zwischen Mann und Frau sieht. Genau hier, so Koch, liege die Relevanz und die Zeitlosigkeit von Dostojewskijs Text. Gleiches ließe sich auch, nur wenig modifiziert, über The man who sold the world sagen. Dostojewskijs Geschichten sind zeitlos in einem wörtlichen Sinne, dass sie eben abgekoppelt von ihrem ursprünglichen Zeit-, Sozial- und Politikkontext funktionieren. Das ist sicherlich nicht ganz unwahr, greift aber zu kurz. Es scheint vielmehr die ambivalente, widersprüchliche, nach einer Interpretation geradezu verlangende Vieldeutigkeit zu sein, die die Relevanz der Texte Dostojewskis ausmacht. Die ver-

22 Vgl. Wolfgang Gast (1993), S. 47. 
meintliche Zeitlosigkeit liegt weniger im nacherzählbaren Sujet selbst als in dem, was sich einer Plotnacherzählung widersetzt. Umgekehrt ist dann aber auch eine Simplifizierung oder Reduzierung des Plots wie im Film Die Spielerin zum Scheitern verurteilt.

Ich möchte abschließend und damit auch zum Ausgangspunkt zurückkehrend gerne nochmal kurz auf Wolfgang Gast zurückgreifen, um die inhaltlichen Aspekte begrifflich greifbarer zu machen. Zweifellos handelt es sich bei den erwähnten Filmen um aktualisierende Adaptionen in dem Sinne, dass die Geschichten in eine jüngere Zeit transportieren werden - das heutige Amerika, Indien, Deutschland, ein fiktives Marokko. Dadurch aber, dass sie deutlich über die psychologischen Aspekte von Figurenkonstellationen und Konfliktlösungen der Vorlage hinausgehen, kann man die Filme mit Gast "psychologische Adaptionen “23 nennen. Mit diesen psychologischen Adaptionen verbunden ist zumeist auch eine Re-Interpretation oder zumindest eine stärkere Akzentuierung solcher Motive, die im Text nur latent angedeutet oder auch gar nicht vorhanden sind. Gibt es eine latente Homoerotik in Dostojewskij Ein schwaches Herz? Ist das tragische Ende von Nastenka den Weißen Nächten implizit? Oder ist das alles lediglich eine recht freie Interpretation der Regisseure? Diese Fragen würde ich gerne im Raum stehen lassen.

23 Vgl. ebd., S. 51. 
Susanne Meister

Requiem für einen Suchenden: Im Gespräch mit Luk Perceval

\section{Susanne Meister}

Der Roman Die Brüder Karamasow ist nicht nur außergewöhnlich lang, sondern auch sehr vielschichtig. Wie findet man als Regisseur sein Thema?

\section{Luk Perceval}

Dostojewskij bietet nicht eine Philosophie als einzig richtige Haltung zum Leben an, vielmehr lässt er mir als Leser viel Zeit, mich auf die Perspektive und die spezielle Wahrheit jeder Figur einzulassen. Der intellektuelle Zynismus Iwans, der Existentialismus Dmitrijs oder Gruschenkas, die pure Frommheit Aljoschas - all diese Überzeugungen enthalten eine Wahrheit, aber jede führt irgendwann zum Exzess, wird heillos. Dostojewskij macht die unterschiedlichsten Positionen plausibel und verführt mich dazu, zu akzeptieren, dass Gut und Böse relativ, dass Wahrheit und Interpretation austauschbar sind. Das hat mich beim Lesen fasziniert, das möchte ich erzählen.

Es ist Dostojewkijs letztes und bedeutendstes Werk. Mönche und Mörder treten darin auf, Christus und der Teufel, die Figuren lieben das Leben und kokettieren gleichzeitig mit dem Selbstmord, sind getrieben von extremen Gefühlen, von Rache und Eifersucht, Liebe und Hass. Warum sucht man sich den Weg durch einen solchen Stoff ausgerechnet mit den Augen Aljoschas, des unschuldigen Novizen?

Aljoscha ist ein Jedermann. Wir alle müssen uns irgendwie in der Welt zurechtfinden, vor allem in der Liebe. Sein geistiger Vater, der Starez, hat ihm aufgetragen: Verlasse das Kloster, geh in die Welt, suche die Liebe im Elend, im Schmerz, im Leid. Man kann darin das Verhältnis von Gott zu Jesus sehen. Ich glaube, dass wir nicht umsonst solche Helden wie Jesus haben.

Dostojewskij hat im Vorwort angekündigt, eine Fortsetzung des Romans mit Aljoscha als Hauptfigur schreiben zu wollen, aber dazu ist es nie gekommen, denn er starb nur wenige Monate nach Veröffentlichung des letzten Kapitels. Sind die Brüder Karamasow eine Exposition für Aljoscha? 
Weil es dieses Buch über Aljoscha nicht gibt, kann man frei phantasieren. Für mich wird er zwischen zwei Todesfällen erwachsen: Am Anfang stirbt sein Starez im Glauben an ein ewiges Leben, am Ende der Selbstmörder Smerdjakow als Nihilist ohne Furcht vor dem Tod. Zwischen diesen beiden Polen suchen wir in unserem beschränkten Leben - wie Lemminge - mit dem Mut der Verzweiflung nach Freiheit, nach Glück, getrieben von unseren Leidenschaften, Ängsten und Frustrationen. Ich sehe das Stück mit Aljoschas Augen, weil mich, wie uns alle, seine Frage beschäftigt: Wie kann man eine Welt voll zerstörerischer Egomanie annehmen, wie in ihr leben? Auch Aljoscha zweifelt, er möchte glauben, ist aber eigentlich ein Suchender, deshalb habe ich so viel Sympathie für ihn.

Manchmal spüre ich auf den Proben eine Antwort. Wenn mich eine Szene berührt, entsteht plötzlich eine merkwürdige Form von Vergebung, ein Mitgefühl auch mit den schrecklichen Figuren. Ich verstehe sie, weil ich ihre Not spüre, und ich merke, dass es in diesem ganzen egomanen Zirkus nur auf die Verbindung zwischen den Menschen ankommt.

Aljoschas Bruder Iwan behauptet, man könne allenfalls den Fernsten lieben, aber niemals den Nächsten. Wenn es keine durch die Religion aufoktroyierten Regeln gibt, kann sich der Mensch selbst kein moralisches Gesetz geben. "Falls es keinen Gott gibt“ so folgert Iwan provokativ, ,ist alles erlaubt." Aljoscha wird erwachsen, aber was geschieht mit Iwan, der sich so verzweifelt gegen die Welt auflehnt?

Ich sehe es als etwas Positives, dass Iwan verrückt wird. Für mich ist jede Krankheit eine Herausforderung, das Leben anders zu sehen. Ich habe die Hoffnung, dass Iwan durch den Wahnsinn soweit kommt, das Leben so zu akzeptieren, wie es ist. Dmitrij ist am Ende des Stückes deshalb so stark, weil er seine Schuld annimmt, obwohl er unschuldig ist. Er geht mit dem, was mit ihm geschieht, positiv und konstruktiv um. Jeder Mensch wird mit Schmerz und Verlusten konfrontiert, die Frage ist: Wie wird man nicht bitter, wie schafft man es, das Leid in der Welt und im eigenen Leben zu akzeptieren?

Mich selbst hat irgendwann die Haltung der Buddhisten überzeugt: "Alles wächst hoch, alles wächst zum Licht". Natürlich verläuft dieses Wachsen, dieser Kreislauf, über Zerfall und Zerstörung, und der Mensch ist zwar ein Karamasow, aber es gibt nicht nur den tödlichen Egoismus, es gibt auch die Sehnsucht nach Nähe, Gemeinschaft, Verbindung, Liebe...

Dem naiven Leser bietet Dostojewski eine spannende Kriminalgeschichte. Mit seinen philosophisch- weltanschaulichen Fragestellungen gelten Die Brüder Karamasow aber als das geistige Vermächtnis des Autors und hatten großen Einfluss auf Autoren von Thomas Mann bis Camus. Was war der persönliche Ansatz bei der ersten Lektüre? 
Es ist toll, dass es vordergründig erst einmal um ein klassisches „who done it“ geht, und um eine Familie, um Sex, um Geld, jeder kennt das oder hat doch zumindest eine Phantasie dazu. Aber dahinter steht eine Frage, die ich nicht einmal richtig formulieren kann, weil sie zu groß ist, nämlich nach dem Sinn, dem Zusammenhang des Ganzen. Was verbindet uns? Sind wir überhaupt Kinder unserer Väter und Müttern oder sind wir nur biologische Lebewesen? Gibt es einen Gott oder gibt es keinen Gott? Hängt alles miteinander zusammen oder ist alles nur Zufall? Wir sind davon besessen, wissen zu wollen, was das für ein Universum ist, was wir bewohnen, und welchen Anteil wir daran haben. Das sind Fragen, die jeden Menschen bewegen, was mich spezifisch fasziniert ist - und deswegen mein Interesse für Aljoscha: Was ist Liebe?

Es berührt mich, wie Aljoscha ständig damit kämpft, wen er beschützen soll, seine Brüder, seinen Vater, er muss sie alle lieben. Gleichzeitig ist er mit Frauen konfrontiert, die ihn sexuell anziehen. Vielleicht sollte er mit allen Frauen schlafen oder mit keiner. Diese Zerrissenheit, diese Liebe zu spüren - im Körper, im Geist, im Herzen -, und sie gleichzeitig, alle zu hassen und kein Gleichgewicht zu finden zwischen Hass und Liebe, das alles berührt mich sehr. Auch, dass wir nie eine Antwort haben, dass wir auf die Welt gekommen sind und ständig eine Aufgabe bekommen, ständig etwas herausfinden, erwachsen werden und die richtigen Entscheidungen treffen müssen. Und je mehr wir wissen, desto sicherer ist nur eines: dass es keine Sicherheit gibt.

Der Autor Manès Sperber zeichnet in einem Essay die Parallelen zwischen Dostojewskijs Leben und seiner Literatur. Er beschreibt, wie verändert Dostojewskij aus Sibirien zurückkam, wohin er nach einer Scheinhinrichtung über vier Jahre verbannt war. In den Brüdern Karamasow wird die Wandlung des Sossima vom Sünder zum Heiligen Mann beschrieben, auch die Übersetzerin Swetlana Geier spricht von den „Metamorphosen“ der Charaktere. Was macht den Kern der Figuren aus?

Auf der Probe sage ich oft diesen wunderbaren Satz des Buddha: „No lotusflower without mud". Es gibt keine Schönheit, es gibt keine Blüte, ohne den Schlamm, aus dem die Blüte emporwächst, beides gehört zusammen. Uns macht zu Menschen, dass wir uns bewusst werden, was wir auslösen, und die Fähigkeit haben, zu reflektieren. Das bedeutet, wir können unser Handeln steuern, wir können unser Leben ändern.

Natürlich kann man auch Iwans Standpunkt einnehmen, dass wir dazu verdammt sind, ewig in der Welt herumzuirren und uns wie Tiere zu verhalten, um zu überleben. Ich aber glaube an den Menschen Iwan, an seine Intelligenz, ich glaube vor allem an seine Liebe. Ich bin mir ziemlich sicher, dass er in seiner Verzweiflung so tief fallen wird, dass auch er den Punkt erreicht, an dem er spürt, dass das einzige, was ihn retten kann, die Akzeptanz, die Liebe, ist. 
Es gibt im Roman eine sehr konkrete Vision von einem „Paradies auf Erden“, Darin enthalten ist die Vorstellung, dass „ein jeder vor allen für alle schuldig ist“, die Menschen sich also der gegenseitigen Verantwortung bewusst werden müssen. Liegt in den Figuren die Möglichkeit, dies zu erkennen?

Ich glaube, dass Dmitrij in diesem Weggesperrt- und Weggeschickt werden eine Chance finden kann, ein solches Paradies zu realisieren, und diese Chance bekommt letztlich auch Iwan. Ich fände es zu katholisch, zu sagen, Iwan wird wahnsinnig, weil er nicht an Gott glaubt, weil er kein sinngebendes System hat, das stimmt so auch nicht, denn er glaubt an den Teufel, also glaubt er auch an Gott. Er glaubt letztendlich an einen Gegenentwurf zu Gott.

Was ist mit den Frauen? Gruschenka wird vom Vater und von Dmitrij umworben, Katerina Iwanowna schwankt zwischen Dmitrij und Iwan, Lise, die Aljoscha verfolgt, verletzt sich selbst, Alle diese Frauen sind sehr stark über ihre Emotionen definiert, welche Möglichkeiten haben sie, auszubrechen?

Man darf auch die toten Mütter nicht vergessen! Sehr schmerzvoll an den Frauenfiguren ist ihre Einsamkeit. Diese Frauen tragen alle eine absolute Liebe in sich, die keine von ihnen realisieren kann, keine. Als ob Dostojewskij zeigen will, dass Frauen und Männer trotz ihrer irrsinnigen Sehnsucht, zusammenzukommen, nicht zusammengehören. Das ist sehr tragisch. Es gibt nicht ein Paar, bei dem man denkt, es könnte gelingen. Alle sind prädestiniert für ein Leben in Einsamkeit. Das gilt auch für die Männer. Ich finde es sehr traurig, dass Dostojewskij erzählt, die Liebe zwischen Mann und Frau sei utopisch. Die einzige Art, Liebe zu realisieren, ist fast asketisch, nämlich über die Distanz. Ich finde die Beziehungen in dem Roman sehr sehr hoffnungslos.

Sind die Figuren zu egozentrisch oder zu sehr mit ihren Konzepten und Vorstellungen beschäftigt?

Meiner Meinung nach spielt das Thema Sterblichkeit eine große Rolle. Der Starez und Smerdjakow sind so stark, weil sie keine Todesangst mehr haben. Diese Versöhnung mit dem Tod kennen die anderen Figuren nicht. Sie sind nervös, denken: "Irgendwann bin ich alt, irgendwann werde ich allein sein und deshalb muss ich mich jetzt binden, weil man mich sonst vergisst". Vor allem ihre Angst vor der Vergänglichkeit macht sie so gierig. Alle haben unglaublich das Bedürfnis, sich an jemandem festzuklammern, und wenn dieser jemand dann sagt, "ach nein, lieber nicht", wie Dmitrij bei Katerina, dann legitimieren sie damit die grausamste Rache. Letztendlich zeigt Dostojewskij sehr ausführlich, wie Katerina sich an Dmitrij rächt. Und die Folge der Rache ist Destruktion, Vernichtung bis zur Selbstvernichtung. 


\section{Wie schafft man es während der Proben, sich den Figuren anzunähern?}

Ich habe selten so lange gebraucht, um Sympathie mit Figuren zu entwickeln. Es war ein richtiger Kampf, irgendwann musste ich zugeben, dass sie mich einfach nicht berühren, weil ich ihren Schmerz, ihre Not nicht spüren konnte. Ganz am Anfang der Arbeit hatte ich das Gefühl, unter einem riesigen Betonklotz beerdigt zu sein. Meine Sympathie entsteht jetzt über die Schauspieler. Auf den Proben fragen wir uns immer: Was ist diese existentielle Angst, was ist die Not, warum reden alle so viel? Das kommt aus diesem irrsinnigen Hunger, sich an etwas festklammern zu wollen, das Sicherheit und Frieden geben könnte im Leben - sei es der Glaube, sei es Gott, der Alkohol, eine Geliebte, oder sei es eine Liebe, die einem das Gehirn wegbrennt, wie bei Dmitrij und Gruschenka. Die beiden wollen leben, saufen und am nächsten Tag sterben, in ihrer Liebe wie zwei Fliegen in der Sonne verbrennen. Alle sind leidenschaftlich und ratlos auf der Suche nach einer Antwort, finden sie aber nicht. Ich merke, dass die Schauspieler eine große Affinität und Nähe zu ihrer Figur haben. Szenisch funktioniert das immer dann, wenn sie sich wie die Wahnsinnigen reinbeißen und für das Recht ihrer Figur kämpfen. Wenn diese Energie da ist, dann fasziniert das Phänomen des Suchens plötzlich, die Verzweiflung, wie sie wie Tiere einen Ausweg ins Freie suchen. Je mehr man zum Schmerzpunkt, zur Not einer Figur vordringt, desto mehr entfaltet sie irrsinnige Energien und Absurditäten, und letztlich auch Humor. Dostojewskijs Figuren sind auch irrsinnig witzig und in einem bestimmten Sinne modern, weil sie alle sehr neurotisch sind.

\section{Hat da die Vorstellung eines paradiesischen Zustandes noch eine Chance?}

Wenn die Figuren einen trotz allem berühren und man über sie lachen kann, taucht wieder kurz das Paradies auf. Dann verstehe ich diese Metapher, dass das Paradies im hier und heute existiert. Wenn der Humor da ist, wenn ich über all das Elend lachen kann. Lachen und Heulen sind beides Formen der Akzeptanz. Wenn ich auf den Proben sitze, muss ich sehr oft lachen über Dinge, die ich kenne, von meinem Vater, meinen Söhnen, von mir selbst... Lachen auch über die Unbedingtheit und Energie, mit der wir etwas verfolgen, über diese Haltung der Lemminge, dieses Alles oder Nichts, dieses Versteckspielen.

\section{Sind wir alle Karamasowsche Naturen?}

Ja klar. Wir sind Tiere, die glauben, aus ihrer Schwäche heraus andere zu Opfern machen zu müssen, um selbst überleben zu können. 
Der Roman des 19. Jahrhunderts, und vor allem Dostojewskij in den Brüdern Karamasow arbeitet mit einer extremen Überforderung des Lesers. Wie gehst du mittlerweile mit der Dimension der Textvorlage um?

Ich kann sehr gut verstehen, dass man irgendwann die Tradition der Haikus erfunden hat, um zu versuchen, mit möglichst wenig Worten das Herz zu treffen, den Kern der Berührung, des Verstehens. Was natürlich nicht ausschließt, dass dies auch mit Figuren möglich ist, die vier Stunden wie wahnsinnig reden. Ich liebe natürlich die abstrakte Periode von Picasso, in der er mit zwei oder drei Strichen einen Don Quixote gezeichnet hat. Der junge Picasso hat einmal ein unglaublich detailliertes und naturalistisches Bild seiner Großmutter gemalt - wenn man dann sieht, wie er sich von diesen Bild zu jenen paar Strichen hin entwickelt hat, dann sieht man einen Weg der Radikalisierung, der Sehnsucht danach, immer mehr zur Essenz vorzudringen. Mich faszinieren diese wenigen Striche. Nach 30 Jahre Regietätigkeit ist meine Sehnsucht: less is more. Für mich entstehen dadurch Musikalität und Absurdität. Und es ist wie bei Shakespeare: wir lieben es dabei zuzusehen, wie jemand verrückt wird, weil wir es wieder erkennen, weil wir uns selber ständig verrückt machen mit unserem Denken. Sich selbst erkennen, seine Angst, seine Eifersucht, seinen Wahnsinn im anderen gespiegelt zu sehen, hat eine große Anziehungskraft. Das ist der Erotik des Theaters.

Warum lässt du diese hochemotionalen Vorgänge, mit denen sich der Zuschauer identifizieren soll, in einem abstrakten, sakralen Raum spielen?

Ich habe von Anfang nicht daran geglaubt, diesen Roman realistisch auf eine Bühne zu bringen. Die Schauspieler sind absichtlich teilweise wesentlich älter als ihre Figuren im Roman. Ich kann mir vorstellen, dass diese schreckliche Geschichte zwanzig, dreißig Jahre später immer noch in ihren Köpfen lebt, und sie sich immer noch fragen, warum das passieren musste, ja sogar, was eigentlich überhaupt passiert ist. Das sind Rückblenden - wie macht man also auf der Bühne glaubwürdig und präsent, dass das eigentlich ältere Schauspieler sind, die mehr oder weniger den Film noch mal zurücklaufen lassen. Bei der Szene zwischen Aljoscha und dem Starez musste ich an meine sechs Wochen in einem Zen-Kloster denken. Dort war man der Überzeugung, dass man gerade in der Stille eine Richtung und einen Sinn, und schließlich auch eine Antwort auf die großen Fragen des Lebens finden kann. Da für mich dieser Roman eigentlich eine große, endlose Sinnsuche ist, braucht man eine Bühne, die ein ritueller Raum ist, ein Raum, der sowohl die Zuschauer als auch die Schauspieler in eine Form von Reflexion versetzt, ihnen ermöglicht, in der Wirklichkeit zu erwachen. Als Kind wurde ich im Internat jeden Morgen von Glocken geweckt, die zur Messe läuteten. Im Buddhismus steht der Klang einer Glocke für the sound of the universe. Materie, die aufeinander prallt, setzt Vibrationen frei, Raum und Zeit werden als körperliche Erfahrung im 
Glockenklang zusammengebracht. Die Glocken läuten wach, bringen zurück in die Wirklichkeit. In der Tiefe des Raums endet das Bühnenbild in einer schwarzen Unendlichkeit, einem Universum, dem All. Es ist kein konkreter, situativer Ort, sondern eher ein Ort der Erinnerung.

Es stellt sich natürlich die Assoziation an einen Kirchenraum ein.

Unter anderem kann es eine Kirche sein. Mein Ziel ist, dass das Ganze dann durch die Klänge der Stahlrohre und die Sprache Dostojewskijs zu einem Requiem wird. Ein „Requiem für einen toten Vater“, oder besser: Requiem für einen Suchenden... für Aljoscha.

Das Interview wurde am 2. April 2013 auf der Probebühne Gaußstraße geführt. 


\title{
Oliver Binder
}

\section{Im Netz der Vermutungen \\ Spurensuchen um und in Mieczysław Weinbergs Oper Der Idiot}

\author{
Es fließen ineinander Traum und Wachen, \\ Wahrheit und Lüge. Sicherheit ist nirgends. \\ Wir wissen nichts von Andern, nichts von uns. \\ Wir spielen immer, wer es weiß, ist klug. \\ (Arthur Schnitzler, Paracelsus)
}

\section{Triebfedern des Schaffens}

Fürst Myschkin ist 26 Jahre alt. Man nennt ihn einen Idioten. Unter anderem, weil er jedem Menschen, offenbar arglos, mit entwaffnend freundlicher Ehrlichkeit begegnet. Mit seinem gutgläubigen Wesen sorgt der Fürst für erhebliche Irritationen, als er wie von einem fremden Stern in den Wahnsinn der Normalität einer korrupten und verlogenen Gesellschaft fällt. Deren waidwundes Opfer, Nastassja, will er retten. Von Mitleid getrieben und, wer weiß, vielleicht doch auch aus Liebe, jagt er sie nur umso gewisser in den Tod: Das ist Myschkins Tragik. Sein Erlösungswerk bleibt Utopie.

Ein ganzes Panorama widersprüchlicher Lebens- und Seelenwelten fächerte der russische Dichter Fjodor Dostojewskij (1821 - 1881) über gut neunhundert Seiten in seinem 1869 abgeschlossenen, personenreichen Roman Der Idiot auf. Aus ihm formte der 1919 im polnischen Warschau geborene und 1996 im russischen Moskau gestorbene Komponist jüdischer Abstammung Mieczysław Weinberg in den Jahren 1985/86 seine gleichnamige Oper. Der Musikwissenschaftler Alexander Medwedjew (1927-2010) - der auch die Libretti zu Weinbergs Opern Die Passagierin (1967/68), Die Madonna und der Soldat (1970/71) und Das Portrait (1980) verfasste - zog dafür die im Roman weit gesponnenen Handlungsstränge rund um den Fürsten konzise zusammen, ohne dabei die Vielschichtigkeit der einzelnen Charaktere aufzugeben. In einer reduzierten Fassung gelangte Weinbergs Idiot erstmals am 19. Dezember 1991 an der Moskauer Kammeroper auf die Bühne. Am 9. Mai 2013 präsentierte das Nationaltheater Mannheim die vollständige Uraufführung des Werkes (Musikalische Leitung: Thomas Sanderling, Inszenierung: Regula Gerber, Bühne: Stefan Mayer, Kostüme: Falk Bauer).

Wann sich Weinberg zur Vertonung des Romans Der Idiot entschied, ist nicht dokumentiert. Er zählte Dostojewskij zu seinen Lieblingsdichtern und bezeichnete 
die Beziehung zu dessen Werk ganz allgemein als »natürlichen Stimulus für meine Arbeit«. Und er glaubte, wie er 1988/89 kurz vor der Auflösung der Sowjetunion in einem Interview mit der Zeitschrift Sovetskaja muzyka erläuterte, dass in Dostojewskijs Idiot »Themen behandelt worden sind, die die Künstler und die Gesellschaft immer erregen werden und dass die Werke der russischen Klassiker den Komponisten und Filmemachern auch in Zukunft kolossale und facettenreiche Möglichkeiten der Interpretation bieten werden - der Interpretation aus einer wahren, zeitgenössischen Perspektive.« Das ist eine ebenso grundsätzliche wie unbestimmte Aussage, mit der keine konkrete Begründung der Stoffwahl verraten wird. $\mathrm{Zu}$ bemerken aber ist: Weinberg greift in Zeiten der (wenngleich schon morschen) Diktatur das Sujet einer rätselhaften Figur auf, deren Wahrheits- und Menschlichkeitsanspruch bewundert wird, die damit jedoch an der Realität zerschellt. Paradoxerweise verbirgt sich dieser Fürst Myschkin aber hinter seiner Aufrichtigkeit. Wenn er auch unverstellt ausspricht, was er denkt, legt er doch sein Seelenleben nicht zur Gänze offen - als ob er die Freiheit seines Innersten doch schützen müsste.

\section{Eine gefährdete Existenz}

Dass die äußere Freiheit, das Leben selbst ein unentwegt bedrohtes Gut war, hatte Mieczysław Weinberg schmerzlich erfahren müssen. Dem Sohn des jüdischen, aus Russland stammenden und in Warschau wirkenden Theatermusikers Samuil Weinberg stand eine glänzende Pianistenkarriere bevor, als im Jahr 1939 das nationalsozialistische Deutschland mit dem Angriff auf Polen den Zweiten Weltkrieg begann, und die bereits begonnene Vernichtung der Juden auch ihn unmittelbar bedrohte. Dem Zwanzigjährigen gelang die Flucht in die weißrussische Hauptstadt Minsk, seine zurückbleibende Familie wurde umgebracht. In Minsk, wo Weinberg am Konservatorium Komposition studieren konnte, war die Lage aufgrund des Bündnisses zwischen Deutschland und Russland und der deshalb in der Stadt präsenten Wehrmachtsoffiziere weiterhin gefährlich. Als im Jahr 1941 Deutschland mit dem Überfall auf die Sowjetunion den bestehenden Nichtangriffspakt brach, brachte Weinberg sich nach Taschkent in Sicherheit. In der 4000 Kilometer entfernten Hauptstadt Usbekistans fand er Arbeit als Korrepetitor am dortigen Opernhaus. Seine erste Sinfonie erregte die Aufmerksamkeit von Dmitri Schostakowitsch (1906 - 1975), der - begeistert von Weinbergs Musik - dafür sorgte, dass der jüngere Kollege im Jahr 1943 seinen Wohnsitz in Moskau nehmen konnte. Zeitlebens blieben Schostakowitsch und Weinberg einander künstlerisch und freundschaftlich eng verbunden.

Als nach dem Zweiten Weltkrieg auch in der Sowjetunion der Antisemitismus in staatliche Säuberungsaktionen umzuschlagen begann und, einem signalhaften Auftakt gleich, Weinbergs Schwiegervater, der auch im Westen gefeierte jüdische Schauspieler und Theaterleiter Solomon Michoëls, auf Geheiß Stalins 1948 ermordet wurde, erzeigte Schostakowitsch der Familie sein Beileid. Und Schosta- 
kowitsch verwandte sich rückhaltlos für Weinberg, als man diesen 1953 offiziell wegen »jüdischem Nationalismus « inhaftierte. Wahrscheinlich war ihm die Verwandtschaft zu Miron Wowsi, dem Onkel seiner Frau, zum Verhängnis geworden, den man als Kopf einer mutmaßlichen Verschwörung von vorwiegend jüdischen Ärzten gegen Josef Stalin ansah. Weinberg verbrachte fast drei Monate in Gefangenschaft, deren Ende er wohl doch vor allem Stalins Tod am 5. März 1953 verdankte. Das Trauma, das Weinberg aus dieser Haft davon trug, ist nicht gering einzuschätzen. Hinzuzurechnen ist die grundsätzliche Einschüchterung von Komponisten durch das Regime, wenn ihre Musik - nach welchen Maßstäben auch immer - nicht einem volksnahen »sozialistischen Realismus « entsprach. Mieczysław Weinberg wurde zwar nicht in solchem Ausmaß am pseudoästhetischen Gängelband geführt wie Dmitri Schostakowitsch, doch man konnte sich nie sicher sein, wie Gnade und Ungnade verteilt wurden. Der Versuch, die eigene Integrität zu bewahren, erforderte ein hohes Maß an Raffinesse. Weinbergs Freund Schostakowitsch wurde dabei zum Meister im Eingravieren unfügsamer Chiffren und im Verwirklichen eines hohen kompositorischen Ethos' selbst in jener Musik, die staatlich repräsentativen Charakter zu haben schien.

\section{Narrenmasken}

1979 gab der Musikwissenschaftler Solomon Wolkow postum die von ihm aufgezeichneten Memoiren des Dmitri Schostakowitsch heraus, deren Authentizität wegen ihrer überraschend widerständig zutage tretenden Haltung des Komponisten zum Teil bis heute von jenen in Frage gestellt wird, die aus unterschiedlichen Gründen nicht vom Bild Schostakowitschs als regimetreuen Staatskünstler lassen wollen. Umgehend wurde damals ein öffentlicher Protest sowjetischer Komponisten gegen diese Publikation veröffentlicht, mit deren Inhalt diese gar nicht vertraut sein konnten. Einer der Unterzeichner war Mieczysław Weinberg. Per Skans, der 2007 viel zu früh verstorbene Weinberg-Kenner, kommentierte: »Von Schostakowitsch ist bekannt, dass er häufig vorgelegte Dokumente unterzeichnete, ohne sie vorher zu lesen. Vielleicht dürfen wir annehmen, dass Mieczysław Weinberg das Gleiche tat, im Gedanken daran, dass sein verstorbener Freund darüber nur geschmunzelt hätte? « Solomon Wolkow skizzierte in den erwähnten Memoiren, was er in seinem Buch Stalin und Schostakowitsch (2004) genauer zu begründen unternahm: dass die Rolle, die Schostakowitsch für sich gefunden hatte, der eines modernen russischen Jurodivyj glich.

Die deutsche Übersetzung von Jurodivyj lautet meist »Gottesnarr « oder »Narr in Christo «, was die Bedeutungsvielfalt des Wortes freilich nur im Ansatz treffen kann. Es leitet sich vom kirchenslawischen »urod « (»der Schwachsinnige«) ab, wird umgangssprachlich als Beiwort für »bescheuert, verrückt « verwendet und meint als Hauptwort im religiösen Zusammenhang zunächst »einen Verrückten, der die Gabe der Prophetie besitzt «. Im Hinblick auf das Pauluswort des 1. Korintherbriefes »Wir sind Narren um Christi Willen« achtete man die oft 
kindlich oder seltsam sich gebärdenden Jurodivyj als Mahner und Künder von unbequemen Wahrheiten. Viele von ihnen verehrte man als Heilige. Im Narren erkannte man den Weisen. Neben den tatsächlich Geisteskranken gab es auch jene, die sich gewitzt hinter der unantastbaren Maske des Narrentums zu verbergen wussten. Freiwillig wählten sie ein Leben am Rand der Gesellschaft, um aus dieser Position heraus die Mächtigen und die herrschenden Zustände zu kritisieren. Wer ein geborener Jurodivyj war und wer sich aus eigenem Antrieb für dieses Dasein entschieden hatte, war oft nicht zu unterscheiden.

In seinem 1825 geschriebenen Drama Boris Godunow setzte Alexander Puschkin dem Typus des Jurodivyj, der selbst den Zaren mit der Wahrheit konfrontieren darf, ein nachhaltiges literarisches Denkmal. 1870 ließ Modest Mussorgski seine gleichnamige Oper mit den Worten des Jurodivyj enden: »Wehe Russland! Weine, russisches Volk, hungerndes Volk! « Dem Dichter Puschkin und dem Komponisten Mussorgski geriet der Jurodivyj fast paradigmatisch zu einer Maske der Künstler selbst. Aus dieser Perspektive fällt auf Weinbergs vage Aussage, dass in Dostojewskijs Idiot »Themen behandelt worden sind, die die Künstler und die Gesellschaft immer erregen werden «, doch noch ein politisch relevantes Licht: Vielleicht ist sie andeutungsweise zu verstehen als Parteinahme für den Künstler als produktiven Querdenker und verstörenden Wahrheitssucher. »Wahrhaftig, Fürst «, sagt Rogoschin zu Myschkin im Roman wie in der Oper, »du bist ja ganz und gar ein Jurodivyj. Und solche hat Gott der Herr lieb!«

\section{Mutmaßungen über Myschkin}

In Dostojewskijs Roman ist es aber nicht ein neutraler Erzähler, der den Fürsten Myschkin als Jurodivyj bezeichnet. Der Dichter legt diese Bezeichnung Rogoschin, einer anderen, durchaus zwielichtigen Figur, in den Mund. Es lässt sich also nicht objektiv feststellen, dass Myschkin durch und durch ein Jurodivyj ist. Dostojewskij und in Folge Weinberg/Medwedjew spielen aber mit diesem Topos, in dem mitunter die Grenzen zwischen Einfalt und Berechnung verschwimmen. Auch wenn Myschkin ein kindliches Gemüt an den Tag legt, benennt er die Dinge mit einem erwachsenen Intellekt. Er ist nicht, wie mitunter behauptet wurde, ein moderner Parzival. Denn als Parzival sein Leben in die Hand nimmt, hat er keinen Begriff von der Welt. Myschkin aber begreift die Welt in weiten Teilen durchaus. Aber er ist vergeblich - bemüht, dem Bösen darin keinen Platz einzuräumen. Durch seine Krankheit, die Epilepsie, wird er für Augenblicke in den Zustand großer Hellsichtigkeit versetzt. Fjodor Dostojewskij litt selber an Epilepsie und machte die Krankheit immer wieder zum Thema in seinem schriftstellerischen Werk. Sigmund Freud deutete sie in seinem 1928 veröffentlichten Aufsatz »Dostojewskij und die Vatertötung « psychoanalytisch als Selbstbestrafung dafür, dass der Dichter den Tod seines unbarmherzigen Vaters gewünscht hätte. Aus dieser Fantasie wurde Realität, als Dostojewskijs Vater, vermutlich von leibeigenen Bauern, tatsächlich ermordet wurde. 
In weiterer Folge beschreibt Sigmund Freud den epileptischen Anfall im weitesten Sinne als Mechanismus der Triebabfuhr. In diesem Zusammenhang verweist er auch darauf, dass schon »die ältesten Ärzte (...) den Koitus eine kleine Epilepsie « nannten. Im Altertum galt die Epilepsie im Übrigen als »heilige Krankheit « - das griechische Wort meint: » von etwas ergriffen sein « - und als Zeichen der Auserwähltheit. Kulturgeschichtlich führen auch von da die Verbindungslinien zum russischen Jurodivyj und zu einer Figur wie Dostojewskijs Fürst Myschkin. Dieser aber ist kein Mahner, kein Ankläger. Seine übermäßige Sensibilität lässt ihn das Gute in jedem Menschen sehen. Mit dem, was er dabei als Wahrheit erkennt, konfrontiert und verstört er die Mitmenschen. Nur sich selbst und das, was ihn antreibt, versteht Myschkin, so scheint es, nicht in gleichem Maße. Er ist bestrebt, im reinsten Sinne christlich - mitleidend und demutsvoll - zu handeln. Dostojewskij selbst hat seinen Fürst Myschkin mit dem »Fürst Christus « in Verbindung gebracht. Der Theologe und Tiefenpsychologe Eugen Drewermann stellt dazu fest: »Schlimmer als Der Idiot endet, kann ein Roman nicht enden: das Scheitern des Christus, nicht indem er gekreuzigt wird, sondern indem der Mensch [Nastassja] auf der Schlachtbank endet, der durch ihn gerettet werden soll!«

Dem von Dostojewskij deutlich hervorgehobenen Christusbezug messen Weinberg und Medwedjew keine ausdrückliche Bedeutung bei. Anders aber als der Roman, an dessen Ende Myschkin über dem Mord Rogoschins an Nastassja schließlich wirklich den Verstand verliert, schließt die Oper mit dem Ausdruck der größtmöglichen Radikalität christlicher Gnade: Der Fürst und der Mörder halten einander in den Armen. Was aber können Myschkin und Rogoschin auch anderes tun? Sind sie doch beide, so führt es Eugen Drewermann aus, »ein und derselbe: Sie tauschen das gleiche Kreuz, sie lieben die gleiche Frau, und sie werden schließlich beide am Katafalk ihres Sarges stehen, und auch Fürst Myschkin wird schuldig an ihrer Ermordung sein, weil er, statt die junge Aglaja zu lieben, die Frau retten wollte, die er im Grunde selber in seinem >Bruder < Rogoschin bedrohte, er selber ein Beispiel der Unmöglichkeit menschlicher Erlösung im Zustand innerer Zerrissenheit. « Das Schlussbild von Weinbergs Oper Der Idiot stellt mit einem Mal auf schrecklich berührende Weise die Einheit des gegensätzlichen Paares Myschkin und Rogoschin her. Die beiden Rivalen, der gescheiterte Erlöser und der verzweifelte Täter, verschmelzen neben der toten Nastassja in eisiger Stille.

\section{Weinbergs Widmung}

Fürst Myschkin, der vermeintliche »Idiot «, ist kein strahlender Held, aber ein Widerstandskörper innerhalb festgefahrener gesellschaftlicher Konventionen. In welchem Grad er bewusst oder unbewusst handelt, bleibt ungewiss - und darin erscheint er tatsächlich als ein Narr im Sinne des zuvor skizzierten russischen Jurodivyj, dessen mögliche Scharfsichtigkeit geahndet würde, fände sie nicht Schutz hinter einer schwer zu durchschauenden Treuherzigkeit. Ob Mieczysław Weinberg den Künstler selbst meinte - als »Gottesnarren«, als Jurodivyj, als Wahrheits- 
künder, unbeirrbar auch im Scheitern dem Prinzip Hoffnung folgend - wenn er in Dostojewskijs Idiot Themen behandelt fand, »die die Künstler und die Gesellschaft immer erregen werden «?

Fest steht, dass Weinberg seinen Idiot schließlich jenem widmete, in dem Solomon Wolkow einen modernen Jurodivyj zu erkennen glaubt. Der Klavierauszug, der noch zu Lebzeiten des Komponisten im Jahr 1994 in der russischen Verlagsgesellschaft »Kompositor « im Druck erschien, trägt auf der Seite des Stückbeginns die Zueignung »Im Angedenken an Dmitri Dmitrijewitsch Schostakowitsch«. Ob Weinberg seine Oper bereits in diesem Angedenken komponierte oder ob und warum er dieses erst nachträglich kenntlich machte, lässt sich zum gegenwärtigen Zeitpunkt nicht herausfinden. Weinbergs Widmung aber bestätigt in gewisser Weise die Sichtweise Wolkows von Schostakowitschs zeitweiliger Rolle als Jurodivyj. Und sie verweist umgekehrt auf Weinbergs mögliche Intention, seinen Idiot auch als verhüllte Hommage an die subversive utopische Kraft der Kunst zu verstehen.

Erschienen im Programmheft zur Uraufführung von Mieczysław Weinbergs Oper Der Idiot nach dem Roman von Fjodor M. Dostojewskij am 9. Mai 2013 am Nationaltheater Mannheim. 


\section{Elena Dobrina}

\section{„Das Mitleid ist das wichtigste und vielleicht einzige \\ Daseinsgesetz der ganzen Menschheit." Dostoevskijs Der Idiot und Schopenhauers Ethik}

„Drama und Epos schildern [...] durchgängig nur kämpfende, leidende, gequälte Menschen, und jeder Roman ist ein Guckkasten, darin man die Spasmen und Konvulsionen des geängstigten menschlichen Herzens betrachtet " ${ }^{\text {, }}$, heißt es im Hauptwerk Arthur Schopenhauers, für den die Literatur das menschliche Handeln, das dem Leben als Leiden ${ }^{2}$ entspringt, als ihren wichtigsten Darstellungsbereich vor allen anderen Künsten für sich erkoren und es zu ihrem „bedeutendste[n] Objekt $^{\text {“3 }}$ gemacht hat. Gerade deshalb spielt ein solcher Wirkungskreis der „Poesie“ - für Schopenhauer ein anderes Wort für die Sprachkunst - besonders für seine Ethik eine enorme Rolle, denn für ihn gilt Literatur als „eine Stütze und Hülfe der Philosophie, eine Fundquelle von Beispielen, ein Erregungsmittel der Meditation, und ein Probierstein moralischer und psychologischer Lehrsätze. Die Poesie verhält sich eigentlich zur Philosophie so, wie die Erfahrung sich zur Wissenschaft verhält. “4 Somit leistet eben diese ästhetische Disziplin eine illustrative Hilfestellung für seine ethischen Abhandlungen, denn nicht umsonst belegt Schopenhauer selbst seine Ausführungen stets mit bebildernden Beispielen aus der Welt der schönen Literatur (Voltaire, Goethe, Shakespeare etc.). Hätte Schopenhauer, der 1860 in Frankfurt am Main aus dem Leben scheidet, Dostoevskijs Werke gekannt, für den vor allem Mitleid eine so entscheidende Rolle spielt - ganz nach

1 Arthur Schopenhauer: Die Welt als Wille und Vorstellung. Zweiter Band. In: Ludger Lütkehaus (Hg.): Arthur Schopenhauers Werke in fünf Bänden. Band II. Frankfurt am Main 2006, S. 669. (Im Folgenden abgekürzt als: WWVII.)

2 Vgl. Arthur Schopenhauer: Metaphysik der Sitten. In: Volker Spierling (Hg.): Philosophische Vorlesungen Teil IV. Aus dem handschriftlichen Nachlaß. München 1985, S. 112. (Im Folgenden abgekürzt als: MS.)

„Dieses Attribut des Leidens erhält alles Lebendige, weil nach Schopenhauer der Wille die Ursache dessen darstellt. Dies bedeutet, dass der Mensch ein von Wünschen und Sehnsüchten getriebenes Wesen ist: „Denn alles Streben entspringt aus Mangel, ist also Leiden, so lange es nicht befriedigt ist: keine Befriedigung ist aber dauernd: vielmehr ist sie stets nur der Anfangspunkt eines neuen Strebens.“ (S. 111)

3 Arthur Schopenhauer: Metaphysik des Schönen. In: Volker Spierling (Hg.): Philosophische Vorlesungen Teil III. Aus dem handschriftlichen Nachlaß. München 1985, S. 118.

4 Ebd. S. 120. 
dem Geschmack des deutschen Philosophen -, hätte er sicherlich noch mehr entsprechende Gleichnisse für seine Ethik schöpfen können.

Eine solche Grundlage würde in diesem Sinne Dostoevskijs Der Idiot (Idiot) bieten. Der Roman eignet sich sogar idealerweise als eine Art Schablone aus Wortgeflechten, mit deren Hilfe der Zugang zur schopenhauerschen Ethik leichter gemacht wird. Vor allem auf Grund der akribischen Darstellung und Ausarbeitung der dostoevskijschen Charaktere lässt sich das Gedankengut des Philosophen nahezu perfekt „andemonstrieren“; anhand des Handlungsverlaufs und der Figurenentwicklung von Dostoevskijs Roman kann man Schopenhauers ethische Elemente sogar im Einzelnen fortlaufend rekonstruieren.

In dem Vorhaben, Schopenhauers Ethik im Groben aus Der Idiot zu extrahieren bzw. diese mit einem Körper auszustatten, kann man Gefahr laufen, den Eindruck zu erwecken, Dostoevskij setze bewusst auf Analogien in seinem Denken zu dem Schopenhauers. Ein kurzer geschichtlicher Exkurs über das Russland des mittleren 19. Jahrhunderts soll Schopenhauers Rezeption in Russland darstellen, um diese und andere Missverständnisse zu vermeiden.

\section{Arthur Schopenhauer in Russland}

Der Idiot entsteht zwischen Herbst 1867 und Januar 1869 und wird stückweise innerhalb eines Jahres zwischen 1868 und 1869 in Russkij Vestnik veröffentlicht. ${ }^{5}$ In dieser Zeit beschäftigt man sich in Russland immer noch mit der sich seit den 1830er Jahren stellenden Frage "nach dem Sinn der russischen Existenz"6 was bedeutet, dass die Debatte um das Westler- (Zapadničestvo) und das Slawophilentum (Slavjanofil'stvo) innerhalb des einheimischen Intellektuellenkreises immer noch andauert, obwohl einige der wichtigsten Vertreter von beiden Strömungen schon tot sind (Tschaadaev und Belinskij sowie Chomjakov und Kireevskij). Dostoevskij selbst hat längst den Westlern den Rücken gekehrt und aus seiner Sympathie mit den Slawophilen seine eigene politische Denkrichtung, das Bodenständigtum (Počvenničestvo), entwickelt. Während Schelling, Hegel und Feuerbach vor allem die an Westeuropa orientierte Bewegung geleiten und somit die Philosophen der Stunde sind, bahnt sich Schopenhauer seinen Weg durch ein Hintertürchen. Nicht die primär politisch interessierten Köpfe bringen ihn nach Russland, sondern die literarischen: Laut dem Schopenhauer-Biografen Arsenij Gulyga wird Turgenev Ende der 1840er Jahre mit der Lehre des Philosophen durch Georg Herwegh bekannt gemacht ${ }^{7}$, wobei er besonders während der 1860er Jahre Schopenhauer in seinem Werk verarbeitet (Väter und Söhne, 1862; Faust, 1855;

5 Der Roman erscheint in den Ausgaben 1-2, 4-12 von 1868 und 2 von 1869. Im Buchformat wird er erst im Jahre 1874 in Sankt Petersburg veröffentlicht.

6 Sergei A. Levitzky: Russisches Denken. Gestalten und Strömungen. Band 1. Von den Anfängen bis Vladimir Solov'ev. Frankfurt am Main 1984, S. 56.

7 Vgl. Arsenij Gulyga, Iskra Andreeva: Šopengauer. Žizn' zamečatel'nych ljudej. http://www.erlib.com/Арсений_Гулыга/Шопенгауэр/30 
Gespenster, $\left.1864^{8}\right)$. Später ist Turgenev davon überzeugt, dass eben er derjenige ist, der diesen „importiert“ habe: „Schopenhauer, ja Schopenhauer, ausgerechnet ich habe ihn nach Russland gebracht ${ }^{\text {"9. }}$. Obwohl Turgenev zweifelsohne Schopenhauer populär gemacht hatte, gilt jedoch als erster berühmter russischer Schopenhauerianer Fürst Vladimir Odoevskij. ${ }^{10}$

1868 ist das Jahr, in dem auch Tolstoj ein begeisterter Leser des deutschen Philosophen wird: In einem Brief an Fet vom August des folgenden Jahres bezeichnet ihn der Schriftsteller sogar als den ,genialste[n] der Menschen "11 - eine große Auszeichnung angesichts Tolstojs kritischer Persönlichkeit. Auch wenn seine enorme Begeisterung für Schopenhauer in den 1880er Jahren ein Ende findet, erlischt damit nicht das Interesse am Durchdringen des vom Philosophen aufgestellten ethischen Gebildes; der Grundton schopenhauerscher Theorien lässt sich am späten Werk Tolstojs deutlich festmachen: 1899 entstehen zwei Werke, die eindeutig schopenhauersche Züge tragen - Die Auferstehung und Vater Sergius, letzteres eine Erzählung, die besonders den Asketismus und das damit verbundene Moment der Willensverneinung zu ihrem Thema erhebt. Doch auch das Portrait Schopenhauers, das Tolstoj während der Zeit der leidenschaftlichen Auseinandersetzung mit dem Philosophen in seinem Arbeitszimmer aufhängt, kann man bis heute in Jasnaja Poljana bewundern.

Afanassij Fet bekommt 1863 zwar Schopenhauers Hauptwerk in die Hände, doch bleibt es vorerst bei einer oberflächlichen Bekanntschaft mit ihm. Erst Tolstoj erweckt sein Interesse und 1879 verkündet Fet seinem Freund, dass er mit der Übersetzung von Schopenhauers Die Welt als Wille und Vorstellung begonnen habe. ${ }^{12}$ In einem Brief an Vladimir Stejn bezeichnet Afanasij Fet seinen Lieblings-

8 Vgl. Sigrid McLaughlin: Schopenhauer in Rußland. Zur literarischen Rezeption bei Turgenev. In: Reinhard Lauer (Hg.): Opera Slavica. Band 3. Wiesbaden 1984, S. 16.

9 So wird Ivan Turgenev von Afanasij Fet in einem Brief an Lev Tolstoj zitiert. Arsennij Arsenjewitsch Fet, Pis'ma L. N. Tolstomu, Nr. 37 vom 3. Februar 1879. http://az.lib.ru/f/fet_ a_a/text_0210.shtml

Diese und die folgenden Übersetzungen aus dem Russischen stammen von der Verfasserin. Die Originalzitate werden in den Anmerkungen wiedergegeben: «А покойный Борисов говорил: 'Вы с Толстым шопенгауэрцы' (подразумевая дураки), а Тургенев мне говорил: 'Да ведь Шопенгауэр, что же Шопенгауэр, ведь я его вывез в Россию'.»

10 Vgl. Wolfgang Kasack: „Schopenhauer in Russland heute“, in: Schopenhauer-Jahrbuch 81. Band (2000), S. 148. In den 1840er Jahren zitiert Vladimir Odoevskij Schopenhauer häufig in einem nicht veröffentlichen Skript. (Vgl. McLaughlin (1984), S. 16.)

11 Lev N. Tolstoj: Polnoe sobranie sočinenij. Serija tret'ja. Pisma. Tom 61. Moskau 1953, S. 219. Das Originalzitat lautet: «Не знаю, переменю ли когда мнение, но теперь я уверен, что Шоп[енгауер] гениальнейший из людей.»

12 Vgl. Afanasij Fet, Brief an Lev Tolstoj Nr. 37 vom 3. Februar 1879.

1886 folgen Schopenhauers Dissertation Über die vierfache Wurzel des Satzes vom zureichenden Grunde und Über den Willen in der Natur, die ebenfalls von Fet übersetzt wurden. Somit gilt Fet als der erste russische Übersetzer Schopenhauers, abgesehen von der 1864 erschienenen 
philosophen sogar als "die Offenbarung "13 und vor allem ist es die Dichterphase zwischen den 1870er und 1880er Jahren, in der sich der schopenhauersche Geist durch Fets Lyrik zieht. ${ }^{14}$

Obwohl die Forschung bei allen drei Schriftstellern eine (meist intensive) Auseinandersetzung mit Schopenhauer nachweisen kann, sollte man betonen, dass ihre Begeisterung eher aus parallelen Überzeugungen heraus entstanden ist als durch einfache Übernahme einer Lehre. So stellt etwa Peter Thiergen am Beispiel von Turgenev fest: „Aus ähnlichem Welt-, Menschen- und Naturbild heraus war Turgenev schon lange vor seiner Kenntnis Schopenhauers Schopenhauianer gewesen. ${ }^{\text {15 }}$

In dieser Aufzählung berühmter russischer Schopenhauer-Leser wird man vergeblich Dostoevskijs Namen suchen, denn in der Dostoevskij-Forschung ist es nicht bekannt, dass der Schriftsteller Schopenhauer jemals im Original gelesen hat, mehr noch: Zwar erwähnt I. A. Bitiugowa Schelling und Schopenhauer, beides „Philosophen, mit denen Dostoevskij bekannt war; Resonanzen auf ihre Ideen lassen sich in seinem künstlerischen Schaffen und in seinem Briefverkehr finden "16, wobei Resonanzen auf Schelling sich eventuell in seiner Korrespondenz nachweisen lassen, doch Schopenhauers Name fällt keinesfalls in Dostoevskijs schriftlicher - publizierter und privater - Hinterlassenschaft. Wladimir Belopol'skij, der in seinem Buch Dostoevskij und die Philosophie (Dostoevskij i filosofija) Schopenhauer und Dostoevskij ein ganzes Kapitel widmet, führt die These M. J. Jarmakovas an, dass, obwohl es „keine expliziten Verweise darauf gibt, dass der Schriftsteller die Werke des deutschen Philosophen gelesen hat, Dostoevskij anscheinend dessen System geläufig war, mit Hilfe der journalistischen Polemik und der Gespräche mit N. N. Strachov, d.h. es ist durchaus möglich, dass er Schopenhauers philosophisches System 'im Ganzen' gekannt hat, dass er in der Lage war, 'seine wichtigsten zentralen Gedanken' zu erfassen, 'aber keine einzelnen Seiten oder Absätze'."17

Schrift Metaphysik der Geschlechtsliebe, die damals als Metaphysik der Liebe ins Russische übertragen wurde.

13 Zitiert nach: Dmitrij Blagoj.: Mir kak krasota. O „Večernich ognjach“ A. Feta.

http://az.lib.ru/f/fet_a_a/text_0020.shtml.

14 Vgl. Afanasij Fet, Brief an Lev Tolstoj Nr. 36 vom 2. Januar 1989.

15 Peter Thiergen: Schopenhauer ist der genialste aller Menschen. Zur Rezeption Arthur Schopenhauers in Russland und in der russischen Literatur. Vortrag gehalten am 13. Januar 2003 in der Bayerischen Akademie der Wissenschaften. http://www.badw.de/aktuell/reden _vortraege/Reden_Texte/2003/01_03_Schopenhauer.html

16 Inna A. Bitiugowa: „Dostoevskij i Šarl' Pegi (Tipologičestikie svjazi)“, in: Dostoevskij. Materialy i issledowanija 14 (1997), S. 255.

Das Originalzitat lautet: «Некоторые положения философии Бергсона явились развитием антиметафизических постулатов Ф.Шеллинга и А.Шопенгауэра, философов, с которыми был знаком Достоевский; отклики на их идеи можно обнаружить в его творческом и эпистолярном наследии.»

17 Vladimir. P. Belopol'skij.: Dostoevskij i filosofija: Svjazi i paralleli. Rostow am Don 1998, S. 65. 
Natalja Tscherepanowa unterstützt diese These, indem sie Dostoevskijs Talent betont, sich bestimmte philosophische und intellektuelle Konstrukte über Darstellungen Zweiter einzuprägen: „Viele Dostojewskij-Forscher haben darauf aufmerksam gemacht, dass Fjodor Dostojewskij die außergewöhnliche Fähigkeit besaß, sich eine fremde Geisteskultur spontan anzueignen und die ihn interessierenden Ideen aufzunehmen, um sie weiter zu entwickeln. “18

Doch fest steht, dass man anhand der hinterlassenen Schriften und des Briefverkehrs von Fëdor Dostoevskij mit einer ziemlichen Sicherheit davon ausgehen kann, dass der Schriftsteller mit dem philosophischen Werk Schopenhauers niemals unmittelbar in Berührung gekommen ist. Einige Forscher - u.a. Vladimir Belopol'skij - untersuchen die Quelle der Gemeinsamkeit im ethischen Verständnis der beiden Denker und leiten die durch Dostoevskij verinnerlichte Idee des schopenhauerschen Grundgedankens aus einem Hörensagen ab. Nicht nur Alexander Herzen und Ivan Turgenev, die Fëdor Dostoevskij beide zur Zeit ihrer Auseinandersetzung mit Schopenhauer kennt, sondern vor allem sein Freund, der Mitherausgeber der Zeitschrift Vremja und Dostoevskijs „Philosophielehrer“19, Nikolaj Strachov, soll es gewesen sein, der ihm den Zugang zu einer Welt im Sinne von Schopenhauer eröffnet. Nicht nur übersetzt Strachov selbst in den 1850ern Kuno Fischers Geschichte der neuern Philosophie, ein Werk, in dem Schopenhauers Name auftaucht (und das ebenfalls Dostoevskijs Bibliothek schmückt) ${ }^{20}$; er schreibt auch die Einleitung zu Afanasij Fets Übersetzung von Die Welt als Wille und Vorstellung, die 1881 erstmals erscheint.

1873 beginnt Dostoevskijs Freundschaft mit Wladimir Solowjow, der ein bekannter Schopenhauer-Kenner ist. ${ }^{21}$ Der Beitrag, den Solowjow für die Dostoevskij-

Das Originalzitat lautet: «Более подробно указанной проблемы касается М.Я.Ермакова. Ею высказано предположение, что, поскольку мы не имеем прямых указаний на чтение писателем сочинений немецкого философа, Достоевский, видимо, был знаком с его системой по журнальной полемике и беседам с Н.Н.Страховым, то есть мог быть знаком с философской системой Шопенгауэра 'в целом', мог уловить 'главнейшие, центральные ее положения, а не отдельные страницы или абзацы'.»

18 Natalja Tscherepanowa: „Schillers Ästhetik im Schaffen von Michail und Fjodor Dostojewskij“, in: Dostoevsky Studies Volume 8 (2004), S. 121. Ähnliches behaupten auch Victor Terras sowie Lew Schestow: Victor Terras: „Religion and Poetics in Dostoevsky“, in: Dostoevsky Studies Volume 7 (2003), S. 109. Lev I. Šestov: Kierkegaard i eksistentsial'naja filosofija. Glaz vopijuščego v pustyne. http://www.vehi.net/shestov/kirkegar/00.html

19 Andrzej De Lazari: „Gegel'janstvo v počvenničeskom vosprijatii (Dostoevskij, Grigorjew, Strachow)“, in: Dostoevsky Studies Volume 8 (2004), S. 123.

20 Vgl. Nina F. Budanova (Hg.): Biblioteka F. M. Dostoevskogo. Opyt rekonstruktsii. Naučnoe opisanie. Sankt-Petersburg 2005, S. 21.

21 Vladimir Solov'ëvs Dissertation setzt sich kritisch mit dem deutschen Denker auseinander (Vgl. McLaughlin (1984), S. 23.). In seinem späteren Werk entwickelt er eine Ethik, die sich wie ein roter Faden durch seine Philosophie hindurchzieht und die ihre Wurzeln bei Schopenhauer findet: Solowjow gibt dem Philosophen Recht bezüglich des nichtlogischen Willens als Ausgangspunkt eines jeden Handelns. Doch in seiner Absicht, eine „universal synthesis of 
Schopenhauer-Forschung leistet, besteht in einer gemeinsamen Reise ins Kloster Optina Pustyn': Nach dieser Besichtigung arbeitet Fëdor Dostoevskij an dem Roman Die Brüder Karamasow, einem Werk, in dem die Forschung offiziell schopenhauersche Tendenzen anerkennt ${ }^{22}$, - eine Tatsache, die man auf Solov'ëvs Einfluss zurückführt.

Arsenij Gulyga vertritt ebenfalls den Standpunkt, Dostoevskij habe Schopenhauer nie gelesen, die einzige sekundäre Quelle, die er ihm einräumt, sei Solowjow und dessen Werk, doch: „In seiner Bibliothek gab es das Buch Das moralische Ideal des Buddhismus in seinem Verhältnis zum Christentum von A. Gusev. Aber Schopenhauer gab es dort nicht. ${ }^{\text {23 }}$ Dem muss jedoch widersprochen werden, denn die aktualisierte Fassung von Dostoevskijs Bibliothek, die 2005 von Puškinskij Dom überarbeitet und herausgegeben wurde, vermerkt, dass Schopenhauers Name in der von Grigorij Fridlender 1958 entdeckten Liste auftaucht. Das darin aufgeführte Werk stellt den ersten Band von Die Welt als Wille und Vorstellung dar, in der bereits erwähnten Übersetzung von Afanasij Fet. Die Ausgabe erscheint an einem unbekannten Tag im Jahre 1881. ${ }^{24}$ Bekanntlich stirbt Fëdor Dostoevskij jedoch bereits am 28. Januar 1881 (Jul. K.). Folglich kann er das Werk kaum gelesen haben.

Viele bibliografische Hinweise auf eine literarische Begegnung zwischen Schopenhauer und Dostoevskij gehen ebenfalls verloren, da der russische Dichter sich in der Zeit der Entstehung von Der Idiot in Westeuropa aufhält und sich einerseits auf seiner Reise vom gelesenen Material trennen muss, andererseits vertraut er die Pflege seiner heimischen Bibliothek in Sankt Petersburg seinem Neffen an, der mehrere Ausgaben seines Onkels gegen Geld eintauscht.

Im Großen und Ganzen beruht die Behauptung, Dostoevskij kenne den Grundton der Philosophie Schopenhauers, auf der unsicheren Annahme, der Schriftsteller habe das Fundament des schopenhauerschen Denkens durch sekundäre Wiedergaben Anderer vernommen. Eine solche Hypothese entbehrt jeglicher Grundlage. Dass die beiden Autoren dennoch ein ähnliches Gedankengut bezüglich der Rolle des Mitleids im zwischenmenschlichen Kontext entwickeln und sich damit gegenseitig ergänzen, soll im Folgenden begründet werden.

science, philosophy, and religion, the attainment of which would require logically perfect Western forms to be united with the spiritual content of Eastern contemplation“, zu kreieren, stimmt Solov'ëv zwar der intuitiven Triebkraft des Menschen zu, doch betont er, dass das ethische Handeln eine Angelegenheit des Intellekts sei, so dass dieser über dem Willen stehen kann (Marina Kostalevsky: Dostoevsky and Soloviev. The Art of Integral Vision. New Haven and London 1997, S. 147.).

22 Vgl. Budanova (2005), S. 148.

23 Gulyga; Andreeva.

24 Vgl. Budanova (2005), S. 148. 


\section{2. „...daß er weniger als andre Leute thun, einen Unterschied macht zwischen sich und Andern" ${ }^{\prime 25}$ : \\ Die besondere Stellung des Mitleids bei Dostoevskij und Schopenhauer}

Es sind nicht nur finanzielle ${ }^{26}$ oder nostalgische ${ }^{27}$ Gründe, die Dostoevskijs Niederschreiben von Der Idiot vorantreiben, sondern es ist vor allem sein konstanter Drang, das Rätsel Mensch zu durchdringen, der den größten Antrieb seines Schaffens darstellt: „Der Mensch ist ein Geheimnis. Man muß es ergründen, und wenn man sein ganzes Leben darauf verwendet, so hat man doch keine Zeit vergeudet; ich gehe diesem Geheimnis nach, weil ich Mensch sein will. “28 Und so findet auch in Der Idiot der Versuch statt, das menschliche Wesen zu offenbaren und „alle Tiefen der Menschenseele ${ }^{\text {“29 }} \mathrm{zu}$ durchleuchten. Auf dieser Odyssee spielt Schopenhauer für den Leser eine immense Rolle, denn kein anderer als er, wie Jordi Morillas schreibt, ist „der 'Hauptschlüssel' nicht nur für die eindringliche Psychologie Dostojewskijs, sondern auch für das richtige Verständnis jeden Charakters. “"

In seiner „Darstellung eines absolut schönen Menschen“31, die sich an einem gewollten Abbild Christi orientiert ${ }^{32}$, bewirkt Dostoevskij auch eine epische Ver-

25 Schopenhauer (1985, MS), S. 215.

26 Dostoevskij reist nach Westeuropa nicht nur auf Grund seines sich stets verschlechternden Gesundheitszustandes, sondern, wie er selbst im August 1867 in einem Brief an Maikow schreibt, weil er verschuldet ist, so dass die Gefahr besteht, er komme in den sogenannten Schuldturm, vor dem er Zeit seines Lebens große Angst verspürte (Vgl. Fjodor M. Dostojewski: Briefe. Leipzig 1981, S. 230.).

27 Im Ausland hat Dostoevskij Heimweh und, um seine Sehnsucht nach Russland zu stillen, bemüht er sich um eine genaue Darstellung der gesellschaftlichen Prozesse des russischen Lebens in seinem Roman Der Idiot. Diesen sozialgerichteten Impetus bezeichnet G. M. Fridlender sogar als einen der zwei von Dostoevskij verfolgten Pläne für das Werk - der andere ist der moral-psychologische (Vgl. Grigorij M. Fridlender: „Roman 'Idiot'.“ In: N. L. Stepanov; D. D. Blagoj; U. A. Gural'nik; B. S. Rjurikov (Hg.): Tvorčestvo Dostoevskogo. Moskau 1959, S. 178.).

28 Fjodor M. Dostojewski: Briefe. Erster Band. Leipzig 1984, S. 17.

29 Fjodor M. Dostojewski: Tagebuch eines Schriftstellers. Notierte Gedanken. München 2004, S. 619.

30 Jordi Morillas: „Bejahung und Verneinung des Willens zum Leben bei Raskolnikow: Schopenhauer und Dostojewskij“, in: Deutsche Dostojewskij-Gesellschaft Jahrbuch 13 (2006), S. 29.

An dieser Stelle soll ein großer Dank an Jordi Morillas ausgesprochen werden, dessen Arbeit ursprünglich nicht nur als Inspiration für die Themenwahl der vorliegenden Arbeit fungierte, sondern der auch selbst eine großartige Leistung in der Betreuung und Korrektur dieses Aufsatzes erbracht hat.

31 Dostojewski (1981), S. 257.

32 In den Entwürfen zu Der Idiot bezeichnet Dostoevskij seinen Hauptprotagonisten Fürst Myschkin als KNJAZ' CHRISTOS (Fürst Christus), ein Gedanke, der in der Forschung oft fehlinterpretiert wird: Viele Forscher verstehen die Leerstelle zwischen KNJAZ' und CHRISTOS als Gedankenstrich. Hier bemerkt Rainer Goldt jedoch, dass diese Interpretation einen Fehlschluss darstellt, da der Gedankenstrich „im Russischen das finite Verb ersetzen 
körperung des grenzenlosen, bedingungslosen Mitleids ganz im Sinne Schopenhauers: Das Mitleid ist es, bei dem ich den fremden Schmerz

„mitempfinde, es als meines fühle, und doch nicht in mir, sondern in einem Andern [...]. Dies aber setzt voraus, daß ich mich mit dem Andern gewissermaaßen identificirt habe, und folglich die Schranke zwischen Ich und Nicht-Ich, für den Augenblick, aufgehoben sei: nur dann wird die Angelegenheit des Andern, sein Bedürfniß, seine Noth, sein Leiden, unmittelbar zum meinigen: dann erblicke ich ihn nicht mehr, wie ihn doch die empirische Anschauung giebt, als ein mir Fremdes, mir Gleichgültiges, von mir gänzlich Verschiedenes; sondern in ihm leide ich mit, trotz dem, daß seine Haut meine Nerven nicht einschließt. ${ }^{\text {“33 }}$

Bei diesen Zeilen denke man nur an die Geschichte zwischen Fürst Myschkin und Nastassja Filippowna, wobei der Erstere mehrere Male seinen eigenen Egoismus zurückstellt und sein eigenes Wohl zugunsten des Wohlergehens der Letzteren vernachlässigt: Oft muss Myschkin sein Leben umwerfen, um der von Unglück gezeichneten, von Egoismus und Bosheit getriebenen Nastassja Filippowna zu folgen und sie vor Schlimmerem zu bewahren. Das Moment der caritas dieser Zweierkonstellation gipfelt im vierten und letzten Teil des Romans, in der Begegnung zwischen der kindlichen, aber resoluten Aglaja Jepantschina, die bereits mit dem Fürsten verlobt ist, und Nastassja Filippowna, wobei die Letztere so wütend auf ihre Konkurrentin ist, dass sie Myschkin dazu auffordert, ihm buchstäblich befiehlt, Aglaja zu verlassen und mit ihr zu gehen. ${ }^{34}$ Myschkins Reaktion auf diese gebieterische Aufforderung mag verblüffen (er bleibt bei Nastassja Filippowna), denn man kann darin einen Widerspruch sehen, welchen auch Jewgenij Pawlowitsch nicht unkommentiert lässt: „Darf man aber um des Mitleids und um ihrer Genugtuung willen eine andere, ein junges Mädchen, das hochgesinnt und rein ist, der Schande preisgeben, sie vor den anderen, den hochmütigen und verhaßten Augen, erniedrigen? Wie weit darf demnach das Mitleid gehen? “35

Die Antwort auf diese Diskrepanz ist bei Schopenhauer zu finden. In seinem Kapitel Metaphysik der Geschlechtsliebe aus dem zweiten Band von Die Welt als Wille und Vorstellung thematisiert er das Phänomen der Verliebtheit. Dieser

kann.“ (Rainer Goldt: „Fürst Myschkin - russischer Christus, Don Quixote, Sisyphos?“, in: Deutsche Dostojewskij-Gesellschaft Jahrbuch 14 (2004), S. 28.) Demnach lässt sich KNJAZ' CHRISTOS nicht als Fürst Christus übersetzen, sondern: Der Fürst ist Christus. Dostoevskij jedoch tauscht bloß den Namen Myschkin durch Christus aus, um damit eine Homogenität zwischen den beiden Persönlichkeiten zu suggerieren.

33 Arthur Schopenhauer: Die beiden Grundprobleme der Ethik behandelt in zwei akademischen Preisschriften. Preisschrift über die Grundlage der Moral. In: Ludger Lütkehaus (Hg.): Arthur Schopenhauers Werke in fünf Bänden. Band III: Kleinere Schriften. Frankfurt am Main 2006, S. 586. (Im Folgenden abgekürzt als: GM.)

34 Vgl. Fjodor Dostojewskij: Der Idiot. Roman in der Neuübersetzung von Swetlana Geier. Frankfurt am Main 2005, S. 825 f.

35 Ebd. S. 840. 
rechnet er das alleinige Ziel der Aufrechterhaltung des Willens oder, in der uns gegebenen Welt der Vorstellung, der eigenen Gattung zu. So schreibt er: „Die wachsende Zuneigung zweier Liebenden ist eigentlich schon der Lebenswille des neuen Individuums ${ }^{\text {"36 }}$. Das Mitleid ist aber im Gegensatz zur Verliebtheit nicht eine

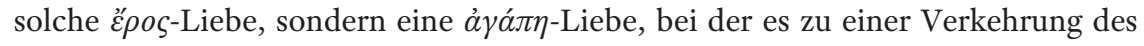
Umgangs zum eigenen Selbst kommt: Im Mitleid nämlich „versagt [der Mensch] sich Genüsse, übernimmt Entbehrungen um fremde Leiden zu mildern “37, anders ausgedrückt: Der Zustand des Mitleids ist eine Kondition, bei der es nicht darum geht, den eigenen Willen in seiner Aufrechterhaltung zu bejahen (siehe $\left.\varepsilon^{\prime} \rho o s\right)$, sondern es kommt in dem Moment des Mitleids zu einer zeitweiligen Zurücknahme der eigenen Bedürfnisse, also zu einer temporären Verneinung des Willens. Der Andere ist mir dabei nicht mehr ein „Nicht-Ich“, sondern ein „Ich noch ein

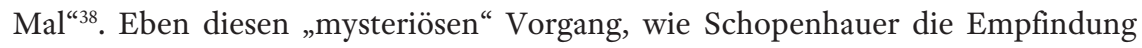
des Mitleids mehrfach bezeichnet, ${ }^{39}$ die wundersame Verschmelzung des Leidenden mit dem Mitleidigen zu einer Einheit in der Empfindung des Letzteren kann man anschaulich in der Parallelität der Ausführung der Handlungen von beiden Protagonisten bestaunen: „Zehn Minuten später saß der Fürst neben Nastassja Filippowna, sah sie unverwandt an und streichelte ihr über das Köpfchen und das Gesicht, mit beiden Händen, wie einem kleinen Kind. Er lachte, wenn sie lachte, und war den Tränen nahe, wenn sie weinte. “40

Der extreme Weg einer solchen vollkommen mitleidigen Figur, wie Fëdor Dostoevskij sich seinen Myschkin ausgedacht hat, schließt auch nur einen einzigen selbstbejahenden Augenblick gänzlich aus, im Gegenteil, auf Grund seines radikal empathischen Charakters muss der Fürst die größte denkbare Selbstentbehrung (Aglaja) auf sich nehmen, um bei der äußerst unglücklichen Nastassja Filippowna zu bleiben und somit sein eigenes Wohl, seinen eigenen Willen mit jedem Schritt immer weiter zu negieren.

36 Schopenhauer (2006, WWV II), S. 622.

37 Schopenhauer (1985, MS), S. 215.

38 Schopenhauer (2006, GM), S. 629.

39 Vgl. ebd. S. 565.

40 Dostojewskij (2005), S. 828.

Die vorliegende Passage aus Dostoevskijs Der Idiot referiert auf eine Stelle aus Paulus' Briefen an die Römer auf (Röm. 12,15): „Freut euch mit den Fröhlichen und weint mit den Weinenden!“ Durch das betonte Sich-Hineinversetzen in den Anderen, was anhand des Parallelismus im Handeln bildlich verdeutlicht wird, erreicht die Demonstration der Menschenliebe ihren Höhepunkt. Diese gegenüber den sonstigen Werten hervorzuheben, stellt für Schopenhauer "das große, auszeichnende Verdienst des Christenthums“ dar (Schopenhauer (2006, GM), S. 585). 


\section{Die drei Grundtriebfedern der menschlichen Handlungen bei Schopenhauer} „Die Welt ist meine Vorstellung“41 - mit diesem Satz setzt Schopenhauer eine Korrelation zwischen dem Subjekt und dem Objekt fest. Gleichzeitig teilt er die Welt in die der Objekte ein, die uns anschaulich gegeben sind, also in die der Vorstellungen, und in die des Willens, des zeitlosen, unveränderbaren, alles durchtränkenden Dings an sich. Für das Subjekt, welches ebenfalls „nur die Erscheinung seines Willens ist ${ }^{\text {“2 }}$, wird das Metaphysikum Wille durchaus erfahrund erkennbar: Vor allem in der eigenen Handlung manifestiert sich der empirische Charakter des Individuums, und in diesem der intelligible Charakter, der Wille an sich.

Nach dem Vollzug einer Tat, die die Demonstration dessen ist, was der Mensch will $^{43}$, gelangt der Agierende auf Grund der ihm offensichtlich vorliegenden Tatsache erst post hoc zu der Erkenntnis seines eigenen Charakters, der sich als den Menschen bewegender Wille anschaulich offenbart. Dieser Charakter ist angeboren, konstant und unfrei ${ }^{44}$, denn sobald ein Motiv auf ihn trifft, muss und wird die Handlung als Objekt des menschlichen Willens notwendigerweise stattfinden, nach Schopenhauer wird sie keinesfalls ausbleiben. Der Indikator, welcher bestimmte Reiz als Motiv auch wirklich die gewisse Aktion auslöst, wird der Charakterbeschaffenheit zugewiesen. In diesem Zusammenhang kommen die drei schopenhauerschen Grundtriebfedern ins Spiel, die die Art der Tat und auch das Objekt, auf das sie sich richtet, bestimmen: Diese sind Egoismus, „der das eigene Wohl will“, Bosheit, „die das fremde Wehe will“, und Mitleid, „welches das fremde Wohl will“. Das Verhältnis zwischen den dreien und der Bezugshandlung wird dabei durch eine Kausalbeziehung festgelegt: „Jede menschliche Handlung muß auf eine dieser Triebfedern zurückzuführen seyn". ${ }^{45}$

An dieser Stelle muss man nochmals auf die von Schopenhauer am Anfang aufgestellte Subjekt-Objekt-Beziehung zurückkommen. Die Handlungen des Egoisten (S) haben also ihn selbst (O) zum Ziel, er befolgt immer und überall das principium individuationis („ich will“). Die Absichten des Boshaften richten sich nach dem Wehe des Anderen, d.h. „dass er [...] einen Unterschied zwischen sich und Andern macht. Dieser Unterschied ist in den Augen des boshaften Charakters so groß, daß ihm fremdes Leiden unmittelbar Genuß ist, den er deshalb ohne weitern eigenen Vortheil, ja, selbst diesem entgegen, sucht ${ }^{\star 46}$ und somit seinen

\footnotetext{
41 Arthur Schopenhauer: Die Welt als Wille und Vorstellung. Erster Band. In: Ludger Lütkehaus (Hg.): Arthur Schopenhauers Werke in fünf Bänden. Band I. Frankfurt am Main 2006, S. 31. (Im Folgenden abgekürzt als: WWVI.)

42 Schopenhauer (1985, MS), S. 105.

43 Der Wille ist die Ursache, der Grund einer jeden Handlung.

44 Vgl. Schopenhauer (2006, GM), S. 532.

45 Ebd. S. 566.

46 Ebd. S. 622.
} 
eigenen Egoismus vernachlässigt. „Fremdes Leiden wird ihm jetzt Zweck an sich “47 und die Welt „ein absolutes Nicht-Ich“48, ganz im Gegensatz zum Mitleidigen, der das Wohlsein des Anderen als seinen letzten Zweck hat. An diesem Punkt erklärt Schopenhauer, warum er der Empathie eine solche immense Bedeutung beimisst: Im Moment des Mitleids nämlich kommt es sozusagen zu dem "Wunder“ der temporären Aufhebung der Subjekt-Objekt-Trennung in dem mitfühlenden Subjekt, denn der Andere ist dem Mitleidigen ein „Ich noch ein Mal“, d.h. die Kluft zwischen dem Ich und dem Gegenüber wird im Augenblick der ả $\gamma \alpha$ á $\eta$ aufgelöst, was das Mitleid für Schopenhauer zu dem „Mysterium der Ethik ${ }^{“ 49}$ macht und die darauf basierende Handlung zu der einzigen, die moralisch wertvoll ist.

Die Verteilung der Grundtriebfedern auf den menschlichen Charakter erfolgt nach keinem mathematischen Prinzip, es gibt keine prozentualen Anteile, sondern jeder Mensch ist als ein höchst komplexes Wesen mit einer Fülle an Kontrasten und Widersprüchen immer auf eine unterschiedliche Weise ausgestattet: „Die drei ethischen Grundtriebfedern des Menschen, Egoismus, Bosheit und Mitleid, sind in Jedem in einem andern und unglaublich verschiedenen Verhältnisse vorhanden. Je nachdem dieses ist, werden die Motive auf ihn wirken und die Handlungen ausfallen. ${ }^{\text {"50 }}$

\section{Egoismus, Bosheit und Mitleid in Der Idiot \\ 4.1. Egoismus}

Schopenhauer selbst könnte nicht besser sein Konzept von Bosheit verdeutlichen, als es Dostoevskij in der Charakterbeschreibung Nastassja Filippownas in Bezug auf ihren Peiniger Tozkij im ersten Teil des Romans gestaltet: „Da ihr nichts mehr teuer war, und sie sich selbst am wenigsten [...], war Nastassja Filippowna imstande, sich selbst zugrunde zu richten, endgültig und schaudererregend, Sibirien und Zuchthaus in Kauf zu nehmen, nur um den Mann zu verhöhnen, gegen den sie einen so unmenschlichen Widerwillen empfand. “51

Aus exakt diesem Grund ist es nicht verwunderlich, dass Nastassja Filippowna gegen Ende des vierten Teils den Befehl ausspricht, Myschkin möge ihretwegen Aglaja verlassen, als Antwort auf die Beleidigungen der eifersüchtigen Konkurrentin. An dieser Stelle erreicht ihre Boshaftigkeit einen Höhepunkt: Nastassja Filippowna als kluge, analytische Figur weiß, dass Myschkins mitleidiger Charakter

\footnotetext{
47 Schopenhauer (1985, MS), S. 201.

48 Schopenhauer (2006, GM), S. 629.

49 Ebd. S. 565.

50 Ebd. S. 609.

51 Dostojewskij (2005), S. 64.
}

Das schopenhauersche Gegenbild dazu lautet: „Ein Anderer, der für boshafte Motive stark empfänglich ist, wird oft, um Andern zu schaden, großen eigenen Nachtheil nicht scheuen. Denn es giebt Charaktere, die im Verursachen des fremden Leidens einen Genuß finden, der das eigene eben so große überwiegt“" (Schopenhauer (2006, GM), S. 610.). 
ihrem Schmerz, der ihrem Machtspruch zugrunde liegt, nicht widerstehen kann, denn dieser ist ein unausweichliches Motiv für die innere Beschaffenheit des Fürsten $^{52}$; und mit dieser Kenntnis spielt sie ihre Macht über Myschkin gegen Aglaja aus. Vor allem aber verletzt sie ihre Mitstreiterin nicht aus dem Affekt heraus, folglich findet keine unmittelbare Folge aus einem aufgetroffenen Motiv statt, sondern ihre Entscheidung basiert auf Reflexion, was sich an dem Stimmungswechsel ihrerseits vor dem Aussprechen des Befehls bemerkbar macht: „Aber plötzlich glomm etwas Neues in ihren Augen, sie starrte Aglaja forschend an

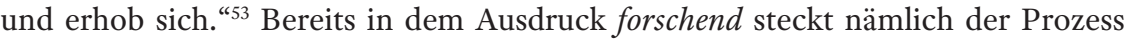
eines Bewusstwerdens; dies ist ein Bewusstwerden der Umstände, aus denen heraus sie ihre Entscheidung trifft, d.h. ihr boshaftes Handeln beruht auf Vorsatz, auf einem sicheren Wissen, was sie bei Aglaja anrichten wird - eine Motivation, die Züge der Grausamkeit annimmt. ${ }^{54}$

Aglajas Provokation animiert vielleicht die boshafte Seite Nastassja Filippownas, doch hat bei der Entscheidung, Myschkin durch Manipulation Aglaja auszuspannen und ihn somit auf ihre Seite zu bringen, ein weiterer Motivator einen ähnlichen Stellenwert, der den Charakter Nastassja Filippownas im Großen ausmacht. Dieser ist der Egoismus, der sie selbst zum Gegenstand ihrer eigenen Tat macht.

Mit ihrem Ausspruch „Und ich, ich bin dir nur davongelaufen, um dich von deinem Versprechen zu entbinden, und jetzt will ich das nicht mehr!" ${ }^{\text {"55 }}$ rechtfertigt Nastassja Filippowna ihren Befehl und offenbart gleichzeitig ihr wahres Wesen. Dieser Satz soll nun in seinen zwei Teilen betrachtet werden.

Dem letzten Segment der vorliegenden Äußerung Nastassja Filippownas („und jetzt will ich das nicht mehr") liegt zugrunde, dass sie nicht mehr auf Myschkins Nähe verzichten möchte, da das Leiden, welches als Attribut diese Figur im großen Format überhaupt ausmacht, bei Myschkin auf Verständnis stößt. Sie will den

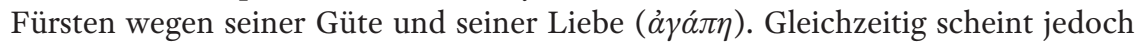
ein Moment des Mitleids vorzuliegen (,ich bin dir nur davongelaufen, um dich von deinem Versprechen zu entbinden"), weil Nastassja Filippowna den Preis dieser Nähe kennt: Myschkins Zurücknahme seines eigenen Egoismus und Entbehrung seines eigenen Glücks (u.a. Aglaja), wobei beides für ihn leidstiftend ist. In einem solchen vom Egoismus angespornten Wunsch sieht sie eine Ähnlichkeit zu dem,

52 Nicht nur Nastassja Filippowna weiß um diese Kausalitätskette bzw. um die Unmöglichkeit eines Ausbleibens der mitleidigen Handlung seitens Myschkin, wenn fremdes Weh auf dem Spiel steht. Ippolit drückt das bereits in Kapitel V aus, wenn er folgende Worte an Myschkin richtet: „Leider, ach, leider können Sie ja nicht anders!“ (S. 753). Gleiches behauptet auch General Iwolgin in Bezug auf Myschkins Güte im Kapitel III: „Ein Herz wie das Ihre kann nicht anders, als einen Leidenden zu verstehen." (S. 704).

53 Ebd. S. 825.

54 Vgl. Schopenhauer (1985, MS), S. $200 f$.

55 Dostojewskij (2005), S. 826. 
was Tozkij ihr angetan hat, und eben dieser Fakt bewahrt sie stets davor, sich dem Verlangen hinzugeben, mit dem Fürsten zusammen zu sein: „Ein solches Kind zugrunde richten? Das wäre ja ganz in der Art von Afanassij Iwanowitsch“56.

Es scheint also ein Kampf zwischen Mitleid und Egoismus im Inneren von Nastassja Filippowna ausgetragen zu werden, doch das täuscht offensichtlich: Zwar hat sie Einblick in Myschkins Leidensprozess, doch verwechselt sie ihn selbst mit Mitleid. Nastassja Filippowna denkt, sie verzichte auf den Fürsten nur seinetwegen, d.h. damit aus ihm keine zweite Nastassja Filippowna wird, in Wahrheit jedoch will sie kein zweiter Tozkij sein. Mit dem Selbstopfer verhindert sie bloß, dass sie exakt wie ihr Mäzen sich als Egoistin offenbart, dass sie wie er für ihr eigenes Wohl (als letzten Zweck ihrer Handlung) bereit ist, fremdes Wehe zu akzeptieren. Diese Tatsache wird ihr bei der Hochzeitszeremonie bewusst, wo sie mit Hilfe der Anschauung durch ihre vollbrachte Tat erkennt, welche Motivation ihrem Handeln zugrunde liegt und was das über ihr Wesen aussagt: „Was tue ich dir an! ${ }^{\text {‘57 }}$ In diesen Worten steckt kein Mitleid, sondern eben diese Erkenntnis, ein Bewusstwerden der eigenen Charakterbeschaffenheit, dass sie, Nastassja Filippowna, nicht aus Mitleid, wie sie es sich wünsche, sondern aus blankem Egoismus handele. Niemand anderer als Schopenhauer legt die Ambivalenz, die in dieser Situation deutlich wird, so klar offen, denn seine Lehre vom Gewissen behandelt eben diese Erkenntnis von der Diskrepanz zwischen dem von moralischen Vorstellungen geprägten Wunsch-Ich und dem tatsächlichen, wahren Ich: „Wir haben ein moralisches Bewußtseyn, ein Gewissen. Aber keineswegs hat dieses moralische Bewußtseyn die Form eines Imperativs, eines Gebots 'dies sollst du thun und dies sollst du lassen'““58, sondern er definiert das Gewissen als "tat twam asi““59, also „die aus der eigenen Handlungsweise entstehende und immer intimer werdende Bekanntschaft mit dem eigenen Selbst. ${ }^{\text {"60 }}$ Eine solche Bekanntschaft ist es eben, die Nastassja Filippownas Erwartungen an sich selbst nicht erfüllt und sie Parallelen mit ihrem Peiniger erkennen lässt. Diese Erkenntnis treibt sie zu drastischen Maßnahmen.

In ihrer Verzweiflung fleht sie den eintretenden Rogoschin an, ihr Hilfe zu leisten: „Rette mich! Bring mich weg!“61, wobei es Nastassja Filippowna nicht darum geht, Myschkin von ihr zu erlösen, sie bittet um ihre eigene Errettung. Das erwünschte Wegbringen bedeutet im Endeffekt, dass Nastassja Filippowna freiwillig in den Tod geht, denn ihr ist während des gesamten Romanverlaufs absolut

\footnotetext{
56 Ebd. S. 246.

57 Ebd. S. 856.

58 Schopenhauer (1985, MS), S. 57.

59 Ebd. S. 219. „Tat twam asi“ oder „Tatoumes“ ist der bei Schopenhauer oft zitierte Ausspruch aus dem Veda: „Dieses Lebende bist du!“

60 Schopenhauer (2006, GM), S. 534.

61 Dostojewskij (2005), S. 859.
} 
bewusst, dass Rogoschin sie eines Tages ermorden wird. ${ }^{62}$ Somit treibt die Erkenntnis von ihrer eigenen charakterlichen Beschaffenheit sie in den Tod, den man durchaus als Freitod begreifen kann. Und nun begegnet man der ersten Art der Verneinung nach Schopenhauer: die der eigenen Erscheinung, die er folgendermaßen beschreibt: „Der Selbstmörder verneint nicht die Species, sondern bloß das

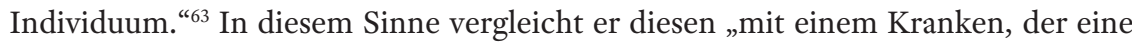
schmerzhafte Operation, die ihn von Grund aus heilen könnte, nachdem sie angefangen, nicht vollenden läßt, sondern lieber die Krankheit behält. " ${ }^{“ 4}$ Nicht der Wille als Ursache der Erscheinung wird verneint, sondern eben bloß die Umstände, denn Nastassja Filippowna will nur so nicht sein, und nicht, wie im Falle der Willensverneinung: Sie will nicht sein.

\subsection{Bosheit}

Die Verneinung als das große Abschlussthema seiner Ethik erfährt bei Schopenhauer zwei weitere Ausprägungen. Eine davon lässt sich bei Dostoevskij in der Szenerie des Mordes an Nastassja Filippowna durch Rogoschin aufzeigen. Weil Rogoschin im Verlauf des gesamten Romans um Nastassja Filippowna in größter Leidenschaft, die an Wahn grenzt, buhlt, - ein Zustand, der eindeutig dem Verfolgen der eigenen Befriedigung zuzurechnen ist, - ist der Mord an ihr dem uneigennützigen Zwecke zuzuordnen, was nach Schopenhauer Bosheit entspricht. ${ }^{65}$ Rogoschin tötet Nastassja Filippowna aus Eifersucht, weil sie kein anderer außer ihm haben darf (auch wenn er selbst sie damit nicht mehr haben kann, was, wie bereits herausgearbeitet, ein typisches Kennzeichen der Bosheit ist, das in der Selbstentbehrung um das Wehe des Anderen willen verwirklicht wird). In dem Sinne richtet er Schaden nicht bloß an ihr an, sondern vor allem an denjenigen, die in Nastassja Filippowna ihr Glück hätten finden können, womit er nach der schopenhauerschen Maxime der Bosheit handelt: „Omnes, quantum potes, laede." ${ }^{\prime 66}$ Damit negiert Rogoschin nicht bloß Nastassja Filippownas Erscheinung, sondern auch den Willen potentieller Anderer, indem er sie zu Verzicht zwingt und ihnen somit Leiden zufügt. Deshalb ist die zweite Art der Verneinung dem boshaften Charakter zuzuschreiben.

\subsection{Mitleid}

Schon zu Beginn von Der Idiot heißt es: „In einem der Waggons dritter Klasse fanden sich, als es zu tagen begann, zwei Reisende einander gegenüber ${ }^{\text {“67 }}$. In diese

\footnotetext{
62 Vgl. ebd. S. 307.

63 Schopenhauer (1985, MS), S. 257.

64 Ebd. S. 257 f.

65 Vgl. Schopenhauer (2006, GM), S. 560.

66 Ebd. S. 557. („Vielmehr verletze alle, so sehr du kannst.“ Übersetzung nach Beibuch zu der Schopenhauer-Ausgabe von Ludger Lütkehaus, S. 148.)

67 Dostojewskij (2005), S. 7.
} 
Ausgangslage werden die zwei Protagonisten auch im letzten Kapitel zurückgeworfen: „Dann setzte [Rogoschin] sich [Myschkin] gegenüber und rückte seinen Stuhl so zurecht, daß ihre Knie sich fast berührten." ${ }^{68}$ In diesem Sich-gegenüberSitzen agieren die beiden nicht, als seien sie Kontrahenten, sondern Rogoschin wird zu Myschkins direktem Spiegelbild, und zwar ganz im Sinne der schopenhauerschen Darstellung des Mitleids: Myschkin ist so von Empathie für Rogoschin ergriffen, dass der „Schleier der Maja “69 fällt, das principium individuationis, das für die Trennung der eigenen Person von der anderen verantwortlich ist, aufgelöst wird, der Egoismus aufgehoben ist, „weil der hohe Grad der Deutlichkeit jener unmittelbaren Erkenntniß die Scheidewand wegnimmt zwischen der eignen Person und der fremden. ${ }^{\text {"70 }}$ Die Erkenntnis, von der Schopenhauer hier spricht, ist die, dass ,[b]loß in der Erscheinung [...] das Böse und das Uebel, der Quäler und der Gequälte verschieden [sind]; bloß durch die Form der Individuation [...] der Unterschied zwischen dem, der das Leiden verhängt, und dem, der es dulden muß “71, besteht. Durch das Gegenübersetzen der beiden Protagonisten wird buchstäblich veranschaulicht, dass Rogoschin, in den Myschkin hineinblickt, dem Fürsten nicht mehr ein „Nicht-Ich“ ist, sondern ein „Ich noch ein Mal“; „er erkennt sein eignes Wesen in Allem. ${ }^{\text {"72 }}$ Myschkin begreift im Moment des Mitleids, dass beide Antipoden, der Boshafte und der Mitleidige, im Grunde einem Willen unterworfen sind, beide somit eine Einheit bilden und bloß durch das Individuationsprinzip voneinander getrennt zu sein scheinen, und eben diese Erkenntnis, zu der er nur durch den Zustand des Mitleids gelangen konnte, löst in Myschkin eine „ganz neue Empfindung ${ }^{\text {"73 }}$ aus:

„Der Fürst saß unbeweglich neben ihm auf dem Kissen und strich dem Kranken jedesmal, sobald er aufschrie oder redete, behutsam mit zitternder Hand über Haar und Wangen, als wollte er ihn liebkosen und beschwichtigen. Aber er verstand nichts mehr von dem, was man ihn fragte, und erkannte die eingetreten und ihn umgebenden Menschen nicht mehr. ${ }^{\text {“74 }}$

Um dieses tragische Ende des „absolut schönen“ Fürsten besser zu begreifen, sind dem nun Schopenhauers Zeilen von dem Zustand der absoluten Verneinung des Willens zum Leben entgegengestellt:

68 Ebd. S. 876. Auch einige Minuten später, nachdem Myschkin Nastassja Filippownas Leiche durch Rogoschin offenbart wurde, heißt es erneut: „Sie gingen hinaus und setzten sich wieder auf dieselben Stühle, wieder einander gegenüber." (S. 877).

69 Schopenhauer (2006, WWVI), S. 456.

70 Schopenhauer (1985, MS), S. 214.

71 Ebd. S. 185.

72 Ebd. S. 229.

73 Dostojewskij (2005), S. 883.

74 Ebd. S. 884. 
„Ihn kann nichts mehr ängstigen, nichts mehr bewegen: denn alle die tausend Fäden des Wollens, welche uns an die Welt gebunden halten, und als Begierde, Furcht, Neid, Zorn, uns hin- und herreißen, unter beständigem Schmerz, hat er abgeschnitten. Er blickt nun ruhig und lächelnd zurück auf die Gaukelbilder dieser Welt, die einst auch sein Gemüth zu bewegen und zu peinigen vermochten, die aber jetzt so gleichgültig vor ihm stehen, wie die Schachfiguren nach geendigtem Spiel, oder wie am Morgen die abgeworfenen Maskenkleider, deren Gestalten uns in der Faschingsnacht neckten und beunruhigten. Das Leben und seine Gestalten schweben nur noch vor ihm, wie eine flüchtige Erscheinung, wie dem Halberwachten ein leichter Morgentraum, durch den schon die Wirklichkeit durchschimmert und der nicht mehr täuschen kann: und eben auch wie dieser verschwinden sie zuletzt, ohne gewaltsamen Uebergang. ${ }^{475}$

Eben solche „abgeworfenen Maskenkleider“ umringen fortan Myschkins Erscheinung. Dostoevskij lässt seinen Helden in eine geistige Umnachtung fallen. Diese Umnachtung könnte man als Allegorie des in der Erscheinung verneinten Willens deuten, der aus dem Zustand des absoluten Mitleids hervorgeht. Wie in einer dunklen Nacht (ein Morphem, aus dem man das Substantiv Umnachtung ableitet) gleicht für Myschkin jedes Gesicht, jede Gestalt der anderen; alles verschwimmt zu einem Ganzen, das Einzelne ist in seinem Detail nicht mehr erkennbar - alle Individuen, alle Erscheinung scheinen sich im Willen aufgelöst zu haben. So hat Myschkin die uns sichtbare Welt durchschaut, „unheilbares Leiden und endlosen Jammer als der Erscheinung des Willens, der Welt, wesentlich erkannt" und nun sieht er „bei aufgehobenem Willen, die Welt zerfließen [...] und nur das leere Nichts" ${ }^{46}$ währt fortan vor seinen Augen.

„Durch diese Betrachtung der Verneinung des Willens zum Leben allein wird das Ganze meiner Philosophie abgeschlossen "77, schreibt Schopenhauer in Metaphysik der Sitten. In diesem Sinne beendet auch Dostoevskij seinen Roman.

75 Schopenhauer (2006, WWVI), S. $502 \mathrm{f}$.

76 Ebd. S. 528.

77 Schopenhauer (1985, MS), S. 227. 


\section{Rezensionen}

Maike Schult: Im Banne des Poeten. Die theologische Dostoevskij-Rezeption und ihr Literaturverständnis, Forschungen zur systematischen und ökumenischen Theologie 126, Göttingen 2012.

Mit dem zu besprechenden Werk, bei dem es sich um die überarbeitete Fassung der im Jahre 2008 von der Philosophischen Fakultät II der Martin-LutherUniversität Halle-Wittenberg angenommenen Dissertation der Vf. handelt, liegt ein eigenständiger und bedeutender Forschungsbeitrag zur Dostoevskij-Rezeption vor: Nach einer instruktiven Einführung in das Forschungsvorhaben werden in einem ersten Schritt unter der Überschrift »Die Anfänge der theologischen Dostoevskij-Rezeption « zunächst Tendenzen der Mythisierung beschrieben, wie sie über einschlägige Publikationen von Literaten (Nina Hoffmann, Dmitrij S. Merežkovskij, Akim L. Volynskij) hinaus bei dem katholischen Theologen Josef Müller begegnen. Wie die Vf. anhand zahlreicher Beispiele deutlich machen kann, sollte die hier begegnende Stilisierung von Dostoevskij als »Prophet « zu einem Topos werden, auf den in der Folgezeit mit Vorliebe zurückgegriffen wurde. Sodann behandelt die Vf. Dostoevskijs Bedeutung für die sog. »Dialektische Theologie «, ein Kapitel, in dem die Vf. nicht nur die zeitgeschichtlichen Hintergründe und das theologische Programm in dichter, sehr eingängiger Form beschreibt, sondern auch die einseitige Bezugnahme auf Dostoevskij deutlich zu machen vermag: seine Funktionalisierung zum Zwecke einer möglichst weiten Verbreitung der eigenen theologischen Ideen. Als drittes und letztes Kapitel schließt sich eine Behandlung der Zeit des Nationalsozialismus an, die in Hinblick auf die Dostoevskij-Rezeption bislang wenig erforscht ist; die Vf. konzentriert sich hier auf die Ansätze des evangelischen Theologen Robert Stupperich und des katholischen Theologen Romano Guardini, die, anders als die Überschrift »Dostoevskij als Ideologem « zunächst vermuten lässt, gerade nicht einer - zumal der herrschenden Ideologie verschrieben waren.

Nach Behandlung dieser eher abstrakt-theoretischen Auseinandersetzung mit Dostoevskij erfolgt in einem zweiten Schritt eine eindrückliche Thematisierung von »Interferenz und Identifikation: Literatur als Lebenshilfe «. Hier werden verschiedene Einzelschicksale geschildert, wie etwa das des reformierten Pfarrers und erklärten Gegners des Nationalsozialismus Wilhelm Schümer, dem Dostoevskij in Zeiten äußerster Bedrängnis Orientierung für sein Handeln bot. Über ihn wie auch die zahlreichen anderen - evangelischen und katholischen - Theologen wie auch 
Nicht-Theologen, die in der Arbeit behandelt werden, finden sich wertvolle Informationen in einem verdienstvollen Anhang, in dem kurze Biogramme samt bibliographischer Angaben geboten werden.

Aus dem bisherigen Inhaltsüberblick sollte deutlich geworden sein, wie weit das historische Feld ist, dass die Vf. mit ihrer Arbeit beschreitet. Wenn die Vf. dabei einen weit gefassten Begriff von »Theologie« verwendet, so ist das zunächst durchaus als Gewinn zu betrachten, weil auf diese Weise deutlich mehr Veröffentlichungen als bei einer engen Begriffsverwendung in Betracht gezogen werden können; Veröffentlichungen, die in ihrer religiösen Deutung Dostoevskijs von besonderem Interesse sind. Das Problem besteht dann allerdings darin, dass auch Ansätze wie z.B. von Dmitrij S. Merežkovskij als »theologisch « attribuiert werden, die mit Theologie im streng akademischen Sinne nichts zu tun haben, ja, sich nicht einmal einem allgemeineren Verständnis von Theologie zuordnen lassen. Abgesehen davon, dass die Vf. damit einer wichtigen Intention ihrer Arbeit, nämlich die Klärung dessen, was »überhaupt als >theologische Forschung< gelten kann und wie diese von dem weithin unklaren Phänomen einer weltanschaulichen - nach Neuhäuser >geisteswissenschaftlichen< - Dostoevskij Rezeption abzugrenzen ist « (S. 21), nicht gerecht wird, hängt mit diesem Problem ein weiteres zusammen, das als methodisches Grundproblem der ganzen Arbeit erscheint: dass nämlich die behandelten Werke unterschiedslos an dem Kriterium gemessen werden, ob sie die »Literarizität der Texte « (S. 25) hinreichend berücksichtigen. Dabei besteht bei der Vf. ein hermeneutischer Anfangsverdacht, der gleich im Vorwort formuliert wird, wenn es dort heißt, dass ein forschungsgeschichtlicher Beitrag geliefert werden soll, »der die Geschichte der theologischen DostoevskijRezeption im deutschen Sprachraum in ihren Grundzügen untersucht und dabei nach Faktoren fahndet, die einen ästhetischen Zugang zur Literatur seitens der Theologie erschweren« (S. 5), ein Verdacht, der sich dann durchgängig bestätigt.

$\mathrm{Zu}$ fragen ist hier zunächst, ob dieses Kriterium in sinnvoller Weise auf jene Ansätze anzuwenden ist, die die Vf. unter der Überschrift »Literatur als Lebenshilfe « beschreibt: ob es nicht beispielsweise auch unter literaturwissenschaftlicher Perspektive als »legitim « erscheint, wenn für den evangelischen Theologen und Widerstandskämpfer Dietrich Bonhoeffer, wie in seinen Briefen aus der Haft dokumentiert, Literatur, darunter Dostoevskij, zu einem »Zufluchtsort « (S. 240) wird, ohne dass Bonhoeffer die literarischen Texte einer Analyse unterzogen hätte, die philologischen Ansprüchen genügen würde. $\mathrm{Zu}$ fragen ist sodann, ob nicht selbst bei jenen Ansätzen, die im engeren Sinne als akademisch-theologisch zu begreifen sind, die Anwendung des Kriteriums problematisch ist. Denn hierbei handelt es sich vor allem um die »Dialektische Theologie «, bei der die Dostoevskij-Rezeption zu einer Zeit erfolgte, in der auch in den slavischen Philologien noch keine hermeneutische Theorie zur Entschlüsselung der literarisch hoch anspruchsvollen Werke Dostoevskijs entwickelt worden war. Wie die Vf. selbst darlegt, erfolgte der entscheidende Paradigmenwechsel in der Dostojevskij-Forschung 
erst durch Michail M. Bachtin, der sein erstes, im Westen zudem viel später rezipiertes Werk »Problemy tvorčestva Dostoevskogo « (1929) zu einem Zeitpunkt veröffentlicht hat, als Eduard Thurneysen sein vielgelesenes Büchlein »Dostojewski « (1921) und Karl Barth seine daran anknüpfende zweite Auflage des »Römerbriefkommentars « (1922) längst geschrieben hatten. Zuletzt ist zu fragen, inwieweit die Vf. ein Bild von »Theologie« zeichnet, das dieser Disziplin in ihrer Vielschichtigkeit und ihrem wissenschaftlichen Anspruch gerecht wird. Wenn die Vf. schreibt, dass sich »die Philologien stark am Konzept der Sprachkunst orientieren und die Interpreten hier einen distanziert-analysierenden Rezeptionsmodus einnehmen «, während »theologische Leser eine involvierte Rezeptionshaltung [favorisieren], da sie nach biblischem Vorbild existentielle Reaktionen auf die Lektüre erwarten, solche auch selbst befördern wollen und statt detektivischer Entschlüsselung der literarischen Welt schnell zum nutzanwendenden >Sprung aus dem Text< ansetzen « (S. 371), dann übersieht die Vf. bei einer solchen Entgegensetzung von »Philologie « und »Theologie«, dass der überwiegende (!) Teil theologischer Forschung selbst »philologisch « ausgerichtet ist und ein wichtiges Ziel bereits des Theologiestudiums darin besteht, eine »Entfremdung « vom biblischen Text zu erwirken, also einer » existentiellen « Lesehaltung mit einer - in der Regel - »historisch-kritischen « Analyse zu begegnen.

Die Vf. belässt es allerdings nicht bei einer ausschließlichen Kritik, sondern führt in einem dritten Schritt den Ansatz des Halleschen Theologen und bedeutenden Ostkirchenkundlers Konrad Onasch vor - als den »einzig umfängliche[n] Versuch, dem ästhetischen Spiel eine eigene heuristische Valenz zuzumessen und es konstruktiv in theologische Werkinterpretationen einzubeziehen « (S. 293). Dieser Versuch ist in der Tat bemerkenswert, und wenn aus theologischer Sicht die von Onasch aufgezeigte Nähe Dostoevskijs zur liberalen protestantischen Theologie seiner Zeit mindestens ebenso interessant ist wie sein methodisch reflektierter Umgang mit literarischen Texten, so ist es gerade Letzteres, was als wichtiger Impuls für die theologische Arbeit aufgenommen werden kann und sollte: dass eine wissenschaftliche Auseinandersetzung mit Dostoevskij nicht eine Tradition fortführen darf, wie sie in der »Dialektischen Theologie « mit ihrer einseitigen Funktionalisierung literarischer Werke geradezu idealtypisch antreffen ist, dass vielmehr bei der Interpretation der eigentümliche literarische Charakter zu berücksichtigen ist, namentlich das, was Onasch als »Spielreiz« und »Verführung « bezeichnet hat. Die Notwendigkeit wie den Gewinn verdeutlicht zu haben, die in der Beachtung der Literarizität liegen, mithin das »Salz des Poetischen « schmackhaft gemacht zu haben, darin liegt ein großes Verdienst dieser vorzüglich geschriebenen Arbeit, der anzumerken ist, dass die Vf. in ihrem literarischen Stil selbst an Dostoevskij und seinen in den Bann ziehenden Werken geschult ist. 
Horst-Jürgen Gerigk: Dostojewskijs Entwicklung als Schriftsteller: Vom Toten Haus zu den Brüdern Karamasow. Fischer-Verlag Frankfurt a. Main 2013, 344 S.

Der Komparatist und Slawist Horst-Jürgen Gerigk hat sich in seiner aktiven Lehrund Forschungszeit und darüber hinaus fast ununterbrochen der Untersuchung des Schaffens des russischen Dichters Fjodor Dostojewskijs gewidmet und dabei immer wieder neue Perspektiven eingenommen, um originäre Befunde ans Tageslicht zu befördern. Eine sehr dichte Lektüre, eine textimmanente Arbeit und eine breite und genaue Kontextanalyse und die Skizzierung geisteswissenschaftlicher Kausalitäten bilden dabei stets seine interpretatorische Basis.

Das vorgelegte Buch, das den Leser durch das Gesamtwerk des russischen Schriftstellers führen soll, schlägt dabei - wie es eben besonders Horst-Jürgen Gerigk demonstrieren kann - viele Nebenpfade ein. Er ist ein souveräner Kenner seines Untersuchungsmaterials; er überzeugt dabei, immer an der richtigen Stelle auf Vergleiche zu verweisen. Er „ruht“ in seinem Wissen über Dostojewskij, erweitert durch kaum überschaubares Detailwissen aus anderen Zusammenhängen, er meidet dabei jene Forschungsstränge zum Schaffen Dostojeskijs, die seinem Verständnis von Textinterpretation zu widersprechen scheinen. Man vermisst deshalb in dem Quellenapparat Werke einiger Dostojewskij-Forscher.

Das Buch besteht aus 5 Kapiteln: Unter Verbrechern in Sibirien; Die geistige Situation der Zeit; Die fünf großen Romane: Schauplatz Deutschland: Der Spieler; Beziehungen zwischen dem Leben und dem Werk Dostojewskijs.

In einem kurzen Vorwort verweist Horst-Jürgen Gerigk auf die Zielstellung seiner Darstellung, die sich „primär an der Verständnislenkung orientiert, die vom Text selber ausgehe“. (Vgl. S.9) Er will das natürliche, nicht literaturwissenschaftlich geschulte Verstehen des Lesers bestärken. Diese Hilfe sei nach Gerigk nötig, da der russische Dichter seine Wahrheit immer verstecke. Horst-Jürgen Gerigk nimmt diese Zielstellung sehr ernst, denn es entsteht ein gut lesbarer Text, der selten die absolute Metaebene sucht und geschickt den potentiellen Leser an die „Hand nimmt“.

Die Aufzeichnungen aus einem toten Haus sieht der Forscher als einen Muttertext an (Vgl. S.10). In diesen Aufzeichnungen wende Dostojewskij - so nach Gerigk - ein Verfahren an, das für seine fünf Romane typisch sei (S.23). Dieses Verfahren bestehe darin, dass eine Wirklichkeit auf Widerruf hergestellt, der Leser einer Evidenztäuschung ausgesetzt werde, um dann mit einer völlig anderen Einschätzung des dargestellten Sachverhalts konfrontiert zu werden. Die Evidenztäuschung dient dazu, trotz starker Beweise einen Rest an Zweifel zu bewahren. Dostojewskij habe unter den Strafgefangenen seine extreme Leiderfahrung in seinem Lagertext und seine Begegnung mit Straftätern verarbeitet und sich damit die Grundlage für seine Philosophie der Freiheit verschafft. Der Mensch könne sich durch Vernunft bestimmen lassen, dieses Vermögen sei menschliche Freiheit. Aber im Unterschied zu Kant sehe Dostojewskij die Religion als das erforderliche Mediums dieses Vermögens an. (Vgl. S.25) 
Die Erfahrungen des Lagerlebens und die Reflexion darüber in den Aufzeichnungen aus einem toten Haus bilden nach Gerigk eine Initialzündung für die Problemformulierungen seiner großen Romane und antizipieren auch sein Menschenbild, in dem der Mörder einen zentralen Platz habe. (Vgl. S.26) Gerigk führt hier die Geschichte Akulkas Mann aus den Aufzeichnungen als eine Art Prototyp einer Mordgeschichte an, die ausführlich analysiert wird. ${ }^{1}$

Die Rezensentin widmet sich aus dem Gesamtkomplex der Darlegungen von Horst-Jürgen Gerigks dem 3. Kapitel und da seinen Ausführungen zum Roman Der Idiot und dem 5. Kapitel.

Nach der Skizzierung von Zeit, Ort und Raum der Handlung des ersten Teils des Romans behauptet der Forscher, dass der Leser nach dem 1. Teil des Romans geradezu im Stich gelassen werde und die Beziehungen zwischen den drei Hauptakteuren (Myschkin, Nastasja und Rogoschin) aus Andeutungen anderer Personen zu erschließen habe. Kalkulierte Aussparung des Wesentlichen werde nun zum Prinzip der Darstellung des russischen Schriftstellers. Das Verhalten des Protagonisten Myschkin könne aus herkömmlichen Motivationen nicht geklärt werden (Vgl. S. 103). Die beiden Männer verkörpern die zwei Seiten des Menschen, seine helle und seine dunkle. (Vgl. S.128)

Der von Dostojewskij hier eingeführte imaginäre Erzähler kann nur von außen die Ereignisse betrachten, selten werden zurückliegende Ereignisse kommentiert. Ein Unterkapitel nennt Horst-Jürgn Gerigk „Verkennung“, um sich auch gleich zu positionieren, dass der Roman Der Idiot als eine Phänomenologie der Verkennung gelesen werden könne. (Vgl. S. 107) Er begründet diese These damit, dass dem russischen Dichter beim Verfassen dieses Romans zwei Gestalten wichtig waren, die von Christus und die von Don Quijote, beide Helden sind der Verkennung ausgesetzt. Ein weiteres Unterkapitel heißt „Zwei Verkennungen“, in diesem werden zwei extrem unterschiedliche Einschätzungen des Fürsten zitiert und dessen Reaktionen darauf, die durch Sprachlosigkeit gekennzeichnet sind. (Vgl. S. 113-120) Interessant sind die daraus folgenden Schlussfolgerungen von HorstJürgen Gerigk, der die Sprachnot des Fürsten nicht als Ergebnis einer Trübung des Wirklichkeitssinns ansieht, sondern als Folge höchster geistiger Klarsicht. Myschkin ist fähig, sein Umfeld zu analysieren, aber er ist unfähig zur Gegenwehr. Dem betrachtenden Erzähler ist nur möglich, diese Reaktion zu schildern, weil ihm ein Einblick in das Innere des Helden ja verwehrt bleiben muss. Auch die epileptischen

1 H.-J. Gerigk führt an dieser Stelle aus, dass die Aufzeichnungen aus einem toten Haus seit 1978 auch als Täterliteratur bezeichnet werden. Dann folgt eine seiner vielen den Leser aufklärenden Abschweifungen, durch die wir als Leser erfahren, dass unter Täterliteratur Werke von Autoren verstanden werden, die selbst im Gefängnis waren, so gehören auch Giacomo Casanovas Memoiren mit der Schilderung seiner Flucht aus den Bleikammern in Venedig wie auch die Briefe Rosa Luxemburg aus verschiedenen Gefängnissen dazu. Trotz der gegebenen Klammer sind diese Werke nicht auf einer Vergleichsebene, da die verschiedenen Kontexte noch Berücksichtigung finden müssen. 
Anfälle sind Ausdruck einer Form von Nichtakzeptanz der unerträglich gewordenen Gegenwart. Und der Anfall, der in einen Schrei mündet, den Myschkin angesichts der Mordabsicht Rogoschin ihm gegenüber bekommt, ist die nach Gerigk adäquate nonverbale Interpretation der Welt, in der der Fürst leben muss. (Vgl. S.120-124) Der Leser wird bestärkt, an die sittliche Integrität des Fürsten zu glauben, gleichzeitig baut der Dichter Freiräume für die Verkennung Myschkins ein.

Die totale Präsenz des Helden Myschkin und die Fokussierung auf den Mittelpunkt begründet der Forscher mit dem zweifachen Standpunkt: zum einen mit dem innerfiktionalen und zum anderen mit dem außerfiktionalen. Nach Gerigk provoziere der Fürst in den anderen ihr eigentliches Selbst, dem sie selbst nicht gewachsen sind, indem er sein eigentliches Selbst ständig lebt. So wird er zu einem Ärgernis, das man versucht, zurückzudrängen, deshalb ist es am einfachsten, ihn als Idioten abzustempeln. (Vgl. S. 125f.)

Horst-Jürgen Gerigk wartet mit einer besonderen poetologischen Provokation in der Einschätzung dieses Romans auf, indem er ausführlich Susan Sontags Essay über Camp dargelegt (Vgl. S. 135-143) und daraus ableitet, dass Dostojewskijs Roman Der Idiot dem Camp zu zuordnen wäre. Er hebt als Merkmale hervor: eine besondere Art von Sensibilität, Phantastik, Leidenschaft, Naivität, eine neue, komplexe Beziehung zum „Seriösen“. Der neue Standard des Camp sei Künstlichkeit als Ideal, das Theatralische als Voraussetzung. Camp-Geschmack sei nur in Gesellschaften möglich, die fähig sind, die Psychopathologie des Luxus wahrzunehmen. Der Forscher sieht im Roman Der Idiot eine Traditionslinie des Schauerromans und seiner neuen Ästhetik. In Beziehung zum Camp-Kanon würden nach Gerigk Qualitäten des Romans positiv frei gelegt, die ansonsten negativ konnotiert wären. Die negativen Bezugsquellen sind vor allem die Bewertungen durch Vladimir Nabokov, der das Werk Dostojewskijs generell nicht schätzte und der Idiotenführer von Sir Galahad. Sie werden dem Werk des russischen Dichters aber nicht gerecht. Um Camp-Qualitäten aufzudecken hebt der Forscher hervor, dass im Roman Der Idiot alles übertrieben, phantastisch und extravagant sei, beginnend beim labyrinthischen Haus von Rogoschin, das aus einem englischen Schauerroman stammen könnte. Viele Details und Vergleiche bis zu Hitchcocks Film Psycho werden benannt, nichts scheint im Roman das zu sein, was es äußerlich vorgibt. Alle Merkmale kreisen um schauerromanartige Zustände, eine femme fatale und ein impotenter Held u.a. Am Ende vergleicht Horst-Jürgen Gerigk die Camp-Qualitäten des Roman mit Oscar Wildes Salome als Oper von Richard Strauss. Er gelangt damit in jene zeitliche Epoche, nämlich in die Moderne, auf der der Fokus der Analyse besonders von Susan Sontag lag.

Nach Ulf Poschardt ${ }^{2}$ steht Camp in einer langen Tradition der Gestaltung von Existenz als ästhetischem Unterfangen. Camp zu sein heißt, sich ästhetisch zur

2 Vgl. Ulf Poschardt: Camp. In. Hubertus Butin (Hg.): Begriffslexikon zur zeitgenössischen Kunst. Köln 2002, S. 45-48. 
Welt zu verhalten und das Geschmacksurteil über alles und jeden so weit stilsicher $\mathrm{zu}$ machen, dass die eigene Existenz selbst diesen Stil abbildet, um sich zum Kunstwerk zu machen. Die eigene Existenz wird dekoriert. Haltung beinhaltet also die Möglichkeit, selbst nicht mehr nur Ursprung der Wertschätzung zu sein, sondern auch deren Objekt. Folgen wir diesem Verständnis von Camp, das auch Horst-Jürgen Gerigk indirekt an einer Stelle mit einer bestimmten Art von Sensibilität (Vgl. S.136) erwähnt, so sind seine abschließend dargelegten Merkmale, die die Zugehörigkeit des Romans Der Idiot zum Camp ausmachen, eher das Sujet und strukturelle Bedingungen, aber markieren keine Haltung des Helden zur Welt, die ihn selbst zum Objekt generieren. Die von Horst-Jürgen Gerigk insgesamt vorgelegte Interpretation des Romans Der Idiot, an deren überzeugendem Ergebnis niemand zweifeln wird, steht in einem gewissen Widerspruch zu den Camp-Thesen.

Das große dritte Kapitel, das alle fünf Romane vorstellt, wird mit einer Nachbemerkung beschlossen, die die Besonderheiten dieses Romanwerks offenbaren will. Auch hier erweist sich Horst-Jürgen Gerigk als Meister des Vergleichs im weltliterarischen Zusammenhang. Er sieht die Vaterlosigkeit als Klammer an, die die Romane zusammenhält, des Weiteren ist die Besessenheit eine Konstante in der Welt von Dostojewskijs Figuren, jeder Roman steht für ein Universum. Er hebt ebenfalls eine maliziöse Erzähltechnik hervor, mit der dem Leser immer gleichzeitig etwas gezeigt und etwas vorenthalten wird, so dass er sich zu einer besonderen Aufmerksamkeit gezwungen sieht, damit ihm nichts entgeht. (Vgl. S.268) Bereits 1993 hat Andreas Guski in seinem Aufsatz Verbergen und Offenbaren bei Dostoevskij dieses Phänomen beschrieben: „Das Sujet der fünf großen Romane Dostoevskijs lässt sich auf eine einfache Formel bringen: Etwas, das lange verschwiegen, verschleiert oder verdrängt wird, tritt schließlich zu Tage und wird offenbar.“3

Im 5. Kapitel stellt der Forscher den Zusammenhang zwischen dem Leben von Fjodor Dostojewskij und seinen Werken her. Nicht die Auffälligkeiten seines Lebens wie Gefängnisaufenthalt, Spielsucht und Epilepsie seien wichtig zu erwähnen, um den Dichter zu verstehen, sondern es ist sein Werk, das Dostojewskij hervorgebracht habe. (S. 303) Horst-Jürgen Gerigk beschreibt die einzelnen dichterischen Stationen mit den besonderen Charakteristika (das kann ein Held sein, die Bewusstseinsdarstellung, die Polyphonie, Orte u.a.) für jedes Werk, jedes stellt sozusagen innerhalb des Oeuvres einen Mosaikstein dar. Nach 344 Seiten sind alle Mosaiksteine von Horst-Jürgen Gerigk gelegt worden, und wir erkennen das besondere Bild des russischen Dichters Fjodor Dostojewskij.

\section{Rezensiert von Gudrun Goes.}

3 Andreas Guski: Verbergen und Offenbaren bei Dostoevskij. In: J.P. Locher (Hg,) Schweizerische Beiträge zum IX. Internationalen Slawistenkongress in Bratislave. Bern 1993 (Slavica Helvetica, Bd. 42), S. 113. 


\section{Autorenverzeichnis}

Peter Bukowski

Sonnenau 17

22089 Hamburg

Oliver Binder

Schöpfergasse 2

A 1120Wien

Elena Dobrina

Friedrichstr. 44

79576 Weil am Rhein

Prof. Dr. Andreas Ebbinghaus

Universität Würzburg

Neuphilologisches Institut - Slavistik

Am Hubland

97074 Würzburg

PD. Dr. Christoph Garstka

Slavisches Institut der Universität Köln

Weyertal 137

50931 Köln

Prof. Dr. Horst-Jürgen Gerigk

Moltkestr. 1

69120 Heidelberg

Prof. Dr. Gudrun Goes

Erlenweg 6

39291 Hohenwarthe

PD. Dr. Hanna Klessinger

Albert-Ludwigs-Universität

Deutsches Seminar II

Platz der Universität 3

79085 Freiburg
Susanne Meister

Thalia-Theater Hamburg

Alstertor

20095 Hamburg

Dr. Jordi Morillas

Nernstweg 19

22765 Hamburg

Dr. Jörg Pottbeckers

TU Chemnitz, Fachbereich Germanistik

Thüringer Weg 11

09126 Chemnitz

PD Dr.Henrike Schmidt

(p)ostkartell.

institut für angewandte kulturforschung

Kulturetage Altona

Große Bergstraße 160

22767 Hamburg

www.postkartell.org

Stefania Torri

Millanderweg 141C

I - 39042 Brixen

Jenifer Wasmuth

Humboldt-Universität Berlin

Lehrstuhl für Kirchen- und

Konfessionskunde

Burgstr. 26

10178 Berlin 


\section{Das Jahrbuch der Deutschen Dostojewskij-Gesellschaft}

Die Deutsche Dostojewskij-Gesellschaft e. V. (DDG), am 13. Mai 1990 gegründet und Mitglied der Arbeitsgemeinschaft Literarischer Gesellschaften und Gedenkstätten e. V. (ALG), ist einem russischen Schriftsteller gewidmet, der durch sein Werk und seine Person das deutsche Kultur- und Geistesleben in besonderer Weise geprägt hat. Ihr Ziel ist es, die Kenntnis Dostojewskijs zu verbreiten, das Studium seiner Werke zu vertiefen und zur eigenständigen Auseinandersetzung mit seiner Roman- und Ideenwelt anzuregen. Die Gesellschaft vermittelt Ergebnisse gegenwärtiger Dostojewskij-Forschung und steht allen offen, die sich für Autor und Werk interessieren.

Ihr Jahrbuch dokumentiert Vorträge, die über das Jahr auf Fachtagungen gehalten wurden, und damit einen grundlegenden Aspekt der Bildungsarbeit der Gesellschaft. Der erste Band erschien 1992. Das Jahrbuch wird von der Vorsitzenden der Gesellschaft herausgegeben, die sich dabei mit den Mitgliedern des Wissenschaftlichen Beirats berät, und bietet auch angehenden Dostojewskij-Forschern die Möglichkeit, ihre Arbeitsergebnisse einer breiteren Öffentlichkeit vorzustellen. Vortragsmanuskripte, Aufsätze und Rezensionen können der Vorsitzenden oder den Mitgliedern des Wissenschaftlichen Beirats zugesandt werden. Über die Veröffentlichung entscheidet die Herausgeberin. Den Inhalt der Beiträge verantworten die Autoren.

Deutsche Dostojewskij-Gesellschaft e.V. (DDG) www.dostojewskij-gesellschaft.de

Vorsitzende: Prof. Dr. Gudrun Goes IFPH Otto-von-Guericke Universität Zschokkestraße 32 39104 Magdeburg

Volksbank Lüneburger Heide eG BLZ: 25891636 Konto-Nr.: 522049100 * Amtsgericht Flensburg VR 1325 
Worldwide Distributor:

ISBN: 978-3-86688-411-3

ISBN (eBook): 978-3-86688-412-0

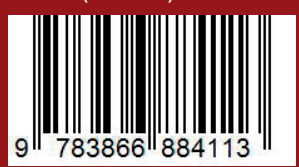

GUBON \& SAGNER

Serving libraries since 1947

Verlag_Qtto_SagnergDigital 